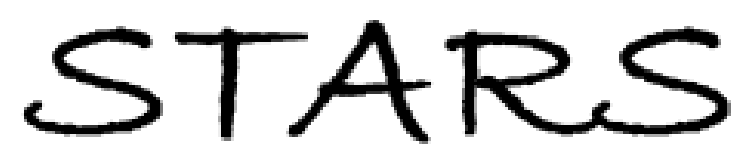

University of Central Florida

STARS

\title{
The Impact of Mobbing and Job-related Stress on Burnout and Health-related Quality of Life: The Case of Turkish Territorial State Representatives
}

Mehmet Yesilbas

University of Central Florida

Part of the Public Affairs, Public Policy and Public Administration Commons

Find similar works at: https://stars.library.ucf.edu/etd

University of Central Florida Libraries http://library.ucf.edu

This Doctoral Dissertation (Open Access) is brought to you for free and open access by STARS. It has been accepted for inclusion in Electronic Theses and Dissertations, 2004-2019 by an authorized administrator of STARS. For more information, please contact STARS@ucf.edu.

\section{STARS Citation}

Yesilbas, Mehmet, "The Impact of Mobbing and Job-related Stress on Burnout and Health-related Quality of Life: The Case of Turkish Territorial State Representatives" (2015). Electronic Theses and Dissertations, 2004-2019. 5021.

https://stars.library.ucf.edu/etd/5021

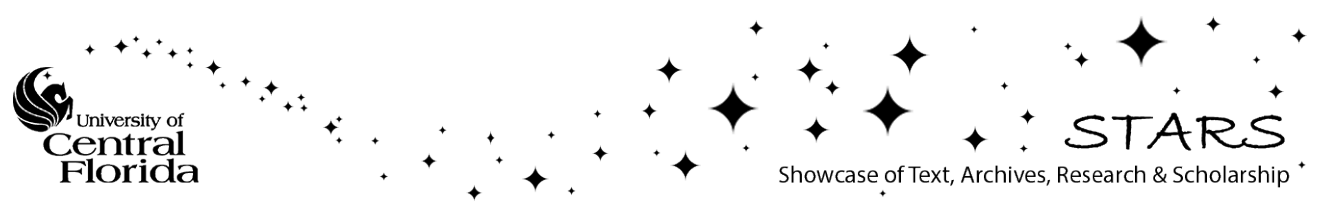




\title{
THE IMPACT OF MOBBING AND JOB-RELATED STRESS ON BURNOUT AND HEALTH-RELATED QUALITY OF LIFE: \\ THE CASE OF TURKISH TERRITORIAL STATE REPRESENTATIVES
}

\author{
by \\ MEHMET YESILBAS \\ LL.B., University of Ankara, 1998 \\ MPA, Public Administration Institute for Turkey and Middle East, 2009 \\ $\mathrm{PhD}$ in BA, University of Dicle, 2012 \\ A dissertation submitted in partial fulfillment of the requirements \\ for the degree of Doctor of Philosophy \\ in the College of Health and Public Affairs \\ at the University of Central Florida \\ Orlando, Florida
}

Summer Term

2015

Major Professor: Thomas T. H. Wan 
(C) 2015 Mehmet Yesilbas 


\begin{abstract}
Job-related stress occurs as one of the most serious issues in modern era in developed nations. It has direct and negative effects on employees' productivity and it may have negative impacts on employees' health. One of the potential results of prolonged stressors at work place is burnout and this response may lead to physical, emotional, and psychological exhaustion that can occur at both individual and organizational levels. Burnout is a job related threat that provokes social stress and can directly affect an individual's health. Health-related quality of life (HRQoL) is commonly used to measure an individual's overall/global health and quality of life. Another serious issue, mobbing, usually leads to some individual and organizational complications. It affects the organizational commitment, motivation and efficiency of staff, job satisfaction of employee, and may lead to potential burnout of the employees. The primary objective of this study is to determine whether stress and mobbing are directly related to burnout; and, whether burnout leads to an adverse effect on the HRQoL of Turkish territorial state representatives (TSRs). This study examines four specific research questions: 1) Whether and to what extent do the levels of perceived job related stress and mobbing affect the level of perceived burnout syndrome of TSRs? 2) Whether and to what extent is the level of perceived burnout syndrome associated with HRQoL of TSRs? 3) To what extent does the level of perceived burnout mediate the effects of job-related stress on HRQoL of TSRs? 4) What are the mediating factors between job burnout and HRQoL? This study is expected to offer valuable and insightful information about the role of job burnout factors influencing the variability in TSRs' HRQoL.
\end{abstract}


The study utilized two statistical analyses, which were descriptive analysis and Structural Equation Modelling (SEM) which allows for the assessment of the relationships specified in the hypotheses and the SEM was used to validate the theoretically driven model.

The findings of the study supported the hypotheses of the study, which asserted that there were correlations between job-related stress and burnout, mobbing and burnout, and burnout and HRQoL. The CFA results established that job-related stress was positively and significantly associated with the burnout of TSRs, while perceived mobbing was positively and significantly related to the burnout of TSRs. Moreover, perceived HRQoL of TSRs was negatively associated with the burnout of TSRs. Further, the findings indicated that the relationship between jobrelated stress and burnout and the relationship between burnout and HRQoL of TSRs were statistically significant. Thus the variable had a positive effect on burnout and a negative effect on the HRQoL of TSRs. In summary, the findings of the study showed that results and propositions of the theoretical frameworks of the study and literature were consistent with one another. 
I dedicate this study to my beloved father Ahmet for his unconditional love, support, and affection. 


\section{ACKNOWLEDGMENTS}

I am grateful for the guidance and support of my dissertation committee chair, Dr. Thomas Wan, who encouraged me to continue working on my dissertation. Without his excellent guidance, support, and patience, this dissertation would never have been accomplished. I would also like to acknowledge the appreciated contributions made by my dear committee members: Dr. Ning Jackie Zhang, Dr. Sophia Dziegielewski, and Dr. Julie Steen, who inspired me to make my dissertation better.

I gratefully acknowledge the moral support and encouragement that my friends and colleagues provided me with during my $\mathrm{PhD}$ education in the US.

I would like to thank the Turkish Government and the Turkish Ministry of Interior for their financial support in my doctoral study in the US.

Last but not least, I am thankful to my wife, Sakine, my kids, Ahmet Berk, Mehmet Yigit, and Duygu, and my parents. They gave their unconditional support and love during this process. Without their support and patience, this dissertation would never be accomplished. 


\section{TABLE OF CONTENTS}

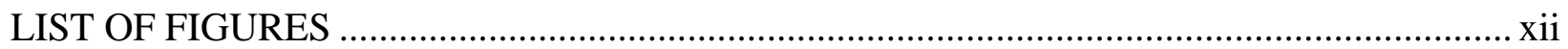

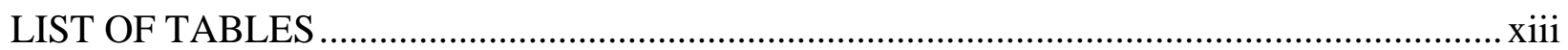

CHAPTER ONE: INTRODUCTION ............................................................................... 1

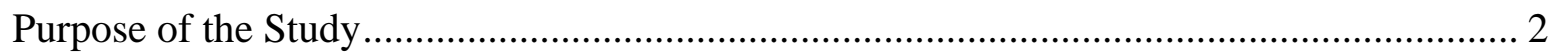

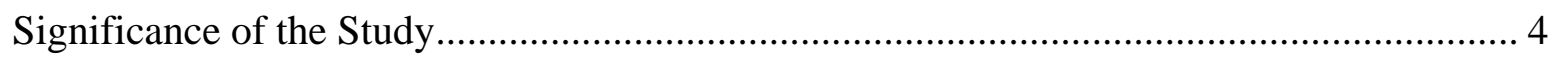

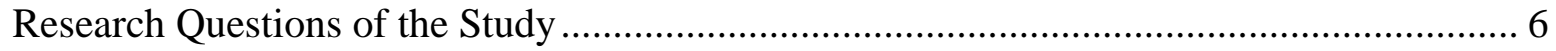

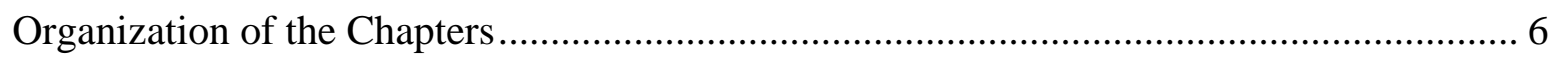

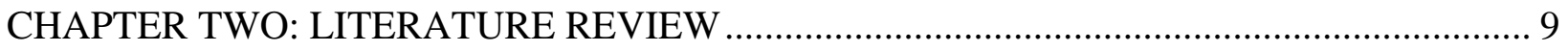

Health Related Quality of Life ......................................................................................... 9

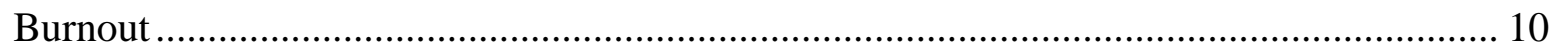

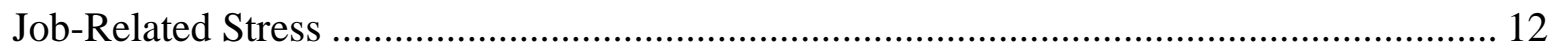

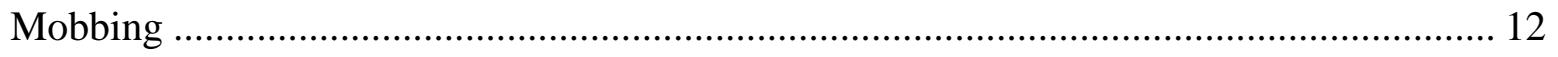

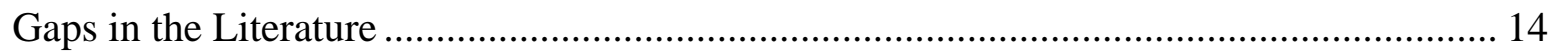

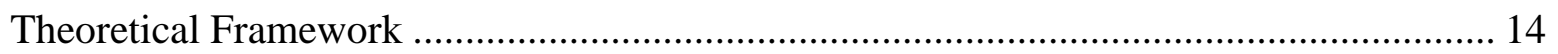

Conceptual Formulation with Causal Specifications ………................................................ 17

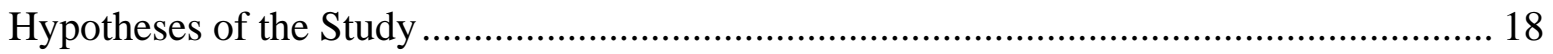

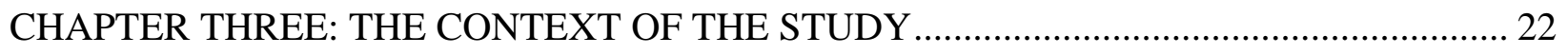

General Principles of the Structure of the Turkish State ………….................................... 22

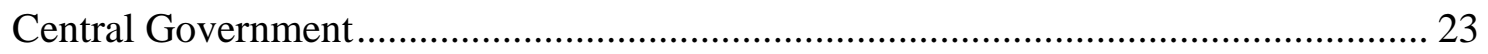

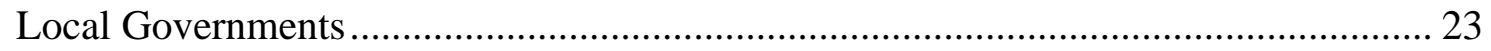

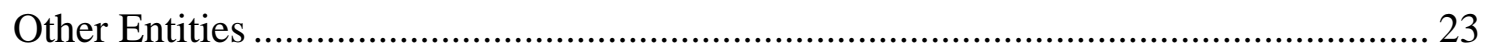


A Brief Overview of Turkish Ministry of Interior .................................................. 24

Provincial and Turkish State Territorial Representatives System ................................. 27

Administrative Organization and Divisions of Turkey............................................... 28

Delegation of Authority: The Principle of Provincial Administration ............................. 29

Structure of the Provincial Administration .................................................................. 30

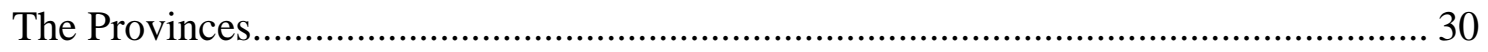

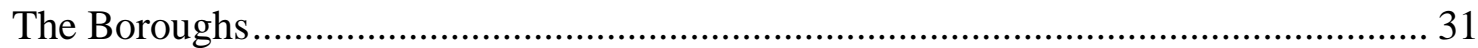

The Occupational Positions of Turkish Territorial State Representatives........................ 31

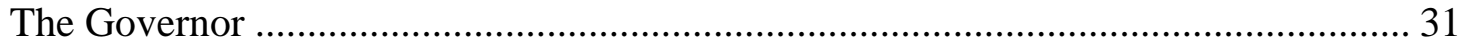

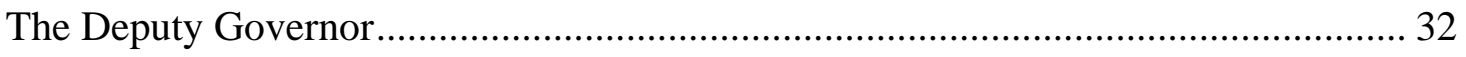

District Governor..................................................................................... 32

Civil Inspectors and Legal Advisors .............................................................. 32

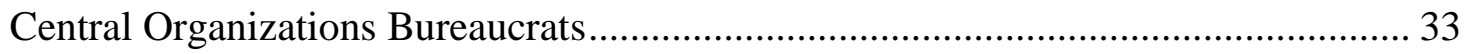

Hiring, Training, and Appointment Process of the TSRs ........................................... 33

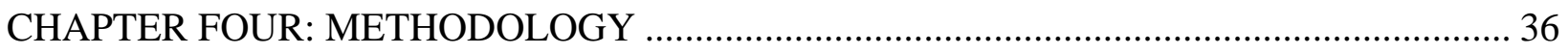

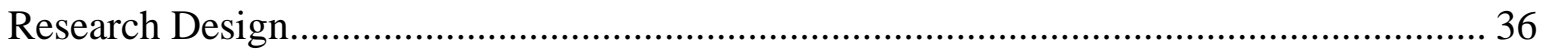

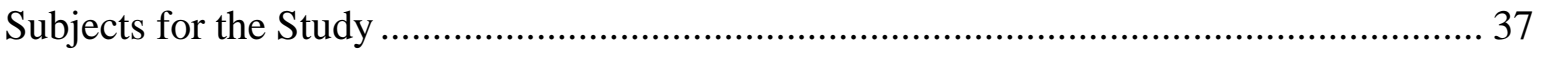

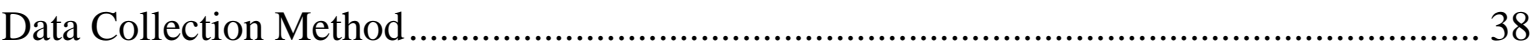

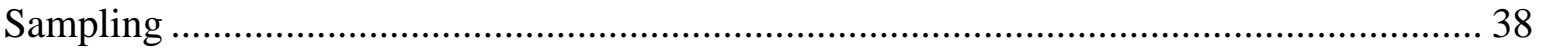

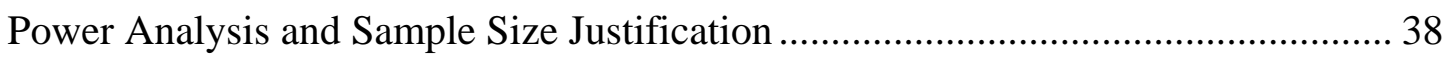

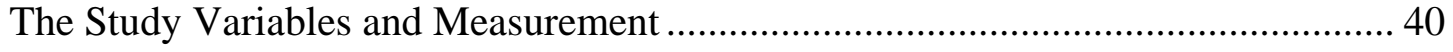

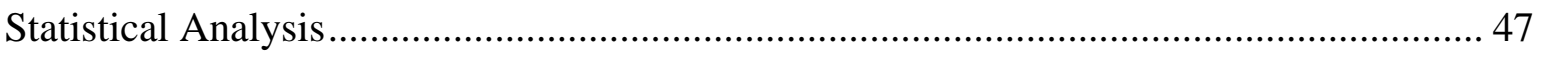




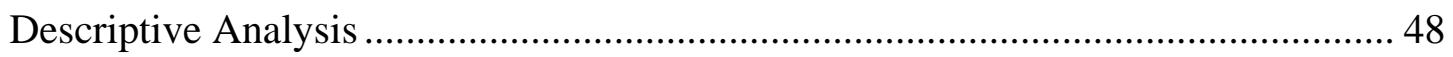

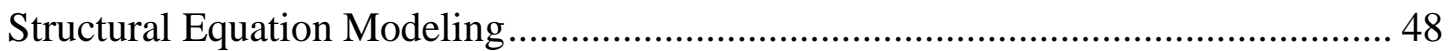

Confirmatory Factor Analysis................................................................................. 49

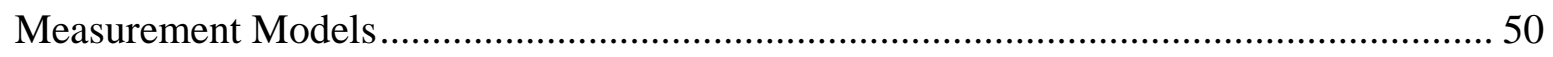

A Second-Order Measurement Model for HRQoL ………...................................... 50

A Second-Order Measurement Model for Burnout .................................................... 52

A Measurement Model for Job-Related Stress ......................................................... 53

A Measurement Model for Mobbing ………………………………………..... 53

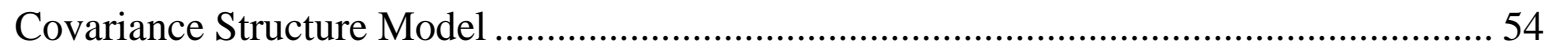

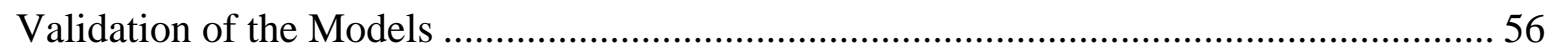

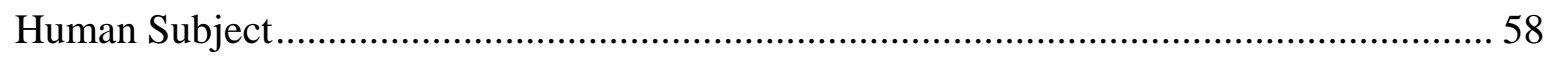

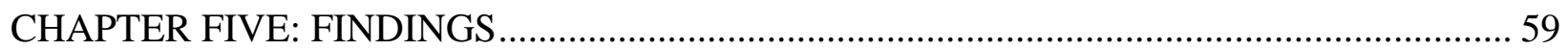

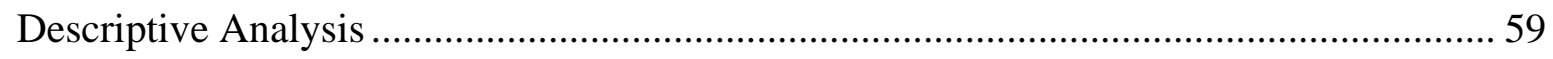

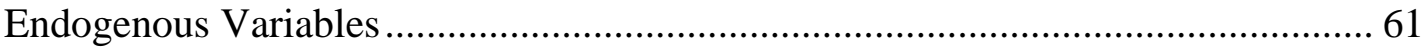

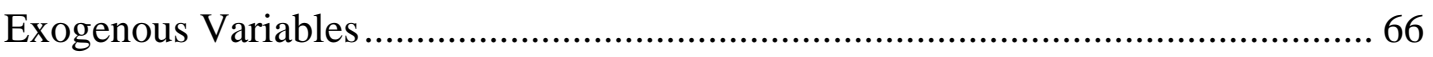

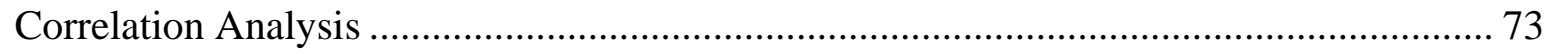

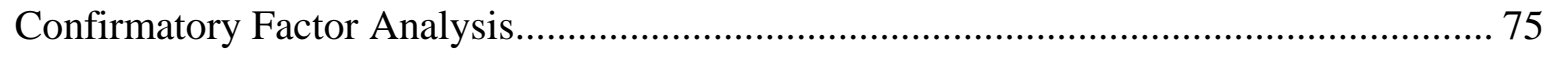

Measurement Model for Health Related Quality of Life............................................. 78

Measurement Model for Burnout........................................................................ 82

Measurement Model for Job Related Stress .............................................................. 85

Measurement Model for Mobbing ......................................................................... 88

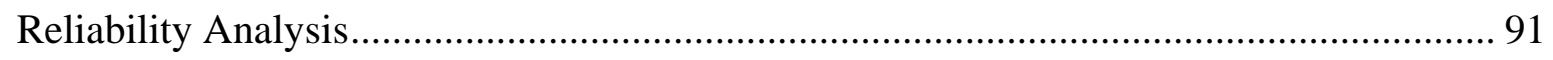


Covariance Structure Model ............................................................................... 92

Hypotheses Testing ...................................................................................... 102

CHAPTER SIX: DISCUSSION, IMPLICATIONS, LIMITATIONS, AND CONCLUSION.. 105

Summary of the Findings and Discussions ....................................................... 105

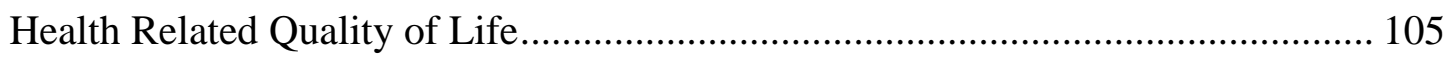

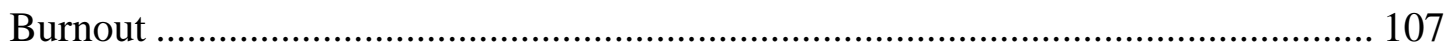

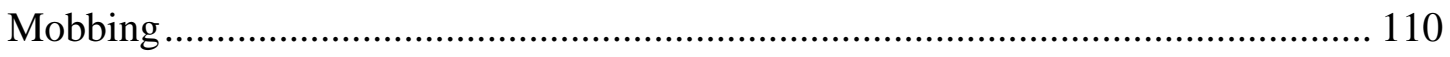

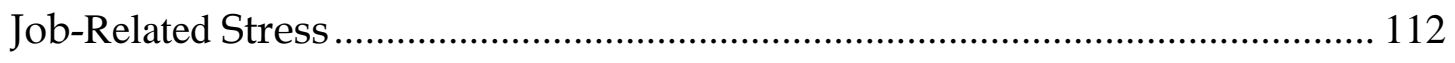

Covariance Structure Model ....................................................................... 114

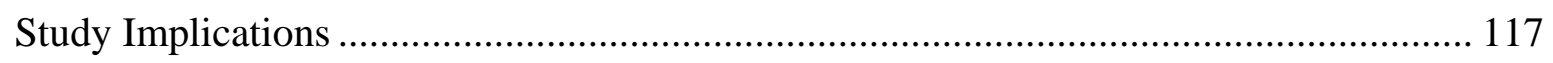

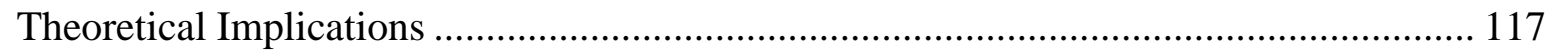

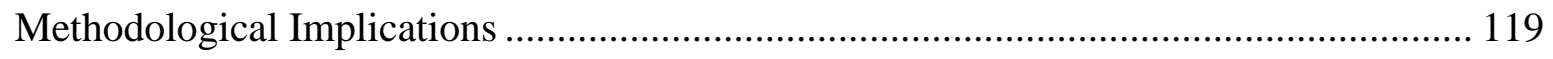

Study Limitations and Directions for Future Studies ............................................ 124

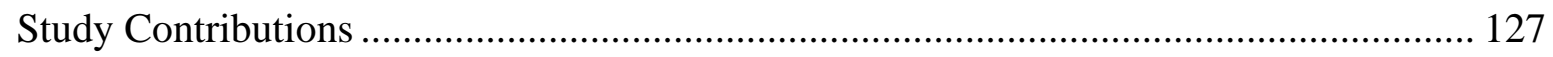

APPENDIX A: LETTER OF SUPPORT BY THE ASSOCIATION OF TURKISH

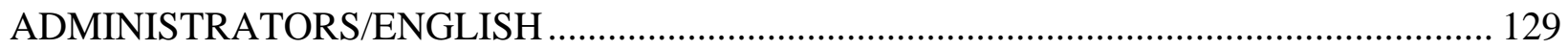

APPENDIX B: LETTER OF SUPPORT BY THE ASSOCIATION OF TURKISH

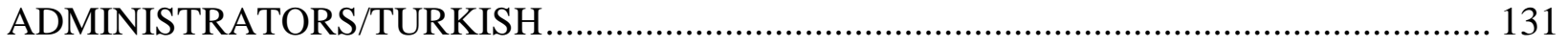

APPENDIX C: LETTER OF SUPPORT TURKISH MINISTRY OF INTERIOR /ENGLISH133 APPENDIX D:LETTER OF SUPPORT TURKISH MINISTRY OF INTERIOR/TURKISH 135 APPENDIX E:LICENSE AGREEMENT OF HRQOL SF-12V2 4-WEEK RECALL SCALE 137 APPENDIX F: HRQOL SF-12V2 4-WEEK RECALL SCALE (ENGLISH VERSION) ......... 139 
APPENDIX G:HRQOL SF-12V2 4-WEEK RECALL SCALE (TURKISH VERSION) 143 APPENDIX H: COPENHAGEN BURNOUT INVENTORY SCALE PERMISSION. 148 APPENDIX I: COPENHAGEN BURNOUT INVENTORY SCALE (ENGLISH VERSION) 150 APPENDIX J: COPENHAGEN BURNOUT INVENTORY SCALE (TURKISH VERSION) 153 APPENDIX K: JOB STRESS SCALE ENGLISH VERSION 156

APPENDIX L: JOB STRESS SCALE TURKISH VERSION 158 APPENDIX M: WORK HARASSMENT SCALE PERMISSION 160 APPENDIX N: WORK HARASSMENT SCALE ENGLISH VERSION 162 APPENDIX O: WORK HARASSMENT SCALE TURKISH VERSION 164

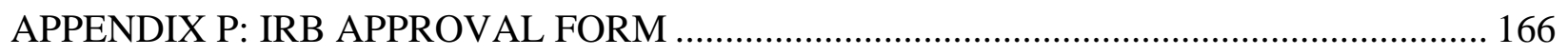
APPENDIX Q: CONSENT FORM FOR TRANSLATIONS ............................................ 168 APPENDIX R: DESCRIPTIVE FINDING ................................................................ 170 APPENDIX S: CORRELATION MATRICES ............................................................... 194

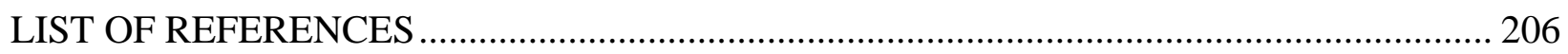




\section{LIST OF FIGURES}

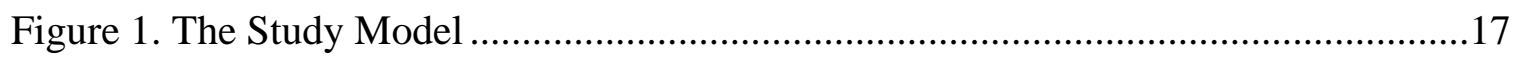

Figure 2. Conceptual Formulation of the Study......................................................18

Figure 3. Organizational Structure of the Turkish Ministry of Interior .........................26

Figure 4. A Second-order Measurement Model for Health-related Quality of Life ..........51

Figure 5. A Second-order Measurement Model for Burnout........................................52

Figure 6. A Measurement Model for Job-related Stress ..........................................53

Figure 7. A Measurement Model for Mobbing ......................................................53

Figure 8. A Covariance Structure Model for HRQoL of TSRs .....................................55

Figure 9. The Frequency Distribution of Job-related Stress of TSRs ............................68

Figure 10. The Frequency Distribution of Mobbing ................................................. 71

Figure 11. Measurement Model for HRQoL (Generic Model)....................................79

Figure 12. Measurement Model for HRQoL (Revised Model) ....................................81

Figure 13. Measurement Model for Burnout (Generic Model) ....................................82

Figure 14. Measurement Model for Burnout (Revised Model) .....................................84

Figure 15. Measurement Model for Job-related Stress (Generic Model) .........................85

Figure 16. Measurement Model for Job-related Stress (Revised Model) ........................87

Figure 17. Measurement Model for Mobbing (Generic Model) .....................................88

Figure 18. Measurement Model for Mobbing (Revised Model)...................................90

Figure 19. Covariance Structure Model (Generic Model) ..........................................94

Figure 20. Covariance Structure Model (Final Revised Model)..................................100

Figure 21. The Conceptual Model with Regression Coefficient Values of the Study Variables 102 


\section{LIST OF TABLES}

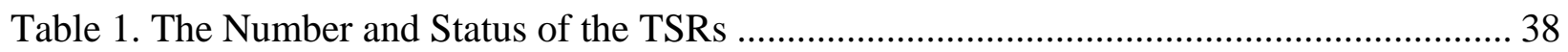

Table 2. Operational Definitions and Measurement Instrument of the Study Variables ............. 45

Table 3. GOF Indices Thresholds for Measurement and CSM Models .................................. 57

Table 4. Parameter Estimates and Regression Weights for HRQoL ..................................... 80

Table 5. Model Fitness Indices for HRQoL................................................................. 81

Table 6. Parameter Estimates and Regression Weights for Burnout ...................................... 83

Table 7. Model Fitness Indices for Burnout .................................................................... 84

Table 8. Parameter Estimates and Regression Weights for Job-related Stress.......................... 86

Table 9. Model Fitness Indices for Job-related Stress ........................................................... 86

Table 10. Parameter Estimates and Regression Weights for Mobbing ................................... 89

Table 11. Model Fitness Indices for Mobbing................................................................... 90

Table 12. Cronbach's Alpha Scores for Measurement Models ............................................. 92

Table 13. Parameter Estimates and Regression Weights for the CSM................................... 95

Table 14. Model Fit Indices of Covariance Structure Model ................................................. 99

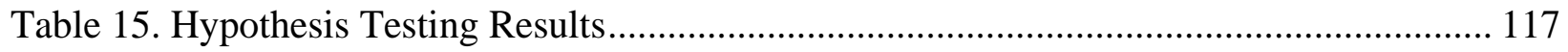

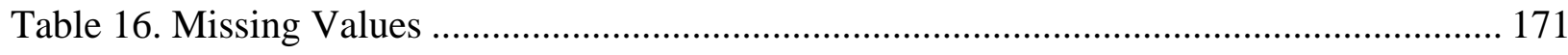

Table 17. Frequency Distribution of the Status of Participants .............................................. 173

Table 18. Frequency Distribution of the Tenure of Participants .......................................... 175

Table 19. Frequency Distribution of the Education Level of Participants ............................. 175

Table 20. Frequency Distribution of the Participants' Gender .............................................. 176

Table 21. Frequency Distribution of Indicators of Perceived HRQoL ................................... 176 
Table 22. Frequency Distribution of Indicators of Perceived Burnout.................................. 180

Table 23. Frequenc y Distribution of Indicators of Job-related Stress .................................... 184

Table 24. Frequency Distribution of Indicators of Mobbing ............................................ 187

Table 25. Correlation Matrix of HRQoL ..................................................................... 195

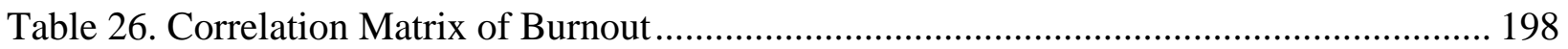

Table 27. Correlation Matrix of Job-related Stress.......................................................... 201

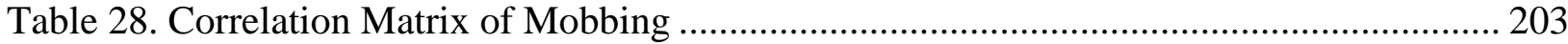




\section{LIST OF ACRONYMS/ABBREVIATIONS}

\begin{tabular}{|c|c|}
\hline AGFI & Adjusted Goodness of Fit Index \\
\hline AMOS & Analysis of Moment Structures \\
\hline $\mathrm{BC}$ & Client Related Burnout \\
\hline $\mathrm{BP}$ & Personal Burnout \\
\hline BW & Work Related Burnout \\
\hline C.R & Critical Value \\
\hline CBI & Copenhagen Burnout Inventory Scale \\
\hline CFA & Confirmatory Factor Analysis \\
\hline CFI & Comparative Fit Index \\
\hline CMIN & Model Chi-square \\
\hline CMIN/df & Relative Chi-square \\
\hline CSM & Covariance Structure Model \\
\hline $\mathrm{d}$ & Measurement Error \\
\hline DF & Degree of Freedom \\
\hline DTIA & The Developmental Theory of Interpersonal Aggression \\
\hline e & Error Term (Disturbance) \\
\hline EDUC & Education Level \\
\hline EU & European Union \\
\hline GEND & Gender \\
\hline GFI & Goodness of Fit Index \\
\hline GOF & Goodness of Fit \\
\hline
\end{tabular}




$\begin{array}{ll}\text { H } & \text { Hypothesis } \\ \text { HRQoL } & \text { Health Related Quality of Life } \\ \text { IFI } & \text { Incremental Fit Index } \\ \text { IRB } & \text { Institutional Review Board } \\ \text { IT } & \text { Information Technology } \\ \text { JD-R } & \text { The Theory of Job Demands-Resources } \\ \text { JS } & \text { Job Stress } \\ \text { MB } & \text { Mobbing } \\ \text { MBI } & \text { Maslach Burnout Inventory } \\ \text { MI } & \text { modification indices } \\ \text { NFI } & \text { Normed Fit Index } \\ \text { NNFI } & \text { Normed Fit Index } \\ \text { P } & \text { Significance Level } \\ \text { RFI } & \text { Relative Fit Index } \\ \text { RMSEA } & \text { Root Mean Square Error of Approximation } \\ \text { RQ } & \text { Research Question } \\ \text { RW } & \text { Regression Weight } \\ \text { SE } & \text { Standard Error } \\ \text { SEM } & \text { Structural Equation Modeling } \\ \text { SF } & \text { Short Form } \\ \text { SPSS } & \text { Statistical Package for the Social Sciences } \\ \text { SRW } & \text { Standardized Regression Weight } \\ & \\ \text { R } & \end{array}$




$\begin{array}{ll}\text { STAT } & \text { Status of the occupational position } \\ \text { TLI } & \text { Tucker-Lewis Index } \\ \text { TMoI } & \text { Turkish Ministry of Interior } \\ \text { TSRs } & \text { Turkish State Representatives } \\ \text { URW } & \text { Unstandardized Regression Weight } \\ \text { US } & \text { United States } \\ \text { WHS } & \text { Workplace Harassment Scale } \\ \chi 2 & \text { Chi-Square } \\ \chi 2 / \mathrm{df} & \text { Chi-square / Degree of Freedom }\end{array}$




\section{CHAPTER ONE: INTRODUCTION}

Burnout is a psychological condition responsive to job-related stressors. This reaction might cause physical, emotional, and psychological exhaustion (Maslach, Schaufeli, \& Leiter, 2001; Etzion, 1984). Its manifestation may have an impact on both individual and organizational behaviors, although this syndrome is generally considered an individual concern. The adverse effects of burnout may lead to deficiencies in organizational commitment and organizational performance such as lack of efficiency and effectiveness. Once these organizational effects become unavoidable, serious, and harmful, burnout results may threaten the survival of an organization (Lee \& Ashforth, 1993).

Mobbing is workplace bullying (Leymann, 1990) and the intentional infliction of emotional distress (Liefooghe, 2004). It is also defined as the activity of an employee to force another person out of the workplace via rumor, innuendo, bullying, humiliation, discrediting, and isolation (Davenport, Schwartz, \& Elliott, 2003). Mobbing may affect the organizational commitment, motivation and efficiency of staff, employee job satisfaction, and potential burnout of the employees (Dziegielewski, Mansur, \& Tengilimoglu, 2010). The impact of mobbing may manifest at the individual or organizational level, sometimes simultaneously. The adverse impacts of mobbing may cause withdrawal of organizational commitment or organizational dysfunction. In addition to Davenport et al.'s definition of mobbing, the behavior is generally defined by others as office bullying (Leymann, 1990), deliberate infliction of emotional suffering (Liefooghe, 2004), workplace offensiveness (Hornstein, 2003), an emotive abuse (Keashly, 1998), a victimization (Wornham, 2003). 
From another perspective, burnout is one of the job-related hazards that might induce social stress and adversely affect health. Although burnout in the health context has been widely studied, some studies portray that other non-medical professional groups may have encountered the same experience as medical professionals with burnout (Martinussen, Richardsen, \& Burke, 2007). However, a few studies depict the causal relationship among job-related stress, burnout, and health-related quality of life (Montgomery, Mostert, \& Jackson, 2005).

Health-related quality of life (HRQoL) measures a person's perceived physical and mental health (Centers for Disease Control and Prevention, 2000). The HRQoL concept reflects individuals' or groups' experiences regarding their health status or specific health-related problems that may affect their lives. According to Pai and Wan (1997), health is either lack of disorder or sickness, and a physical, mental, or social wellbeing. According to Wan (2002), health is an elusive concept with a variety of meaning, which is why health care providers try to find a perfect instrument that allows a quick and accurate evaluation of an individual's health. The HRQoL is one of these tools measuring the individual health condition; it generally measures a person's global health and well-being, and emphasizes the effect of health conditions on an individual's perceived quality of life.

\section{Purpose of the Study}

The purpose of this study was to examine the relationship between important personal factors associated with burnout and health-related quality of life among Turkish Territorial State Representatives (TSRs). The primary objective was two-fold: First, to determine whether stress and mobbing are related to burnout; and second, to determine whether burnout affects HRQoL of TSRs. 
The Turkish central government appoints its territorial state representatives, who are typically provincial and district governors. Governors are responsible for administration of all public agencies in Turkish provinces and also function as the supervisor to district governors whose districts are in the same province. In other words, the districts governors report to their respective provincial governor. Turkey has a strict centralized administrative system and defined hierarchical structure between district governors in province and governors and the undersecretariat of Ministry of Interior and also Ministers (www.illeridaresi.gov.tr, 2014). According to the Law of Province Administration of 1949, the governor is the head of all-public services in a province, under whose authority the public officials in the province work. Only some military personnel and judicial personnel are outside of the terms of governor's authority. Governors also have power of administrative tutelage over the local governments in the public field (Gozler, 2003). There are several public services such as health services, education services, agriculture services, social aid and orphanage services, security services (police and gendarmerie), religious services, infrastructure of rural areas and villages, road building services, culture and tourism services, and tax services, which fall under the responsibility of governors. Each service has its own ministry, or central organization. For example, Ankara, the capital city of Turkey, has its own organization and provincial director in the province although these directors are directly responsible to the governor.

Responsibilities and duties of district governors are too numerous to accomplish alone; province or district directors of services and their agencies conduct services and the duties in support of the governor. However, governors or district governors have the authority to supervise, regulate, and investigate them. It can be a challenging issue to govern and supervise 
such a wide range of services. This situation may affect health conditions of TSRs, as maintaining a healthy lifestyle is important for TSRs in order to effectively perform their duties.

This scientific investigation was expected to offer valuable information about the factors contributing to the variation in burnout and explain how they may decrease the adverse effects of job stressors on TSRs. Since the public services responsibilities of TSRs are of significance, it was fundamental to determine the level of burnout and the factors associated with burnout for TSRs, as well as the resulting effect on their HRQoL.

\section{Significance of the Study}

Although the literature concerning the importance of stress and burnout in the Western world is plentiful, there was limited information about the causes and impacts of stressful events—-such as burnout and job dissatisfaction on an individual's health—in Turkey. No Turkish studies focused on territorial state representatives. However, numerous studies were conducted for various professional groups. There was no specific research on TSRs to ascertain the causal relationships among perceived levels of burnout, mobbing, job-related stress, and health related quality of life (Kutanis \& Karakiraz, 2013; Okutan, Yildiz, \& Konuk, 2013; Akbolat \& Isik, 2008; Tumkaya, Cam, \& Cavosoglu, 2009; Ari \& Tuncay, 2010; Deliorman, Boz, Yigit, \& Yildiz, 2010, Dziegielewski et. al., 2010).

The study of Kutanis and Karakiraz (2013) measured burnout levels of academicians in Turkey to identify the burnout level of academicians, while Okutan et al. (2013) examined the burnout level of employees working in small and medium size entrepreneurs. Akbolat and Isik (2008) studied burnout levels of employees at a public hospital. Tumkaya et al. (2009) investigated the reliability and validity of Turkish adaption of burnout inventory scale with the 
participants of teachers in a state university of Turkey, while Deliorman et al. (2010) examined the relationship among some burnout constructs with a sample of academicians in a state university of Turkey. Dziegielewski et al. (2010) investigated the impact of mobbing on organizational commitment in a state university of Turkey with a sample of administrative employees. Thus, this type of research contributed to the literature and identified the factors contributing to the current burnout level and HRQoL of TSRs.

Since organizational outcomes of burnout would result in serious consequences of failure or disorganization, the analysis of the job related stress of TSRs was essential to identify potential mechanisms for eradicating job stress and burnout and enhancing the quality of services provided by public servants. From theoretical, methodological, and practical points of view, this study made an important contribution to the literature on mobbing, job-related stress, burnout, and HRQoL of Turkish TSRs as the current Turkish findings did not examine the Turkish TSRs. Hence, this study made a significant contribution to the literature and tried to identify those factors that contributed to the current job-related stress, mobbing, burnout level and HRQoL of TSRs.

Moreover, the study identified some important tasks for Turkish Ministry of Interior policy makers, specifically to concentrate on the wellbeing of TSRs and to eliminate or decrease the level of job-related stress, mobbing, and burnout of TSRs. From theoretical, methodological, and practical viewpoints, the new information and findings provided by this study were key contributions to the existing body of knowledge that suggest decision makers should focus on creating some relevant preventive strategies and governance mechanisms for improving the 
sanctity of organizational management, and on improving the quality of the work life of those who are high ranking officers of the Turkish administrative system.

One of the other important contributions of this study was its use of a structural equation modeling (SEM) method, as it is ideal when testing theories with latent variables. This study was the only study that employed the SEM method to examine the hypothesized relationships regarding TSRs.

\section{Research Questions of the Study}

There are four research questions in this study.

The first research question (RQ1) is: Whether and to what extent do the levels of perceived job related stress and mobbing affect the level of perceived burnout syndrome of TSRs?

The second research question (RQ2) is: Whether and to what extent is the level of perceived burnout syndrome associated with HRQoL of TSRs?

The third research question (RQ3) is: To what extent does the level of perceived burnout mediate the effects of job-related stress on HRQoL of TSRs?

The fourth research question (RQ4) is: What are the mediating factors between job burnout and HRQoL?

\section{$\underline{\text { Organization of the Chapters }}$}

The following chapters provide a literature review, a theoretical framework, context of the study, methodology, findings, and discussion, and conclusion. Chapter two provides a literature review on previous studies and examines the variables of the study, which are HRQoL, burnout, job related stress, and mobbing. The theoretical framework provides a brief review of 
the Administrator Stress Cycle Model, Theory of Job Demands-Resources Model, Developmental Theory of Interpersonal Aggression, and Social Stress Theory. Finally, there is an examination of conceptual formulation with causal specifications and hypotheses of the study. Chapter three provides the context of the study, a discussion of the general principles of the Turkish state, and a discussion of the Turkish Ministry of Interior and provincial and TSRs system.

Chapter four outlines the methodology section of the study. This section examines the research design, subjects of the study, data collection method, sampling, measurement, and statistical analysis. The statistical analysis section provides discussion regarding descriptive analysis, the SEM, and Confirmatory Factor Analysis (CFA). An examination of the human subject of the study is also discussed in the chapter four.

Chapter five gives the data analysis and findings of the study. In the first part of this chapter, a discussion of the descriptive analysis of each variable gives readers a general idea about the frequency distribution of the responses. In the following part of the chapter, the correlation matrix of Statistical Package for the Social Sciences (SPSS) is used to examine the multicollinearity issue. The CFA is conducted to validate the measurement models. To examine the internal consistency of the measurement models, an examination of the reliability analysis is discussed. Then, all measurement models including control variables are merged into the CSM model, which is examined using the SEM.

Chapter six gives the results of the analysis, implications, and limitations of the study. The chapter first provides the summary of the findings and discussions; then, theoretical and 
methodological implications are discussed. Finally, study limitations, directions for the future research, and study contributions are reviewed. 


\section{CHAPTER TWO: LITERATURE REVIEW}

This section provides a systematic review of the literature to identify the study variables and to establish the theoretical support for formulation of the research hypotheses. The first part of the literature review examined the concepts of health, health related qualify of life, burnout, job-related stress, and work harassment (mobbing). Then, gaps in literature and the theoretical background of the study are briefly discussed. The Administrators Stress Cycle Model (Gmelch \& Gates, 1998), the Theory of Job Demand-Resources Model (JD-R) (Bakker \& Demerouti, 2007; Demerouti, Bakker, Nachreinier, \& Schaufeli, 2001), the Developmental Theory of Interpersonal Aggression (Buss, 1961), and Social Stress Theory (Aneshensel, 1991; Wan, 1982) frame this research study. A conceptual and logic map with theoretical hypotheses constitutes the final part of the literature review section.

\section{$\underline{\text { Health Related Quality of Life }}$}

Health is identified not only as the absence of disorder or sickness, but also as physical, mental, and social wellbeing (Wan \& Pai, 1997). According to Wan (2002), health is an elusive concept, since it carries several meanings. Thus, health care providers seek an accurate instrument that will allow a quick and accurate evaluation of an individual's health (Wan, 2002). Health-related quality of life is one of these tools because it represents a latent concept that has multiple dimensions measuring individual physical, mental, emotional, and social wellbeing. The concept is generally used to measure a person's health and average life span, and focuses on the impact of health conditions on a person's quality of life.

The Centers for Disease Control and Prevention (2000) asserted that HRQoL is an individual's or group's perceived physical and mental health over time. Furthermore, the HRQoL 
notion assesses individuals' or groups' experiences concerning their health status to determine specific health-related problems that might influence the different scales of individuals' or groups' life. Some argued that ongoing stress generally had a negative impact on the health of an individual.

\section{$\underline{\text { Burnout }}$}

Burnout is a psychological situation that arises as a consequent reaction to job-related stressors (Maslach et al., 2001). Although burnout in the healthcare field had been studied, some studies depicted that other professional groups had the same issue with burnout, too (Martinussen et al., 2007). Some studies, on the other hand, exposed the causal and consistent relationship among job-related stress, burnout, and HRQoL (Montgomery et al., 2005). Chang, Daly, Hancock, Bidewell, Johnson, and Lambert (2006) found that job related-stress had a negative impact on personal health. According to Schaufeli and Enzmann (1998), job demands and the lack of job resources were significant organizational stressors. Leiter and Maslach (2000) also emphasized that job demands and lack of resources were also significant sources of organizational stress.

Scholars studied burnout syndrome among many professional groups, divisions, and positions because it was assumed that burnout was a common problem for all employees from all organizational types (Cahoon \& Rowney, 1989). Maslach et al. (2001) emphasized that, though burnout is related to employees in the human services and health care fields, it is a prevailing phenomenon in other professional groups. They categorized burnout research into two groups: the pioneering stage and the empirical stage (Maslach et al., 2001). 
In the pioneering stage, the study was exploratory and the objective was to articulate the burnout concept. The early studies in the U.S. were conducted in the 1970 s and the main contribution of these studies was to describe the basic concept of burnout, name it, and they revealed that burnout was not an unusual response. These initial studies were based on the practice of people employed in human services and health care professions, fields in which the employees' purpose was to provide help and service to clients in need, and which might then be categorized by emotional and interpersonal stressors (Maslach et al., 2001). The pioneer researchers of this phase were Freudenberger (1975) and Maslach (1976).

In the empirical stage the research on burnout shifted to more empirical studies. These studies were more quantitative in nature, employing survey, methodology, and examining larger subjects. Specific concentrations of these studies focused on the evaluation of burnout and the creation of some different measures. The scale used most widely by scholars during this period was the Maslach Burnout Inventory (MBI), which was specifically developed for use in human service professions (Maslach \& Jackson, 1981). But, in reaction to the attention given to burnout by educators, a new form of the scale is created to conduct in school professions (Maslach et al., 2001). As other empirical studies developed, new suggestions regarding the progressive path of burnout over time were generated (Maslach et al., 2001).

In order to prevent drawbacks and weaknesses of the popular MBI, the Copenhagen Burnout Inventory questionnaire (CBI) was created in Denmark by Kristensen, Borritz, Villadsen, and Christensen (2005). Understanding of social and traditional variances between people from America and Europe caused suspicions that were socially and customarily delicate 
(Kristensen, Borritz, Villadsen, \& Christensen, 2005). Burnout arises as a potential consequence of chronic job related stress (Martinussen, Richardsen, \& Burke, 2007).

\section{$\underline{\text { Job-Related Stress }}$}

Job stress arises as one of the most critical issues in modern era in developed nations (Gill, Flaschner, \& Shachar, 2006). Job-related stress is defined as a mental and physical problem having direct and negative impacts on an employee's productivity, efficiency, effectiveness, and the quality of work. It can be conceptualized as an employee's reactions to negative work climate characteristics that emerge as threatening to the employee's wellbeing (Gill et al., 2006). According to Ursin and Eriksen (2004) and Mohren and his associates (2003), prolonged job-related stress may have a negative effect on individual health. Cropanzano, Rupp, \& Byrne (2003) and Lee and Ashforth (1993) alleged that job-related stress may have a negative effect on attitudes towards organizations. One of the potential outcomes of prolonged stressors at work place is burnout (Martinussen et al., 2007).

The association between burnout and job-related stress was first noted by Freudenberger (1974), while Wiese et al (2003) emphasized the causal relationship between burnout and jobrelated stressors. Some demographic characteristics, such as age, rank, and gender are also associated with job related stress (Ortega, Brenner, \& Leather, 2007).

\section{Mobbing}

Leymann (1990) defined mobbing as workplace bullying, while Liefooghe (2004) describes it as intentional infliction of emotional distress. Hornstein (2003) defined mobbing as office rudeness, Keashly (2001) defined it as emotive misuse, and Wornham (2003) defined it as victimization. Davenport et al. (2003) defined mobbing as the activity of an employee to force 
someone out of the workplace via rumor, innuendo, bullying, humiliation, discrediting, and isolation.

The manifestation of mobbing may affect both individuals and organizations. The adverse effect of mobbing might cause deficiencies in organizational commitment and organizational performance such as lack of efficiency and effectiveness. According to Dziegielewski et al. (2010), mobbing may affect the organizational commitment, motivation and efficiency of staff, employee job satisfaction, and potential burnout of the employees.

While there had been no exact solution for workplace mobbing, some studies related to prevention were conducted, but only by a handful of researchers worldwide since the 1980s, particularly Keashly, Trott, \& MacLean (1994) in Canada, Leymann (1990) in Scandinavia, Adams (1992) in the UK, and the Namie and Namie (2000) in the U.S.

European researchers examined both mobbing and its effects on the workplace more frequently than American researchers did. In Europe, Leymann (1990) studied the issue of workplace bullying in the 1980s and concentrated on psychological abuse not specified under protected groups, which was labeled as the phenomenon called mobbing (Grunau, 2007). Leymann (1990) found that nearly $15 \%$ of total of the suicides of Sweden each year were the victims of work related mobbing. Over 50 percent of Swedish Salaried Staff and Civil Service Staff Union associates who resigned from their jobs with no job waiting for them, did so because they could not tolerate their involvement of work related mobbing, while $1 \%$ (20,000 in Norway) of union workers surveyed in Norway had experienced workplace mobbing behavior (p. 122). The silent epidemic remained as illustrated by Leymann (1996). Leymann's behaviors typology was the description of mobbing among 2,400 workers (p.176), claimed to represent the all 
workers. Outcomes revealed 154,000 members of the workers of nearly 4.5 million male and female workers suffered from mobbing (Leymann, 1996, p.175).

\section{Gaps in the Literature}

Although there are many studies about this topic, there is no research on specifically examining the relationship between job-related stress, mobbing, and burnout among TSRs in Turkey. Existing studies in Turkey focused on other occupational groups instead of TSRs (Kutanis \& Karakiraz, 2013; Okutan et al., 2013; Akbolat \& Isik, 2008; Tumkaya et al., 2009; Ari \& Tuncay, 2010; Deliorman et al., 2010). Thus, this dissertation research is an attempt to contribute to literature surrounding burnout and health through an examination of the current burnout, job-related stress, mobbing, and HRQoL level of TSRs in Turkey.

\section{Theoretical Framework}

The theoretical framework of the study consists of the theory of the Administrator Stress Cycle Model, the Job Demands-Resources Model, Developmental Theory of Interpersonal Aggression, and Social Stress Theory. A brief review of each theory follows.

\section{The Administrator Stress Cycle Model}

There are four stages in the Administrator Stress Cycle Model (Gmelch \& Gates, 1998). In the first stage, administrators were forced to face the causes of stress while they observed and evaluated the stress-inducing factors, which were called as stressors. In the following stage, reaction to administrators and overcoming supervisory policies occured. When the managers thought stress-inducing factors could be damaging, and if they believed they could bypass these factors, they entered the third phase by reacting to the stress-inducing factors and began to use the coping strategies. In the fourth stage, the administrators took notice of the results and the 
long-term influences of stress. Thus, burnout occured as a result of stress (Gmelch \& Gates, 1998).

\section{The Theory of Job Demands- Resources (JD-R)}

The Theory of Job Demands-Resources (JD-R) explained the relationship between jobrelated stress and burnout (Bakker \& Demerouti, 2007; Demerouti et al., 2001). This theory assumed that all occupations had their own job characteristics associated with burnout, such as job resources (the essential elements to reach a job's goal), decline in job responsibilities required by employees, and stimulation of employees' performance improvement (Halbesleben \& Buckley 2004; Bakker \& Demerouti, 2007). Wiese et al. (2003) claimed that there was a direct relationship between job-related stress and burnout. In a parallel study, Leiter (1993) found that exhaustion was one measurement of burnout that was strongly related to job demands. The other dimension of the burnout, cynicism, was strongly associated to job resources (Leiter, 1993).

\section{Developmental Theory of Interpersonal Aggression}

Buss (1961) created a theoretical outline for classifying individual assault, which was divided into the following categories of behavior to define mobbing: verbal and physical, direct and indirect, and active and passive (Baron \& Neuman, 1996). The Developmental Theory of Interpersonal Aggression (DTIA), developed by Bjorkqvist, improved the outline of Buss and applied it in a new way. Bjrökqvist et al. created the Workplace Harassment Scale (WHS), which was the first scale to be used worldwide to examine specific aspects of the mobbing (Grunau, 2007).

Blasé and Blasé (2003) examined the United States institutions that were considered to be untouchable. For instance, bureaucratic rule-oriented educational organizations provided the 
setting for this study that examined the substantial misuse of teachers. An institute was one where change, for instance globalization, would reasonably be embraced; however Blasé and Blasé (2003) revealed that a decreasing rate of work-related mobbing, though unseen, was prevalent (Grunau, 2007, p.7).

Still, the mobbing and burnout connection remained under-studied in the U.S Grunau, 2007). Grunau (2007) found that the enduring behaviors of mobbing that arose at work were perceived as negative and caused damage to personnel; when experienced by the participants in the sample these behaviors had a statistically significant relationship to burnout. According to this study, which used the WHS, almost 50 percent of the participants reported being mobbed. The research data, on the other hand, depicted that mobbing significantly affected burnout (Grunau, 2007). Moreover, no gender difference was identified in personal burnout, work burnout, or colleague burnout.

\section{Social Stress Theory}

According to Social Stress Theory, stress led to poor psychological wellbeing and adversely affected physical wellbeing. Burnout was one of the stressors that reflected social stress. In other words, burnout was one of the occupational hazards that might provoke social stress. The HRQoL factor was an endpoint to reflect personal perceptions of general wellbeing. Wan (1982) empirically examined these causal links.

Stress demonstrated adverse impacts upon health related to psychological and physical wellbeing, but these results captured only part of the cause related to stress (Aneshensel, 1992). When distinct health results were examined, many of those harmed by stress were counted as unharmed, since they revealed stress reactions as other results (Aneshensel, 1991). According to 
Aneshensel (1992), the total costs of stress in terms of the social, psychological, and economic impacts had not been carefully evaluated. Since only some indications had been considered, the costs of social stress might well have comprised the results relevant to fields of sociological interests in medical sociology, crime and delinquency, educational and professional accomplishment, job creativity, and social mobility.

\section{Conceptual Formulation with Causal Specifications}

In the light of the above-mentioned literature and theoretical perspectives, Figure 1 depicts the study model. As Figure 1 reveals, stressors lead to burnout and burnout affects the health related quality of life of employees.

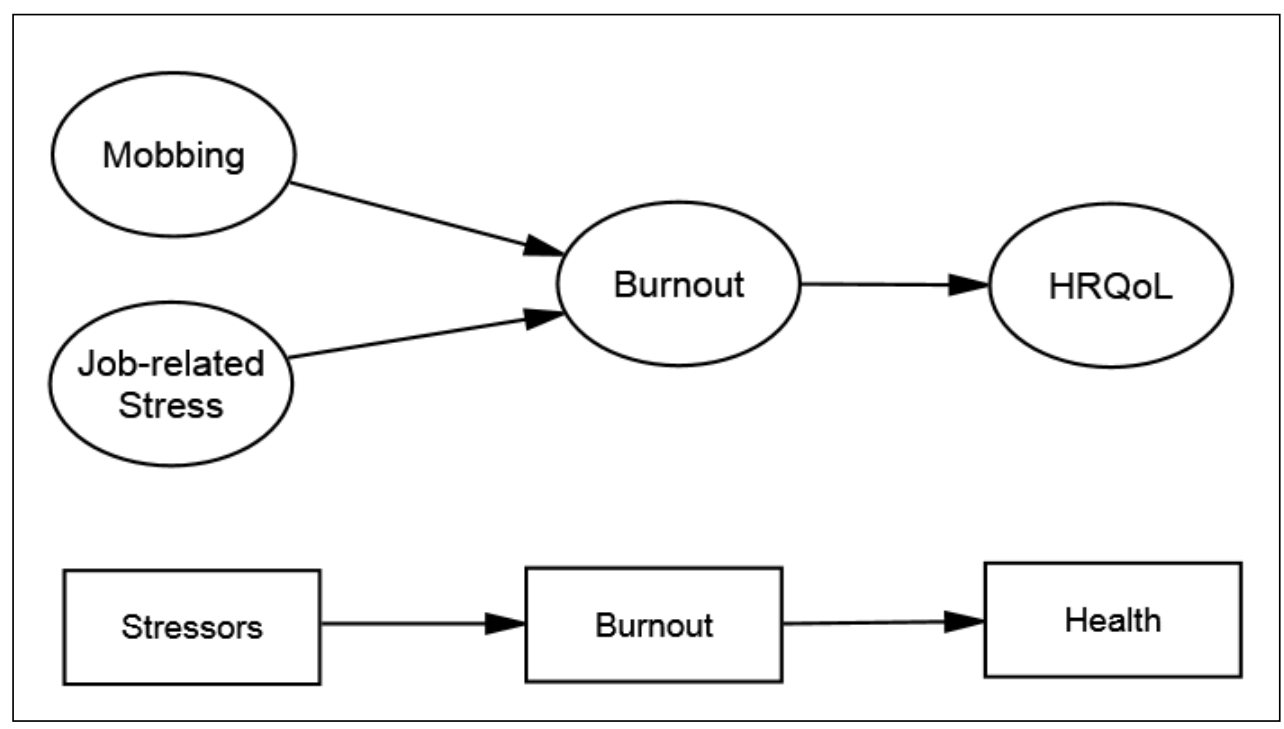

Figure 1. The Study Model

Figure 1 portrays the conceptual framework of the study. The model comprised two main exogenous variables and two endogenous variables. Mobbing and job-related stress of TSRs were exogenous variables, burnout of TSRs was the mediating endogenous variable, and HRQoL of the TSRs was the endogenous variable of the research. Personal burnout, work-related 
burnout, and client-related burnout were latent sub-categories of burnout, while physical health and mental health were latent sub-categories of HRQoL of TSRs. Status, gender, tenure, and education level were the control variables.

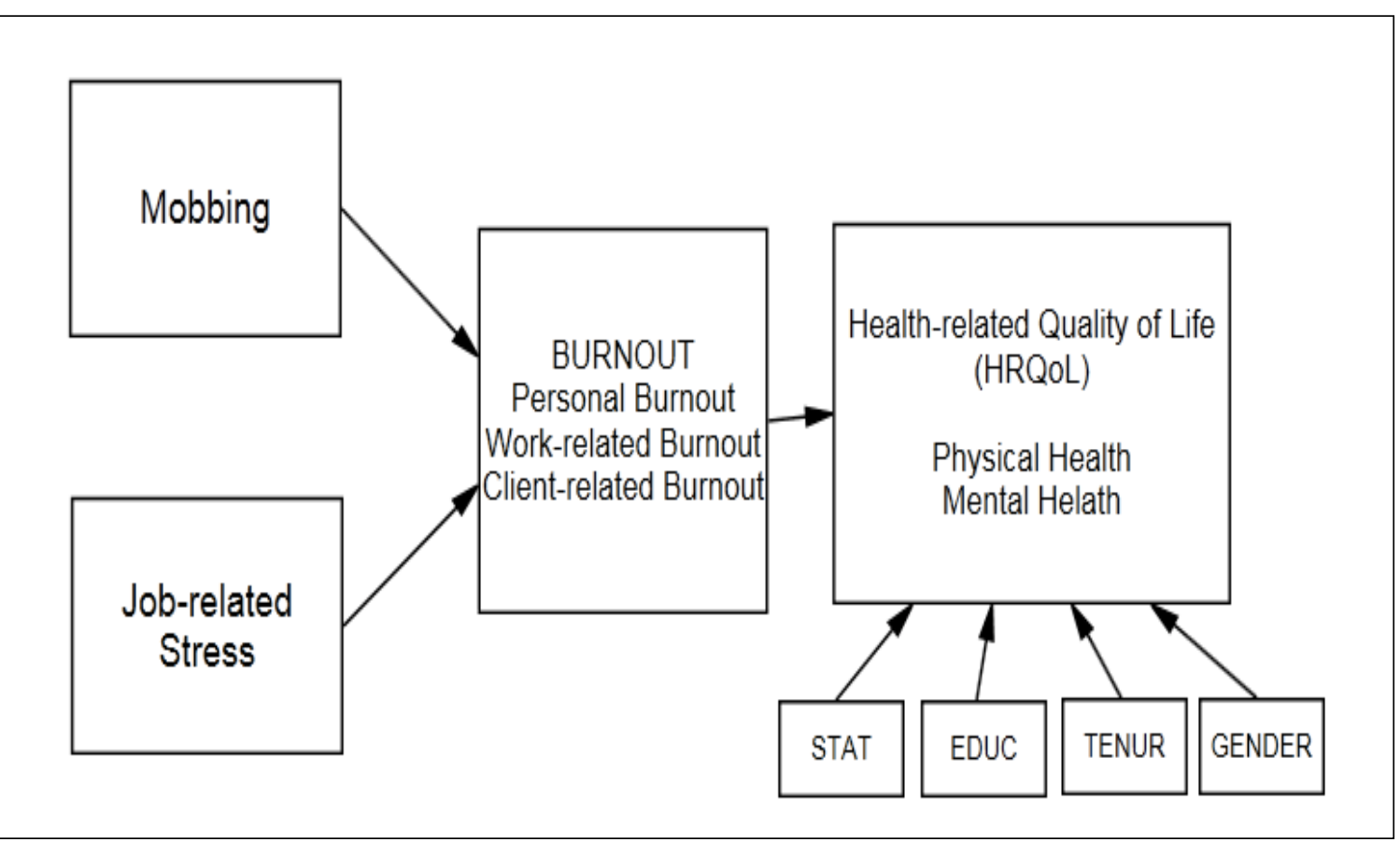

Figure 2. Conceptual Formulation of the Study

\section{Hypotheses of the Study}

In the light of existing literature and above-mentioned theoretical framework, this study generated four hypotheses. As mentioned earlier, job stress was a mental and physical problem that had direct and negative effects on employee productivity and quality of work, particularly because stress was as an employee's response to undesirable work climate features that appeared as threatening to that employee's wellbeing (Gill, Flaschner \& Shachar, 2006). Freudenberger (1974) found a relationship between burnout and job stress, while Wiese and his associates (2003) highlighted the causal relationship between burnout and job stressors. Ortega et al. 
(2007), on the other hand, found a relationship between job-related stress and some demographic characteristics, such as age, rank, and gender.

The first hypothesis had been derived in the light of the Administrator Stress Cycle Model and the theory of Job-Demand Resources (JD-R). The Administrator Stress Cycle Model assumed that administrators took notice of the results and the long-term influences of stress in the last stage. Thus, burnout occurred as a result of stress (Gmelch \& Gates, 1998).

The JD-R Model assumed that all jobs had their own characteristics related to burnout such as job resources, decline in job responsibilities, and stimulation of employees' performance improvement (Halbesleben \& Buckley 2004; Bakker \& Demerouti, 2007). Wiese et al. (2003) found that there was a direct relationship between job-related stress and burnout. Leiter (1993) found that exhaustion was one measurement of the burnout that was strongly associated with job demands. Responsibilities and duties of TSRs were too numerous to achieve alone. Because of this characteristic, TSRs may be exposed to job-related stress and this may cause burnout. In light of the literature and theoretical framework mentioned above, the study developed the following hypothesis to test:

H1: Perceived job-related stress is positively related to perceived burnout of Turkish Territorial State Representatives.

The second hypothesis was derived in the light of the Theory of Interpersonal Aggression. Mobbing and work harassment were described as workplace bullying, workplace incivility, emotional abuse, victimization, or intentional infliction of emotional distress (Leymann, 1990; Liefooghe, 2004; Hornstein, 2003; Keashly, 1998; Wornham, 2003). Leymann (1990) found that several employees resigned their jobs, since they could not tolerate their 
experience of workplace harassment. On the other hand, Blasé and Blasé (2003) examined the bureaucratic rule-oriented educational organizations in the U.S. as the setting of their study of major abuse of teachers. Blasé and Blasé (2003) found that the prevalence of workplace harassment was not only was mobbing present, but also was burnout. Grunau (2007), on the other hand, claimed that mobbing's enduring behaviors lead to damage to employees and found a statistically significant relationship between burnout and mobbing. In light of the abovementioned literature and theoretical framework, the study developed the following hypothesis to test:

H2: Perceived mobbing is positively related to perceived burnout of Turkish Territorial State Representatives.

According to Wan and Pai (1997), health was the lack of disorder or sickness; and physical, mental, and social wellbeing. In this case, the HRQoL was the physical, mental, emotional, and social wellbeing of Turkish territorial state representatives. The HRQoL in this study was the perceived physical and mental health of TSRs over time. Furthermore, the HRQoL concept assessed the experiences of TSRs and their health status to determine specific healthrelated problems that may have affected their lives. Some claim that ongoing stress had a generally negative effect on the health of individuals. According to Martinussen et al. (2007), job burnout was one of the most notable job stressors among the stressors or stressful events.

The Social Stress Theory assumed that stress caused poor psychological wellbeing and then adversely affected physical wellbeing. Burnout was one of the stress-inducing factors that reflected social stress. In other words, burnout was a job-related threat that provoked social stress. The HRQoL was an endpoint to demonstrate personal perceptions of overall wellbeing 
(Wan, 1982). Stress reflected adverse effects on health related to psychological and physical wellbeing, but these results captured only part of the cause related to stress (Aneshensel, 1992). In light of the literature and theoretical framework mentioned, the research assumed that there was a negative relationship between perceived burnout and the HRQoL of TSRs. The study developed the following hypotheses to test:

H3: HRQoL is negatively related to perceived burnout of Turkish Territorial State Representatives.

H4: Perceived burnout mediates the effects of perceived job-related stress on HRQoL of Turkish Territorial State Representatives. 


\section{CHAPTER THREE: THE CONTEXT OF THE STUDY}

\section{General Principles of the Structure of the Turkish State}

Turkey is organized as a unitary state using a democratic parliamentary system with a very centralized organization (Sezen, 2011). The citizens use their dominion directly via the elections, and indirectly by means of the official bodies, namely the Legislative, the Executive, and the Judiciary powers based on the principle of separation of powers (Diab, 2015). The Turkish Grand National Assembly consists of 550 Members of Parliament, which carries the legislative power. Turkish citizens elect members of the Assembly to a 4-year term while the President is elected by an election for a 5-year term (The Turkish Constitution of 1982). The Executive function is exercised by the President of the Republic while the Prime Minister leads the Ministerial Cabinet. The Ministerial Cabinet consists of both the Prime Minister and the Ministers. The President has the authority to appoint the Prime Minister from among the members of Parliament. The Judiciary power is fulfilled by independent courts (The Turkish Constitution of 1982).

Integral unity of administration is stated as follows: “... The organization and functions of the administration are based on the principles of centralized and decentralized administration..." (The Turkish constitution of 1982, article 123). "In terms of the central administrative structure, Turkey is divided into provinces on the basis of geographical and economic circumstances, and public service requirements; provinces are further divided into lower levels of administrative subdivisions" (The Turkish Constitution of 1982, article 126).

Turkey classifies its administrative units into three main categories: central government, local governments, and other entities. 


\section{Central Government}

The central government represents the organizational units constituting the chief administrative organization of Turkey making and implementing political, administrative, and economic decisions regarding the general administration of the state. The central government of the state consists of central and provincial entities (The Turkish Constitution of 1982, article 123).

The Turkish executive branch consists of the Presidency, the Prime Ministry, and the Cabinet Council. Provincial units of the government constitute the branch offices and local agents of the central government in provinces and districts to implement the policies and decisions of the central government. Turkish state representatives ultimately manage these units. The provincial administration system is based on the deconcentration principle (The Turkish Constitution of 1982, article 126).

\section{Local Governments}

Local governments are democratic units established outside the central government to deliver local public services at the local level. Local government units of Turkey are categorized into three main categories: special provincial administrations, municipalities, and villages.

\section{Other Entities}

Other entities can be classified into three categories: functionally decentralized organizations, professional public organizations, and advisory and supervisory organizations. The main function of decentralized organizations is to deliver certain public services within their areas of specialization throughout the country. Some prominent examples of these entities are Social Security Institution, the Radio and Television Supreme Council, the Public Procurement 
Authority, Banking Regulation and Supervision Agency, and universities. Professional public organizations are created to meet the common needs and to contribute improvement of the members of a specific field such as bar associations and professional chambers of engineers.

In principle, advisory and supervisory organizations have no executive power. The main role of these organizations is to provide guidance and advice to the bodies of the state in many areas. The National Security Council, State Inspection Board, and Court of Audit and Higher Inspection Board are the prominent examples of these organizations.

\section{$\underline{\text { A Brief Overview of Turkish Ministry of Interior }}$}

In the Turkish administrative system, each Ministry has the following organizational structures: main service units, advisory and supervisory units, auxiliary units, affiliated entities, and temporary or permanent boards (Act of 3046. 27.09.1984). Each ministry has its own individual main service units established by its particular regulation and works as part of the executive branch of the state.

During the Ottoman Empire and the Republic era, the Turkish Ministry of Interior, which has a well-rooted position in Turkey's public administration system, always had the role of undertaking and effectively enforcing several significant tasks in the life of the Turkish State and society (TMoI, 2014).

The history of the Turkish Ministry of Interior has its roots in the establishment of Chamberlain of the Grand Vizier, namely the Sadrazam Kethüdalığı, which was a division of the 
government organization before the Tanzimat Period ${ }^{1}$ in the Ottoman Empire, in time it gained more importance and, after various transformations, shaped today's Turkish Ministry of Interior. Table 1 depicts organizational structure of the Turkish Ministry of Interior.

${ }^{1}$ The Tanzimat (known as Ottoman Reform) is a period of reformation reorganizing of the Ottoman Empire lasted from 1839 to 1876. 


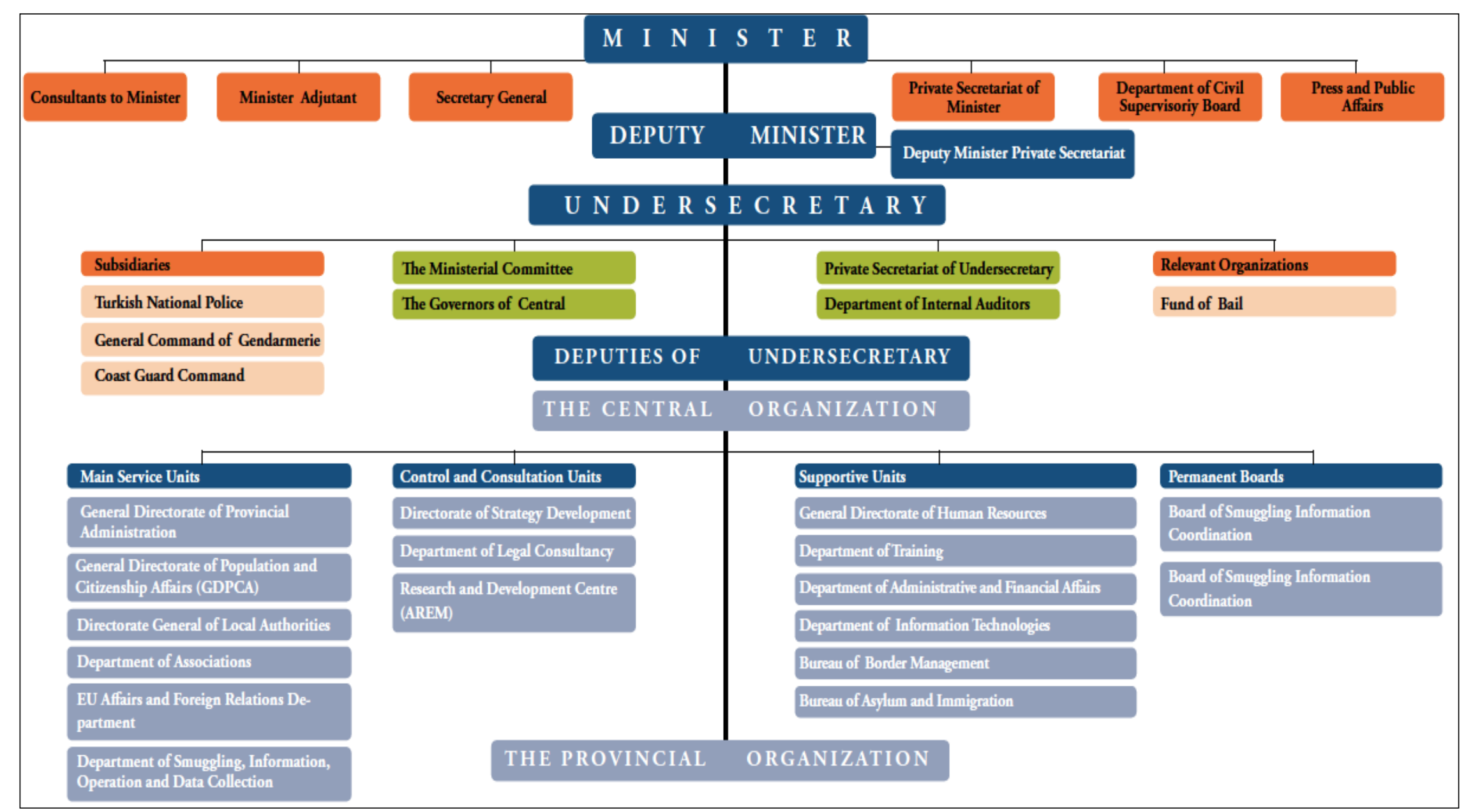

Figure 3. Organizational Structure of the Turkish Ministry of Interior

Source: Turkish Ministry of Interior Introductory Book, www.diab.gov.tr (2015) 
The main responsibilities of the Turkish Ministry of Interior are as follows: undertaking homeland security and maintaining the public order; safeguarding public safety; running the general administration of the provinces; supervising the local administration units and assisting local authorities to improve by means of legal measures taken administratively; performing the population registry and citizenship transactions; and deploying civil defense services in cases of possible wars and natural disasters. The Turkish Ministry administers these very important tasks through its central and provincial organisations (TMoI, 2014).

\section{$\underline{\text { Provincial and Turkish State Territorial Representatives System }}$}

The Provincial Administration Regulations of 1864, or known in Turkey as Idare-i Vilayet Nizamnamesi, is considered the foundation of the Turkish civil administration system. The provincial administration has applied the system in the Turkish central government for more than one century. According to this system, the country is divided into administrative units called provinces. The fundamental logic underlying the provincial system is the delegation of hierarchical duties and responsibilities of the government and the separate ministries regarding the organizations in that particular province to the provincial administration. Correspondingly, the central government bodies must be founded in accordance with the division of the civil administration and all public organizations in the province must be accountable to the provincial governor.

The main legal texts defining the peripheral administration system are the 1982 Constitution, the Act of 5442 of Provincial Administration, and the Act of 3046 regarding the Principles of the Establishment and Tasks of Ministries. It is stated in the first paragraph of the Article 126 of the Turkish Constitution of 1982 that "Turkey is divided, in terms of the central 
government establishment, into provinces, and the provinces into other subdivisions, based on the geographical location, economic conditions and the requirements of the public services." And the third paragraph of the same Article decrees that "central government organizations composed of more than one provinces can also be established with the purpose of attaining efficiency and harmony in delivering public services."

The Constitution does not regulate what the successive divisions are under the province. These divisions and the other details regarding the provincial system have been arranged in the Act of 5442 of Provincial Administration. According to the Act of 3046, the ministries can be organized in the field in three ways:

1) The provincial institutions affiliated with the provincial governor

2) The borough institutions affiliated with the district governor, and

3) Peripheral institutions affiliated directly to the central government.

The Act of 3046 uses a provincial system of peripheral organization of ministries, the center of which is its local authority.

As stated above, the provincial system, or the civil administration system, is a system enabling the central government principle to be practiced all around the country, while at the same time eliminating, or at least moderating, the drawbacks of the central government.

\section{Administrative Organization and Divisions of Turkey}

According to the current constitution of Turkey (the 1982 Constitution), the Turkish administration system is based on the provincial system. The previous constitutions of the 1921, 1924, and 1961 proposed the same system; there were no middle administrative divisions established between the "center" and the "province." 
The first two Turkish constitutions of 1921 and 1924 state the sub-divisions of the provinces; however, the following constitutions of 1961 and 1982 did not create these branches. These constitutions have left this area to be arranged by the secondary laws. As a consequence of this constitutional requirement, the Turkish Parliament has the authority to create new provinces and boroughs or to combine the existing administrative structures.

\section{Delegation of Authority: The Principle of Provincial Administration}

The delegation of the authority is the main principle of the administration of the provinces. The principle of the delegation of the authority requires delegating of some of the decision making and execution powers of the central government to the next sub-hierarchical level to that particular authority.

Delegation of authority necessitates the use of the authority given to an administration in the location of that work. The central government is the basis of the delegation of the authority. The concentration and the delegation of authority are the two main contexts of the centralization. The chief element regarding the delegation of authority and condensation is whether the provincial authority representing the central government has the authority to make decisions for itself within its specific area, or whether it just conducts the paperwork and delays the necessary information to the central government for the decisions. Adopting the delegation of authority method provides for the ability to handle the routine works by the authorities in the provinces while the most important works come to the desks of the central governments.

The local organizations were administrated by the central organizations during the republic era of Turkey in accordance with the centralized approached discussed above. As a result of the fact that the delegation of authority was adopted as the sole principle in the 
provincial administration in the Turkish Constitution of 1961, this interpretation in a way shaped the constitutional arrangement. Similarly, the Turkish Constitution of 1982 adopted the delegation of authority as the main principle in the provincial administration.

\section{$\underline{\text { Structure of the Provincial Administration }}$}

According to the Act of 5442 on Provincial Administration, which is the law that organizes the provincial administration, provincial administrations are composed of the "provincial" and "borough," both of which constitute the two main administrative units of Turkish provincial divisions. In other words, the provincial administration is described as the peripheral organization of the central government and the units where the administration regarding the local services is given to the delegates of the local people are assigned as the local bodies. Provincial administration (provincial governorate) and borough administration (district governorate) constitute the main bone of the civil administration, while special provincial administration, municipalities, and villages constitute the local administrative units of Turkey. A provincial governor has the power to supervise all public agencies in the province, except military and judicial bodies. The administrative relationship between provinces and boroughs is based on the vertical hierarchy. This system requires the district governors, the head of the boroughs, to work hierarchically under the provincial governors.

\section{The Provinces}

Currently, there are 81 provinces in Turkey designed on the basis of province-borough division (TMoI, 2015). Provinces are the part of the legal entity of the Turkish state as the peripheral extension of the central government. Thus, the province governorates, just as the ministries, are within the scope of the legal entity of the state. In the provincial system, a 
provincial governor is the representative of the State, the central government, and the individual provincial ministries in which he/she charges (The Act of 5442 Provincial Administration).

\section{The Boroughs}

The second unit of Turkish administration level is the borough, which is governed by appointed officials, district governors, called Kaymakam. The 1876 Constitution brings the term 'borough' to the administration system as an administration level. The Turkish Constitution of 1921 and 1924 also kept it as an administration level. In administrative terms, a borough is a part of a province, covering more than one villages, towns, or municipalities.

\section{$\underline{\text { The Occupational Positions of Turkish Territorial State Representatives }}$}

The main TSR positions in Turkish Administration System are Governor, Deputy Governor, District Governor, the central organization bureaucrats of the ministry, Civil Inspectors, and Legal Advisors.

\section{The Governor}

Basic legal texts govern the status of the Governor: the Act of 1700 on Civil Servants of Internal Affairs, the Act of 5442 of the Provincial Administration, the Act of 3152 of Organization and Duties of the Turkish Ministry of Interior, and the Act of 657 of the Civil Servants. The legal status of the Governor is enacted by the Turkish Constitution of 1982 regulates. Except for the judicial and military institutions, the Provincial Governor is the most authorized superior of all the staff working in the ministries branches and in other public organizations in the province. A provincial governor has the power of monitoring and supervising over all public agencies located in the province. As a natural consequence of this fact, all ministerial branch directors are accountable to the Provincial Governor. 


\section{The Deputy Governor}

The Deputy Governor position is not listed among Turkish territorial state representatives by the Act of 1700 on Civil Servants of Internal Affairs. However, the Act of 5442 lists this position in the provinces to assist the provincial governors. The duties and responsibilities of deputy governors are determined and delegated by the provincial governor with a governorate directive of tasks distribution (Kubilay, 1998). In order to be appointed as a deputy governor, one has to have at least six years of district governor experience with a required two-year Eastern region experience.

\section{District Governor}

A District Governor is the representative of the central government and top-ranking officer of the public servants in the district. According to Karasu (2002), district governors are the basic bone of the provincial system. The main role of a district governor is to take responsibility for general administration and supervising the district where he/she is in charge. In a similar way of governors, district governors are the head of district managerial branch and represent the central government. They perform their job under the supervision of the provincial governor. The main difference between the positions of provincial governor and district governor is that a provincial governor represents the state and the government while a district governor represents the government.

\section{Civil Inspectors and Legal Advisors}

The Regulation on the Appointment Procedures and Principles of the Turkish Civil Inspectors and the Inspector Board Regulations regulate the necessary requirements for being a civil inspector. A district governor has to have at least six years of a district governor or central 
positions experience or deputy governor with required passing the oral exams. The main roles and duties of the civic inspector are to inspect works, transactions, expenditures, and services provided or carried out by the organizations working under supervision of the Turkish Ministry of Interior.

The roles of the legal advisors are regulated by the Act of 3152 of Organization and Duties of the Turkish Ministry of Interior (Act of 3152, article 16). The main responsibility and duty of the legal advisors regulated by the Act of 3152 is to express and send the opinions on the legal issues or questions sent by the other units of the ministry (Act of 3152, article 17).

\section{Central Organizations Bureaucrats}

Despite the fact that the main function of TSRs is a territorial job, a small part of the TSRs is employed at the central organization of the Turkish Ministry of Interior with several ranks. The central bureaucrats of the ministry are Undersecretary, Deputy Undersecretaries, General Managers, Deputy General Managers, Heads of Departments, and Branch Managers.

\section{Hiring, Training, and Appointment Process of the TSRs}

The Act of 1700 on Civil Servants of Internal Affairs regulates the main basic prerequisite characteristics to be appointed as a district trainee, which are: a) graduation from the departments of political science, law, economics, business, and public affairs programs; b) age limitation; c) proof of good health; d) to be successful in the entrance exam having written and oral exams; and e) a clean criminal background record. After the selection process, TSRs are sent to provinces for the provincial training period under the monitoring and supervision of provincial governors. Territorial state representatives are provided an opportunity to observe the provincial level administration by closely working with deputy governors. 
The second phase is to work at the district level under supervision of senior district governors. This period gives TSRs the opportunity to observe district level administration issues, procedures, and duties carried out by district governors and branch managers. The third phase is to work with a senior civil inspector of the Ministry, which gives TSRs time to observe and learn the inspection process of districts and provinces. Following training processes are training at the ministry center, attending training abroad, working as an interim district governor, and finally attending the district governorship course. The main two training processes at the Ministry level are an orientation course and a preparation for foreign language course. Each district governor is sent to abroad for one year to gain international experience and improve foreign language skills.

One of the most important course outcomes is to be appointed as an interim district governor, which is a position that is given the full authorities of the highest-ranking officer over all public units at the district level. This process gives TSRs a powerful and experiential opportunity to confront real public issues. One of the important functions of this experience is to observe and evaluate the abilities, performances, public relations, and management skills of TSRs.

In the final phase of the program, TSRs take a district governorship course, which is held at the capital city. This course provides TSRs with important information ranging from leadership, crisis management and effective speech, to personality development with parallels to some occupational information (Atilgan, 2005). Before completing this course, each district governor trainee is required to submit a dissertation examining public affairs or occupational issues. During the dissertation process, a thesis supervisor is chosen by the Turkish Ministry of Interior from among senior TSRs and assigned to assist the trainees. The trainees defend their 
dissertation in front of a committee consisting of high-ranking TSRs working at the central organization of the ministry. The dissertation process aims to improve the academic and research skills of TSRs. 


\section{CHAPTER FOUR: METHODOLOGY}

This section provides the methodological information of the study. The main method adopted by this study is quantitative research method (Creswell, 2009). Structural Equation Modeling is the main statistical technique of this study. First, a summary is presented on research design, subjects for the study, data collection, sampling, power analysis, sample size justification, measurement, survey instruments, and operational definitions of the study variables. Second, statistical analysis, measurement models, covariance structure model, and the validation of the models are detailed.

\section{$\underline{\text { Research Design }}$}

Since the study had neither control and experimental groups, nor an intervention, the research design adopted by this study was a non-experimental design (Trochim, 2001; Gliner \& Morgan, 2000). A cross-sectional survey was constructed and administered to TSRs and because the study collected, measured, and analyzed data at one time, Dillman's Internet-based survey design (Web survey) was used. The e-survey provided a mechanism to handle international limitations as important obstacles to make surveys. Once the electronic data collection system was developed, the survey cost was minimized in comparison to a traditional survey and time required for survey can be decreased (Dillman, 2007).

Dillman's five step strategies were used in order to get a maximum response rate. In the first step, an instructive e-letter was sent to the participants to clarify the significance of the survey. The same e-letter also emphasized the importance of the participation to the study and notified that a survey link was delivered. According to Dillman (2007), several studies constantly reveal that a pre-notice letter maximizes the response rate. In this study, first two steps were 
merged in one step, and pre-notice letter was sent to the participants with the existing email having survey link. The consent form — which stressed that the participation of respondents is voluntary — was placed at the beginning of the survey. The same consent form guaranteed confidentiality and that no personal identifiable information was gathered.

Dillman's (2007) third step occurred at the end of the questionnaire. In this step a 'thank you' or 'appreciation note' was delivered automatically to the participants as a way to express appreciation for their participation in the research. Since the study reached adequate sample size, the following two steps, replacement contact and replacement prompt, were not employed (Millar \& Dillman, 2011, Messer \& Dillman 2011).

\section{$\underline{\text { Subjects for the Study }}$}

The unit of analysis of the study was the TSRs of Turkey who worked under supervision of the Turkish Ministry of Interior. The administrative system of Turkey is mainly based on the provincial system. There are 81 provinces and 919 districts in Turkey. The TSRs of Turkey consist of provincial governors, district governors, deputy governors, civil inspectors, and midranking and high-ranking officials working at the central organization of the Turkish Ministry of Interior. A reflected in Table 1, the total number of TSRs in Turkey is 1,688, and a participation rate of $30 \%$ of this population was obtained. 
Table 1. The Number and Status of the TSRs

\begin{tabular}{ll}
\hline Status & Number \\
\hline District Governors & 865 \\
Deputy Governors & 498 \\
Civil Chief Inspector & 191 \\
TSRs at Central Bureaucracy & 134 \\
Total & 1688 \\
\hline
\end{tabular}

Source: www.icisleri.gov.tr (2015)

\section{$\underline{\text { Data Collection Method }}$}

Four copyrighted survey scales, consisting of 59 items (with 5 control variables), were used to construct a survey questionnaire. The response set was designed in accordance with the five-point and three-point Likert scales. In this research, TSRs were reached via the online egovernment system of the Turkish Ministry of Interior, which included all provinces and districts in Turkey. The researcher received authorization to conduct the study and gain access to the Turkish Ministry of Interior e-government network system.

\section{$\underline{\text { Sampling }}$}

The unit of analysis and the population of the study are Turkish TSRs. Since the survey was sent to the entire study population of the TSRs, the study reached close to a $30 \%$ sample size.

\section{Power Analysis and Sample Size Justification}

Power analysis technique is required to identify the maximal chance to reject the null hypotheses when they are false (Trochim, 2001; Zhang \& Wang, 2009). For this study, the researcher performed power analysis based on the confidence level desired for the results. Hence, this study set the confidence level at .05 , which is called $\mathrm{p}$ value. Thus, the confidence 
interval of the study was $95 \%$, which meant the study provided $95 \%$ confidentiality rate and with any study sample would provide the same results (Trochim, 2001). The population consisted of 1,688 TSRs. Hence, the researcher made efforts to recruit all members of the population. Then, the researcher compared demographics of the resulting sample to the demographics of the population in order to identify the representativeness of the sample to match with the total population of TSRs. Structural equation modeling (SEM) was used to examine the relationship among the study variables. The sample size justification could be based on several perspectives to calculate the ideal sample size for an SEM model.

The first perspective is Rule of Thumb. The rule of thumb requires the multiplication of the number of unknown parameters by 5-20 (Kline, 2010). The second one is Less Optimal and Minimum Sample Size Perspective. According to Kline (2010), the sample size for SEM should be in the range of $100-200$, as 100 is the less optimal sample size, while some propose 200 is satisfactory number for the minimum sample size for the SEM (Boomsma and Hoogland (2001). However, this number might be increased according to complexity of the model. This study adopted the perspective of Boomsma and Hoogland (2001). Thus, the study reached the adequate sample size with 502 participants out of 1,688 Turkish TSRs. The Hoelter index also asserted that the study must have an adequate sample size. Hoelter index helps to determine whether the study has an adequate sample size for the model fit evaluation. The Hoelter's critical index, which has value higher than 200 , suggests that the study has an adequate sample size, while the values between 75 and 200 means the study has acceptable sample size (Garson, 2012). According to findings, this study had a 244 Hoelter's critical N, which meant it had adequate sample size. 


\section{The Study Variables and Measurement}

The study have two exogenous and two endogenous variables. Exogenous variables of the study are mobbing and job-related stress, while endogenous variables are burnout and health related quality of life.

The first exogenous variable of the study is mobbing. This variable was measured using the WHS questionnaire with 13 items to examine the work harassment level. The second exogenous variable is job-related stress. This variable was measured via the job stress scale using 11 items. Job-related stress of TSRs was measured to distinguish the nature of the connections among some possible stress making factors that were chosen based of the literature and experience of the TSRs, the first level outcome, and work related stress. It also examined the dimensionality of job stress more closely in order to determine to what extent the dimensions were differentially affected by different stressors.

The first endogenous variable is burnout. This variable was measured via the CBI questionnaire. This latent construct had first-order and second-order factors. Burnout was measured with three first-order latent factors that were personal burnout, work related burnout, and client related burnout.

The last endogenous variable of the study is health-related quality of life. The HRQoL was a latent concept that had multiple dimensions including physical, mental, emotional, and social wellbeing. It was measured with 12 items and inquired about participants' health status to what extent their health status affected their physical and mental wellbeing, which were the

first-order factors of HRQoL. Furthermore, the HRQoL evaluated experiences of TSRs regarding 
their health status to determine specific health-related problems that might influence the lives of TSRs.

The study aimed to examine the relationships between latent exogenous variables and latent endogenous variables, which were discussed in the previous paragraph. Since personal attributes may influence the variation in perceptions, it was imperative to include variables such as status, gender, and tenure status as control variables in the analysis.

The copyright scales used by this study were:

1. HRQoL SF-12v2TM 4-week recall (Ware et al, 1998).

2. Copenhagen Burnout Inventory Scale (Kristensen et al., 2005)

3. Work Harassment Scale (Bjrökqvist and Osterman, 1992)

4. Job Stress Scale (Parker and DeCotiis, 1983)

HRQoL SF-12v2 TM 4-week recall

The study used the Health Survey Short Form (SF)-12v2 developed by Ware and his coworkers (Ware et al., 1998). The survey measured the multiple dimensions of HRQoL with 12 items (Pai \& Wan, 1997) and asked about participants' health status, (to what extent their health affects their physical and social well-being, etc.). The HRQoL $\mathrm{SF}-12 \mathrm{v} 2^{\mathrm{TM}}$ four-week recall instrument was indicated in the SEM model as a first-order and second-order latent construct, because it had physical health and mental health as first-degree factors. Physical health consisted of physical functioning, role physical, bodily pain, and general health, while mental health consisted of vitality, social functioning, role emotional, and mental health. The physical health first-degree latent construct consisted of the indicators of $\mathrm{H} 1, \mathrm{H} 2 \mathrm{a}$, 
$\mathrm{H} 2 \mathrm{~b}, \mathrm{H} 3 \mathrm{a}, 3 \mathrm{Hb}$, and $\mathrm{H} 5$, while mental health first-degree latent construct consists of the indicators of H4a, H4b, H6a, H6b, H6c, and H7.

The SF-12v2 Scale (Ware et al., 2002) offered significant improvements in the measurement of health condition. Twelve items of the survey were obtained directly from the SF-36v2. Findings revealed that the improvements in the SF-12v2 were parallel to the improvements made to the SF-36v2. Much of the research used to design the SF surveys showed that different ways of running organizations might affect survey results (Maruish \& Turner-Bowker, 2009).

Studies depict that reliable estimate of health status scores throughout the range of health levels (Gandek et. al., 1998; Ware, et. al., 2000; Ware et al., 2003). SF 12v2 measures yield directly comparable estimates of average population scores (Maruish \& DeRosa, 2009). Maruish and DeRosa's study (2009) found that SF-12v2 survey scale had convergent validity (percentage of hypothesized item-component summary measure correlations that are .30 or greater), discriminant validity, consistent responses (percentage of respondents with a response consistency index of zero), item internal consistency (percentage of hypothesized item-scale correlations that are .40 or greater), and item discriminant validity (percentage of hypothesized item-scale correlations that are higher than the alternative item-scale correlations). As for scale reliability of SF 12v2, the Cronbach's Alpha score $(>.70)$ showed that the scale was considered reliable (Maruish \& DeRosa, 2009).

Keller et al. (1998) examined the construct validity of HRQoL scale in 10 countries, from the United States to Denmark. According to results, HRQoL scale and physical and mental health measures had comparable explanations throughout nations and the construct validity of 
HRQoL was confirmed (Keller et al., 1998). Moreover, Bhandari (2012) found that HRQoL instrument used in his study was recognized to have good reliability and validity with other population with .80 Cronbach's alpha score. Similarly, in Anagnostopoulos et al.'s study (2010), internal consistency of HRQoL scale was measured by Cronbach's alpha score from .71 to .89.

\section{Copenhagen Burnout Inventory Scale}

The CBI Scale (Kristensen et al., 2005) is a questionnaire (Appendix H) created in Denmark by scholars Kristensen et al. (2005) to prevent drawbacks of the well-known MBI Questionnaire. Understanding of cultural differences between the U.S. and European groups resulted in questions that were culturally sensitive (Kristensen et al., 2005, p. 195). According to Kristensen et al. (2005), three first-order latent factors of burnout were personal burnout, work related burnout, and client related burnout. Kristensen et al. (2005) found that the CBI scale had a satisfactory internal reliability and validity. The Cronbach's alpha for internal reliability was .86 (Kristensen et al., 2005). The same study also proved that CBI scale had high face validity, convergent validity, and divergent validity (Kristensen et al., 2005).

\section{Job Stress Scale}

The study named "Organizational Determinants of Job Stress" proposed to be a partial test of the short version of the model with 11 items (Appendix J). Particularly, the authors created to determine the nature of the relations among some possible stressors chosen on the basis of the literature and information of the population, the first-level result, and work related stress. They also examined the dimensionality of job stress more closely, in order to identify the extent to which the scopes were differentially affected by different stressors (Parker \& DeCotiis, 1983). The internal consistency of the scale was determined with an average coefficient alpha of 
.89 and the Cronbach's alpha score of the scales were .86 and .74 (Parker \& DeCotiis, 1983). Xie and Johns (1995) found the reliability coefficient of job stress scale as .82 in their study. Similarly, Jamal (1999) found that the alpha reliability of the job stress scale is .85 and confirmed that the reliability of job stress scale is sufficient. According to Touringy et al.'s study (2005), the reliability of the job stress scale was .89 .

\section{Work Harassment Scale}

Multicultural resemblances in expression of hidden and evident assault were well examined by the researchers and revealed in the WHS (Bjrökqvist and Osterman, 1992; Osterman et al., 1998). Bjrökqvist et al. (1992) created the WHS, which was the first scale to be used worldwide to examine specific aspects of the mobbing (Grunau, 2007). This scale particularly examined the work harassment by coworkers. The scale was converted to the Turkish version (Appendix M, N). Bjrökqvist et al. (1992a) confirmed the reliability of the WHS scale with Cronbach's alpha score .95. In the other study of Bjrökqvist et al. (1994a), the internal consistency of the scale was alpha $=.86$. Table 2 illustrates the operational definitions and measurement instrument of the study variables. 
Table 2. Operational Definitions and Measurement Instrument of the Study Variables

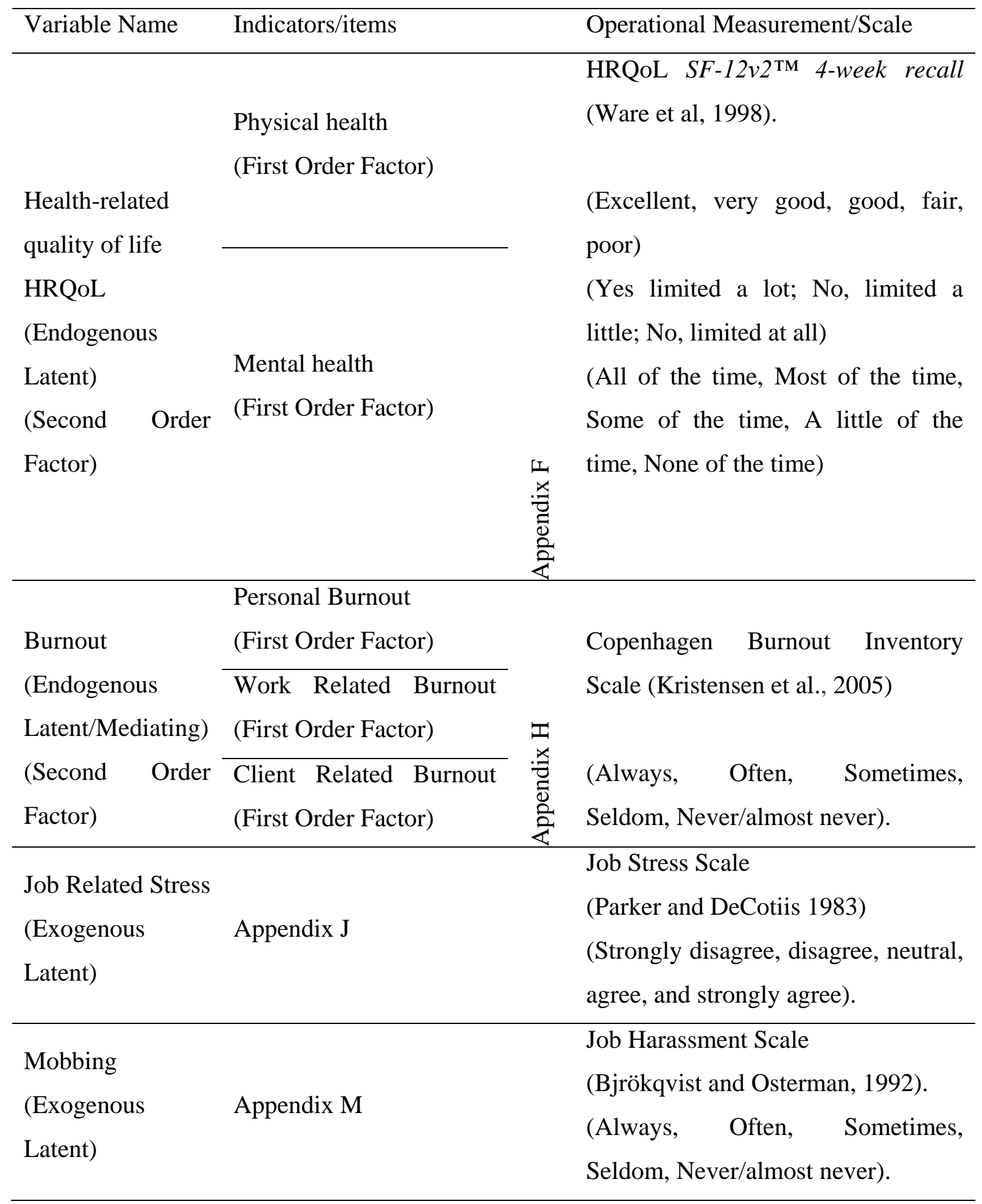




\section{Control Variables}

\begin{tabular}{|c|c|c|c|c|}
\hline Status & $\begin{array}{l}\text { What is your occupational } \\
\text { position? }\end{array}$ & \multirow{4}{*}{\multicolumn{2}{|c|}{$\begin{array}{ll}\text { Self } & \text {-structured } \\
\text { asking } & \text { participant } \\
\text { features } & \end{array}$}} & \multirow{3}{*}{$\begin{array}{l}\text { questionnaire } \\
\text { demographic }\end{array}$} \\
\hline Gender & What is your gender? & & & \\
\hline Tenure & $\begin{array}{l}\text { How many years have you been } \\
\text { working in public sector? }\end{array}$ & & & \\
\hline Education Level & What is your education level? & & & \\
\hline
\end{tabular}




\section{Measurement Reliability}

Measurement reliability is one of the vital issues for any survey instrument for the consistency or repeatability of the measures. The main role of the measurement reliability is to examine whether scales create consistent results over time or not. The Cronbach's Alpha coefficient is used to evaluate the extent to which a measurement produces reliable results at different times (Cronbach, 1951; Kline, 2011). The threshold level for Cronbach's Alpha coefficient is as follows: bigger than .9 is excellent, bigger than .8 is good, while bigger than .70 is acceptable (George \& Mallery, 2003). Kline (2010) emphasizes that Cronbach's score bigger than .70 provides that a latent variable has satisfactory internal consistency. Hence, .70 is identified as the threshold for the reliability of the survey.

Some scholars, on the other hand, suggest that the composite reliability index is a second way to check the internal consistency of a latent variable by using the formula developed by Werts et al. (DeShon, 1996). According to this index, a score bigger than .70 indicates satisfactory internal consistency for a latent variable (Delmas \& Toffel, 2008). Thus, this study adopted Cronbach's Alpha score of .70 as the threshold for its measurement reliability.

\section{$\underline{\text { Statistical Analysis }}$}

The study mainly utilized two statistical analyses, which were descriptive analysis and SEM. First, descriptive analysis method will be discussed briefly, then confirmatory factor analysis, measurement models, covariance structure model, and validation of the models will be summarized within the SEM context. 


\section{Descriptive Analysis}

Before performing the structural equation modeling, descriptive analysis was implemented to examine the main features of the dataset. Descriptive statistics of SPSS provided frequency tables and the distribution of the variables. A frequency table of each study variable was provided independently to show how the responses were distributed. Descriptive analysis also helped to check the dataset whether there were any missing values or not. When some missing values were detected, missing value analysis of SPSS was performed to handle the missing values. Moreover, multicollinearity issue was handled via correlation matrix of SPSS in order to find the highly correlated variables. This study adopted the Spearman's rho to check the multicollinearity among the variables (Kline, 2011). According to Kline (2011), multicollinearity arose if two indicators primarily measured the same one. Thus, keeping both of these two indicators was unnecessary and it was necessary to remove at least one these indicators. The threshold to detect the multicollinearity issue accepted commonly by the scholars was .70 (Meyers, Gamst, and Guarino, 2013). However, some researchers adopted the higher multicollinearity threshold of .85 (Kline, 2011; Garson, 2012).

\section{Structural Equation Modeling}

The study used SEM, since the approach is ideal when testing theories that include latent variables, such as burnout, job-related stress, HRQoL, and mobbing. The SEM consists of the measurement model and the structural model. The structural model allows for the assessment of the relationships specified in the hypotheses (Hox \& Bechger, 1998; Hoyle, 1995). Specifically, the path coefficients were examined with attention to the strength, direction, and significance of the relationships. In addition, the model as a whole was assessed through the goodness of fit 
indices. The criteria regarding the indices are detailed in the validation section. The SEM was used to validate the theoretically driven model (Wan, 2002).

The model validation comprised both measurement and CFA. The structural model comprised each measurement model and observable variables. Then, validation was checked to see whether the SEM model clarifies the variance in the endogenous variable of the study, health-related quality of life by the variables; namely, job-related stress, burnout, and mobbing.

\section{Confirmatory Factor Analysis}

This study used a CFA method to create and validate the measurement models for the unobservable (latent) variables. The CFA was a construct based on theoretical understanding that determined the variation and covariation between the observed variables, which were indicators and latent variables, unobserved variables, and measurement errors (DeCoster, 1998). It identified whether the number of factors and loadings of the measured variables on them conformed to what was expected on the basis of pre-established theory. Hence, CFA attempted to explain the variation and covariation in a set of observed variables in terms of a set of theoretical and unobserved factors (Wan, 2002).

The three assumptions of CFA were a) latent and observable variables are measured as deviations from their means; b) the figure of observable variables in the indicators was bigger than the number of unobservable variables; and c) and the common and also unique factors were not correlated. The CFA provided researchers with hypothesis-testing capability (Wan, 2002; Brown \& Tinsley, 2000).

One of the key strengths of CFA is that researchers could identify the fit of the measurement model prior to estimating the SEM model. The CFA also provides researchers a 
chance to create relationship between variables, which means researchers can identify their models providing separate estimations of relationships amongst the latent constructs and their corresponding indicators. Because of CFA, we establish a strong theoretical construct before analyzing the data and researchers have a causal inference model (Williams, 1995). The CFA provides researchers with the means apply purposeful limitations on measurement model, which is considered to be the main advantage of CFA (Wan, 2002). The study adopted the following validation steps. First was to develop a generic model for each construct. However, when the model did not fit well with the dataset, a revision was made for the generic model by removing the weak items, which have low factor loading from the subscale. Second was to provide a better model after removing the weak items from each latent construct in the measurement models (Wan, 2002). And third, some indices were used to revise the model and finally modification indices (MI) were used to revise the model. The details will be given in detail in the subsequent section.

\section{$\underline{\text { Measurement Models }}$}

The latent constructs to be measured in this study were the endogenous variable of HRQoL, the endogenous mediating variable of burnout, and the exogenous variables of mobbing and job-related stress.

\section{A Second-Order Measurement Model for HRQoL}

The endogenous variable of HRQoL is the first measurement model shown in Figure 4. It was measured with two first-order latent variables and 12 indicators (Appendix F). Participants' HRQoL was measured by asking their general health status to what extent their health statuses affect their mental and physical wellbeing. Physical health consists of physical functioning, role 
physical, bodily pain, and general health, while mental health consists of vitality, social functioning, role emotional, and mental health. Physical health first-degree latent construct's indicators are the indicators of $\mathrm{H} 1, \mathrm{H} 2 \mathrm{a}, \mathrm{H} 2 \mathrm{~b}, \mathrm{H} 3 \mathrm{a}, \mathrm{H} 3 \mathrm{~b}$, and $\mathrm{H} 5$, while mental health first-order latent construct consists of the indicators of $\mathrm{H} 4 \mathrm{a}, \mathrm{H} 4 \mathrm{~b}, \mathrm{H} 6 \mathrm{a}, \mathrm{H} 6 \mathrm{~b}, \mathrm{H} 6 \mathrm{c}$, and $\mathrm{H} 7$.

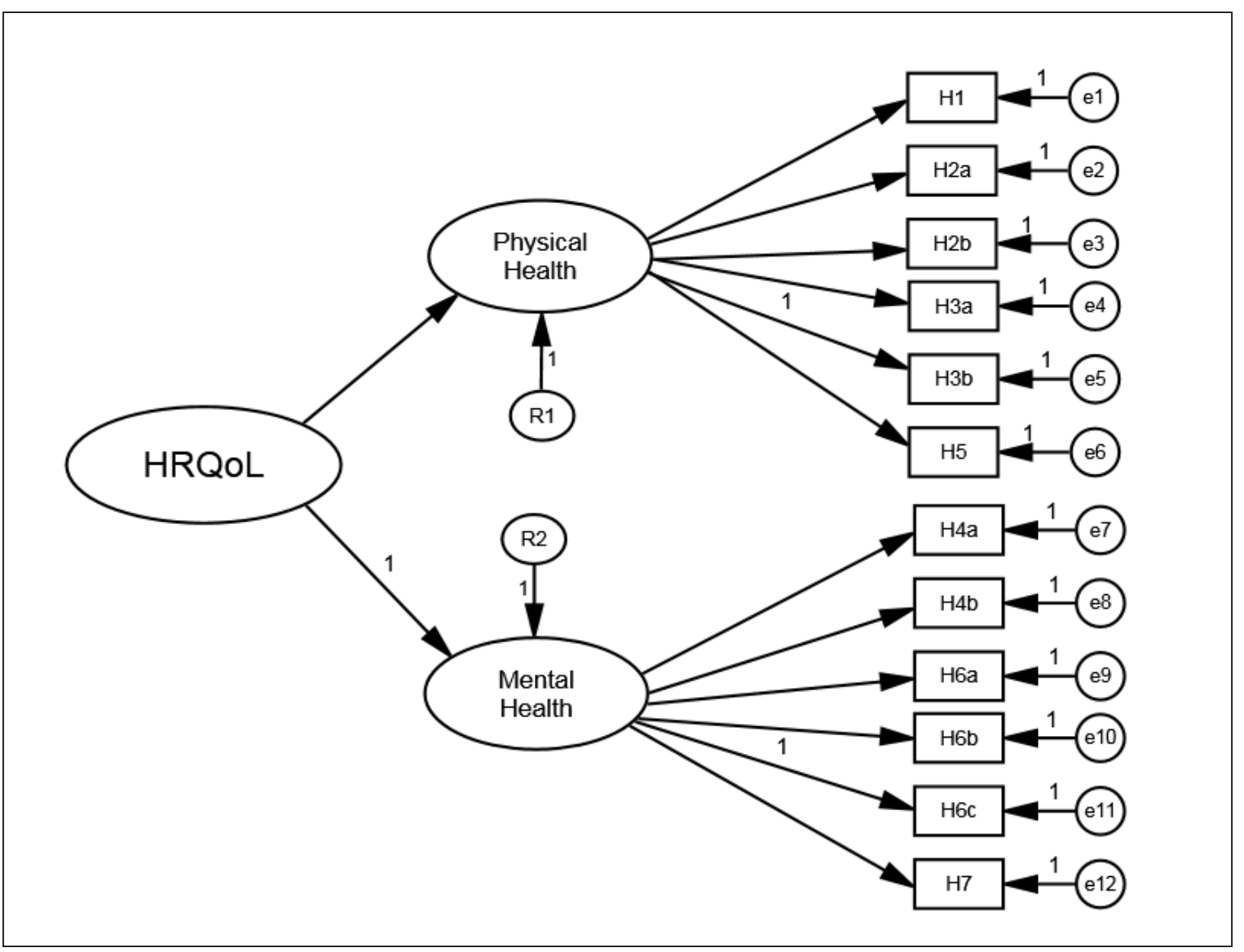

Figure 4. A Second-order Measurement Model for Health-related Quality of Life 


\section{A Second-Order Measurement Model for Burnout}

Figure 5 illustrates the endogenous variable of burnout, a second-order common factor.

Burnout was also a mediator latent construct. It was measured by three first-order factors,

personal burnout, work related burnout, and client related burnout with a total of 13 indicators based on BCI Scale (Appendix H). These items or indicators were structured in a manner in which to ask TSRs about their feelings for their jobs.

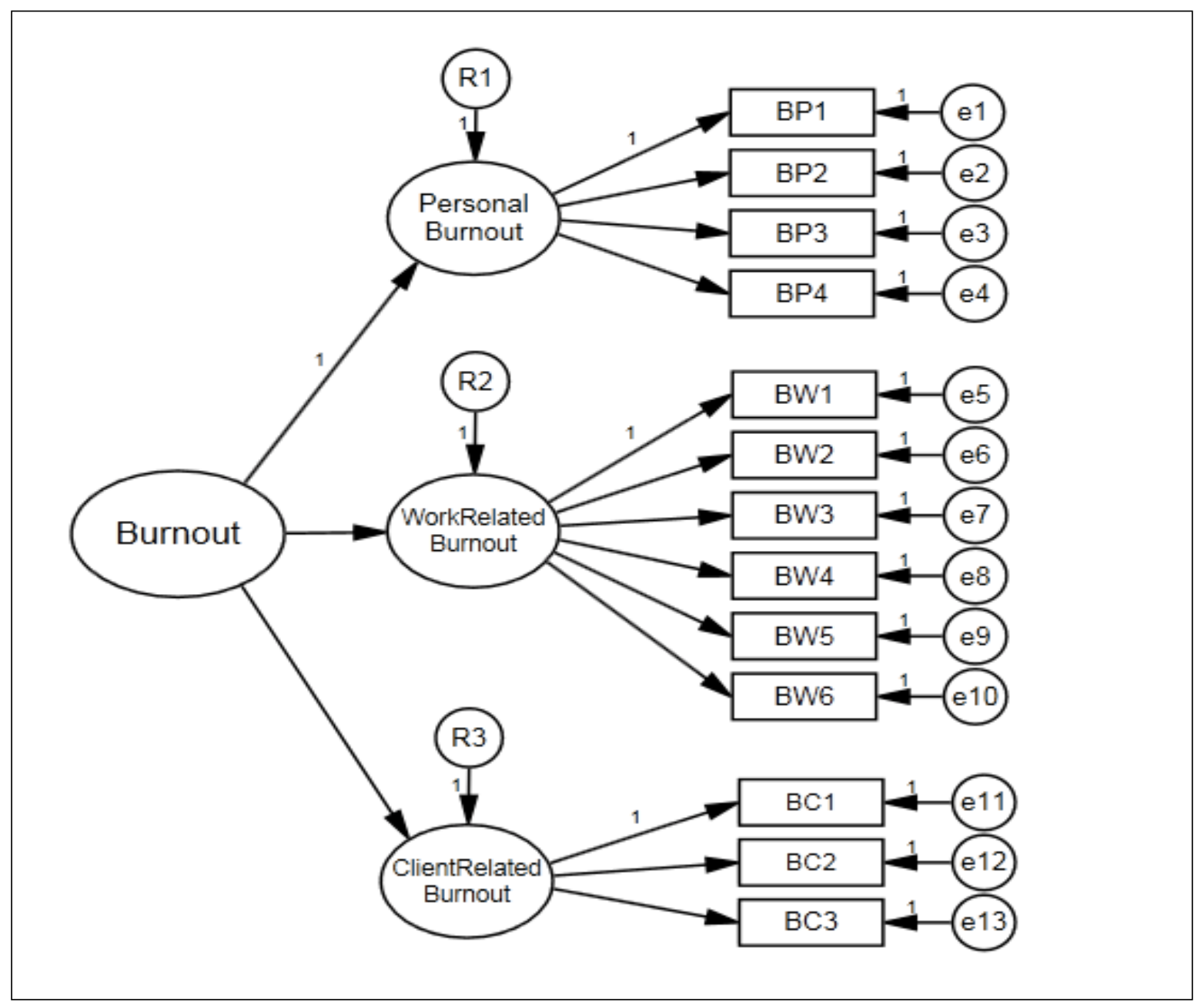

Figure 5. A Second-order Measurement Model for Burnout 


\section{A Measurement Model for Job-Related Stress}

A third measurement model was built for the exogenous variable of job related stress (Figure 6). Job-related stress was measured with 11 indicators (Appendix J).

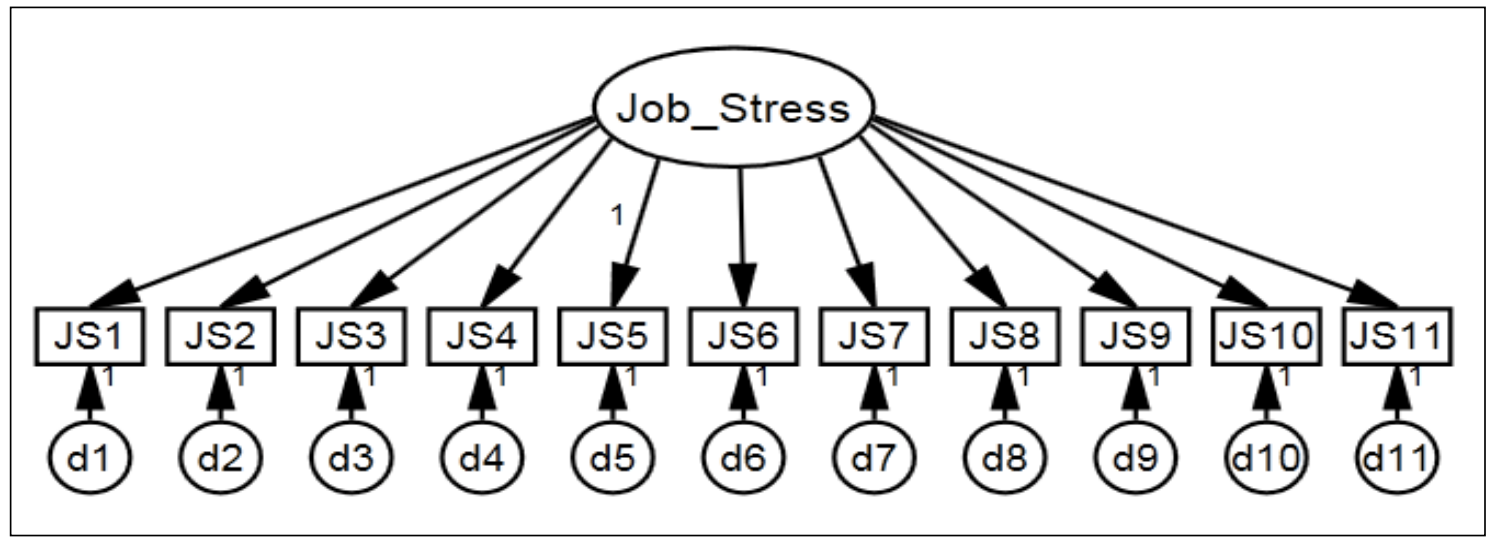

Figure 6. A Measurement Model for Job-related Stress

\section{A Measurement Model for Mobbing}

Figure 7 depicts the fourth measurement model built for the exogenous variable of mobbing (work harassment). For this construct, 18 indicators were used to measure to what extent who are exposed to mobbing (Appendix M).

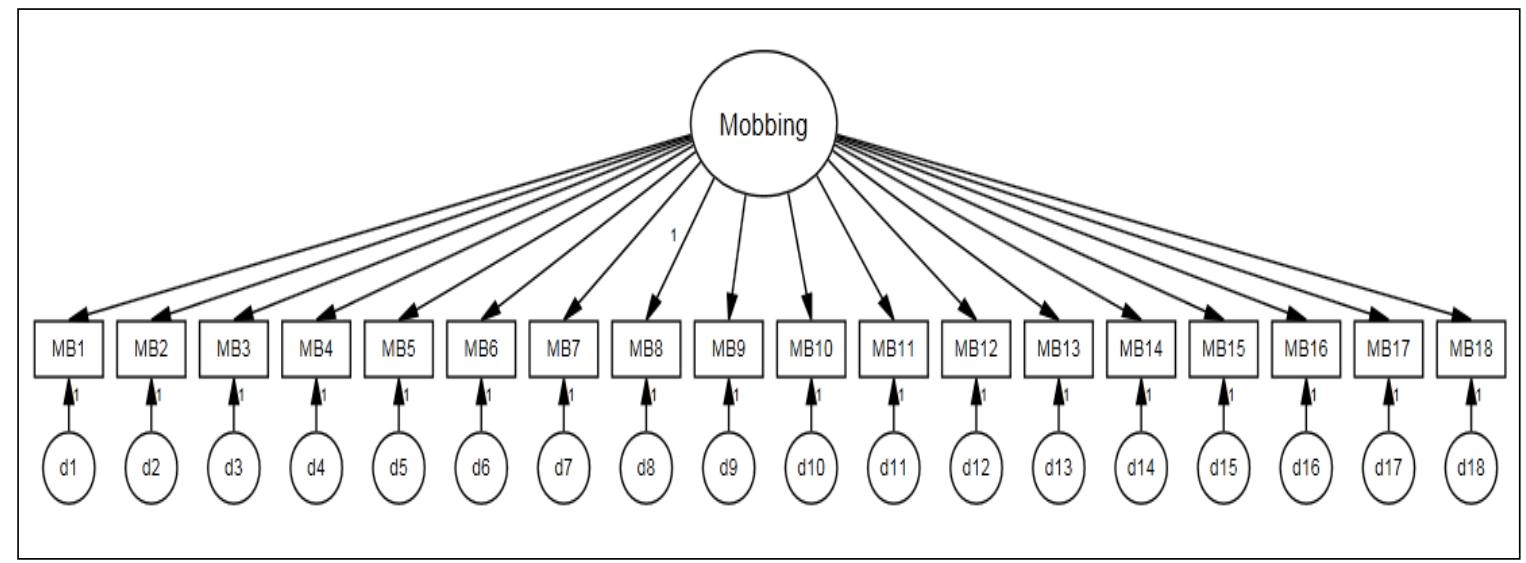

Figure 7. A Measurement Model for Mobbing 


\section{Covariance Structure Model}

The CSM was created after validating all measurement models of the study. The model examines all exogenous latent variables, endogenous latent variables, control variables, and measurement error terms. It also includes the first and second-order factors (Figure 8). The structural relationships between job-related stress, mobbing, and burnout, and the relationship between burnout and health quality of life of TSRs of Turkey were examined using the CSM. 


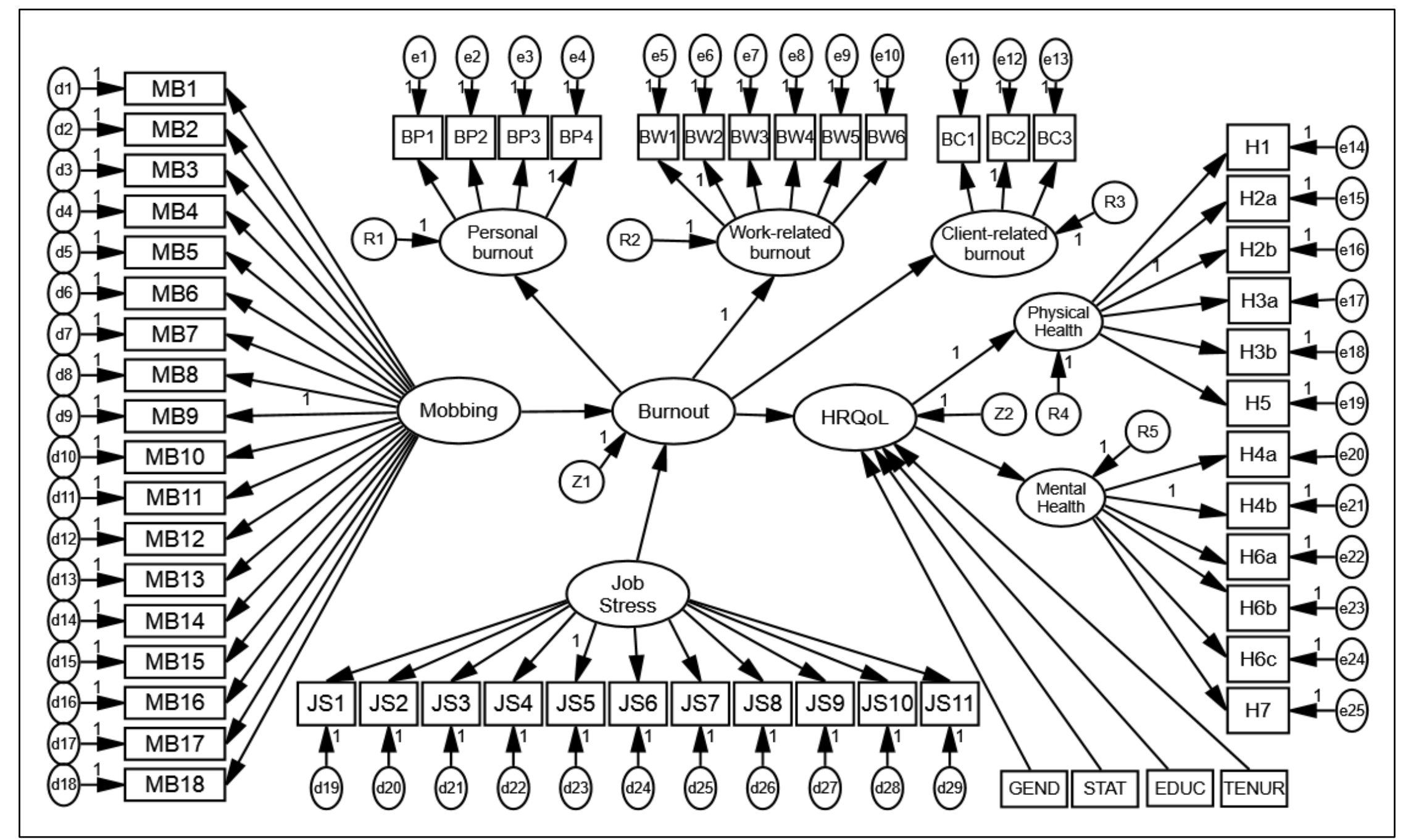

Figure 8. A Covariance Structure Model for HRQoL of TSRs 


\section{Validation of the Models}

First, one of the indicators for each construct or latent variable was selected as a scale factor. Then the regression weight of 1 was assigned to this indicator to create estimates of other factor loadings (Wan, 2002). Validation of all measurement models and CSM model was tested. The study used the goodness of fit (GOF) statistics to evaluate the fitness of the measurement and covariance structure models. The first step was to develop a generic model for each construct. But, when the model does not fit well with the dataset, a revision was made for the generic model by removing the weak items, which have low factor loading from the subscale. The following step provided a better model by removing the weak items from each latent construct in the measurement models (Wan, 2002).

The study used some indices to determine the validity of the models. Initially, each critical value (C.R. or t-value) must be bigger than 1.96 to say the model fits very well. Likelihood ratio $\left(\chi^{2} / \mathrm{df}\right)$, goodness of fit index (GFI), adjusted goodness of fitness index (AGFI), incremental fit index (IFI), normed fit index (NFI), comparative fit index (CFI), and root mean square error of approximation (RMSEA) were the other indices, which were commonly used in

the validation of the models. However, some scholars recommended not using GFI and AGFI for the complex models (Garson, 2012).

Schermelleh et al. (2003) recommended using RMSEA, TLI, and CFI for complex models. Smaller Chi-square value (lower than 4) was required to get a good model fit. The ratio of Chi-square $\left(\chi^{2} / \mathrm{df}\right)$ divided by DF was used to obtain a reasonably well model. The GFI, AGFI, CFI, and TLI must be bigger than .9 and RMSEA must be smaller than .05 with a view to considering the model is reasonably fit (Hooper et al., 2008; Maydeu-Olivares A., C Garc1'a- 
Forero, 2010). This study adopted Hoelter's Critical N. Hoelter index to determine whether the study had an adequate sample size for the model fit evaluation. The Hoelter's critical $\mathrm{N}$ having values higher than 200 meant the study had an adequate sample size, while the values between 75 and 200 meant the study had an acceptable sample size (Garson, 2012). Thus, this study adopted the goodness of fit indices Likelihood ratio, CFI, TLI, RMSEA, and Hoelter indices.

Moreover, the MI values were checked for highly correlated measurement errors of the indicators to improve and revise the generic model and get a well-fitted model (Newsom, 2012). After checking the GOF results provided by AMOS, when the model did not fit well with the data, further model revisions was made. Initially, insignificant factor loadings were excluded from the model. When eliminating insignificant factor loadings did not give the satisfactory GOF statistics, measurement errors of factor weights were correlated with other to reach a good fit by checking the MI. Table 3 indicates the model fit indices adopted by this study for measurement and covariance structure models.

Table 3. GOF Indices Thresholds for Measurement and CSM Models

\begin{tabular}{ll}
\hline Index & Criterion \\
\hline Chi-square (x2) & Low \\
Degree of freedom $(\mathrm{df})$ & $\geq .020$ \\
Likelihood ratio ( $\left.\mathrm{x}^{2} / \mathrm{df}\right)$ & $<4$ \\
Comparative Fit Index $(\mathrm{CFI})$ & $\geq .90$ \\
Tucker Lewis Index (TLI) & $\geq .90$ \\
Root Mean Square Error of Approximation (RMSEA) & $\leq .05$ \\
Hoelter's Index & $\geq .75$ \\
\hline
\end{tabular}




\section{Human Subject}

Since the study has human subjects, it was required to gain Institutional Review Board (IRB) approval. Thus, the protocol and all survey and research recruitment materials were submitted to the IRB for approval before starting the study and applying the survey. As discussed above, all of survey instruments were copyrighted and designed in a way to prevent any harm done to the participants. Participating and completing the survey were voluntary and data was confidential. To ensure confidentiality, no personal identifiable information was gathered. 


\section{CHAPTER FIVE: FINDINGS}

This chapter presents the data analysis and findings of the study. In the first part of the chapter, descriptive analysis of each variable will be discussed to give readers a general idea about the frequency distribution of the responses. In the following part of the chapter, multicollinearity issue will be examined via correlation matrix of SPSS in order to find the highly correlated variables and to remove one of the highly correlated indicators. The confirmatory factor analysis will be conducted to validate the measurement models by removing the insignificant indicators from the each model. The reliability analysis of the study will be discussed to examine the internal consistency of the measurement models. The scales having low reliability scores will be modified. Then, all measurement models including control variables will be merged in a CSM model that will be examined by the SEM. The final part will provide the SEM results to check whether the study hypotheses are supported or not.

\section{$\underline{\text { Descriptive Analysis }}$}

This section provides the descriptive statistics of the study. Before performing the SEM, descriptive analysis was implemented to examine the main characteristic of the dataset. Descriptive statistics of SPSS provided frequency tables and the distribution of the variables.

The survey with an electronic link was sent to 1,688 participants of Turkish TSRs. The total number of respondents is 502. As discussed in the previous section, this sample size was adequate for the SEM analysis. However, descriptive analysis also provided that there were some missing values in the dataset. Thus, these missing values were handled by using missing value analysis of the SPSS. 
Table 17 (Appendix P) provides the missing value statistics before and after the analysis. As the table indicates, there were some missing values in the dataset. Despite the fact that the number of missing values was not a significant number, a missing value analysis was conducted by using SPSS Expectation Maximization technique to account for the missing values.

As discussed in the subject of the study section, the administrative system of Turkey is mainly based on the provincial system. The number of provinces is 81 , and the number of districts is 919 in Turkey. The TSRs of Turkey consist of provincial governors, district governors, deputy governors, civil inspectors, and mid-ranking and high-ranking officials working at the central organization of the TMoI. The total number of TSRs in Turkey is 1,688, and a participation rate of about $30 \%$ of this population was obtained.

Table 18 (Appendix P) provides the frequency distribution for the participants' occupational positions. According the table, district governors constitute the majority part of the participants at 44\%. The remaining TSRs groups were deputy governors (25\%), central organization bureaucrats $(11.7 \%)$, district governor trainees $(10.9 \%)$, and civil inspectors $(8.5 \%)$.

Table 19 (Appendix P) provides the frequency distribution for the participants' tenure. According the table those who have more than 20 years of experience constitute the largest part of the participants with $37.4 \%$, while those who have 16-20 years of experience constitute the minority part of the participants $(7.5 \%)$.

Table 20 (Appendix P) indicates the frequency distribution for the education level of participants. The table illustrates that those having undergraduate education level constitute the majority part of the participants $(48.3 \%)$ while those having doctoral and upper education level constitute the minority part of the participants $(11.3 \%)$. The table briefly depicts that the 
education level of Turkish state representatives is very high, since the total number of master and doctoral level and upper level degrees is 257 , which constitutes the majority of participants $(51.7 \%)$.

The frequency distribution of the participants' gender is shown in Table 21 (Appendix P). According to the table, vast majority of the participants is male $(97.8 \%)$. The table depicts that 486 of the participants are male, while 11 of them are female.

As the table shows, the overwhelming majority of the participants is male. According to the Act of Civil Servants of Internal Affairs, district governor candidates were used to be selected among only men instead of women candidates since 1992. As discussed above, the results of Table 19 (Appendix P) indicated that those who have experience between 11 and 15 years and those having experience more than 20 years constitute the majority part of the participants. This explains why the female participation rate is low when compared to male participants.

\section{Endogenous Variables}

This section gives brief descriptive information on endogenous variables of the study. The study had two endogenous variables, which were HRQoL and burnout. Burnout was a mediating endogenous variable, which mediated the relationship between job-related stress, mobbing, and HRQoL of TSRs.

\section{Health Related Quality of Life (HRQoL)}

The first endogenous variable of the study was HRQoL measured by the Health Survey Short Form (SF)-12v2 ${ }^{\mathrm{TM}} 4$-week recall (Ware et al., 1998). The variable was measured by the multiple dimensions of HRQoL using 12 items (Wan \& Pai, 1997) to identify information about 
participants' general and mental health status. The HRQoL SF-12v2 ${ }^{\mathrm{TM}}$ was indicated in the SEM model as a first-order and second-order latent construct, since it had physical health and mental health as first-order factors. Physical health consisted of physical functioning, role physical, bodily pain, and general health, while mental health consists of vitality, social functioning, role emotional, and mental health.

The frequency distribution of indicators of HRQoL of TSRs was shown in Table 22 (Appendix P). The first question measured the general health level of TSRs. According to Table 22 , the general health level of Turkish state representatives was generally good and above the good. Those who said their health was good constituted the vast majority of the respondents.

The second two questions were about activities that the respondents might perform during a typical day. The main role of these two questions was about physical functioning. The questions measured whether and to what extent the participants' health limited their activities such as moving a table, pushing a vacuum cleaner, cycling, or swimming. As the table depicts, the majority of the respondents said that their health level did not limit some moderate activities at all. A small proportion of the participants thought that their health level limited a lot of given activities (5.1\%), while $27.3 \%$ thought that their health level limited the given activities only a little. Moreover, $76 \%$ of TSRs thought that their health level did not limit climbing several flights of stairs at all, while a small portion of TSRs thought that it limited these activities a lot $(2.5 \%)$ and $21.5 \%$ think thought it limited them a little. Thus these two questions were consistent with the first question of the survey.

The following two questions ( $\mathrm{H} 3 \mathrm{a}$ and $\mathrm{H} 3 \mathrm{~b}$ ) were about role physical of TSRs. The questions asked during the past four weeks, how much of the time they had any problem given in 
the scale with their work or other regular daily activities as a result of their physical health. The majority of the respondents say that during the past four weeks, they had accomplished less than they did. They also mostly thought that during the past four weeks, they were limited in the kind of some activities.

The questions of $\mathrm{H} 4 \mathrm{a}$ and $\mathrm{H} 4 \mathrm{~b}$ were about role emotional of TSRs. These two questions asked during the past four weeks, how much of the time did they have any problem with their work or other regular daily activities as a result of any emotional problems such as feeling depressed or anxious. According to the results, those who thought that they accomplished less than they did all of the time, most of the time, some of the time, and a little of the time constituted vast majority of the respondents.

The question five was about bodily pain of TSRs. It asked during the past four weeks, how much did pain interfere with their normal work (including both work outside the home and housework). As results showed $49 \%$ of the respondents thought that pain did not interfere with their normal work at all, while $51 \%$ of the respondents thought that the pain somehow interfered their work.

The questions of H6a, H6b, and H6c were about vitality and mental health of TSRs. These questions were about how TSRs feel and how things have been with them during the past four weeks. For each question, they gave the one answer that came closest to the way they have been feeling. Vast majority of TSRs thought that they felt calm and peaceful and they had a lot of energy all of the time, most of the time, or some of the time during last four weeks, while very small proportion of them thought that they did not feel calm and peaceful and did not have a lot of energy during four weeks. Moreover, 11 participants thought that they felt downhearted and 
depressed all of the time, 74 of them felt most of the time, 147 of them felt some of the time, and 178 of them felt a little of them. Only 85 of them think that they felt downhearted and depressed none of the time.

The last question was about social wellbeing and functionality of TSRs. The question measured how much of the time did the TSRs' physical health or emotional problems interfere with their social activities such as visiting with friends, relatives etc. According to results, 11 respondents thought that their physical health or emotional problems interfered with their social activities all of the time, 66 of them thought most of the time, 156 of them thought a little of the time, while 124 of them thought none of the time.

\section{Burnout}

Burnout was a mediating endogenous variable. It was measured by the CBI Scale (Kristensen et al., 2005) with a 19-item questionnaire. Burnout was a first-order and secondorder latent construct. The three first-order latent factors of burnout were personal burnout, work-related burnout, and client related burnout. Table 23 (Appendix P) provides the frequency distribution of indicator of perceived burnout of TSRs.

The first four questions were about perceived personal burnout of TSRs, which was a state of prolonged physical and psychological exhaustion. As findings depict, those who always, often, and sometimes feel tired constituted the vast majority of TSRs. Similarly, a majority of them always (5.8\%), often (34.6\%), and sometimes (36.6\%) were physically exhausted. The participation rate of those who were never or almost never emotionally exhausted was $4.4 \%$. As for the last question of personal burnout, those who think always constituted $1.2 \%$ of TSRs, while often made up $10.9 \%$ and sometimes constitute $27.5 \%$. The proportion of those who 
never/almost never think they can't take it anymore is $31.2 \%$. Thus, it is accurate to assert that TSRs mostly think that they can't take it anymore.

The second set of six questions was about perceived work-related burnout among TSRs that was brought on by a state of prolonged physical and psychological exhaustion, which is believed to be related to the work of TSRs. The first two questions of work-related burnout of TSRs were about emotional exhaustion and feeling burned out because of the work. As the table indicates (appendix p), most of the TSRs think that their work is emotionally exhausting. The minority of the participants who agreed to a very low degree constitutes only $3.8 \%$ of TSRs. Moreover, those who feel burn out because of their work from 'to a very high degree' was $6.7 \%$ to 'somewhat' constitute $27 \%$, whichh reflected the $35.3 \%$ majority of the TSRs.

The rest of the work-related burnout questions were about feeling worn out at the end of the work day, feeling exhausted in the morning at the thought of another day at work, feeling every working hour was tiring for them, and having enough energy for family and friends during leisure time. Results indicated that TSRs suffered from work-related burnout.

The last three questions were about client-oriented burnout of TSRs, which was a state of prolonged physical and psychological exhaustion and perceived to be related to the TSRs' work with citizens. The first question of the client-oriented burnout of TSRs was to what extend does burnout drain TSRs' energy to work with citizens. As findings indicated, those who thought it drained their energy to work with citizen from 'to a very high degree' (7.8\%) to 'somewhat' (28.9\%) constituted a $35.1 \%$ majority of the TSRs. The last two questions of the client-oriented burnout of TSRs addressed being tired of working with citizens and wondering how long they 
will be able to continue working with citizens. Thus, it is safe to say that TSRs suffered from client-related burnout.

\section{Exogenous Variables}

This section discusses the descriptive information of exogenous variables of the study. The study had two endogenous variables, which were job-related stress and mobbing.

\section{Job-related Stress}

The first exogenous variable of the study was job-related stress. Parker and DeCotiis (1983) suggested a partial test of the short version of the model with 11 items. They structured their study to determine the nature of the relations among certain potential stressors selected on the basis of the literature and information of the population, the first-level result, and work related stress. They also studied the dimensionality of job stress more closely, in order to identify the extent to which the scopes were differentially affected by different stressors (Parker \& DeCotiis, 1983).

Table 24 outlines the results (Appendix P) and Figure 8 shows that Turkish state representatives somehow agree to the assertions of the job-related stress scale, while they disagree with some arguments. The participation rate of those who disagreed and strongly disagreed with the idea of that they cannot readily identify issues because they spend so much time at work is $58.2 \%$. Of the TSRs surveyed, $42.8 \%$ disagreed and strongly disagreed with the idea that working as a TSR leaves little time for other activities, while $49.3 \%$ of participants disagreed and strongly disagreed with the argument that they frequently get the feeling they are married to the company with a percentage of 36.3 . 
As Figure 9 indicates, $41.5 \%$, or 256 of the TSRs, disagreed and strongly disagreed with the idea of having too much work and too little time to do it in. Similarly, $67.8 \%$ of participants did not feel guilty when they took time off from their job. Furthermore, 52.5\%, or 261 TSRs, did not feel like they never have a day off. Of TSRs surveyed, $46.3 \%$ agreed or strongly agreed that they felt fidgety or nervous as a result of their jobs. More than half of the TSRs agreed and strongly agreed that their jobs made it difficult to spend enough time with their family, their jobs affect them more than they should, and finally that they sometimes dread the telephone ringing at home because the call might be job-related. Moreover, more than half of the TSRs (55.1\%) think that too many TSRs get burned out by their jobs. 


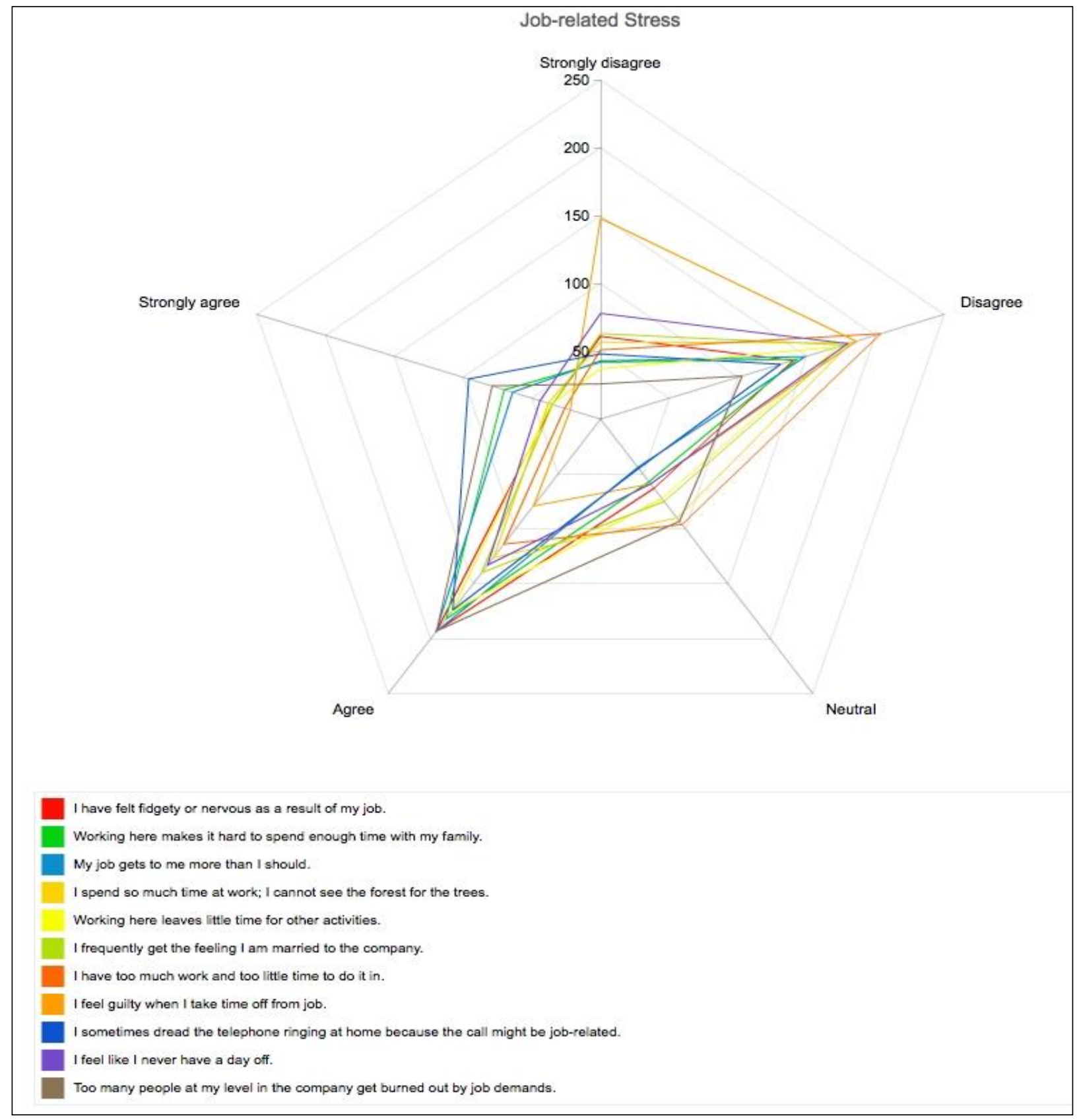

Figure 9. The Frequency Distribution of Job-related Stress of TSRs

Considering the results of burnout, the descriptive results of the last question of jobrelated stress was consistent with the descriptive result of burnout. As discussed in the burnout section of this study, 35.3\% of TSRs feel burn out because of their work from 'a very high 
degree' $(6.7 \%)$ to 'somewhat' $(27 \%)$. These results indicate that TSRs feel burnout because of the work. Similarly, TSRs agree (39\%) and strongly agree (16.1\%) with the perception that too many TSRs develop burnout out by job demands.

\section{Mobbing}

The second exogenous variable was mobbing measured by the work harassment scale of Bjrökqvist and Osterman (1998) using 18 items. This original scale particularly examined the work harassment by coworkers. However, it was converted to the Turkish version. In the Turkish version, the scale particularly examined the mobbing by supervisors. As shown in Table 25 (Appendix P), the scale asked TSRs to choose the number that came closest to their own experience.

In the first five questions, they were asked whether their supervisors unduly reduced opportunities to express their ideas, unduly disrupted them, unduly shouted at them loudly, unduly criticized them, and were isolated by their supervisors. The next six questions asked them whether they were directly threatened, they were exposed to insinuative glances and/or negative gestures, being exposed to accusations, being sneered at, refusal to speak with them, and belittling of their opinions by the supervisors. The last seven questions of work harassment scale examined whether TSRs were being treated as non-existent, exposed to words aimed at hurting them, being given meaningless tasks, having malicious rumors spread behind their back, being ridiculed in front of others, having their work judged in an incorrect and insulting manner, and having their sense of judgment questioned.

As shown by Figure 10, respondents never (25.8\%), rarely (32\%), and occasionally agreed (30.8\%) with the argument of unduly reduced opportunities to express their ideas to their 
supervisors. A small part of the TSRs often or very often agreed with this argument. Similarly, they never, rarely, or occasionally agreed with the arguments of being unduly disrupted, being shouted at loudly, being unduly criticized, being isolated, and being exposed to direct threats. A very small number of the participants often or very often agreed with the arguments; a significant number of the TSRs (230) thought that they were never exposed to insinuative glances and/ or negative gestures, $53.2 \%$ of them thought that they were rarely, occasionally, often, or very often exposed to insinuative glances and/or negative gestures by their supervisors. Of the participants, $43.6 \%$ thought that they were never exposed to accusations, while $56.3 \%$ of them rarely, occasionally, often, or very often thought that they were being accused by the supervisors. The number of those who thought that they were never being sneered at was 213 , while the number of those who rarely, occasionally, often, or very often thought that they were rarely, occasionally, often, or very often thought they were being sneered at by their supervisors was 278.

The vast majority of TSRs thought that they were never refused the opportunity to speak with their supervisors, while the rest of the participants rarely $(22.6 \%)$, occasionally $(7.1 \%)$, often $(3.3 \%)$, or very often $(1 \%)$ thought they were refused the chance to speak with them. Those who rarely, occasionally, often, or very often thought that their opinions were belittled were $39.8 \%, 16.8 \%, 9.3 \%$, and $1.4 \%$ respectively. More than half of the participants $(53.1 \%)$ never felt that they were treated as non-existent by their supervisors, while the rest rarely $(29.5 \%)$, occasionally $(11.1 \%)$, often $(4.8 \%)$, or very often $(1.4 \%)$ thought they were being treated as nonexistent. Of the participants $59.5 \%$ were never exposed to words aimed at hurting them. Of the respondents 248 believed they were never given meaningless tasks by their supervisors, which 
was a proportion $50.1 \%$ of the total respondents. A majority of the respondents were never exposed to malicious rumors spread behind their backs $(65.8 \%)$, ridicule in front of others $(81.2 \%)$, and having their works judged in an incorrect and insulting manner (70.5\%). Finally, 313 of the respondents (more than half of the total respondents) thought that they were rarely $(41 \%)$, occasionally $(16 \%)$, often $(4 \%)$, or very often $(2.2 \%)$ exposed to having their sense of judgment questioned.

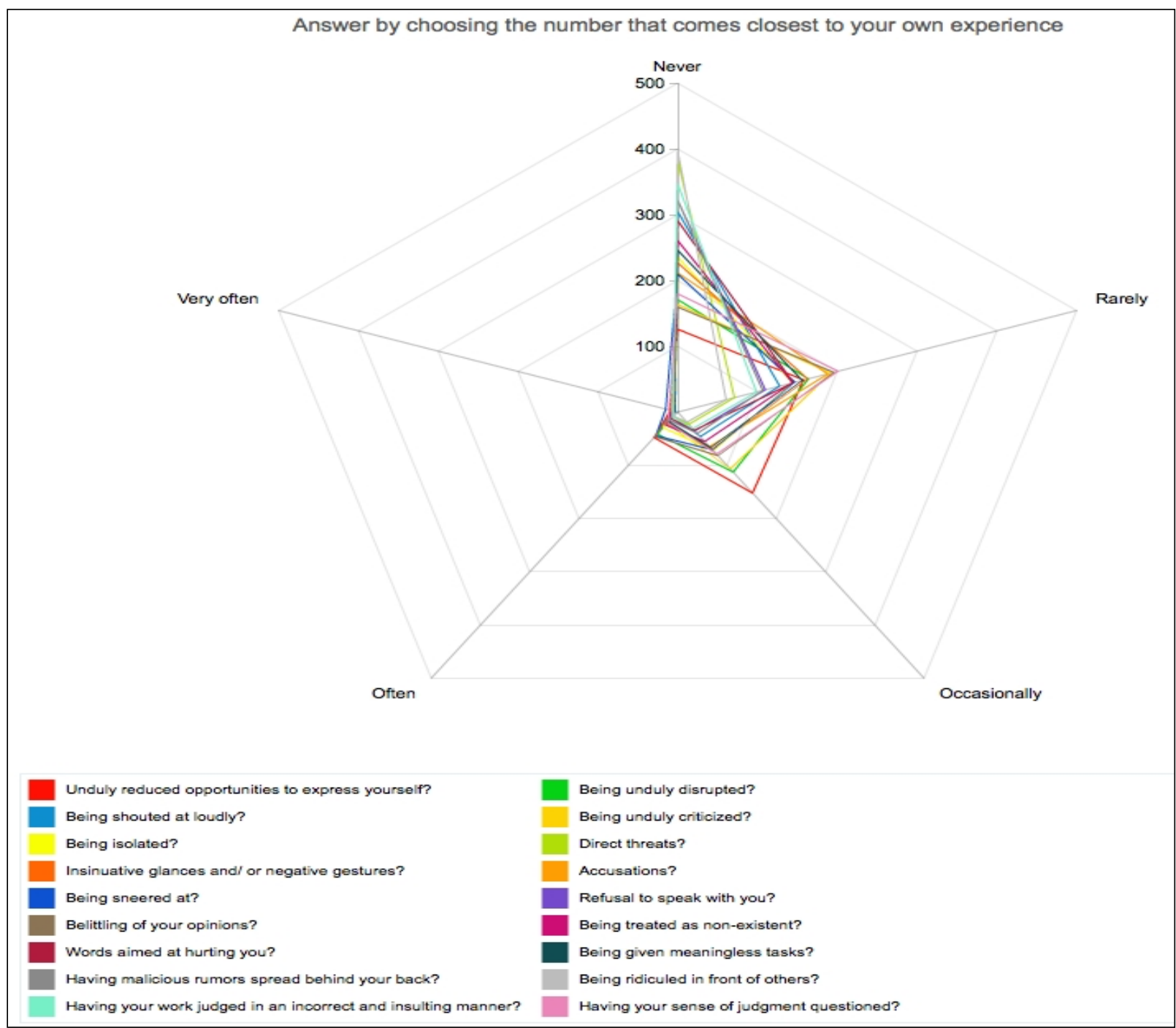

Figure 10. The Frequency Distribution of Mobbing 
This section provided the descriptive statistics of the dataset. Descriptive analysis was performed to examine the main characteristic of the dataset by using frequency tables and the distribution of the study variables. The missing values detected by the descriptive analysis were handled by using missing value analysis of the SPSS. The total number of TSRs in Turkey is 1,688 , and a $30 \%$ rate of participation rate was obtained.

In sum, the descriptive statistics findings indicated that the indicators of HRQoL, mobbing, job-related stress, and burnout have a relatively varied distribution of responses. According to the descriptive findings, the general health level of Turkish state representatives was generally good and above the good; however, those who thought that the pain interfered with their normal work from an extremely to a little bit level constituted the more than half of the respondents (51\%). Furthermore, the descriptive findings showed that TSRs' physical or emotional problems mostly interfered with their social wellbeing and functionality from a little of the time to all of the time level with a percentage of 75.1. Descriptive statistics results of burnout showed that majority of the participants fell tired, and physically and emotionally exhausted. Similarly, TSRs mostly thought that they couldn't take it anymore and their work was emotionally exhausting and they had work-related and client-related burnout. The descriptive findings of job-related stress results indicated that nearly half of the TSRs felt fidgety or nervous as a result of their jobs and more than half of them agreed and strongly agreed that a) their jobs made it hard to spend enough time with their family, b) their jobs affected them more than they should, and c) they sometimes dreaded the telephone ringing at home because the call might be job-related. Further, $55.1 \%$ of the TSRs thought that too many TSRs get burned out by their jobs. 
Descriptive findings of mobbing results indicated that more than half of the TSRs were (rarely, occasionally, often, or very often) exposed to insinuative glances and/or negative gestures, and accusations by their supervisors. About $32 \%$ of the TSRs were never belittled for their opinions, while more than half of the participants $(53.1 \%)$ never felt they were treated as non-existent by their supervisors. Furthermore, a majority of the respondents thought that they were (rarely, occasionally, often, or very often) exposed to having their senses of judgment questioned.

\section{Correlation Analysis}

One of the main functions of correlation analysis is to examine the multicollinearity issues of the latent constructs. Multicollinearity issue in this study was handled via correlation matrix of SPSS in order to find the highly correlated variables. The study adopted the Spearman's rho to check the multicollinearity among the variables (Kline, 2011). According to Kline (2011), multicollinearity arises if two indicators primarily measure the same one. Hence, keeping both of the highly correlated indicators is unnecessary, it is required to remove at least one of these two indicators. The threshold to detect the multicollinearity issue accepted commonly by the scholars is .70 (Gamst et. al., 2013). However, some researchers accept the higher multicollinearity threshold of .85 (Kline, 2011; Garson, 2012). The multicollinearity threshold adopted by this study was .85 .

The correlation matrix of the endogenous variable of HRQoL is given in Table 26 (Appendix R). The correlation among 12 indicators of HRQoL showed that the correlation coefficient values for the indicator pairs ranged from .287 to .921 . The indicator pair with the lowest correlation occurred between 'general health' (H1) and 'accomplisehd less-emotionial' 
(H4a). and 'general health' (H1) and 'activities less carifully than others' (H4b). while the highest correlation occurred between 'accomplished less-physical health (H3a) and 'limited in the kind of activities' (H3b) with the coefficient values of .287 and .921 respectively. As the table indicates. all indicators were statistically significant correlated with each other at .01 level. Since two of the correlation values exceeded the threshold of .85. one of these two variables was removed from the measurement model for HRQoL.

Table 27 (Appendix R) provides the correlation matrix of the endogenous variable of burnout. The table indicates that the lowest correlation occurred between 'how long you will be able to continue working with clients' (BC3) and 'having enough energy for family and friends during leisure time' (BW6). while the highest correlation occurred between 'tired of working with clients' (BC2) and 'draining energy to work with clients' (BC1) with the coefficient values of -.241 and .867 respectively. As the table indicates. all indicators were statistically significant correlated with each other at .01 level. The only multicollinearity issue among variables occurred between 'tired of working with clients' (BC2) and 'draining energy to work with clients' (BC1) with a .868 coefficient value. which exceeded the threshold of .85 . Thus. one of these variables (draining energy to work with clients) was removed from the measurement model for burnout.

Table 28 (Appendix R) provides the correlation matrix of the exogenous variable of jobrelated stress. The correlations among 11 indicators of job-related stress showed that the correlation coefficient values for the indicator pair ranged from .238 to .701 and all indicators were statistically significant correlated with each other at the significant level of .01. According to the table. the lowest correlation occurred between 'feeling guilty when taking time off from job' (JS8) and 'feeling fidgety or nervous as a result of job' (JS1). and the highest correlation 
occurred between 'my job gets to me more than I should' (JS3) and 'working here makes it hard to spend enough time with my family' (JS2) with the coefficient values of .238 and .701 respectively. Since there was no multicollinearity issue occurring among variables. all 11 indicators were kept in the measurement model for job related stress.

Table 29 (Appendix R) provides the correlation matrix of the exogenous variable of mobbing. The table shows that the lowest correlation occurred between 'direct threats' (MB6) and 'unduly reduced opportunities to express yourself' (MB1). while the highest correlation occurs between 'being unduly disrupted' (MB2) and unduly reduced opportunities to express yourself' (MB1) with the coefficient values of .438 and .809 respectively. According to the table. all indicators were statistically significant correlated with each other at the significant value of .01. Since there was no multicollinearity issue occurring among variables. it was safe to say that there was no need to exclude any indicators from the measurement model of mobbing.

Consequently, all indicators were significantly correlated with each other at the significant level of .01. Correlation matrices of the tables provided that there were only three multicollinearity issues occurring between variables. These highly correlated variables were excluded from the related measurement models to eliminate the multicollinearity issue.

After examining the descriptive overview of the data and the correlation analysis of the latent constructs, the following section will perform the CFA of measurement models to create the final measurement models, which will constitute the base of the CSM.

\section{$\underline{\text { Confirmatory Factor Analysis }}$}

The study performed the CFA to create and validate the measurement models for latent constructs. As it was discussed earlier, the CFA is based on a theoretical understanding, 
determining the variation and covariation between the observed variables, which are indicators and latent variables, unobserved variables, and measurement errors (DeCoster, 1998). Thus, CFA tries to explain the variation and covariation in a set of observed variables in terms of a set of theoretical and unobserved factors and assesses the construct validation of the study (Wan, 2002).

The study adopted the three steps technique of Wan (2002). This technique determined the better model for each latent construct. Prior to conducting the analysis, one of the indicators for each construct was picked as the scale factor. Then the regression weight of 1 was assigned to these indicators to calculate estimates of other factor loadings (Wan, 2002). Validation of all measurement models and CSM model was tested via SPSS AMOS 22 software. The study developed a generic model for each construct. However, when the model did not fit well with the dataset, a revision was made for the generic model by removing the weak items, which had low factor loadings from the subscale. The following step provided a better model after removing the weak items from each latent construct in the measurement models (Wan, 2002).

In the first step, the factor loadings of the indicators were checked for the appropriateness of indicators in the generic models. A critical value (C.R) and p value were used in order to examine whether an indicator significantly affect the latent construct. When each critical value (C.R. or t-value) is equal or bigger than 1.96 , or equal or lower than -1.96 , it is safe to assert that the model fits very well and the effect of an indicator on the latent variable is statistically significant at the .05 level. When the factor loading is not statistically significant, it concludes that this indicator is not a suitable measure for the latent construct. The stronger factor loading means the stronger influence of that indicator on the latent construct (Byrne, 2010; Wan, 2002; 
Bickel, 2007); further, the standardized regression weights are checked to identify the strength of the each factor loading. The threshold for this study was set at .30 (How, 2008). Thus, an indicator bigger than .30 was considered as an important indicator and was not removed from the model.

In the second step, some indices are generally used to determine the validity of the models. Likelihood ratio ( $\left.\chi^{2} / \mathrm{df}\right)$, GFI, AGFI, IFI, NFI, CFI, and RMSEA are the main indices, which were commonly used in this step to validate the models. However, as discussed earlier some researchers suggest not using GFI and AGFI for the complex models (Garson, 2012). Schermelleh et al. (2003) suggest using RMSEA, TLI, and CFI for complex models. Smaller Chi-square value (lower than 4) will be required to achieve a good model fit. The ratio of Chisquare ( $\left.\chi^{2} / \mathrm{df}\right)$ that is divided by DF will be used to obtain a reasonably sound model. The CFI, TLI, IFI must be bigger than .9 and RMSEA must be smaller than .05 to establish the model as reasonably fit (Hooper et al., 2008; Maydeu-Olivares A., C Garc1'a-Forero, 2010). Moreover, the Hoelter index helps to determine whether the study has an adequate sample size for the model fit evaluation. The Hoelter index uses a critical N with values higher than 200 to mean the study has an adequate sample size, while values between 75 and 200 mean the study has an acceptable sample size (Garson, 2012). Thus the goodness of fit indices adopted by this study were Likelihood ratio, CFI, TLI, RMSEA, and Hoelter index. In the final step, the MI values were used to check for highly correlated measurement errors amongst indicators of the latent constructs to get a well-fitted model (Newsom, 2012).

After checking the results provided by AMOS 22, the insignificant factor loadings were excluded from the model. When eliminating the insignificant factor loadings did not provide the 
satisfactory GOF statistics, measurement errors of factor weights were correlated with other to reach a good fit by verifying the MI. Before performing the CFA some of the variables were recoded by using SPSS to make sure all Likert scales followed the same directions.

\section{Measurement Model for Health Related Quality of Life}

Figure 11 depicts the generic measurement model for the endogenous variable of HRQoL. As the figure illustrates, HRQoL was measured by two first-order latent factors with 12 items. The two first-order latent factors of HRQoL were physical health and mental health. Physical health was measured using the items of physical functioning, role physical, bodily pain,

and general health, while mental health was measured using the items of vitality, social functioning, role emotional, and mental health.

As discussed in the correlation analysis part of the study, the correlation matrix of the HRQoL detected two multicollinearity issues occurring among the indicators of $\mathrm{H} 3 \mathrm{a}$ and $\mathrm{H} 3 \mathrm{~b}$ and $\mathrm{H} 4 \mathrm{a}$ and $\mathrm{H} 4 \mathrm{~b}$. Thus $\mathrm{H} 3 \mathrm{a}$ and $\mathrm{H} 4 \mathrm{a}$ were removed from the measurement model of the HRQoL. 


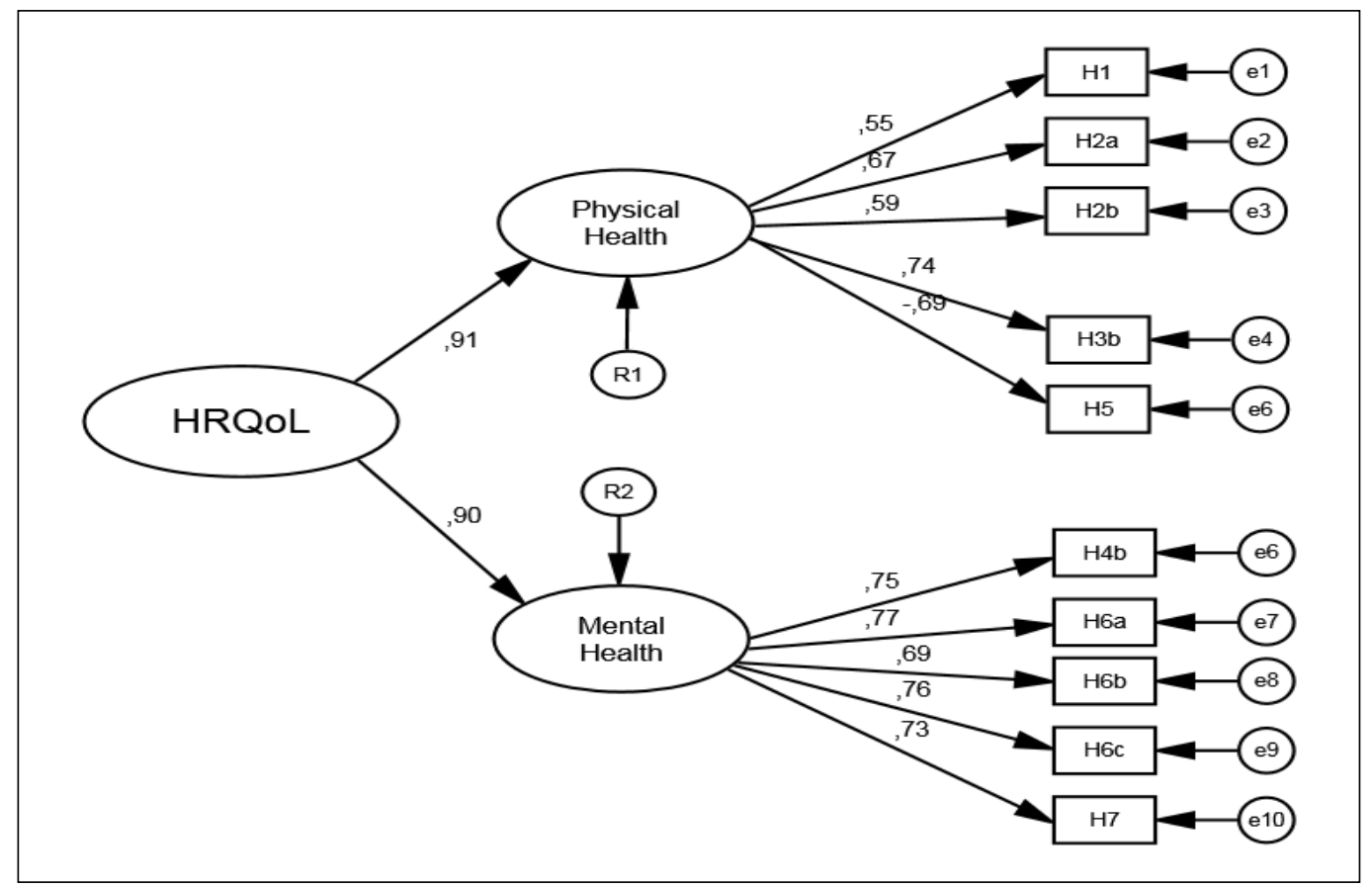

Figure 11. Measurement Model for HRQoL (Generic Model)

The regression parameter estimates of the generic model for HRQoL depicted that all of the items of HRQoL were statistically significant at the significance level of .01. Moreover, all of the factor loadings exceeded the predetermined criteria of .30. As a consequence of the given results, all items were kept for the measurement model of HRQoL.

Model fitness indices of both the generic model and revised model for the HRQoL are given in Table 4. The table shows that none of the statistics for the generic model provided the sufficient indices for a well-fit model, except Hoelter index. Thus, a revision was made to improve and get a better-fit model. 
Table 4. Parameter Estimates and Regression Weights for HRQoL

\begin{tabular}{|c|c|c|c|c|c|c|c|c|}
\hline \multicolumn{5}{|c|}{ Generic Model } & \multicolumn{4}{|c|}{ Revised Model } \\
\hline Indicators & SRW & URW & $\mathrm{SE}$ & $\mathrm{CV} / \mathrm{p}$ & SRW & URW & SE & $\mathrm{CV} / \mathrm{p}$ \\
\hline $\mathrm{H} 1$ & .546 & .456 & .043 & $10.611 / *$ & .560 & .463 & .046 & $10.109 / *$ \\
\hline $\mathrm{H} 2 \mathrm{a}$ & .666 & .509 & .039 & $12.899 / *$ & .602 & .455 & .043 & $10.682 / *$ \\
\hline $\mathrm{H} 2 \mathrm{~b}$ & .593 & .384 & .033 & $11.526 / *$ & .529 & .338 & .036 & $9.439 / *$ \\
\hline $\mathrm{H} 3 \mathrm{~b}$ & .743 & 1.000 & & & .750 & 1.000 & & \\
\hline H5 & -.688 & -.832 & .063 & $-13.305 / *$ & & & & \\
\hline $\mathrm{H} 4 \mathrm{~b}$ & .746 & 1.000 & .065 & $15.457 / *$ & .745 & .964 & .063 & $15.307 / *$ \\
\hline H6a & .770 & .854 & .053 & $15.982 / *$ & .713 & .767 & .053 & $14.593 / *$ \\
\hline H6b & .694 & .827 & .058 & $14.332 / *$ & .620 & .715 & .057 & $12.473 / *$ \\
\hline $\mathrm{H} 6 \mathrm{c}$ & .756 & 1.000 & & & .781 & 1.000 & & \\
\hline $\mathrm{H7}$ & .730 & 1.019 & .067 & $15.105 / *$ & .751 & 1.016 & .066 & $15.408 / *$ \\
\hline
\end{tabular}

In the next step, MIs were verified for highly-correlated indicators to revise the generic model and achieve a better-fit model. Measurement errors were correlated by using MI to revise the model (Figure 12). Since the factor loading of H5 had a negative value, the indicator was removed from the measurement model before revising the model. 


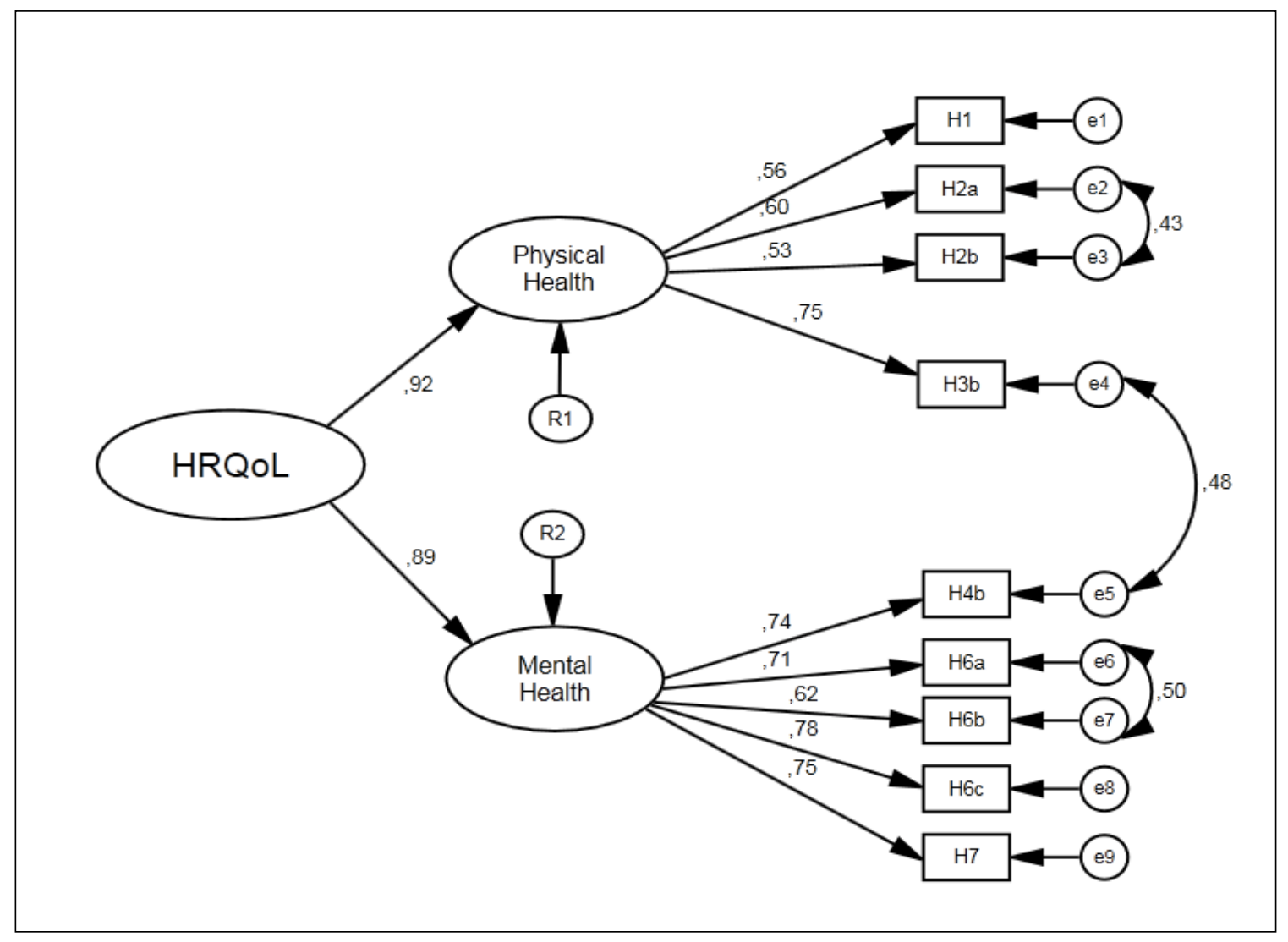

Figure 12. Measurement Model for HRQoL (Revised Model)

Table 5 indicates excellent fit indices for the revised model of the HRQoL. All of the model fit indices met all predetermined thresholds for an excellent model fit. Table 5. Model Fitness Indices for HRQoL

\begin{tabular}{lccccl}
\hline Model & $\mathrm{X}^{2} / \mathrm{df}$ & CFI & TLI & RMSEA & Hoelter \\
\hline Generic & 9.113 & .862 & .817 & .134 & .82 \\
\hline Revised & 1.791 & .990 & .984 & .042 & .454 \\
\hline
\end{tabular}

Now that model fit was achieved, the evaluation and interpretation of the relationship between indicators will be discussed. Table 5 indicats the possible impacts of the items on the latent variable of HRQoL. The table depicts that feeling downhearted and depressed (H6c) has 
the biggest effect, while limiting in some activities such as climbing several flights or stairs (H2b) has the smallest effect on HRQoL with standardized weights of .529 and .781 respectively. Based on the analysis of the Tables 5 and 6, the measurement model for the HRQoL latent construct was validated and was ready for the covariance structure model.

\section{Measurement Model for Burnout}

Burnout is a mediating endogenous variable. It is measured by the CBI Scale of Kristensen et al. (2005) by using 13 indicators. Burnout is a first order and second order latent construct. The three first-order latent factors of burnout are personal burnout, work related burnout, and client related burnout. As discussed in the correlation analysis, there was a multicollinearity issue between $\mathrm{BC} 1$ and $\mathrm{BC} 2$. Thus, one of these variables (BC1) was removed from the measurement model for burnout (Figure 13).

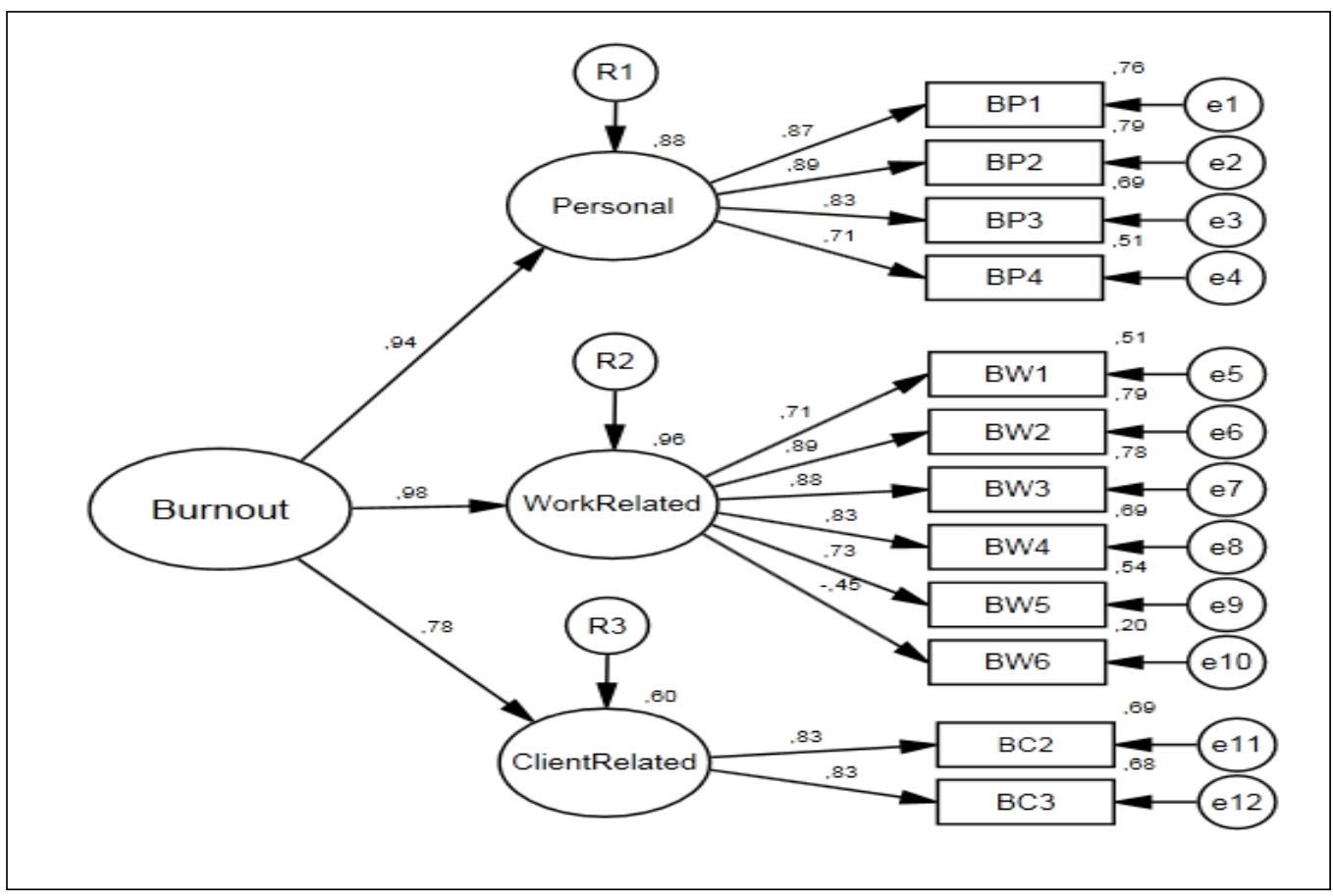

Figure 13. Measurement Model for Burnout (Generic Model) 
The regression weights and parameter estimates of the generic model for burnout is given in Table 6. According to the table, all of the indicators of burnout are statistically significant at the significance level of .01 . Besides, all factor loadings provided sufficient results in terms of the strengths of the factor loadings and exceeded the predetermined threshold of .30 . Thus, all indicators were kept for the measurement model of burnout.

Table 6. Parameter Estimates and Regression Weights for Burnout

\begin{tabular}{lcccccccc}
\hline Generic Model & & & \multicolumn{5}{c}{ Revised Model } \\
\hline Indicators & SRW & URW & SE & CV/p & SRW & URW & SE & CV/p \\
BP1 & .870 & 1.000 & & & .831 & 1.000 & & \\
BP2 & .889 & 1.052 & .041 & $25.857 / * * *$ & .851 & 1.054 & .038 & $27.917 / * * *$ \\
BP3 & .831 & 1.034 & .045 & $22.854 / * * *$ & .847 & 1.103 & .052 & $21.175 / * * *$ \\
BP4 & .714 & .978 & .055 & $17.861 / * * *$ & .736 & 1.051 & .063 & $16.799 / * * *$ \\
BW1 & .711 & 1.000 & & & .689 & 1.000 & & \\
BW2 & .888 & 1.414 & .077 & $18.258 / * * *$ & .875 & 1.438 & .072 & $20.073 / * * *$ \\
BW3 & .883 & 1.200 & .066 & $18.168 / * * *$ & .888 & 1.246 & .073 & $17.104 / * * *$ \\
BC2 & .831 & 1.000 & & & .834 & 1.000 & & \\
BC3 & .825 & 1.131 & .069 & $16.470 / * * *$ & .822 & 1.122 & .069 & $16.315 / * * *$ \\
BW4 & .833 & 1.320 & .077 & $17.154 / * * *$ & .832 & 1.362 & .084 & $16.156 / * * *$ \\
BW5 & .734 & 1.066 & .071 & $15.105 / * * *$ & .721 & 1.082 & .076 & $14.154 / * * *$ \\
BW6 & -.446 & -.653 & .071 & $-9.183 / * * *$ & & & & \\
\hline
\end{tabular}

Table 7 gives the model fitness indices of both the generic model and revised model for the burnout. The table indicates that most of the goodness of fit indices for the generic model provided the sufficient results for a well-fit model, except RMSEA and likelihood ration indices. Thus, a revision was made to improve and get a better-fit model. Table 7 provides excellent fit 
indices for the revised model of the burnout. All of the model fit indices met all predetermined thresholds for an excellent model fit.

Table 7. Model Fitness Indices for Burnout

\begin{tabular}{lcccll}
\hline Model & $\mathrm{X}^{2} / \mathrm{df}$ & CFI & TLI & RMSEA & Hoelter \\
\hline Generic & 5.304 & .944 & .928 & .098 & .114 \\
Revised & 2.043 & .991 & .985 & .48 & 368 \\
\hline
\end{tabular}

In this step, MIs were checked to see highly correlated indicators to revise the generic model and get a better-fit model for the measurement model of burnout (Figure 14). Since the factor loading of BW6 has a negative value, the indicator was removed before revising the model.

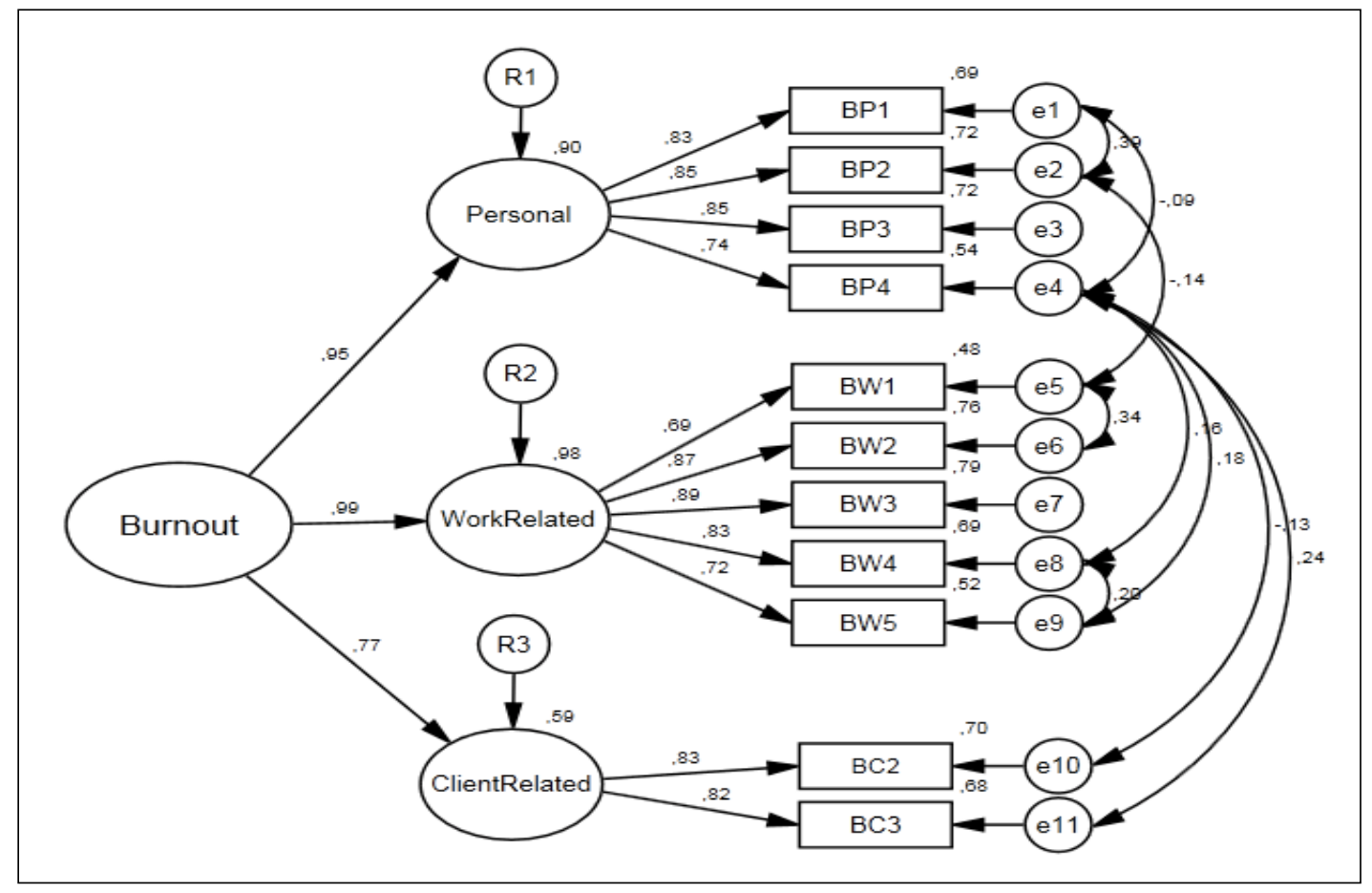

Figure 14. Measurement Model for Burnout (Revised Model) 
As the model fit was achieved, the relationship between indicators can be evaluated. The potential impacts of the items on the latent variable of burnout were given in Table 7 . The table shows that feeling worn out at the end of the working day (BW3) had the greatest effect with a standardized weight of .888. The indicator of work was emotionally exhausted (BW1) had the smallest effect on burnout with a standardized weight of .689. Based on the analysis of Tables 7 and 8 , measurement model for the burnout latent construct was validated and ready for the covariance structure model.

\section{Measurement Model for Job Related Stress}

The first exogenous variable of the study was job-related stress. It was measured by 11 indicators. As discussed in the correlation analysis section, there was no multicollinearity issue among indictors. Thus, all indicators were kept in the model. Figure 15 illustrates the measurement model for job-related stress.

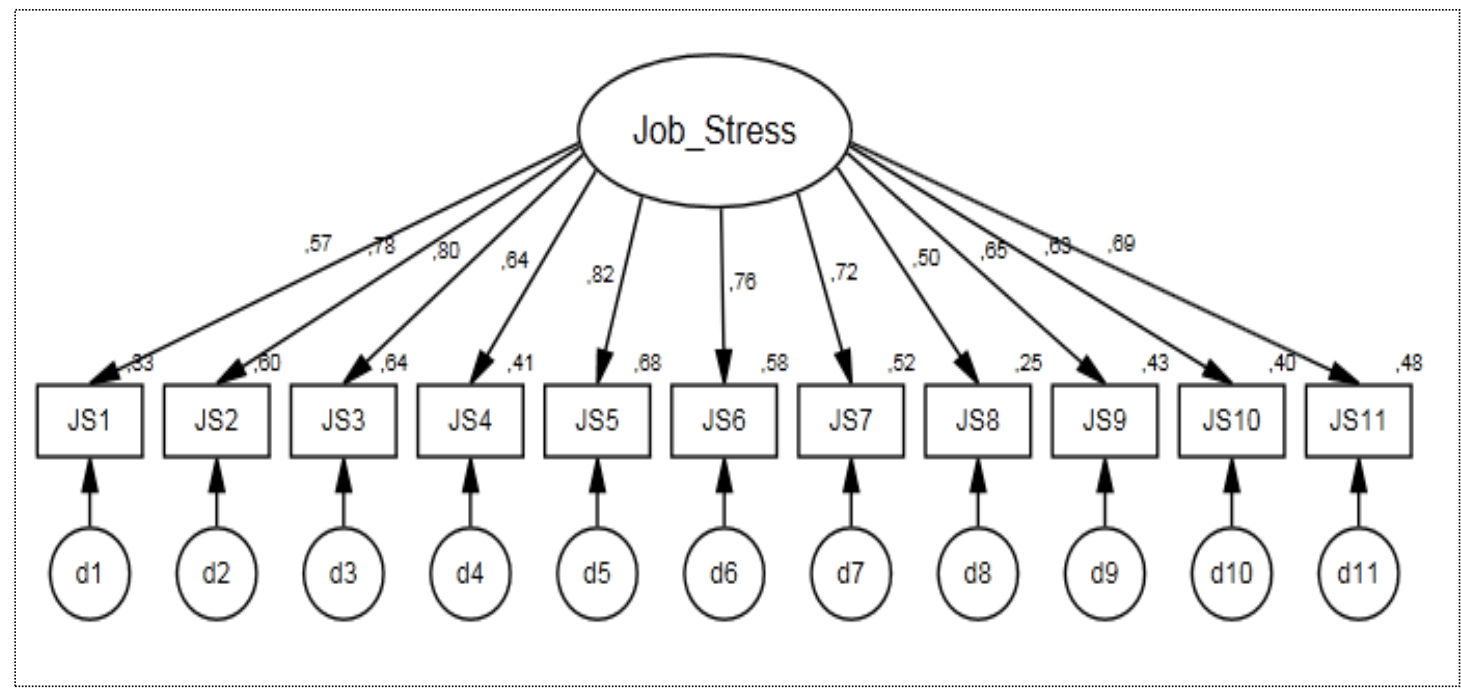

Figure 15. Measurement Model for Job-related Stress (Generic Model) 
Table 8 indicates the parameter estimates of the generic model for job-related stress.

According to the table, all indicators of job-related stress variable were statistically significant at the significance level of .01. The values of the factor loadings show that all factor loadings exceeded the predetermined criteria of .30 . Thus, none of the items were removed from the measurement model for job-relate stress.

Table 8. Parameter Estimates and Regression Weights for Job-related Stress

\begin{tabular}{lllllllll}
\hline \multicolumn{2}{l}{ Generic Model } & \multicolumn{6}{c}{ Revised Model } \\
\hline Indicators & SRW & URW & SE & CV/p & SRW & URW & SE & CV/p \\
\hline JS5 & .824 & 1.000 & & & .823 & 1.000 & & \\
\hline JS4 & .640 & .798 & .055 & $14.551 / * * *$ & .613 & .766 & .055 & $13.817 / * * *$ \\
\hline JS3 & .800 & 1.066 & .054 & $19.608 / * * *$ & .808 & 1.078 & .056 & $19.404 / * * *$ \\
\hline JS2 & .776 & 1.027 & .055 & $18.783 / * * *$ & .794 & 1.051 & .056 & $18.774 / * * *$ \\
\hline JS1 & .574 & .731 & .057 & $12.747 / * * *$ & .560 & .715 & .058 & $12.405 / * * *$ \\
\hline JS6 & .761 & .955 & .052 & $18.281 / * * *$ & .764 & .960 & .052 & $18.429 / * * *$ \\
\hline JS7 & .721 & .831 & .049 & $16.981 / * * *$ & .704 & .812 & .049 & $16.472 / * * *$ \\
\hline JS8 & .499 & .624 & .058 & $10.833 / * * *$ & .525 & .658 & .059 & $11.168 / * * *$ \\
\hline JS9 & .652 & .899 & .060 & $14.917 / * * *$ & .645 & .888 & .061 & $14.544 / * * *$ \\
\hline JS10 & .632 & .842 & .059 & $14.330 / * * *$ & .645 & .856 & .060 & $14.257 / * * *$ \\
\hline JS11 & .692 & .832 & .052 & $16.089 / * * *$ & .689 & .830 & .052 & $16.048 / * * *$ \\
\hline
\end{tabular}

Goodness of fit indices of both the generic model and revised model of job-related stress is given in Table 9. As the table indicates, some of the statistics for the generic model of jobrelated stress did not provide the sufficient indices for a well-fit model, except CFI and Hoelter index. As a consequence of this fact, a revision was made to improve and get a better-fit model. Table 9. Model Fitness Indices for Job-related Stress

\begin{tabular}{lcccll}
\hline Model & X2/df & CFI & TLI & RMSEA & Hoelter \\
\hline Generic & 6.069 & .910 & .888 & .106 & 102 \\
Revised & 2.063 & .985 & .976 & .049 & 312 \\
\hline
\end{tabular}


In the following step, modification indices were examined to see highly correlated indicators to revise the generic model and get a better-fit model for job-related stress variable. In order to revise the model, measurement errors were correlated by using the MIs (Figure 16).

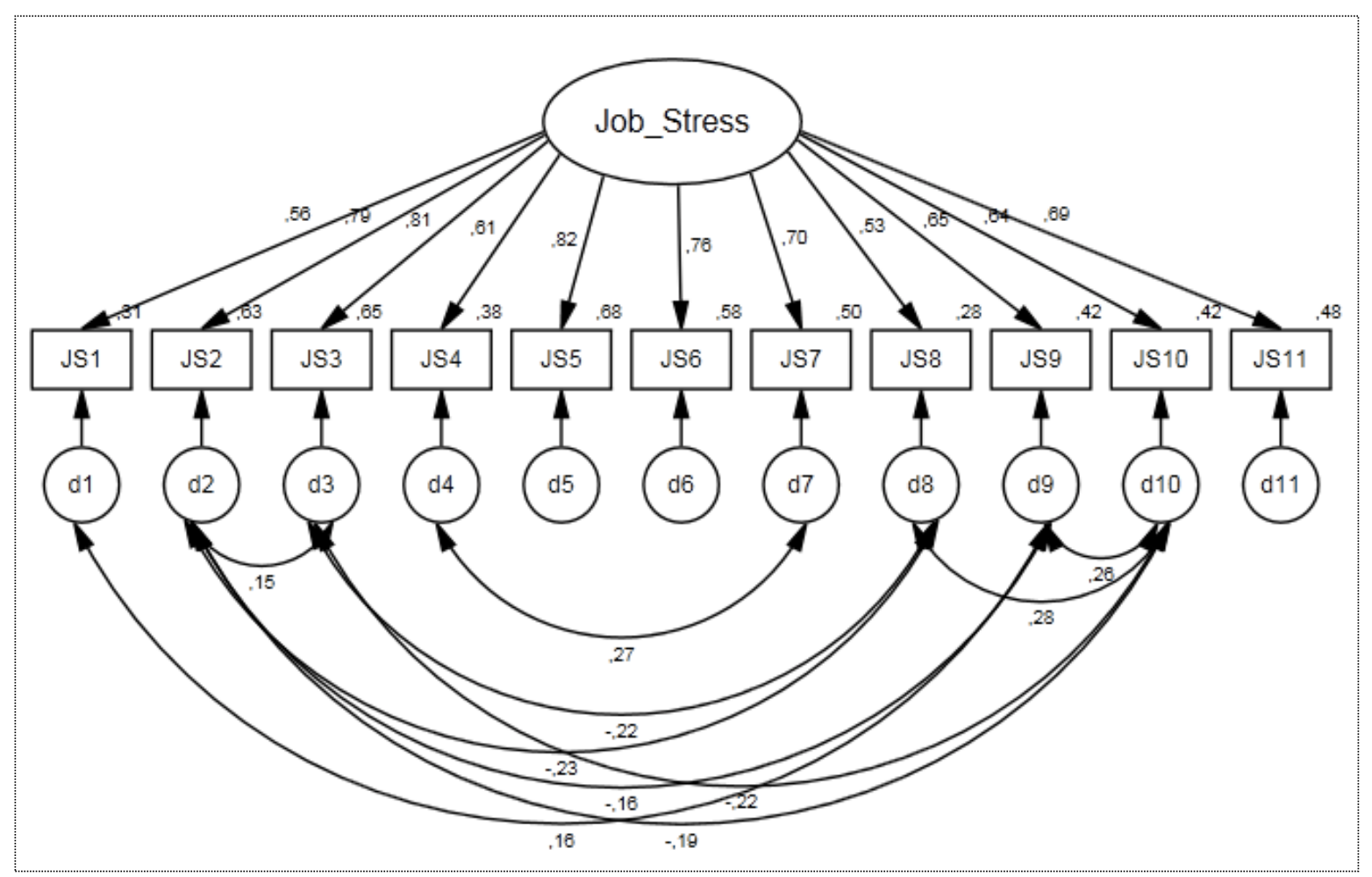

Figure 16. Measurement Model for Job-related Stress (Revised Model)

After revising the model, there is a significant improvement in the model fitness indices of the job-related stress. As Table 10 shows, all of the goodness of fit indices for the revised model met all predetermined thresholds for an excellent model fit. After accomplishing the model fit, the evaluation and interpretation of the relationship between indicators will be discussed in the following part. Table 9 shows the possible effects of the indicators on the latent variable of job-related stress. The table indicates that JS5 has the greatest effect, while JS8 has the smallest effect on job-related stress with standardized weights of .823 and .525 respectively. 
As a consequence of the results of the analysis given above, the measurement model for the jobrelated stress latent construct was validated.

\section{Measurement Model for Mobbing}

Mobbing was one of the two exogenous variables of the study. In order to measure to what extent participants were exposed to mobbing, the WHS scale with 18 items was used. The Figure 17 provides the CFA results for the initial generic model of the mobbing model. As correlation analysis indicated, there are no variables having multicollinearity issues. Thus, all indicators were kept in the measurement model of mobbing. Figure 16 depicts the measurement model for the study variable of mobbing.

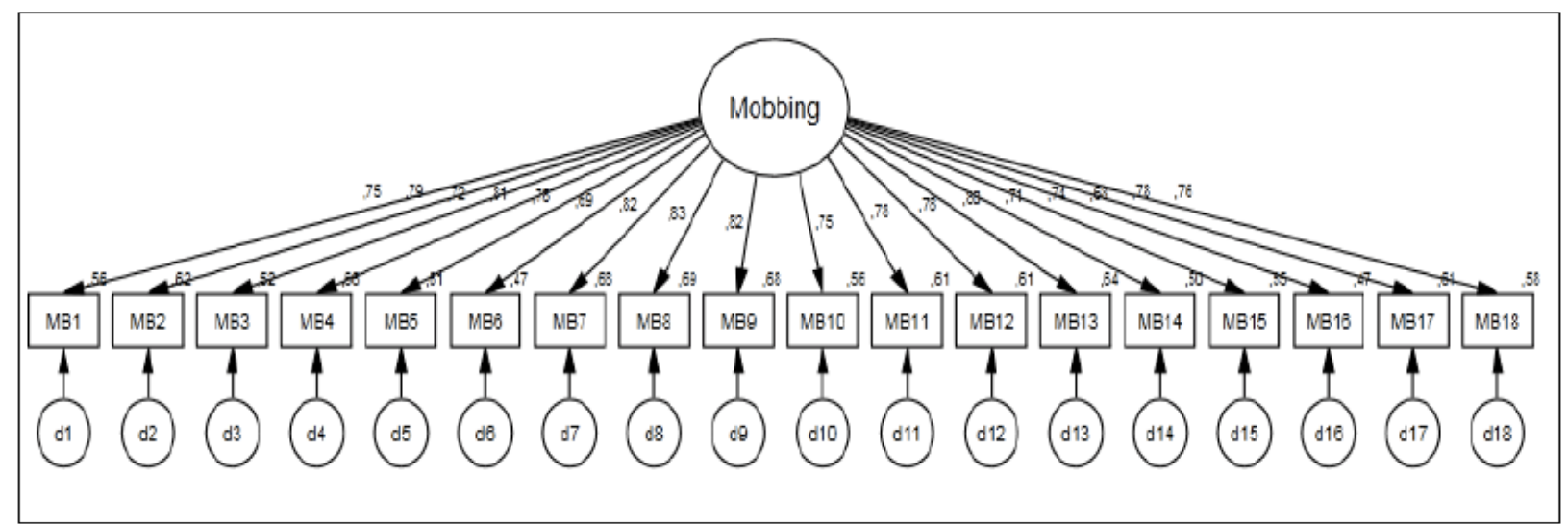

Figure 17. Measurement Model for Mobbing (Generic Model)

Table 10 displays the regression weights and parameter estimates of the generic model for mobbing. As the table indicates, all of the indicators of mobbing were statistically significant at the significance level of .01. All factor loadings provided sufficient outcomes in terms of the strengths of the factor loadings and exceeded the predetermined threshold of .30. Consequently, all indicators were kept for the measurement model of mobbing. 
Table 10. Parameter Estimates and Regression Weights for Mobbing

\begin{tabular}{lccllllll}
\hline \multicolumn{1}{l}{ Generic Model } & & \multicolumn{6}{c}{ Revised Model } \\
\hline Indicators & SRW & URW & SE & CV/p & SRW & URW & SE & CV/p \\
MB8 & .828 & 1.000 & & & .833 & 1.000 & & \\
MB7 & .823 & 1.040 & .049 & $21.435 / * * *$ & .820 & 1.032 & .048 & 21.347 \\
MB6 & .686 & .662 & .040 & $16.491 / * * *$ & .687 & .660 & .040 & 16.504 \\
MB5 & .779 & .999 & .051 & $19.717 / * * *$ & .780 & .995 & .050 & 19.750 \\
MB4 & .812 & .972 & .046 & $21.002 / * * *$ & .810 & .962 & .042 & 22.788 \\
MB9 & .822 & 1.216 & .057 & $21.401 / * * *$ & .824 & 1.212 & .057 & 21.448 \\
MB10 & .748 & .830 & .045 & $18.581 / * * *$ & .747 & .825 & .044 & 18.549 \\
MB11 & .778 & 1.038 & .053 & $19.697 / * * *$ & .777 & 1.028 & .055 & 18.640 \\
MB12 & .783 & .972 & .049 & $19.878 / * * *$ & .777 & .959 & .049 & 19.613 \\
MB13 & .799 & .898 & .044 & $20.481 / * * *$ & .785 & .878 & .044 & 19.942 \\
MB14 & .708 & .851 & .049 & $17.232 / * * *$ & .712 & .851 & .049 & 17.380 \\
MB15 & .739 & .858 & .047 & $18.263 / * * *$ & .757 & .873 & .046 & 18.808 \\
MB16 & .683 & .647 & .039 & $16.413 / * * *$ & .669 & .629 & .040 & 15.910 \\
MB17 & .784 & .861 & .043 & $19.897 / * * *$ & .781 & .850 & .043 & 19.659 \\
MB18 & .764 & .973 & .051 & $19.187 / * * *$ & .765 & .969 & .047 & 20.649 \\
MB3 & .720 & .735 & .042 & $17.622 / * * *$ & .833 & 1.000 & & \\
MB2 & .786 & 1.040 & .052 & $19.995 / * * *$ & .820 & 1.032 & .048 & 21.347 \\
MB1 & .749 & 1.019 & .055 & $18.639 / * * *$ & .687 & .660 & .040 & 16.504 \\
\hline
\end{tabular}

Table 11 provides the goodness of fit indices of both the generic model and revised model for the mobbing. The table indicates that none of the model fitness indices for the generic model provided the sufficient indices for a well-fit model, except the Hoelter index. As a result of the analysis, a revision required to improve and get a better-fit model for mobbing. 
Table 11. Model Fitness Indices for Mobbing

\begin{tabular}{llllll}
\hline Model & $\mathrm{X}^{2} / \mathrm{df}$ & $\mathrm{CFI}$ & $\mathrm{TLI}$ & RMSEA & Hoelter \\
\hline Generic & 6.071 & .894 & .880 & .106 & .97 \\
Revised & 2.063 & .985 & .976 & .049 & 312 \\
\hline
\end{tabular}

In the following step, highly correlated indicators were examined by using modification indices to revise the model. Figure 18 indicates the revised measurement model for mobbing.

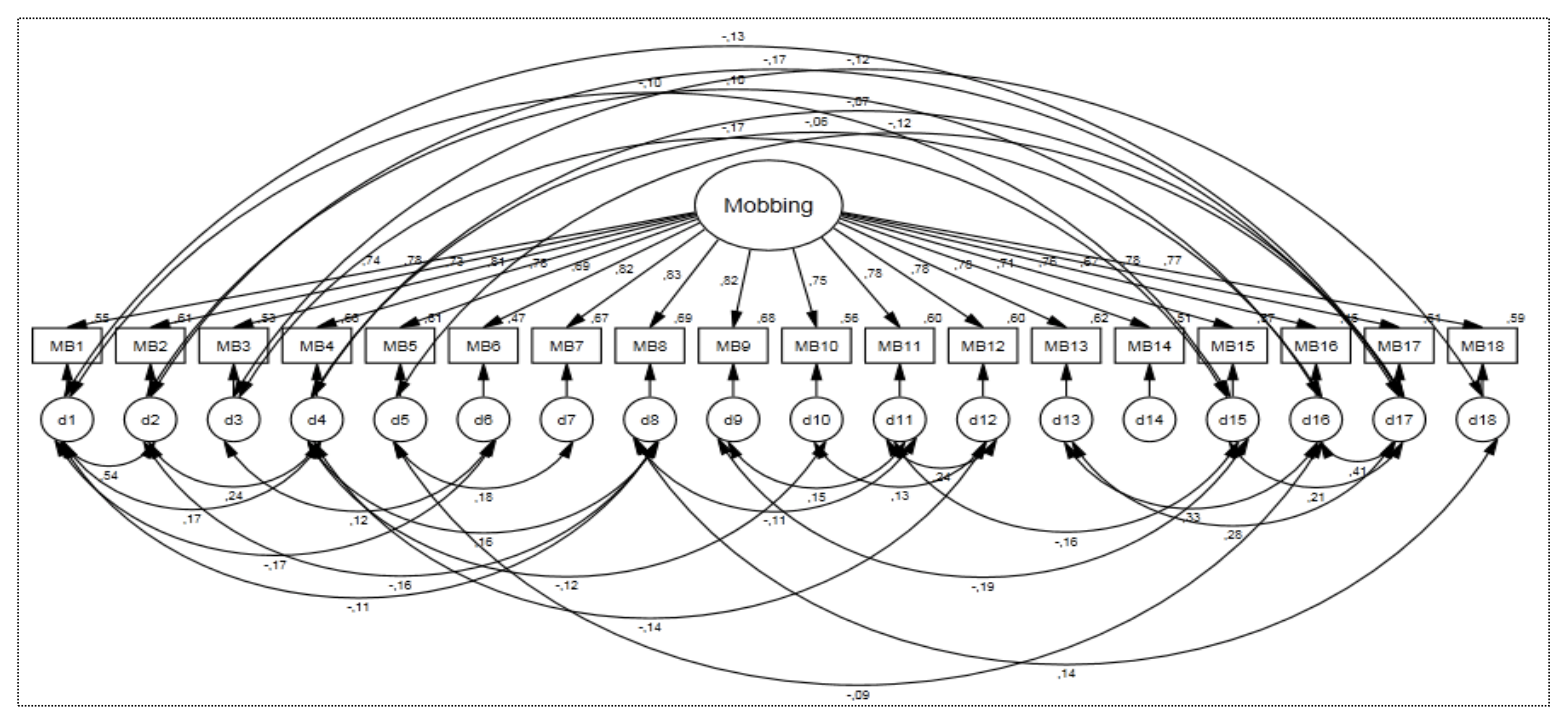

Figure 18. Measurement Model for Mobbing (Revised Model)

After revising the model, there was a significant improvement in the model fit indices of the study variable of mobbing. As Table 12 shows, all of the goodness of fit indices for the revised model met all predetermined thresholds for an excellent fit model.

After achieving the model fit for the study variable of mobbing, the next step was to give brief information on the evaluation and interpretation of the relationship between indicators. Table 11 shows the possible effects of the indicators on the latent variable of mobbing. The table indicates that MB8 and MB3 had the biggest effect, while MB16 had the smallest effect on 
mobbing with standardized weights of .833 and .669 respectively. The results of the analysis provided that the measurement model for the mobbing latent construct was validated with excellent goodness of fit indices.

This part of the study examined the validation of the measurement models of the latent constructs via CFA by using SPSS AMOS 22 software. The following section of the study focuses on the reliability analysis of the measures, and later, the covariance structure model.

\section{$\underline{\text { Reliability Analysis }}$}

Measurement reliability is an important instrument for the consistency or repeatability of the measures. As discussed earlier, the main function of the measurement reliability is to analyze the reliability whether measures create consistent results over time or not. The Cronbach's Alpha coefficient is one of the common techniques used to evaluate the extent to which a measurement creates reliable results at different times (Cronbach, 1951; Kline, 2011). George and Mallery (2003) accepted threshold that was bigger than .8 was good, while Kline (2010) accepted a Cronbach's score greater than .70 as a satisfactory internal consistency. Hence, .70 was identified as the threshold for the reliability of the survey for this study.

Table 12 indicates the Cronbach's Alpha scores for all measurement models of each latent construct of the study. Since the alpha scores of all measurement models met the predetermined criteria of .70 , there was no need to revise measurement models. The reliability of the measurement models for this study ranged from .843 to .962 , which were good and excellent scores. 
Table 12. Cronbach's Alpha Scores for Measurement Models

\begin{tabular}{llcl}
\hline Measurement Models & Number of Items & Threshold & $\begin{array}{l}\text { Cronbach's alpha } \\
\text { scores of the Study }\end{array}$ \\
\hline HRQoL & 12 & .70 & .843 \\
Burnout & 13 & .70 & .912 \\
Job Stress & 11 & .70 & .908 \\
Mobbing & 18 & .70 & .962 \\
\hline
\end{tabular}

The scale of mobbing measures had the highest reliability score with a 962 Cronbach's Alpha value, while the scale of HRQoL received the lowest reliability score with .843 . Thus Cronbach's Alpha scores showed that the measurement models of burnout, job-related stress, and mobbing had an excellent internal consistency, and the measurement model of HRQoL had a good internal consistency (Table 12). As the all measurement models were validated via CFA with a high reliability, the following sections discuss the covariance structure model to perform the hypotheses testing.

\section{Covariance Structure Model}

Covariance structure model (CSM) was created after validating the measurement models of each latent construct. The main function of CFA was to evaluate the causal relationship among variables. The CSM included all exogenous variables, endogenous variables, control variables, and measurement error terms. It also included the first and second-order factors for HRQoL and burnout latent constructs. The structural relationships between job-related stress, mobbing, and burnout, and the relationship between burnout and health-related quality of life of territorial state representatives of Turkey were examined by the covariance structure model. The $\mathrm{R}^{2}$ values for endogenous variables were calculated to show the significance of the hypotheses 
paths and explanatory power of the models. According to Kaplan (2000), the main function of $\mathrm{R}^{2}$ is to show the total variation of endogenous variables which are explained by the exogenous variables.

As mentioned earlier, the analysis was conducted using a three-step technique: 1) weak items with low factor loadings were verified and removed when necessary, 2) the validity of the model was verified using some indices, and 3) the modification indices for highly correlated measurement errors of the indicators to improve and revise the generic model and get a wellfitted model were verified. When the model did not fit-well with the date, further revisions were made. Figure 19 displays the covariance structure model with all measurement models and the relationships between constructs. 


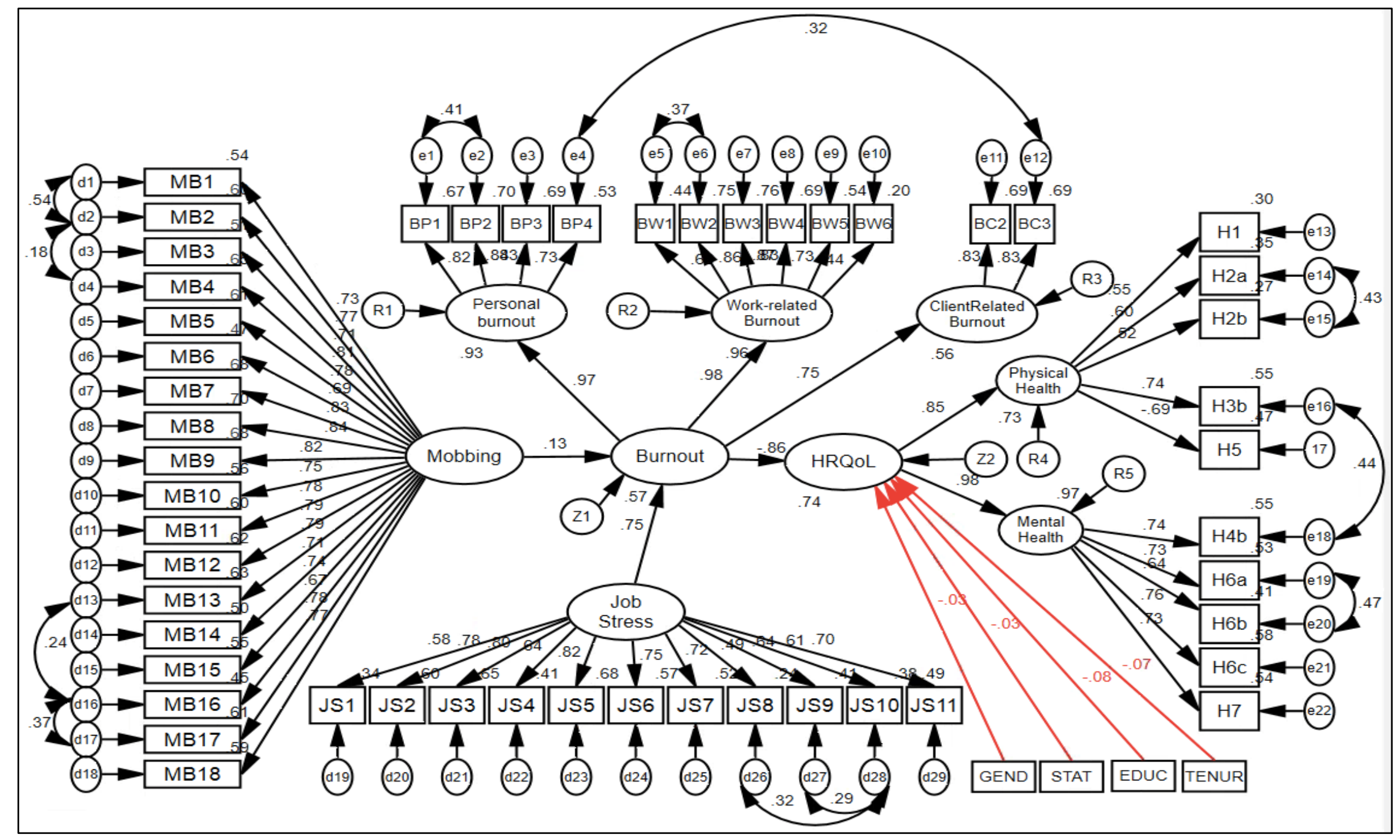

Figure 19. Covariance Structure Model (Generic Model) 
Each single arrow between variables symbolizes the hypothesized causal relationships between endogenous and exogenous variables of the study, while each single arrow between indicators and variables symbolizes the predictive capacity of each item of the latent variables. The variables having insignificant relationships were shown in red.

Table 13 provides the parameter estimates of both the generic model and revised model for covariance structure model. As the table indicates, all of the indicators and correlations amongst measurement errors were statistically significant at the significant level of .01, except four control variables, tenure, education, status, and gender. Since they had significant values lower than the significant level of .01 , they were removed for the final revised model of the covariance structure model.

Table 13. Parameter Estimates and Regression Weights for the CSM

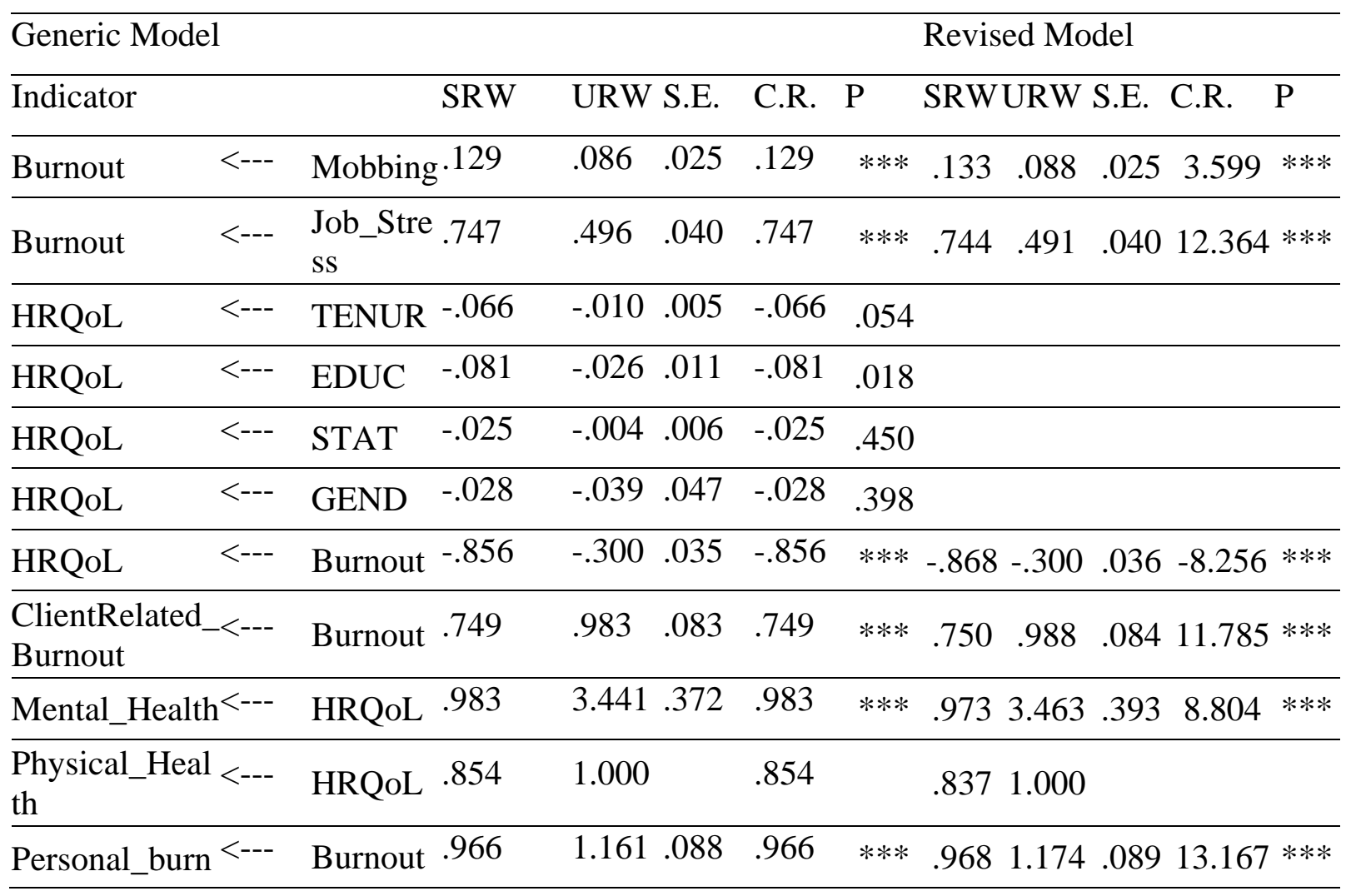




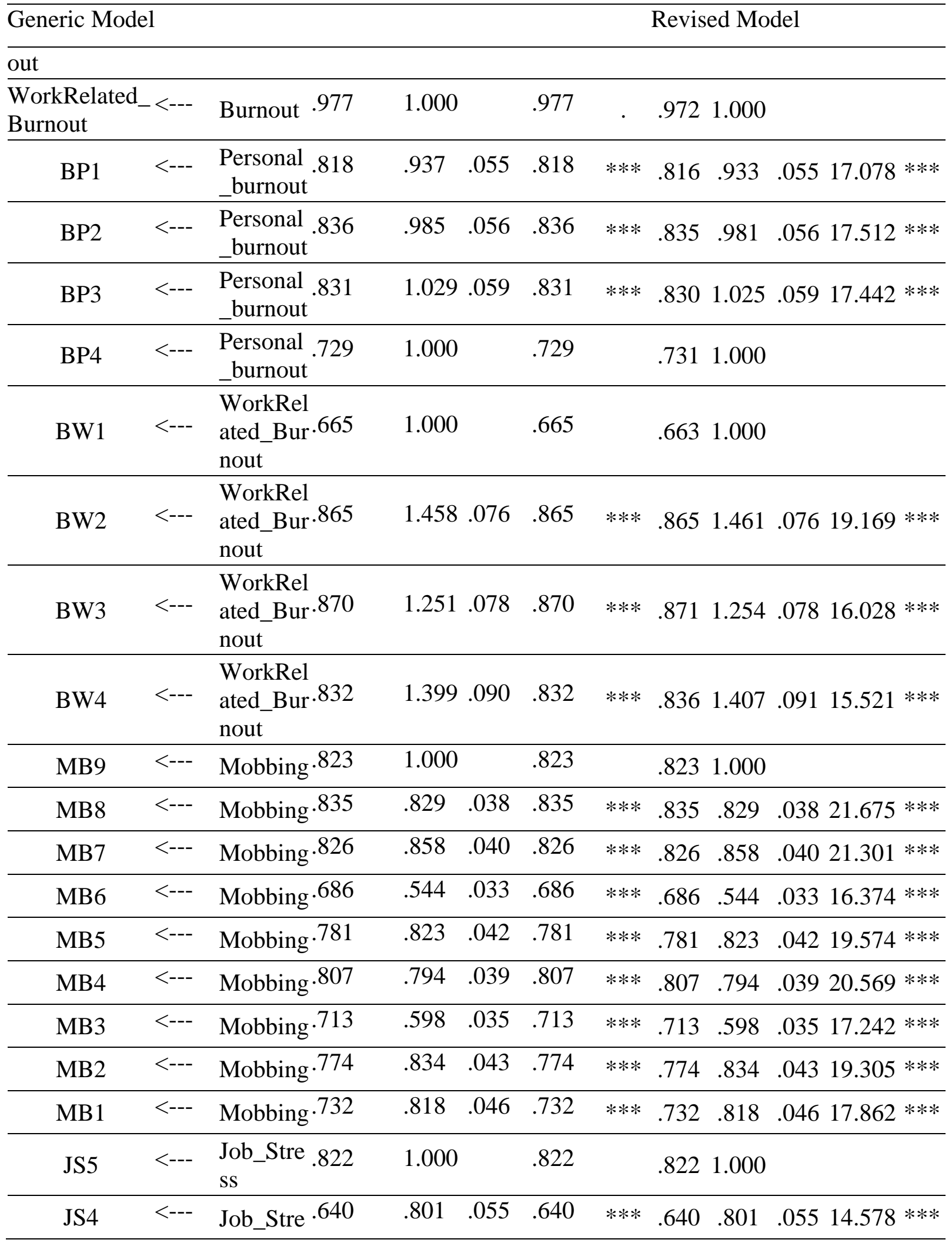




\begin{tabular}{|c|c|c|c|c|c|c|c|}
\hline & & SS & & & & & \\
\hline JS3 & $<---$ & $\begin{array}{l}\text { Job_Stre } .804 \\
\text { ss }\end{array}$ & 1.074 & .054 & .804 & $* * *$ & .8041 .075 .05419 .753 *** \\
\hline $\mathrm{JS} 2$ & $<---$ & $\begin{array}{l}\text { Job_Stre } .775 \\
\text { ss }\end{array}$ & 1.029 & .055 & .775 & $* * *$ & $\begin{array}{llll}775 & 1.029 & 055 & 18.758 \text { **** }\end{array}$ \\
\hline JS1 & $<---$ & $\begin{array}{l}\text { Job_Stre } .584 \\
\text { ss }\end{array}$ & .746 & .057 & .584 & $* * *$ & $\begin{array}{llll}.585 & .747 & 057 & 13.045\end{array}$ **** \\
\hline JS6 & $<---$ & $\begin{array}{l}\text { Job_Stre } .754 \\
\text { ss }\end{array}$ & .949 & .053 & .754 & $* * *$ & $\begin{array}{llll}.754 & 949 & 053 & 18.058 \text { *** }\end{array}$ \\
\hline $\mathrm{BC} 2$ & $<---$ & $\begin{array}{l}\text { ClientRe } \\
\text { lated_Bu.828 } \\
\text { rnout }\end{array}$ & 1.000 & & .828 & & .8251 .000 \\
\hline BC3 & $<---$ & $\begin{array}{l}\text { ClientRe } \\
\text { lated_Bu.829 } \\
\text { rnout }\end{array}$ & 1.148 & .072 & .829 & $* * *$ & $\begin{array}{llll}832 & 1.154 & 072 & 16.000\end{array}$ *** \\
\hline BW5 & $<---$ & $\begin{array}{l}\text { WorkRel } \\
\text { ated_Bur.733 } \\
\text { nout }\end{array}$ & 1.136 & .081 & .733 & $* * *$ & $\begin{array}{llll}735 & 1.141 & 082 & 13.940\end{array}$ *** \\
\hline BW6 & $<---$ & $\begin{array}{l}\text { WorkRel } \\
\text { ated_Bur-.443 } \\
\text { nout }\end{array}$ & -.700 & .079 & -.443 & $* * *$ & $* * *$ \\
\hline MB10 & $<--$ & Mobbing.749 & .684 & .037 & .749 & $* * *$ & $\begin{array}{lllll}.749 & 684 & 037 & 18.461 & * * * *\end{array}$ \\
\hline MB11 & $<---$ & Mobbing. 777 & .852 & .044 & .777 & $* * *$ & $\begin{array}{llll}.777 & .852 & .044 & 19.458\end{array}$ **** \\
\hline MB12 & $<--$ & Mobbing.786 & .802 & .041 & .786 & $* * *$ & $\begin{array}{lllll}786 & .802 & .041 & 19.764\end{array}$ **** \\
\hline MB13 & $<--$ & Mobbing.795 & .735 & .037 & .795 & $* * *$ & $\begin{array}{llll}.795 & .735 & 037 & 20.092 \\
\end{array}$ \\
\hline MB14 & $<--$ & Mobbing.711 & .701 & .041 & .711 & $* * *$ & $\begin{array}{lllll}.711 & .701 & .041 & 17.159 * * *\end{array}$ \\
\hline MB15 & $<--$ & Mobbing.742 & .708 & .039 & .742 & $* * *$ & $\begin{array}{llll}.742 & 708 & 039 & 18.193 \\
0 * * *\end{array}$ \\
\hline MB16 & $<--$ & Mobbing $\cdot 674$ & .518 & .032 & .674 & $* * *$ & $\begin{array}{llll}674 & 518 & 032 & 15.983\end{array}$ **** \\
\hline MB17 & <--- & Mobbing. .781 & .705 & .036 & .781 & $* * *$ & $\begin{array}{lllll}781 & 705 & .036 & 19.579\end{array}$ **** \\
\hline JS7 & $<---$ & $\begin{array}{l}\text { Job_Stre .723 } \\
\text { ss }\end{array}$ & .836 & .049 & .723 & $* * *$ & $\begin{array}{llll}.723 & .836 & 049 & 17.063\end{array}$ **** \\
\hline JS8 & $<---$ & $\begin{array}{l}\text { Job_Stre .485 } \\
\text { ss }\end{array}$ & .608 & .058 & .485 & $* * *$ & $\begin{array}{llll}485 & .608 & 058 & 10.490\end{array}$ **** \\
\hline JS9 & $<---$ & $\begin{array}{l}\text { Job_Stre } .644 \\
\text { ss }\end{array}$ & .889 & .061 & 644 & $* * *$ & $\begin{array}{llll}.644 & .889 & 061 & 14.668 * * *\end{array}$ \\
\hline
\end{tabular}


Generic Model

Revised Model

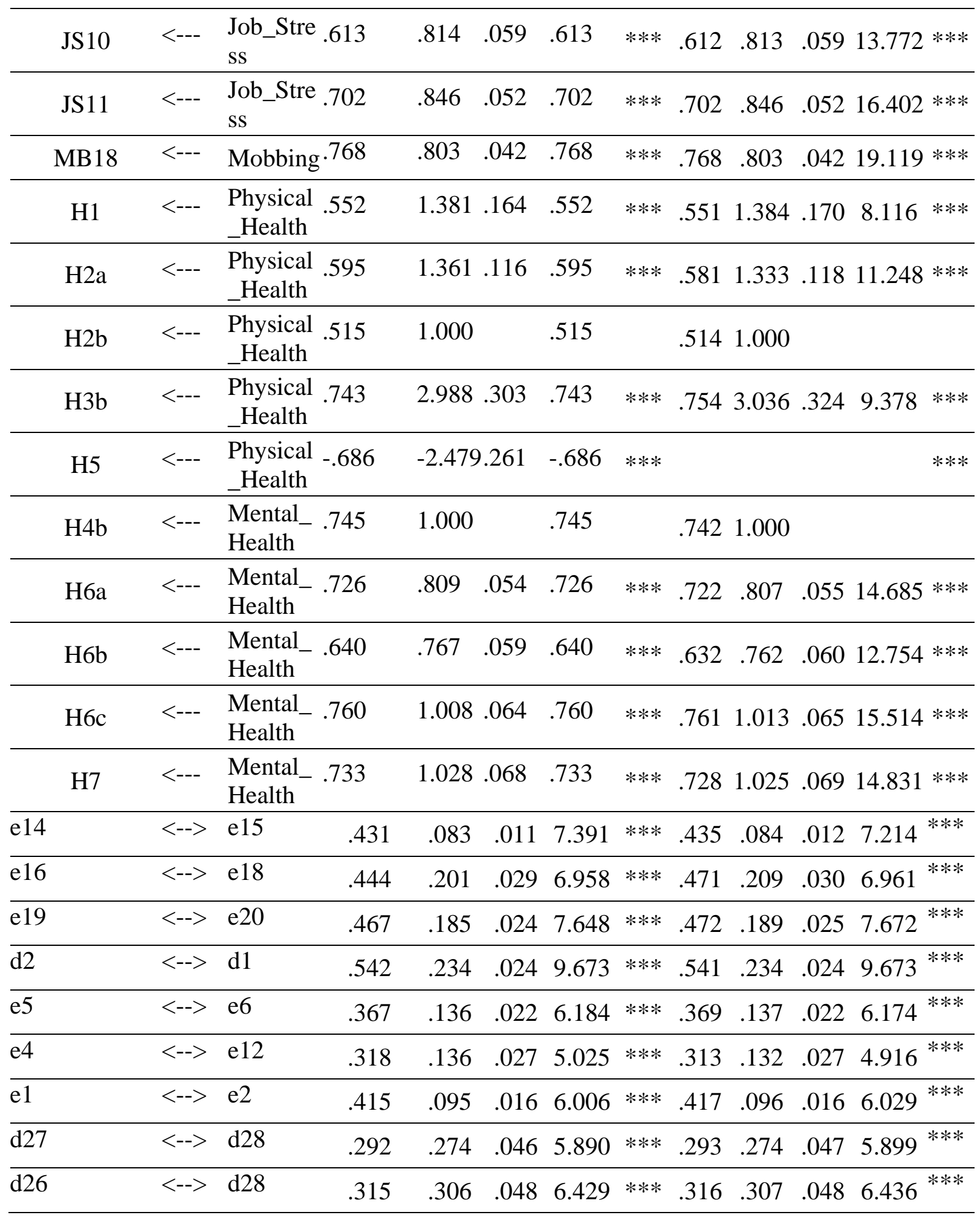




\begin{tabular}{llllllllllll}
\hline \multicolumn{2}{l}{ Generic Model } & & \multicolumn{1}{c}{ Revised Model } \\
\hline $\mathrm{d} 16$ & $<-->$ & $\mathrm{d} 17$ & .370 & .098 & .014 & 7.183 & $* * *$ & .370 & .098 & .014 & $7.183^{* * *}$ \\
\hline $\mathrm{d} 4$ & $<-->$ & $\mathrm{d} 2$ & .177 & .058 & .014 & 4.098 & $* * *$ & .177 & .058 & .014 & $4.098^{* * *}$ \\
\hline $\mathrm{d} 13$ & $<-->$ & $\mathrm{d} 16$ & .236 & .062 & .013 & 4.971 & $* * *$ & .236 & .062 & .013 & $4.971^{* * *}$ \\
\hline
\end{tabular}

Goodness of fit indices of both the generic model and revised model of covariance structure model is shown in Table 14. As the table depicts, all statistics for both models provided the sufficient indices for a well-fit covariance structure model. However, since the control variables were not statistically significant in the generic model, a new revised model was created. Figure 20 depicts the revised covariance structure model of the study.

Table 14. Model Fit Indices of Covariance Structure Model

\begin{tabular}{llllll}
\hline Model & $\mathrm{X}^{2} / \mathrm{df}$ & $\mathrm{CFI}$ & $\mathrm{TLI}$ & RMSEA & Hoelter \\
\hline Generic & 2.036 & .911 & .906 & .048 & 241 \\
Revised & 2.031 & .928 & .923 & .048 & 244 \\
\hline
\end{tabular}




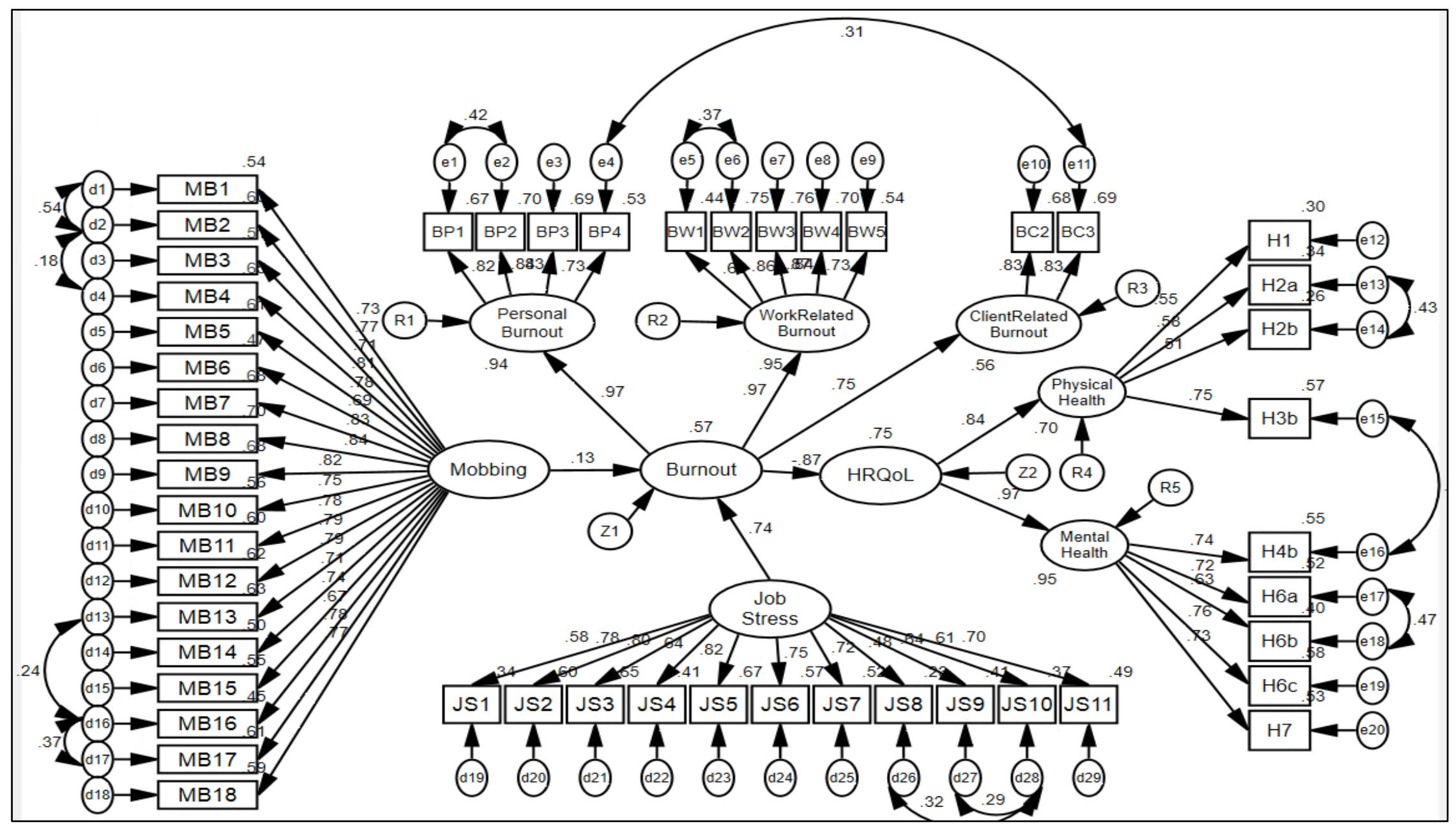

Figure 20. Covariance Structure Model (Final Revised Model) 
Since the fit model was successfully achieved, the importance of the study variables of the CSM was evaluated. Table 14 indicates that all paths among variables and measurement errors were statistically significant at the significance level of .05 . The results of the covariance structure model, as shown in Table 14, shows that both perceived mobbing and job-related stress had indirect effects on the HRQoL of TSRs via perceived burnout. According to the revised model results, burnout had the strongest relationship with health related quality of life of TSRs, while mobbing had the weakest relationship with burnout among all variables with standardized regression weights of -.868 and .133 , respectively. Burnout had a negative effect on HRQoL. Moreover, job-related stress and burnout also had a very strong relationship with a standardized regression weight of .744 .

Furthermore, as discussed in the variables section of the study, burnout was a mediation latent variable. It mediated the relationship between job-related stress, mobbing, and HRQoL of TSRs. The indirect relationships between job-related stress, mobbing, and HRQoL via burnout can be computed by multiplying the standardized regression weights of these variables. The indirect effect of job-related stress on HRQoL was -.645 $\left(, 744^{*},-868\right)$, while the indirect effect of mobbing on HRQoL was -.115 (,133*,-868). Thus both variables had positive effects on burnout and negative effects on the HRQoL of TSRs, which means perceived mobbing and job-related stress increased the perceived burnout, while burnout, job-related stress, and mobbing decreased the perceived level of the HRQoL of the Turkish TSRs. As it was shown in the generic model of covariance structure model, none of the control variables has as significant relationships with the HRQoL of TSRs. 
The results of CSM analysis showed that perceived mobbing and job-related stress accounted for $57 \%$ of burnout. Further, the variance in HRQoL measures explained by all exogenous variables, job-related stress, and mobbing, and mediating endogenous variable of burnout was $75 \%$, which means the endogenous variable of the study, HRQoL, is explained by the above-mentioned variables with a very high percentage.

\section{Hypotheses Testing}

This study tested four hypotheses. This section will discuss whether and to what extend the hypotheses were supported by the dataset based on the structural equation modeling analysis results.

The study conceptual model in Figure 21 depicts the standardized regression weights of the relationships between variables. The insignificant correlations between variables are shown in red. The study conceptual model depicted in Figure 21 illustrates the standardized regression weights of the relationships between variables.

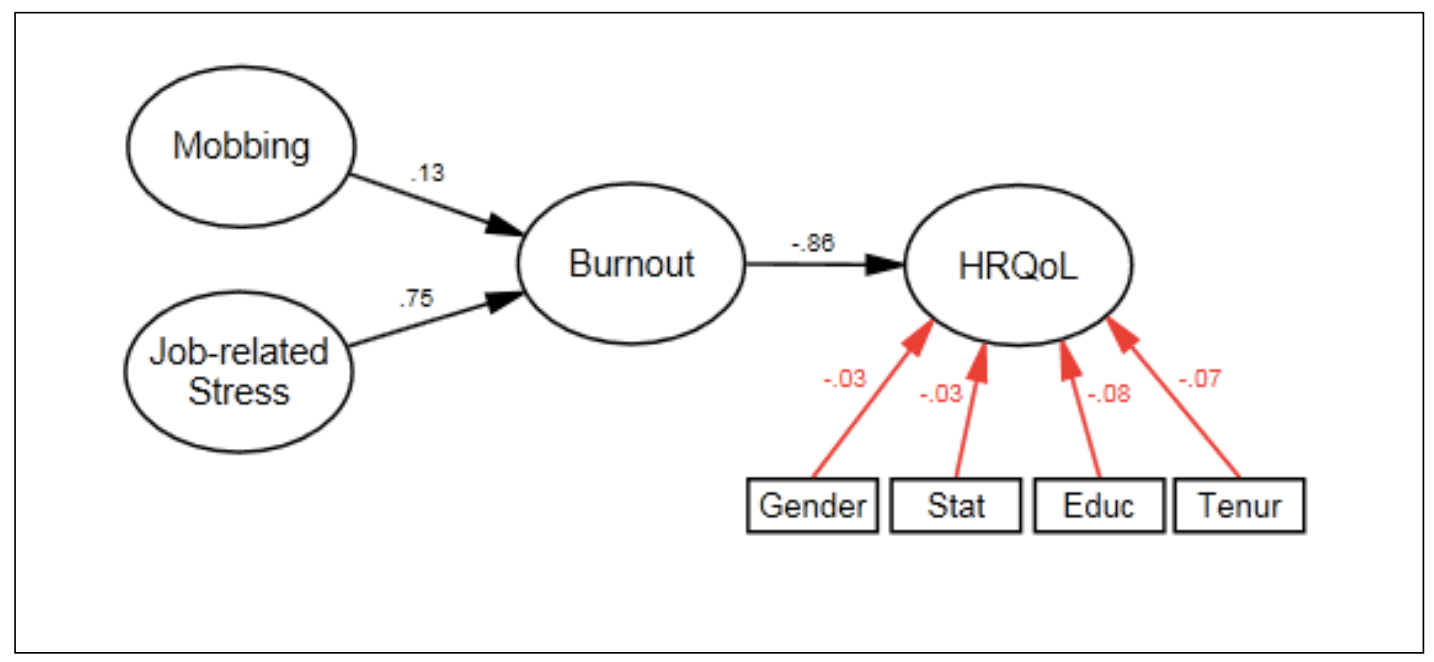

Figure 21. The Conceptual Model with Regression Coefficient Values of the Study Variables 
H1: Perceived job-related stress is positively related to perceived burnout of Turkish territorial state representatives.

The first hypothesis was about the relationship between perceived job-related stress and perceived burnout of the Turkish territorial state representatives. The findings of the study showed that job-related stress was positively and significantly related to burnout of the TSRs with a .746 standardized regression weight at .95 confidence level with a $p$ value of $<.01$. Thus, the results indicated that the hypothesis was supported by the study data. Also, the URW of .491 among the study variables indicated that one unit of increase in job-related stress led to a .491 unit of increase in burnout of the TSRs.

H2: Perceived mobbing is positively related to perceived burnout of Turkish territorial state representatives.

The second hypothesis was about the relationship between perceived mobbing and perceived burnout of the Turkish TSRs. The results of analysis indicated that perceived mobbing was positively and significantly related to the burnout of the TSRs with a .133 standardized regression weight at .95 confidence level with a p value of $<.01$. This means the results confirmed that the hypothesis was supported by the study data. Further, the URW of .088 among the study variables indicated that one unit of increase in job-related stress led to a .088 unit of increase in burnout of the TSRs.

H3: HRQoL is negatively related to perceived burnout of Turkish territorial state representatives.

The third hypothesis assumed that perceived HRQoL of TSRs was negatively related to perceived burnout level of the Turkish TSRs. According to findings provided by the analysis, 
perceived HRQoL was related to the burnout of the TSRs with a negative .868 standardized regression weight at .95 confidence level with a p value of $<.01$. The results indicated that the direct relationship between burnout and HRQoL was also statistically significant and the direction of the path was negative, which means the hypothesis was supported by the study data. Moreover, the URW of -.300 among the study variables indicated that one unit of increase in burnout led to a .300 unit of decrease in HRQoL of the TSRs.

H4: Perceived burnout mediates the effects of perceived job-related stress on HRQoL of Turkish territorial state representatives.

The last hypothesis supposed that job-related stress affected the HRQoL of the Turkish TSRs indirectly via perceived burnout of the TSRs. In order for this hypothesis to be supported, the relationship between job stress and burnout, and the relationship between burnout and HRQoL of TSRs should be statistically significant. As computed above, the indirect effect of job-related stress on HRQoL is -.645 $\left(, 746^{*},-848\right)$. Thus both variables had positive effects on burnout and negative effects on the HRQoL of TSRs. This means perceived job-related stress increase the perceived burnout, while burnout and job-related stress decrease the perceived level of the HRQoL of the Turkish TSRs. The results showed that the relationship between job-related stress and burnout was statistically significant at .95 confidence level with a p value of <.01. As a result, burnout mediated the relationship between job-related stress and HRQoL of TSRs and the hypothesis was supported by the study data.

As a summary, the findings provided that all hypotheses of the study were supported by the study data. In the next chapter, the results of the analysis, implications, and limitations of the study will be discussed in depth. 


\section{CHAPTER SIX: DISCUSSION, IMPLICATIONS, LIMITATIONS, AND CONCLUSION}

In this chapter, the results of the analysis, implications, and limitations of the study will be discussed in depth. The main sections of this chapter will be summary of the findings and discussions, implications, limitations of the study, and directions future research. The evaluation on the possible theoretical and methodological implications will be the second part of this chapter. Finally, study limitations and potential future research directions will be explained.

\section{Summary of the Findings and Discussions}

In this section, statistical analysis results of the study variables will be discussed.

\section{Health Related Quality of Life}

According to Wan and Pai (1997), health is not only the absence of disorder or sickness, but also physical, mental, and social wellbeing. Wan (2002) argues that health is a vague concept, because it has several meanings. As a consequence of this fact, an accurate instrument for health is been seeking to find a quick and accurate assessment of a people's health (Wan, 2002). The HRQoL concept is one of these instruments because it has several dimensions that measure a person's health ranging from the physical to emotional.

Health-related quality of life was one of the endogenous variables of the study, and is a first and second-order factors latent construct. It has more than one dimension measuring physical, mental, emotional, and social wellbeing. The study adopted $S F-12 v 2^{\text {TM }} 4$-week recall scale, which is the short version of the scale. The survey measures the multiple dimensions of HRQoL with 12 items to measure participants' wellbeing. The SF-12v2 ${ }^{\mathrm{TM}}$ four-week recall was indicated in the structural equation model as a first-order and a second-order latent construct, since HRQoL has two first-order factors which are physical wellbeing and mental wellbeing. 
Physical health was measured by physical functioning, role physical, bodily pain, and general health, while mental health was measured by vitality, social functioning, role emotional, and mental health.

Literature indicated that the developments in the SF-12v2 are similar to the developments made to the SF-36v2 and several research presented that different ways of running may affect survey results (Maruish \& Turner-Bowker, 2009). Several researchers revealed reliable estimates of health status scores throughout the range of health levels (Ware et. al., 1998; Ware et. al., 2000; Ware et al., 2003). As discussed earlier, the short version of the HRQoL measures yield directly similar estimates of average population scores (Maruish \& DeRosa, 2009). According to Maruish and DeRosa (2009) SF-12v2 survey scale had convergent validity, discriminant validity, consistent responses, item internal consistency, and item discriminant validity. According to Maruish and De Rosa (2009), SF 12v2 is a reliable scale with a Cronbach's Alpha score bigger than .70. The construct validity of HRQoL scale was studied in several countries (Keller et al., 1998). Also, Bhandari's (2012) study with HRQoL scale had good reliability and validity with other population with a very reliable alpha score $(.80)$. Correspondingly, Anagnostopoloulos et al. (2010) found that the consistency of the scale is measured by Cronbach's alpha score from .71 to .89 . With parallels to the results of previous studies, this study also revealed that the SF-12v2 scale had good measurement reliability with a .843 Cronbach's alpha score. Findings, on the other hand, revealed that the scale and physical and mental health measures had similar explanations throughout countries and the construct validity of the scale was confirmed (Keller et al., 1998). 
The correlation results showed that the correlation coefficient values for the indicators of HRQoL ranges from .287 to .921 and all indicators had statistically significantly correlated with each other at the significant level of .01. However, two of the correlation values exceed the multicollinearity threshold of .85. These variables are H3a (accomplished less/physical), H3b (less in kind) and H4a (accomplished less/mental) and H4b (less careful). Thus, H3a and H4a from the measurement model for HRQoL and the rest kept in the model.

The parameter estimates of the generic measurement model of HRQoL showed that all indicators of the variable are statistically significant and all factor loadings exceeded the predetermined threshold of .30 . However, most of the goodness of fit indices did not provide a well-fit model for the HRQoL. As a consequence of this fact, a model revision was made to improve the model. Modification indices between measurement errors were used to see highly correlated indicators and the nested model was revised. This revision provided a better model with excellent goodness of fit indices.

The CFA results indicated that feeling downhearted or depressed (H6c) had the greatest effect, while limiting in activities such as climbing several flights or stairs $\mathrm{H} 2 \mathrm{~b}$ had the smallest effect on HRQoL of Turkish state representatives with standardized weights of .529 and .781 respectively.

\section{Burnout}

Maslach, Schaufeli, and Leiter (2001) defined burnout as a psychological condition that resulted as a response to job-related stress making factors. Despite the fact that burnout in the healthcare field has been mostly studied, several studies also revealed that other occupational groups have the same issue, as well (Martinussen et al., 2007); and it is a common problem for 
all employees from all organizational types (Cahoon \& Rowney, 1989). Similarly, Maslach, Schaufeli, and Leiter (2001) argued that, although burnout is associated with employees in the human services and health care areas, it is a prevailing fact in other occupational groups as well. Montgomery et al. (2005) claimed that there is a causal and consistent relationship between jobrelated stress, burnout, and HRQoL; while Change et al. (2006) claimed that job-stress had an adverse effect on individual health.

These studies regarding burnout were more quantitative in nature, employing survey, methodology, and examining larger groups. The main concentration of this body of researches focused on the assessment of burnout and the creation of some different measures. The scale used most widely by researchers throughout this period was the MBI scale, which was particularly created for use in human service groups (Maslach \& Jackson, 1981). However, in response to the attention given to burnout by educators, a new version of the scale was developed to perform in educational fields (Maslach, Schaufeli, \& Leiter, 2001). The CBI scale was developed by Kristensen et al. (2005) with a view to eliminating weaknesses of the popular MBI Questionnaire. It was mainly based on the concept of understanding of social and traditional variances between people from America and Europe (Kristensen et al., 2005). The main reason why this study adopted the CBI questionnaire was that Turkey is located between Europe and Asia and is still in the European Union membership process, so Turkey had more common social and traditional facts with Europe vice the United States.

Burnout was a mediating endogenous variable of the study. It was also a first-order and second-order factor latent construct. It was measured via CBI questionnaire. The first-order 
factors of the burnout latent construct were personal burnout, work-related burnout, and client related burnout.

Kristensen et al. (2005) revealed that the CBI scale had a satisfactory internal reliability and validity. According to their study, the Cronbach's alpha for internal reliability was .86, which established a good level of reliability (Kristensen et al., 2005). They also proved that CBI had high face validity, convergent validity, and divergent validity (Kristensen et al., 2005). With parallel to the above-mentioned studies, this study also revealed that the CBI had excellent measurement reliability with a .912 Cronbach's alpha value.

As discussed in finding section, the correlation matrix of the endogenous variable of burnout indicated that the lowest correlation among variables arose between BS3 (drained energy to work) and BW6 (every working day is tiring), while the highest correlation occurred between $\mathrm{BC} 2$ (frustrating to work with clients) and $\mathrm{BC} 1$ (hard to work with client) with the coefficient values of -.241 and .868 respectively. The matrix provided that all indicators were statistically significant correlated with each other at the significant level of .01. The only multicollinearity issue that surfaced among variables was between BC2 (frustrating to work with clients) and BC1 (hard to work with client) with a .868 coefficient value. Since this value exceeded the predetermined threshold of .85 , one of these variables (BC1) was removed from the measurement model.

According to the regression weights and parameter estimates of generic measurement model results, all indicators were statistically significant at the significant level of .01 and all factor loadings exceeded the predetermined criteria of .30. Since some of the model fit indices 
did not provide sufficient results for fit-model, the generic measurement model for burnout was revised to improve the model.

As a result of revising the model, a well-fit model was achieved. The final results indicated that feeling worn out at the end of the working day (BW3) had the greatest effect with a standardized weight of .888 and the indicator of work was emotionally exhausting (BW1) had the smallest effect on burnout with a standardized weight of .689.

\section{Mobbing}

As discussed earlier, mobbing is a workplace bullying (Leymann, 1990), intentional infliction of emotional distress (Liefooghe, 2004), office offensiveness (Hornstein, 2003), emotive misuse (Keashly, 1998), victimization (Wornham, 2003), or any activity of an employee to force someone out of the office via rumor, innuendo, bullying, disgrace, and isolation (Davenport et al., 2003). The appearance of mobbing may impact both employees and organizations. The negative impact of mobbing may lead to insufficiencies in organizational commitment and organizational performance, lack of efficiency and effectiveness, decreasing staffs' motivation, employees' job satisfaction, and employees' potential burnout as it is claimed by Dziegielewski et al. (2010).

Bjrökqvist et al. created the Workplace Harassment Scale (WHS), which was used for this study. Grunau (2007) found a statistically significant relationship between mobbing and burnout. In his study, which used the WHS scale, almost half of the participants reported being mobbed.

Mobbing was one of two exogenous variables of the study. It was measured by WHS questionnaire with 13 items to examine the work harassment level of Turkish state 
representatives. This scale was the first scale used worldwide to observe specific sides of the mobbing (Grunau, 2007).

Bjrökqvist et al. (1992a)'s study confirmed that the measurement reliability of the scale was excellent with a Cronbach's alpha score of .95. Another study of Bjrökqvist et al. (1994a), also found the internal consistency of the alpha level of .86. As the above-mentioned studies found, this study also had similar reliability results. The measurement reliability of this study had a Cronbach's Alpha score of .962, which means the study had an excellent internal consistency and reliability of measurement.

The correlation matrix of mobbing depicted that the lowest correlated variables were MB6 (insulting comments) and MB1 (express yourself) and the highest correlated variables were MB2 (lies about you) and MB1 (express yourself). The matrix, moreover, provided that all indicators were statistically significant correlated with each other at the significant value of .01. Since no multicollinearity issue was detected among variables, all indicators were kept in the measurement model for mobbing.

As the parameter estimates of the generic model for mobbing showed. all indicators were statistically significant at the significance level of .01 and all factor loadings had sufficient outcomes in terms of the strengths of the factor loadings and exceeded the predetermined threshold of .30. As a consequence. none of the indicators were removed from the measurement model of mobbing. However. since most of the model fit indices of the generic model for the mobbing did not provide sufficient GOF statistics for a well-fit model. a model revision was made to improve the generic model for mobbing. Modification indices were used to revise the model. After revising the generic model. the new model provided excellent goodness of fit indices with a 
significant improvement. The parameter estimates of the measurement model for mobbing indicated that 'accusations' (MB8) and 'being shouted at loudly' (MB3) had the greatest effect (.833) on the perceived level of mobbing of TSRs. The 'being ridiculed in front of others' (MB16) had the smallest effect (.669) on perceived mobbing of TSRs. The results of the analysis provided that the measurement model for the mobbing latent construct was validated with excellent goodness of fit indices.

Job-Related Stress

Job-related stress is a mental and physical problem that has direct and adverse effect on employees' productivity and the quality of work they do. According to Gill et al. (2006), it is one of the important issues in developed countries and they defined stress as an employees' reactions to negative work climate features arising as threatening to the employees' health. Similarly, as discussed in the literature section, prolonged job-related stress might negatively affect the individual's wellbeing (Ursin and Eriksen, 2004; Mohren et al. 2003). Moreover, job-related stress might have a negative impact on behaviors towards organizations (Cropanzano et al. 2003; Lee and Ashforth (1996). Researchers claimed that one of the potential results of prolonged stressors at work place is burnout (Martinussen et al., 2007). According the Job DemandsResources Model (JD-R), there was a relationship between job-related stress and burnout (Bakker \& Demerouti, 2007; Demerouti et al., 2001). This theory claimed that all jobs have their specific job features related to burnout, such as job resources, decline in job responsibilities required by employees, and stimulation of employees' performance improvement (Halbesleben \& Buckley 2004; Bakker \& Demerouti, 2007). Wiese et al. (2003) found that there is a direct relationship between job-related stress and burnout. 
Job-related stress was the last exogenous variable of the study. It was measured by job stress scale with 11 items, which was created by the study of 'Organizational Determinants of Job Stress' (Parker \& DeCotiis, 1983). Job-related stress of Turkish state representatives was measured to distinguish the nature of the relations among some potential stressors that were chosen based of the literature and experience of the TSRs. Parker \& DeCotiis, (1983) studied the dimensionality of job related stress more closely, in order to determine the extent to which the scopes are differentially impacted by different stress making factors.

The study of Parker and DeCotiis (1983), and the study of Touringy et al. (2005) examined the reliability of the scale and found that the internal consistency of the scale was determined with an average coefficient alpha score of .89 and the Cronbach's Alpha score of the scales are .86 and .74 . Moreover, the study conducted by Xie and Johns (1995) had a .82 reliability coefficient while the study of Jamal (2000) has the alpha reliability of .85 . Thus the above-mentioned studies confirmed that the reliability of the scale was sufficient and good. As for this study, the measurement reliability of the scale was .908 , which means the scale had an excellent internal consistency and reliability of the measurement.

The correlation matrix of job related stress showed that the correlation coefficient values for the indicators ranged from .238 to .701 . Also, all indicators of job-related stress were statistically significantly correlated with each other at the significant level of .01. The indicators with the lowest correlation values were JS8 (feeling married to company) and JS1 (fidgety or nervous), while the indicators with the highest correlation values were JS3 (jobs get to me more) and JS2 (spend enough time with family). Since the correlation matrix did not detect any multicollinearity issue among variables, all indicators were kept in the measurement model. 
The regression weights and parameter estimates of the generic model for job-related stress indicated that all items were statistically significant at the significance level of .01 and all the factor loadings exceeded the predetermined criteria of .30. Consequently, all indicators were kept in the measurement model. However, since some of the model fit indices did not provide the sufficient threshold for well-fit model, a model revision was made to improve and achieve a better-fit model. Modification indices were used to improve the model. After revising the model, results indicated that all model fit indices met the predetermined criteria for an excellent model for job-related stress. Parameter estimates and regression weights showed that JS5 affects most, with a regression weight of .823 , while JS8 affects less, with a regression weight of .525 , perceived job-related stress of TSRs. As sum, the perceived idea which was "there are lots of times when my job drives me right up the wall," had the biggest effect on perceived job related stress of Turkish state representatives.

\section{Covariance Structure Model}

In this section of the chapter, structural equation modeling findings will be discussed. As it was already discussed, SEM is ideal when testing theories that include latent variables. The structural model allows for the evaluation of the relationships specified in the hypotheses (Hox \& Bechger, 1998; Hoyle, 1995). In this study, the path coefficients were specifically examined with attention to the strength, direction, and significance of the relationships. After validating all measurement models, a covariance structure model comprising all exogenous and endogenous latent variables, control variables, and measurement errors was created. Burnout and HRQoL latent constructs have first-order and second-order factors. The structural relationships between 
job-related stress, mobbing, and burnout, and the relationship between burnout and HRQoL of TSRs of Turkey were examined by using the covariance structure model.

Structural equation modeling was used to answer the following research questions of the study: Whether and to what extent do the levels of perceived job related stress and mobbing affect the level of perceived burnout syndrome of TSRs? Whether and to what extent is the level of perceived burnout syndrome associated with HRQoL of TSRs? To what extent does the level of perceived burnout mediate the effects of job-related stress on HRQoL of TSRs? What are the mediating factors between job burnout and HRQoL?

Covariance structure model was used to examine the hypothesized relationships between mobbing and burnout; job-related stress and burnout; and burnout and HRQoL of Turkish state representatives. Besides, the mediation effect of burnout on HRQoL was also examined. The indirect relationships between job-related stress, mobbing, and HRQoL via burnout was computed. The main theoretical guidance to examine the predictors of perceived burnout and HRQoL of TSRs were the administrator stress cycle model, the theory of job demands resource, developmental theory of interpersonal aggression, and social stress theory.

In the light of literature and theoretical framework discussed earlier, this study had four hypotheses examining the relationships between study variables. The first hypothesis of the study was about the positive relationship between perceived job-related stress and perceived burnout of Turkish territorial state representatives. The SEM findings revealed that job-related stress was positively and significantly related with the burnout of the TSRs $(\beta=.744, \mathrm{p}<.01)$ as it was hypothesized by the study. The results were consistent with literature provided by this study, which congruently found the relationships between stress and burnout (Martinussen at al., 2007; 
Freudenberger, 1974; while Wiese et al., 2003; Maslach, Schaufeli, \& Leiter, 2001; Montgomery et al., 2005; Gmelch \& Gates, 1998).

The second hypothesis of the study was about the positive relationship between perceived mobbing and perceived burnout of the TSRs. The SEM results indicated that that perceived mobbing is positively and significantly related with the burnout of the TSRs $(\beta=.133, \mathrm{p}<.01)$ as it was hypothesized by the study. The results regarding the hypothesis were consistent with the literature (Dziegielewski et al., 2010; Grunau, 2007).

The third hypothesis of the study was about the negative relationships between perceived HRQoL and perceived burnout level of the Turkish TSRs. According to the SEM findings, perceived HRQoL of TSRs is negatively related with the burnout of the TSRs $(\beta=-.868, \mathrm{p}<.01)$ as it was hypothesized by the study. The results were consistent with the literature provided by this study (Wan, 1982; Montgomery et al., 2005, Aneshensel, 1992).

The last hypothesis of the study was about the indirect relationship of perceived jobrelated stress and perceived HRQoL of TSRs mediated by perceived burnout of TSRs. The findings indicated that both the relationship between job-related stress and burnout $(\beta=744, \mathrm{p}<$ $.01)$, and the relationship between burnout and HRQoL of TSRs $(\beta=-868, \mathrm{p}<.01)$ were statistically significant. As computed before, the indirect effect of job-related stress on health related quality of life is -.645. Thus the variable had a positive effect on burnout and negative effect on the health related quality of life of TSRs. As a consequence, burnout mediated the relationship between job-related stress and HRQoL of the TSRs as it was hypothesized by the study, which was also consistent with the literature (Change et al. 2006). Table 15 displays the hypothesis testing results. 
Table 15. Hypothesis Testing Results

\begin{tabular}{lll}
\hline & Hypotheses & Results \\
\hline H1 & $\begin{array}{l}\text { Perceived job-related stress is positively related to perceived burnout } \\
\text { of Turkish territorial state representatives. }\end{array}$ & Supported \\
H2 & $\begin{array}{l}\text { Perceived mobbing is positively related to perceived burnout of } \\
\text { Turkish territorial state representatives. }\end{array}$ & Supported \\
H3 & $\begin{array}{l}\text { HRQoL is negatively related to perceived burnout of Turkish } \\
\text { territorial state representatives. }\end{array}$ & Supported \\
H4 & $\begin{array}{l}\text { Perceived burnout mediates the effects of perceived job-related stress } \\
\text { on HRQoL of Turkish territorial state representatives. }\end{array}$ & Supported \\
\hline
\end{tabular}

As shown by the generic model of the covariance structure model, none of the control variables had significant relationships with the HRQoL of TSRs. The control variables of tenure, education level, status, and gender had standardized regression weights of -..066, -.081, -.025, and -.028 respectively. Thus all control variables were removed from the generic model in order to improve the model.

\section{$\underline{\text { Study Implications }}$}

The study examined whether and to what extend stress and mobbing are related to burnout; and whether and to what extend burnout affects HRQoL of Turkish state representatives. In the light of findings discussed above, the study implications will be discussed in terms of theoretical and methodological perspectives.

\section{$\underline{\text { Theoretical Implications }}$}

In this study, theory of the Administrator Stress Cycle Model, the Job DemandsResources Model, Developmental Theory of Interpersonal Aggression, and Social Stress Theory were used as the main theoretical frameworks to explain and examine the relationships between study variables. 
As social stress theory explained, there is a relationship between stress and physiological and physical health. The theory assumes that stress adversely impacts physical wellbeing and reduces the psychological wellbeing. Besides, burnout is accepted as one of the stress making factors reflecting social stress. The HRQoL is the endpoint to reflect individual opinions of general health. Stress has a negative effect on health related to psychological and physical wellbeing, however these results captured only part of the cause related to stress (Aneshensel, 1992). When distinctive health results were observed, several individuals who were negatively affected by stress were counted as unharmed, because they exposed stress responses as other outcomes (Aneshensel, 1991).

Moreover, as discussed earlier, the Developmental Theory of Interpersonal Aggression (DTIA), developed by Bjorkqvist, improved the outline of Buss' categorizations (Baron \& Neuman, 1996) and applied it in a new way. Bjrökqvist et al. created the Workplace Harassment Scale (WHS), which was used for this study. Blasé and Blasé (2003) found that the prevalence of workplace harassment was not only mobbing present, but also burnout. Grunau (2007), on the other hand, claimed that mobbing's enduring behaviors lead to damage to employees and found a statistically significant relationship between burnout and mobbing, which is consistent with the results of this study.

The Job Demands-Resources Model (JD-R) assumed that there is a relationship between job-related stress and burnout (Bakker \& Demerouti, 2007; Demerouti et al., 2001). According to this theory, all jobs have their specific job characteristics regarding burnout, such as job resources, decline in job responsibilities required by employees, and stimulation of employees' performance improvement (Halbesleben \& Buckley 2004; Bakker \& Demerouti, 2007). 
According to Wiese et al (2003), there was a direct relationship between job-related stress and burnout, which was consistent with the results of the study.

The Administrator Stress Cycle Model proposed some stages for the job-related stress and assumed that administrators take notice of the results and the long-term effects of stress in the last stage. Therefore, burnout happens as a result of stress (Gmelch \& Gates, 1998), which was consistent with the findings of this study. As Gill, Flaschner, and Shachar (2006) discussed, job stress is a mental and physical problem having direct and negative impact on productivity and quality of work and specifically stress is an employee's reaction to unwanted work conditions arising as threatening to that employee's health. Freudenberger (1974) and Wiese et al. (2003), moreover, found a relationship between burnout and job stress.

In sum, the findings of the study indicated that results and propositions of the theoretical frameworks of the study and literature are consistent with each other. The study results showed and confirmed that perceived job-related stress and mobbing have positive effects on perceived burnout. Perceived HRQoL of TSRs is negatively associated with perceived burnout, as it was discussed the theoretical framework and literature examined by this the study.

\section{$\underline{\text { Methodological Implications }}$}

The first methodological strength of the study was the use of the SEM, since the model is ideal when testing theories including latent variables, such as burnout, job-related stress, HRQoL, and mobbing latent constructs of this study. The SEM provided for the evaluation of the relationships specified in the hypotheses (Hox \& Bechger, 1998; Hoyle, 1995). The path coefficients were particularly examined with attention to the strength, direction, and significance of the relationships. Consequently, SEM gave an opportunity to validate the theoretically driven 
model (Wan, 2002). Moreover, having latent constructs and first-order and second-order factors was also the other methodological strength of the study. Especially the utilization of the scales of (SF)-12v2 ${ }^{\mathrm{TM}}$ 4-week recall (Ware et al., 1998) and CBI Scale (Kristensen et al., 2005) were used to examine the unobservable variables of HRQoL and burnout by using some first-order and second-order factors.

Operational definitions and measurement instruments of the study variables were the second methodological implication of the study. The study examined the relationships between latent exogenous variables of mobbing and job-related stress and latent endogenous variables of burnout and HRQoL. Since personal characteristics may affect the variation in perceptions, control variables such as status, gender, and tenure were examined in the analysis, as well. Four copyright and literature driven scales were used to construct the survey questionnaire. They are as follows: SF-12v2 TM 4-week recall (Ware et al, 1998), Copenhagen Burnout Inventory Scale (Kristensen et al., 2005), Work Harassment Scale (Bjrökqvist and Osterman, 1992), and Job Stress Scale (Parker and DeCotiis, 1983).

Before initiating the SEM analyses, the SF-12v2 ${ }^{\text {TM }}$ 4-week recall dataset was analyzed using Health QualityMetric Health Outcomes ${ }^{\text {TM }}$ Scoring Software 4.0. Since the results of this scoring software changed the number of items, the software was not used to analyze the dataset. Directions of the Likert scales were converted to make sure all scales were set in the same directions. Recoding the SPSS feature into different variables allowed for the recode and conversion of the variables. It provided the mechanism to transform the original variables into new variables, which meant that the changes in the variables were not applied to the original ones, but instead were applied to a duplicate of the original variable under a new variable name. 
The measurement reliability and CFA results depicted that all scales had very high levels of measurement reliability and validity as it was proved by previous researches for the scale of HRQoL ((Bjorner \& Ware, 1998; Ware, Bjorner, \& Kosinski, 2000; Ware et al., 2003; Maruish \& DeRosa, 2009; Keller et al., 1998; Anagnostopoloulos et al. 2010), for the scale of burnout (Kristensen et al. 2005), for the scale of mobbing (Bjrökqvist et al. 1992a), and for the scale of job-related stress (Parker and DeCotiis, 1983, Touringy et al. 2005; Xie and Johns, 1995; Jamal, 2000). Thus it was accurate to state that mobbing, job-related stress, burnout, and HRQoL scales were reliable and acceptable latent constructs and they could be safely used to measure similar relationships in other studies and measures may create consistent results overtime. Moreover, all measurement models and covariance structure model were validated via confirmatory factor analysis.

The only concern might be the multicollinearity issue. As discussed in the findings section, all indicators were significantly correlated with each other at the significant level of .01. However, correlation matrices of the tables detected that there are three multicollinearity issues occurring amongst variables. In this case, the scales having highly correlated variables should be revised and indicators numbers can be reduced for the future research, since the highly correlated indicators mainly measure the same thing.

Three scales were translated into Turkish version since the target group's native language is Turkish. Since HRQoL provided both English and Turkish versions of the scale, there was no need to acquire an approval of the Turkish version of the scale. The Copenhagen Burnout, JobRelated Stress, and Work Harassment questionnaire were revised and converted to shorter 
versions of the scales. The translated versions were controlled by $\mathrm{PhD}$ Turkish native speakers who are also Turkish TSRs.

Online survey instrument was the other methodological implication of the study. Dillman's Internet-based survey design (Web survey) was used to deliver the questionnaire. The electronic questionnaire was created to handle international limitations and important obstacles to the survey. Besides, e-survey, the electronic data collection system minimized the survey cost and saved time with compared to a traditional survey (Dillman, 2007). Surveey.com website was used to deliver the questionnaire. It eased and enabled collecting the data and creating and downloading the data in SPSS, xls, or html format. It also enabled to download detailed and cross reports supported with graph and charts. One of the main drawbacks of using online tool was that the online questionnaire was able to send to the participants more than one time with no cost that contributed to an increase in the response rate to the survey.

IT opportunities were also important methodological implication of the study because it eased the process. Those TSRs who were the participants of this study were reached via the online e-government system of the Turkish Ministry of Interior. All TSRs were members of this electronic system. All official and work-related correspondences were conducted via this esystem. Since the researcher had authority to conduct the study and gain access to the Turkish Ministry of Interior e-government network system, the survey link was sent via TSRs' official email address by using e-government system of TMoI.

Two letters of support were obtained from two organizations in order to encourage TSRs to fill out the questionnaire. The first support letter was obtained from the Turkish Association of Turkish Administrators (Appendix A-B). The Association of Turkish Administrators is the 
biggest and the only association in Turkey offering the membership for the Turkish territorial state representatives. All TSRs are the members of this association. Thus, the letter of support eased the process and encouraged TSRs to take part in the study survey. The letter committed to support the research. The Association published the survey link, which was created by this study, on the association website and the survey link was sent to all TSRs who are currently members of the association. Moreover, the association sent an official SMS text with a survey link to all TSRs who are currently in the Association's SMS delivery system. The second letters of support was provided by the Turkish Ministry of Interior (Appendix C-D). The letter committed to support the research and encourage the TSRs to participate the survey.

Furthermore, the survey link was shared via some Twitter accounts, for instance the chief editor of the Voice of Turkish Administrator and the former head of Department for Administrative Development Affairs via their official twitter account. Since majority of their followers were the Turkish state representatives, it contributed to the increased response rate of the study.

Lastly, the mail merge application of Microsoft was used to increase the respondents' rate. Mail merge is a software based on the inter communication of Microsoft word, excel, and outlook. It describes the creation of multiple large numbers of documents from a single format and a systematized data source. It is a powerful instrument to send a personalized e-mail to a large number of recipients at the same time. It enables to create a label with each receiver's personalized information, such as first name, last name, occupational position, or physical address. A short personalized single email containing the survey link was sent out to all participants using their first name with a proper salutation. It saved on costs and time. 


\section{$\underline{\text { Study Limitations and Directions for Future Studies }}$}

As one would know, the CSM is a confirmatory perspective and it is a theory driven matter. CSM is one of the influential ways to represent the association between variables yet it doesn't show the causality between them. However, further research on theories may get different results with other models. The sample, besides, might not be generalizable to all organizations because of the fact that organizational features might differ.

Covering more social-economic factors in the model might be the other limitations of this study. For instance, in economics, a latent variable model is strictly developed with a good measurement error in structural equation model, too. Thus, most scholars in economics area might not accept the idea of multiple indicators for latent variables. Moreover, CSM has a limitation if complicated social-economic elements are comprised in one model. Thus, it is difficult to conceptualize in several complicated situations.

The data used in covariance structure models, on the other hand, mostly follows the critical assumptions. Critics claimed that categorical variables commonly used in social science studies don't require any theoretical explanation for the assumption the data has a multivariate normal distribution, so the maximum likelihood method should not be used.

The CSM may also be sensitive to the data and changing model specifications to advance fit can lead to non-generalizable results (MacCallum et. al., 1992). Moreover, there would be some parallel models that might portray the context of the study with similar GOF outcomes, yet in spite of the theoretically different justifications of these models, they are usually ignored (MacCallum et al., 1992). 
The other limitation factor is related to sampling issue, that is, selecting elements process from the population to analyze the sample, academics may catch a chance to generalize their results back to the population from which they were picked (Gliner \&Morgan, 2000). Sample representation is the other issue for this study. As one would know, the participants selected as a sample may not represent all of the comparable population. Therefore, the problem that may be stemming from this issue may arise as a generalizability limitation and it may be difficult to generalize the results to the comparable populations. So, replication would be a method for this limitation and duplicate the research with dissimilar sample and at different period could increase the external validity (Gliner \&Morgan, 2000). Picking sample from only one occupational group is not satisfactory to obtain valid results for research. To obtain more reliable results, researchers may select the participants from more than one organization or institution by selecting randomly when studying more general positions instead of some specific groups such as Turkish state representatives. Hence, the researchers could obtain more representative samples (Calder, Phillips, \& Tybout, 1982). To eliminate these limitations, some replications of the modeling method may require.

The large coefficient between job-related stress and burnout may be due to the inclusion of items that measure both constructs. As findings indicated. some of the measurement overlaps. so that the two constructs are not clearly differentiated and some of the effect might not be due to a relationship between the two constructs. Overlapping of the constructs might be an issue. Some other results can be found when further researchers eliminate the issue. 
Picking variables would be the last limitation of the study. It would probably be to obtain different results than this report offers when future studies select other variables than the variables that were used in this study.

One further problem might be that many researchers who employ the CSM don't totally understand the computer processes nor do they realize that despite parameter values being created, the data used does not fundamentally mean that it is actually properly statistically identified or has a rational justification (Breckler, 1990).

Aneshensel (1992) claimed that the total cost of stress in terms of the social, psychological, and economic effects have not been prudently analyzed. Since only some indications have been considered, the cost of social stress may well include the results relevant to areas of sociological interests in medical sociology, crime and delinquency, educational and professional accomplishment, job creativity, and social mobility.

Schaufeli and Enzmann (1998) stressed that job demands and the lack of job resources were significant organizational stress making factors. Similarly, Leiter and Maslach (2000) highlighted that job demands and lack of resources were also significant sources of organizational stress. Thus, future researchers could work on lack of resources and job demands. Job-related stress may have a negative effect on performances towards organizations (Cropanzano et al. 2003; Lee and Ashforth, 1996). The researcher found that one of the potential outcomes of prolonged stressors at work place was burnout (Martinussen et al., 2007). Thus, examining the effect of stressors and burnout on organizational behaviors and performance would contribute to the field that was not examined by this study. 
Similarly, Leiter (1993) argued that exhaustion is one of the measurements of burnout that was strongly related to job demands. The other dimension of the burnout, cynicism, is strongly connected to job resources (Leiter, 1993). Thus, future researchers may examine the relationship between cynicism, exhaustion and burnout. Furthermore, the relationship between job resources and burnout would be worth the study by using Maslach's burnout scale to examine the difference between USA and European countries.

As Thompson et al. (2005) found that employees who are not supported by their colleagues or family members are more vulnerable to stress. This perspective is worth the study in terms of the effect of coping mechanisms-strategies and social or supervisor supports on job related stress. Supervisors and colleagues' supports are accepted as buffer to the stressors. Cullen et al. (1985) claimed that supervisor support significantly decreased the impacts on stress making factors. Thus, in order to see the relationship between social and supervisor or coworkers' supports and stressors, it is worth the study by future researchers.

\section{$\underline{\text { Study Contributions }}$}

The study makes an important contribution to the literature on mobbing, job-related stress, burnout, and the HRQoL of Turkish state representatives. As discussed earlier, literature regarding the importance of stress and burnout in the Western world is plentiful. However, there are limited studies about the sources and effects of stressful events, such as burnout and work harassment on an individual's health in Turkey. Existing Turkish findings do not focus on TSRs. Although there are many studies about this topic conducted by various professional groups, there is no research specifically examining the relationships between the perceived levels of burnout, mobbing, job-related stress, and HRQoL of TSRs. Therefore, this study made a significant 
contribution to the literature and attempted to identify the factors that contribute to the current job-related stress, mobbing, burnout level, and HRQoL of TSRs.

Moreover, it proposes some significant implications for Turkish Ministry of Interior decision makers to focus on the wellbeing of TSRs and to eliminate or decrease the level of jobrelated stress, mobbing, and burnout of TSRs. Since organizational outcomes of burnout, jobrelated stress, or mobbing would lead to some serious effects of failure or disorganization, the analysis of the above mentioned factors is essential to identify mechanisms to eradicate job stress and burnout and to enhance the quality of services provided by TSRs. From theoretical, methodological, and practical perspectives, the new information and findings provided by this study are very important contribution, and the decision makers should focus on creating some relevant preventive strategies, governance mechanisms for improving the sanctity of organizational management, and improving the quality of the work life of those who are responsible for the Turkish administrative system.

The last important contribution of the study is that this study employed a SEM method, since it is ideal when testing theories having latent variables, such as burnout, job-related stress, HRQoL, and mobbing of this study variables. This study is the only study that employed SEM technique to examine the above-mentioned hypothesized relationships regarding TSRs to date. 
APPENDIX A: LETTER OF SUPPORT BY THE ASSOCIATION OF TURKISH ADMINISTRATORS/ENGLISH 


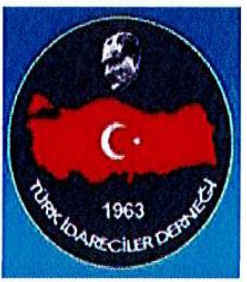

\section{A. Ufuk Hascakal}

Member of the Board

Deputy Head of EU and Foreign Relations Department

Turkish Interior Ministry

E-mail: a.ufuk.hascakal@icisleri.gov.tr

www.tid.web.tr

Ankara/TURKEY

$5 / 10 / 2014$

Mr. Mehmet Yesilbas,

Subject: Mehmet Yesilbas who is the Deputy Head of EU and Foreign Relations of Turkish Interior Ministry is a PhD student at UCF in Governance and Policy Research Track.

We commit that the survey link provided by Mr. Yesilbas will be delivered by the Turkish Administrator Association website and sent all territorial state representatives who are currently members of the association.

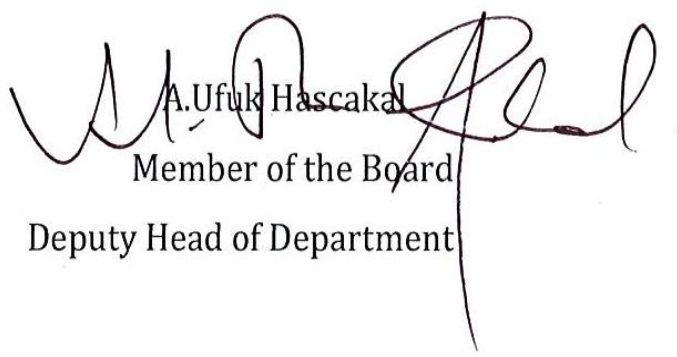


APPENDIX B: LETTER OF SUPPORT BY THE ASSOCIATION OF TURKISH ADMINISTRATORS/TURKISH 


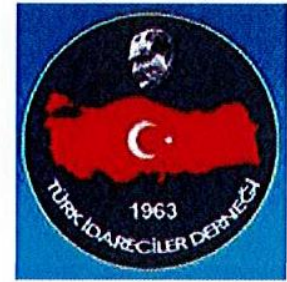

\section{A. Ufuk Hascakal}

Yönetim Kurulu Üyesi

$\mathrm{AB}$ ve Dış İlişkiler Dairesi Başkan Yardımcısı

T.C. İçişleri Bakanlığı

E-posta: a.ufuk.hascakal@icisleri.gov.tr

www.tid.web.tr

Ankara/TÜRKIYE

$5 / 10 / 2014$

Sayın Mehmet Yesilbas,

Konu: Türkiye Cumhuriyeti İçişleri Bakanlığı AB ve Dış İlişkiler Dairesi Başkan Yardımcısı olan Mehmet Yeşilbaş, Yönetişim ve Siyasi Araştırmalar alanında UCF'de Doktora öğrencisidir.

Sayın Yeşilbaş tarafından ibraz edilen anket linkine Türk İdareciler Derneği internet sayfasına konacağını ve hâlihazırda derneğe üye tüm devlet taşra temsilcilerine gönderileceğini taahhüt ederiz.

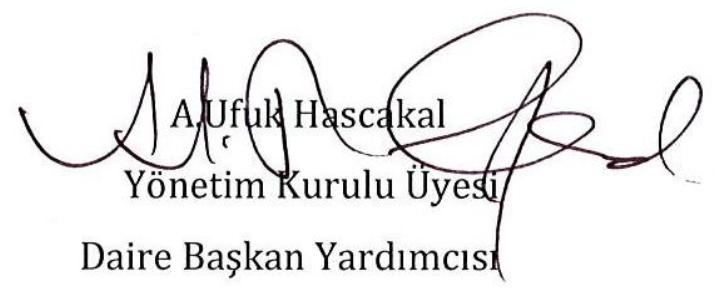


APPENDIX C: LETTER OF SUPPORT BY TURKISH MINISTRY OF INTERIOR /ENGLISH 


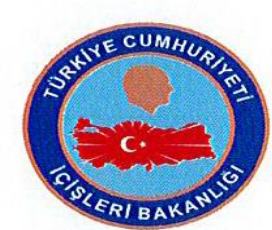

\section{Abdurrahman Korucu}

Head of EU Affairs and Foreign Relations Department Interior Ministry of Turkey

Tel: +90.312.4172741

E-mail: abdurrahman.korucu@icisleri.gov.tr

www.diab.gov.tr

www.icisleri.gov.tr

Ankara/TURKEY

To whom it may concern,

Subject: Mr. Mehmet Yesilbas, Survey.

Mehmet Yesilbas who is the Deputy Head of EU and Foreign Relations of Turkish Interior Ministry is a PhD student at UCF in Governance and Policy Research Track. He is planning to conduct a survey for his dissertation named "The Predictors of Burnout and the Health Related Quality of Life of Turkish Territorial State Representatives (TSRs)' to measure the perception of the TSRs of Turkey regarding the issue.

We appreciate your support.

With my best regards,

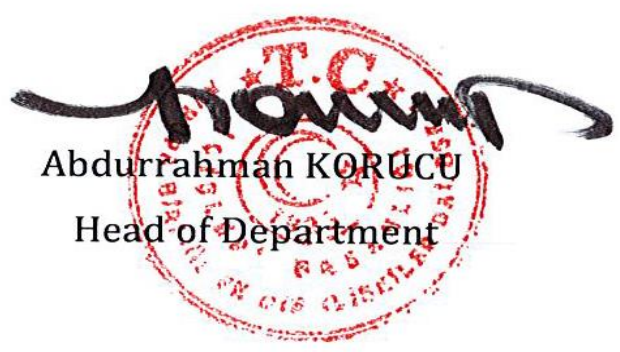


APPENDIX D: LETTER OF SUPPORT BY TURKISH MINISTRY OF INTERIOR /TURKISH 


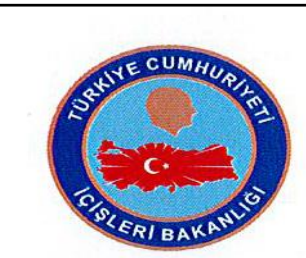

\section{Abdurrahman Korucu}

AB ve Dış İlişkiler Dairesi Başkanı

Tel: +90.312 .4172741$

E-mail: abdurrahman.korucu@icisleri.gov.tr

www.diab.gov.tr

www.icisleri.gov.tr

Ankara/TURKEY

$5 / 2 / 2014$

Konu: Mehmet Yesilbas, Mülki İdare Amirleri Algı Araştırması

Sayın Mülki İdare Amiri,

Amerika Birleşik Devletlerinde University of Central Florida bünyesinde Goveranance and Policy Research dalında doktora eğitimine devam etmekte olan kurumumuz daire başkan yardımcısı Mehmet Yeşilbaş'ın 'Mülki İdare Amirlerinin Meslekte Tükenmişlik Algılarını Belirleyen Hususlar ile Bu Tükenmişlik ve MİA’nın Yaşam Kaliteleri Arasındaki İlişkiler' isimli doktora tezi çalışmasına ilişkin olarak düzenlemiş olduğu alan araştırmasına vereceğiniz katkıdan dolayı teşekkür ederiz.

Rica ederim,

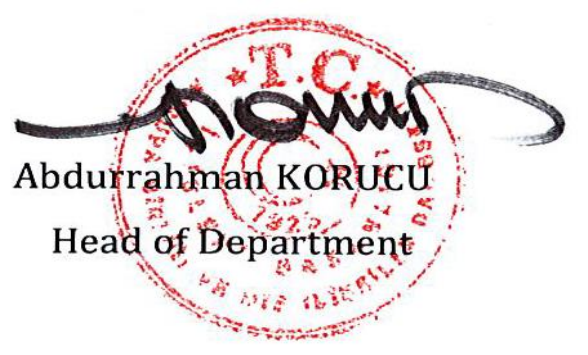


APPENDIX E: LICENSE AGREEMENT OF HRQOL SF-12V2 4-WEEK RECALL SCALE 


\section{Q}

NON-COMMERCIAL LICENSE AGREEMENT Office of Grants and Scholarly Research (OGSR)

License Number:

QM023471

Licensee Name: Mehmet Yesilbas c/o University of Central Florida

Licensee Address: $4000 \mathrm{New}$ Broad Circle \#302, , Oviedo, FL 32765

Approved Purpose: Non-commercial academic research and/or thesis - Unfunded Student.

Study Name: $\quad$ The effect of burnout on HRQoL of Turkish district governors

Study Type:

Thesis/Dissertation

Data Collection Method: 3rd Party Online

Therapeutic Area: Mental Health and Behavior

Royalty Fee: $\quad$ None, because this License is granted in support of the non-commercial Approved Purpose

Other Definitions: As indicated on Appendix B "License Agreement - Details", including without limitation: Licensed Surveys, Modes of Administration, Fees, Administrations, Services, Approved Languages and (if applicable) Study Term

Licensee accepts and agrees to the terms of this Non-Commercial License Agreement (the "Agreement") from the Office of Grants and Scholarly Research (OGSR) of Optumlnsight Life Sciences, Inc. (f/k/a QualityMetric Incorporated) ("Optuminsight") as of the date of last signature below (the "Effective Date").

Subject to the terms of this Agreement, including the Optuminsight Non-Commercial License Terms and Conditions attached as Appendix A: Optuminsight grants to Licensee, and Licensee accepts, a non-exclusive, non-transferable, non-assignable, non-sublicensable worldwide license to use, solely for the Approved Purpose and during the License non-assignable, non-sublicensable worldwide license to use, solely for the Approved Purpos Languages indicated on Appendix B and to administer the Licensed Surveys only up to the approved number of Administrations (and to make up to such number of exact reproductions of the Licensed Surveys necessary to support such Administrations) in any combination of the specific Licensed Surveys and Approved Languages, Data Collection Methods, and Modes of Administration and to use any related software provided by Optuminsight.

Capitalized terms used in this Agreement shall have the meanings assigned to them above, or in Appendices $\mathrm{A}$ and $\mathrm{B}$ attached hereto. Appendices $\mathrm{A}$ and $\mathrm{B}$ attached hereto are incorporated into and made a part of this Agreement for all purposes.

EXECUTED, as of the Effective Date, by the duly authorized representatives as set forth below.

OptumInsight Life Sciences, Inc.

[Optuminsight]

Signature:

$\begin{array}{ll}\text { Name: } & \text { G. Gardner } \\ \text { Title: } & \text { President \& COO } \\ \text { Date: } & \text { /9MAR2014 }\end{array}$

Mehmet Yesilbas c/o University of Central Florida [Licensee]

Signature:

Title: Phi) Studert

Date: $3 / 18 / 2014$ 
APPENDIX F: HRQOL SF-12V2 4-WEEK RECALL SCALE (ENGLISH VERSION) 
Your Health and Well-Being

This survey asks for your views about your health. This information will help keep track of how you feel and how well you are able to do your usual activities. Thank you for completing this survey!

For each of the following questions, please mark an $\bigotimes$ in the one box that best describes your answer.

1. In general, would you say your health is:

\begin{tabular}{ccccc|}
\hline Excellent & Very good & Good & Fair & Poor \\
$\square$ & $\square$ & $\square$ & $\square$ & $\square$ \\
$\square 1$ & $\square 2$ & $\square 3$ & $\square 4$ & $\square 5$
\end{tabular}

2. The following questions are about activities you might do during a typical day. Does your health now limit you in these activities? If so, how much?

\begin{tabular}{ccc|} 
Yes, & Yes, & No, not \\
limited & limited & limited \\
a lot & a little & at all
\end{tabular}

a Moderate activities, such as moving a table, pushing

a vacuum cleaner, bowling, or playing golf.

$\square 1$

$\square 2$

b Climbing several flights of stairs

2

3. During the past 4 weeks, how much of the time have you had any of the following problems with your work or other regular daily activities as a result of your physical health? 


\begin{tabular}{ccccc}
\hline All of & $\begin{array}{c}\text { Most of } \\
\text { the time }\end{array}$ & $\begin{array}{c}\text { Some of } \\
\text { the time }\end{array}$ & $\begin{array}{c}\text { A little of } \\
\text { the time }\end{array}$ & $\begin{array}{c}\text { None of } \\
\text { the time }\end{array}$
\end{tabular}

a Accomplished less than you

would like.

1

2................ $\square 3$

….............. $\square 4$

b Were limited in the kind of

work or other activities..

1

2............... $\square 3$

3 ................ $\square 4$

4. During the past 4 weeks, how much of the time have you had any of the following problems with your work or other regular daily activities as a result of any emotional problems (such as feeling depressed or anxious)?

\begin{tabular}{|ccccc|}
\hline $\begin{array}{c}\text { All of } \\
\text { the time }\end{array}$ & $\begin{array}{c}\text { Most of } \\
\text { the time }\end{array}$ & $\begin{array}{c}\text { Some of } \\
\text { the time }\end{array}$ & $\begin{array}{c}\text { A little of } \\
\text { the time }\end{array}$ & $\begin{array}{c}\text { None of } \\
\text { the time }\end{array}$
\end{tabular}

a Accomplished less than you

would like

1

2.

3 ….............. $\square 4$

b Did work or other activities

less carefully than usual

5. During the past 4 weeks, how much did pain interfere with your normal work

(including both work outside the home and housework)?

$\begin{array}{ccccc}\text { Not at all } & \text { A little bit } & \text { Moderately } & \text { Quite a bit } & \text { Extremely } \\ \square & \square & \square & \square & \square \\ \square 1 & \square 2 & \square 3 & \square 4 & \square 5\end{array}$


6. These questions are about how you feel and how things have been with you during the past 4 weeks. For each question, please give the one answer that comes closest to the way you have been feeling. How much of the time during the past 4 weeks...

\begin{tabular}{|ccccc|}
\hline $\begin{array}{c}\text { All of } \\
\text { the time }\end{array}$ & $\begin{array}{c}\text { Most of } \\
\text { the time }\end{array}$ & $\begin{array}{c}\text { Some of } \\
\text { the time }\end{array}$ & $\begin{array}{c}\text { A little of } \\
\text { the time }\end{array}$ & $\begin{array}{c}\text { None of } \\
\text { the time }\end{array}$ \\
\hline
\end{tabular}

a Have you felt calm and

peaceful?

$\square 1$

.............. $\square 2$ 2............. $\square 3$

….......... $\square 4$,............ $\square$

5

b Did you have a lot of energy? ....... $\square$

$1 \ldots \ldots \ldots \ldots . . \square 2 \ldots \ldots \ldots \ldots . \square$

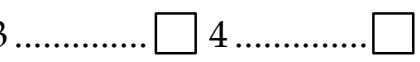

5

c Have you felt downhearted

and depressed?

5

7. During the past 4 weeks, how much of the time has your physical health or emotional problems interfered with your social activities (like visiting with friends, relatives, etc.)?

\begin{tabular}{ccccc|}
$\begin{array}{c}\text { All of } \\
\text { the time }\end{array}$ & $\begin{array}{c}\text { Most of } \\
\text { the time }\end{array}$ & $\begin{array}{c}\text { Some of } \\
\text { the time }\end{array}$ & $\begin{array}{c}\text { A little of } \\
\text { the time }\end{array}$ & $\begin{array}{c}\text { None of } \\
\text { the time }\end{array}$ \\
$\square$ & $\square$ & $\square 3$ & $\square 4$ & $\square 5$
\end{tabular}

Thank you for completing these questions! 
APPENDIX G: HRQOL SF-12V2 4-WEEK RECALL SCALE (TURKISH VERSION) 


\section{Sağlı̆̆ınız ve İyilik Haliniz}

Bu soru formu size sağlığınızla ilgili görüşlerinizi sormaktadır. Bu bilgiler sizin nasıl hissettiğinizi ve her zamanki faaliyetlerinizi ne rahatlıkla yapabildiğinizi izlemekte yardımcı olacaktır. Bu formu doldurduğunuz için teşekkürler!

Aşağıdaki her soru için lütfen en uygun cevabın karşısındaki kutuyu $\bigotimes$ ile işaretleyin.

1. Genel olarak sağlı̆̆ınızı nasıl değerlendirirsiniz?

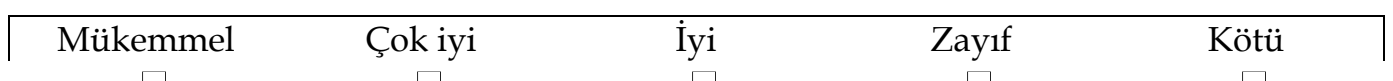

$\square 1 \quad \square 2 \quad \square 3 \quad \square 4 \quad \square 5$

2. Aşağıdakiler normal olarak gün içerisinde yapıyor olabileceğiniz bazı

faaliyetlerdir. Su sıralarda sağlığınız sizi bu faaliyetler bakımından kısıtlıyor $\underline{\text { mu}}$ ? Kisitliyorsa ne kadar?

\begin{tabular}{|ccc|}
\hline Evet, & Evet, & Hayır, \\
oldukça & biraz & hiç \\
kısıtllyor & kisıtllyor & kısıtla
\end{tabular}


a Orta zorlukta faaliyetler, örneğin masa

kaldırmak, süpürmek, ya da bisiklete

binme, yüzme gibi hafif spor yapmak

.............................. $\square 1$

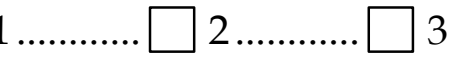

b Birkaç kat merdiven çıkmak

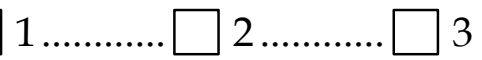

3 Geçtiğimiz 4 hafta boyunca, işinizde veya diğer günlük faaliyetlerinizde, bedensel sağlığınız nedeniyle aşağıdaki sorunların herhangi biriyle ne sıklıkla karşılaştınız?

a Yapmak istediğinizden daha azını yapabilmek

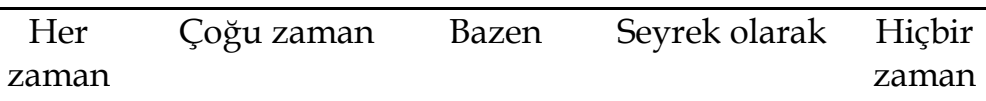

Yapabildiğiniz iş türünde ya da diğer faaliyetlerde kisitlanmak

1 2 $\square 3$ 4 
4. Geçtiğimiz 4 hafta boyunca işinizde veya diğer günlük faaliyetlerinizde duygusal problemler nedeniyle aşağıdaki sorunların herhangi biriyle ne sıklıkta
a Yapmak istediğinizden daha azını yapabilmek 5
b İş ya da diğer uğraşları her zamanki gibi dikkatlice yapamamak 5

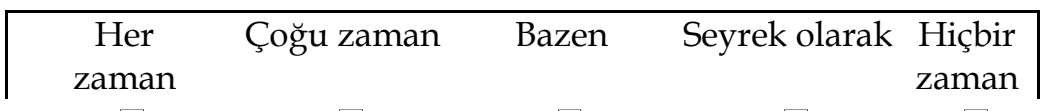 karşılaştınız (bunalım veya fazla heyecan hissetmek gibi)?

5. Geçtiğimiz 4 hafta boyunca, ağrı normal işinize (ev dışında ve ev işinde) ne kadar engel oldu?

\begin{tabular}{|ccccc|}
\hline Hiç olmadı & Biraz & Orta derecede & Epey & Çok fazla \\
$\square$ & $\square$ & $\square$ & $\square$ & $\square$ \\
$\square 1$ & $\square 2$ & $\square 3$ & $\square 4$ & $\square 5$
\end{tabular}

6. Aşağıdaki sorular geçtiğimiz 4 hafta boyunca kendinizi nasıl hissettiğinizle ve işlerin sizin için nasıl gittiğiyle ilgilidir. Lütfen, her soru için nasıl hissettiğinize en yakın olan cevabı verin. Geçtiğimiz 4 hafta içinde ne sıklıkla... 


\begin{tabular}{|ccccc|}
\hline $\begin{array}{c}\text { Her } \\
\text { zaman }\end{array}$ & $\begin{array}{c}\text { Çoğu } \\
\text { zaman }\end{array}$ & Bazen & $\begin{array}{c}\text { Seyrek } \\
\text { olarak }\end{array}$ & $\begin{array}{c}\text { Hiçbir } \\
\text { zaman }\end{array}$ \\
\hline
\end{tabular}
a Sakin ve huzurlu hissettiniz?
1.
$\square 2$
$\square 3$
$\square 4$
5
b Çok enerjiniz oldu?.
1
……........ $\square 2$
2 …........... $\square 3$
3
5
c Çökkün ve kederli oldunuz? .................. $\square 1$
1 ................ $\square 2$
2 ................. $\square 3$
3 ................ $\square 4$ 5

7. Geçtiğimiz 4 hafta boyunca, bedensel sağlığınız ya da duygusal problemleriniz, ne sıklıkla sosyal faaliyetlerinize (arkadaş, akraba ziyareti gibi) engel oldu?

\begin{tabular}{|ccccc|}
\hline $\begin{array}{c}\text { Her } \\
\text { zaman }\end{array}$ & $\begin{array}{c}\text { Çoğu } \\
\text { zaman }\end{array}$ & Bazen & $\begin{array}{c}\text { Seyrek } \\
\text { olarak }\end{array}$ & $\begin{array}{c}\text { Hiçbir } \\
\text { zaman }\end{array}$ \\
$\square$ & $\square$ & $\square$ & $\square$ & $\square$ \\
$\square 1$ & $\square 2$ & $\square 3$ & $\square 4$ & $\square 5$
\end{tabular}


APPENDIX H: COPENHAGEN BURNOUT INVENTORY SCALE PERMISSION 


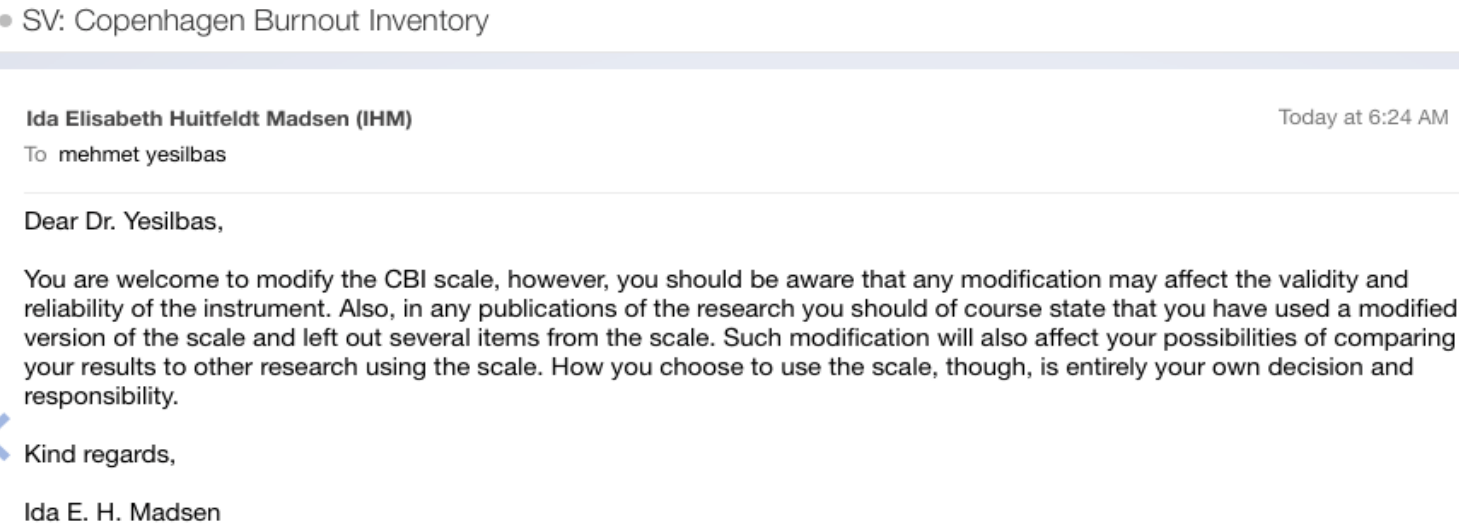

You are welcome to modify the $\mathrm{CBI}$ scale, however, you should be aware that any modification may affect the validity and reliability of the instrument. Also, in any publications of the research you should of course state that you have used a modified version of the scale and left out several items from the scale. Such modification will also affect your possibilities of comparing your results to other research using the scale. How you choose to use the scale, though, is entirely your own decision and responsibility.

Kind regards,

Ida E. H. Madsen

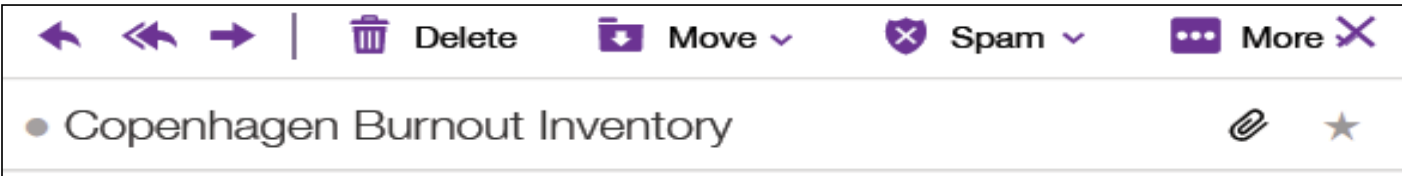

Ida Elisabeth Huitfeldt Madsen (IHM)

To yesilbas2001@yahoo.com

Dear Dr. Yesilbas,

I have received your query regarding the use of the Copenhagen Burnout Inventory (CBI) and am happy to inform you that the instrument is freely available for use in your research. I attach here a methods paper concerning the CBI which might be of interest to you, and wish you the best of luck with your project.

Kind regards,

Ida E. H. Madsen

Ida Elisabeth Huitfeldt Madsen

Forsker, Cand.scient.san.publ., ph.d.

TIf: 39165294

e-mail: ihm@arbejdsmiljoforskning.dk

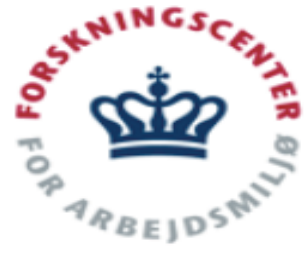

Det Nationale Forskningscenter for Arbejdsmiljø

Lersø Parkallé 105

2100 København $\varnothing$

TIf: 39165200

Fax: 39165201

www.arbejdsmiljoforskning.dk 
APPENDIX I: COPENHAGEN BURNOUT INVENTORY SCALE (ENGLISH

VERSION) 


\section{Part one: Personal burnout}

Definition: Personal burnout is a state of prolonged physical and psychological exhaustion.

\section{Questions:}

1. How often do you feel tired?

2. How often are you physically exhausted?

3. How often are you emotionally exhausted?

4. How often do you think: "I can't take it anymore"?

\section{Part two: Work-related burnout}

Definition: Work-related burnout is a state of prolonged physical and psychological exhaustion, which is perceived as related to the person's work.

Questions:

1. Is your work emotionally exhausting?

2. Do you feel burnt out because of your work?

3. Do you feel worn out at the end of the working day?

4. Are you exhausted in the morning at the thought of another day at work?

5. Do you feel that every working hour is tiring for you?

6. Do you have enough energy for family and friends during leisure time?

\section{Part three: Client-related burnout}

Definition: Client-related burnout is a state of prolonged physical and psychological exhaustion, which is perceived as related to the person's work with 
clients*.

*Clients, patients, social service recipients, elderly citizens, or inmates.

Questions:

1. Does it drain your energy to work with clients?

2. Are you tired of working with clients?

3. Do you sometimes wonder how long you will be able to continue working with clients? 
APPENDIX J: COPENHAGEN BURNOUT INVENTORY SCALE (TURKISH VERSION) 
Böliüm 1 Kişisel Tükenmişlik

(1 Her zaman, 2 Çoğu zaman, 3 Bazen, 4 Seyrek olarak,5 Hiçbir zaman)

1. Ne kadar sıkl1kta yorgun olduğunuzu hissediyorsunuz

2. Ne kadar siklıkta fiziksel olarak bitkin olduğunuzu hissediyorsunuz.

3. Ne kadar sıklıkta duygusal olarak bitkin olduğunuzu hissediyorsunuz?

4. Ne kadar sıklıkta 'artık dayanamıyorum' diye düşünüyorsunuz?

Bölüm 2 İş odaklı tükenmişlik

(Illk iki soru: : 1 Çok yoğun olarak, 2 yoğun olarak,3 biraz, 4 düşük seviyede, 5 çok düşük seviyede)

(Son 4 soru: 1 Her zaman, 2 Çoğu zaman, 3 Bazen, 4 Seyrek olarak,5 Hiçbir zaman)

1. İşiniz duygusal olarak yıpratıcı mıdır?

2. İşinizden dolayı kendinizi bitkin hissediyor musunuz?

3. İş gününün sonunda kendinizi bitkin hissediyor musunuz?

4. Diğer işgününü düşünmenizden dolayı sabahları bitkin hissediyor musunuz:

5. Günlük mesainiziniz her saatinin yorucu olduğunu hissediyor musunuz?

6. Dinlenme zamanlarınızda aile ve arkadaşlarınız için yeterli enerjiniz olduğunu düşünüyor musunuz?

Bölüm 3 Vatandaş odaklı tükenmişlik

(1. soru: 1 Çok yoğun olarak, 2 yoğun olarak,3 biraz, 4 düşük seviyede,5 çok düşük seviyede) (Son iki soru: 1 Her zaman, 2 Çoğu zaman, 3 Bazen, 4 Seyrek olarak,5 Hiçbir zaman)

1. Vatandaşlarla uğraşmak enerjinizi tüketiyor mu? 
2. Vatandaşlarla uğraşmak sizi yoruyor mu?

3. Zaman zaman vatandaşlarla uğraşmaya daha ne kadar tahammül edebileceğinizi düşündüğünüz oluyor mu? 


\section{APPENDIX K: JOB STRESS SCALE ENGLISH VERSION}


1 I have felt fidgety or nervous as a result of my job.

2 Working here makes it hard to spend enough time with my family.

3 My job gets to me more than I should.

4 I spend so much time at work; I cannot see the forest for the trees.

$5 \quad$ Working here leaves little time for other activities.

6 I frequently get the feeling I am married to the company.

7 I have too much work and too little time to do it in.

$8 \quad$ I feel guilty when I take time off from job.

9 I sometimes dread the telephone ringing at home because the call might be job-related.

10 I feel like I never have a day off.

11 Too many people at my level in the company get burned out by job demands.

\begin{tabular}{|c|c|c|c|c|}
\hline Strongly Disagree & Disagree & Neutral & Agree & Strongly Agree \\
1 & 2 & 3 & 4 & 5 \\
\hline
\end{tabular}


APPENDIX L: JOB STRESS SCALE TURKISH VERSION 
(1 Kesinlikle katılıyorum, 2 katılmıyorum, 3 kararsizım, 4 katılıyorum, kesinlikle 5 katılıyorum)

1. İşimden dolayı kendimi huzursuz ve gergin hissediyorum

2. İşimden dolayı aileme yeterli zaman ayıramıorum.

3. Mesleğim, beni olması gerekenden fazla meşgul ediyor.

4. Detaylar islerle çok zaman harcadığımdan esas fotoğrafı göremiyorum.

5. İşimden dolayı diğer aktivitelere vakit ayıramıyorum.

6. Sıklıkla işimle evli olduğum düşüncesine kapılmaktayım.

7. Aşırı iş yüküme rağmen onları yapabilmek için çok az zamanım var.

8. İzne ayrıldığım zaman kendimi suçlu hissediyorum.

9. Zaman zaman mesai dışında telefonum çaldığında isle ilgili olabileceğinden dolayı endişe duyuyorum.

10. Hiç izne ayrılmayacakmışım gibi hissediyorum.

11. Pek çok mülki idare amiri iş yükü nedeniyle kendilerini bitkin hissetmektedirler. 
APPENDIX M: WORK HARASSMENT SCALE PERMISSION 


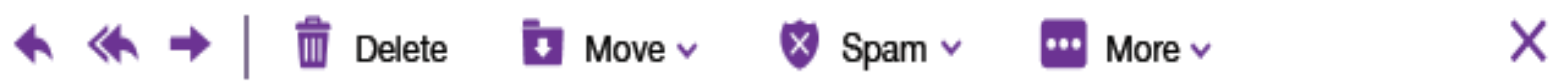

- Re: Scale permission

kbjorkqv@abo.fl

Feb 26

To mehmet yesilbas

Dear Mehmet,

By all means, please feel free to use it, free of charge. I firmly

believe in the freedom of science. I wish you the best of luck with your research!/Kaj

Kaj Björkqvist, Prof.

Developmental Psychology \& PEACE Programme, Åbo Akademi Univ.

President-Elect, International Society for Reseach on Aggression

P.O.B. 311, FIN-65101 Vasa, Finland

Phones: +358-6-3247469, +358-45-8460100

Web page: www.users.abo.fi/kbjorkqv/ 
APPENDIX N: WORK HARASSMENT SCALE ENGLISH VERSION 
(Answer by choosing the number that comes closest to your own experience. 0 never, 1 rarely, 2 occasionally, 3 often, 4 very often)

Have you been exposed to:

1. Unduly reduced opportunities to express yourself?

2. Being unduly disrupted?

3. Being shouted at loudly?

4. Being unduly criticized?

5. Being isolated?

6. Direct threats?

7. Insinuative glances and/ or negative gestures?

8. Accusations?

9. Being sneered at?

10. Refusal to speak with you?

11. Belittling of your opinions?

12. Being treated as non-existent?

13. Words aimed at hurting you?

14. Being given meaningless tasks?

15. Having malicious rumors spread behind your back?

16. Being ridiculed in front of others?

17. Having your work judged in an incorrect and insulting manner?

18. Having your sense of judgment questioned? 
APPENDIX O: WORK HARASSMENT SCALE TURKISH VERSION 
Not: Amir, taşrada valileri, merkezde sıralı üst amirleri ifade etmektedir.

Aşağıdaki durumlara hiç maruz kaldınız mı?

(1 Hiçbir zaman, 2 Seyrek olarak, 3 Bazen, 4Çoğu zaman, 5 Her zaman)

1. Amirlerim tarafından kendimi ifade etme şansım haksız olarak kısıtlanmaktadır

2. Amirlerim tarafından haksız bir şekilde engellenmekteyim

3. Amirlerim tarafından yüksek sesle bağırılmaktayım

4. Amirlerim tarafından haksız şekilde eleştirilmekteyim

5. Amirlerim tarafından dışlanmakta ve izole edilmekteyim.

6. Amirlerim tarafından doğrudan tehdit edilmekteyim

7. Amirlerim tarafından imalı bakışlar ve olumsuz hareketlere maruz kalmaktayım

8. Amirlerim tarafından zaman zaman gereksiz yere suçlanmaktayım

9. Amirlerim kibirli tavır takınmakta ve beni küçük görmektedir

10. Amirlerim benimle konuşmayı reddetmektedir

11. Amirlerim, fikirlerimi önemsememektedir.

12. Amirlerim ben adeta yokmuşum gibi davranmaktadırlar

13. Amirlerim sözleriyle beni incitmeyi amaçlamaktadır

14. Amirlerim bana anlamsız görevler vermektedir

15. Amirlerim arkamdan kötü niyetli ve kasitlı dedikodular yaymaktadır

16. Başkalarının önünde benimle alay edebilmektedir

17. Amirlerim işlerimi uygunsuz ve aşağılayıcı bir üslupla değerlendirmektedir.

18. Karar verme ve değerlendirme anlayışım amirlerim tarafından sorgulanmaktadır. 
APPENDIX P: IRB APPROVAL FORM 
University of Central Flonida Institutional Review Board Office of Research \& Commercialization

12201 Research Parkway, Suite 501

Orlando, Florida 32826-3246

Telephone: 407-823-2901 or 407-882-2276

www research.ucf.edu/compliance/irb hml

\section{Approval of Exempt Human Research}

From: $\quad$ UCF Institutional Review Board \#1

FWA00000351, IRB00001138

To: Mehmet Yesilbas

Date: June 23, 2014

Dear Researcher:

On 6/23/2014, the IRB approved the following activity as human participant research that is exempt from regulation:

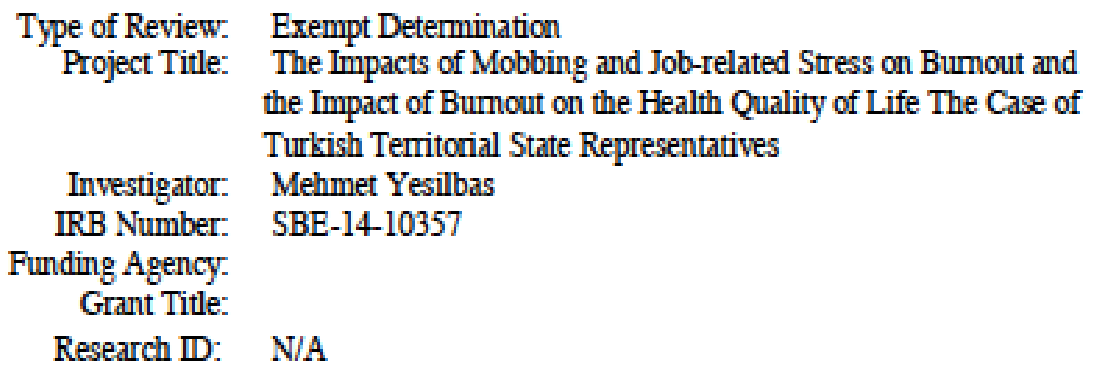

This determination applies only to the activities described in the IRB submission and does not apply should any changes be made. If changes are made and there are questions about whether these changes affect the exempt status of the human research, please contact the IRB. When vou have completed vour research. please submit a Study Closure request in iRIS so that IRB records will be accurate.

In the conduct of this research, you are responsible to follow the requirements of the Investigator Manual.

On behalf of Sophia Dziegielewski, Ph.D., L.C.S.W., UCF IRB Chair, this letter is signed by:

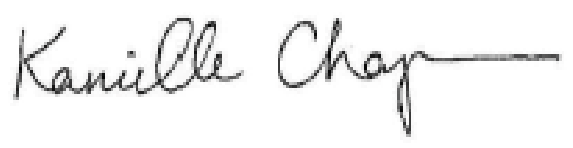

IRB Coordinator 
APPENDIX Q: CONSENT FORM FOR TRANSLATIONS 


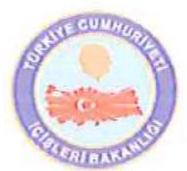

Cihan Demirhan, PhD

District Governor

Civil Chief Inspector

Turkish Interior Ministry

Tel: +90 (505) 4664019

E-mail: cihandemirhan@gmail.com

Ankara/TURKEY

RE: Mehmet Yesilbas

\section{To Whom It May Concern:}

I've had examined the consent form, which was sent me by Mr. Yesilbas to review. I reviewed both Turkish and English versions of the scales listed below. I predicate and verify that both translations show consistency with each other and correct.

Scales:

- HRQoL SF-12v2 ${ }^{\text {TM }} 4$-week recall

- Copenhagen Burnout Inventory Scale

- Job Stress Scale

- Work Harassment Scale

Yours respectfully,

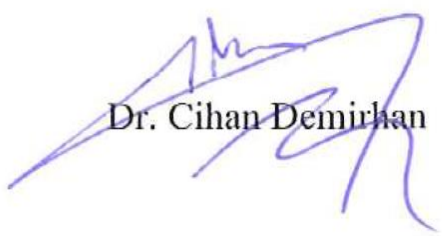


APPENDIX R: DESCRIPTIVE FINDING 
Table 16. Missing Values

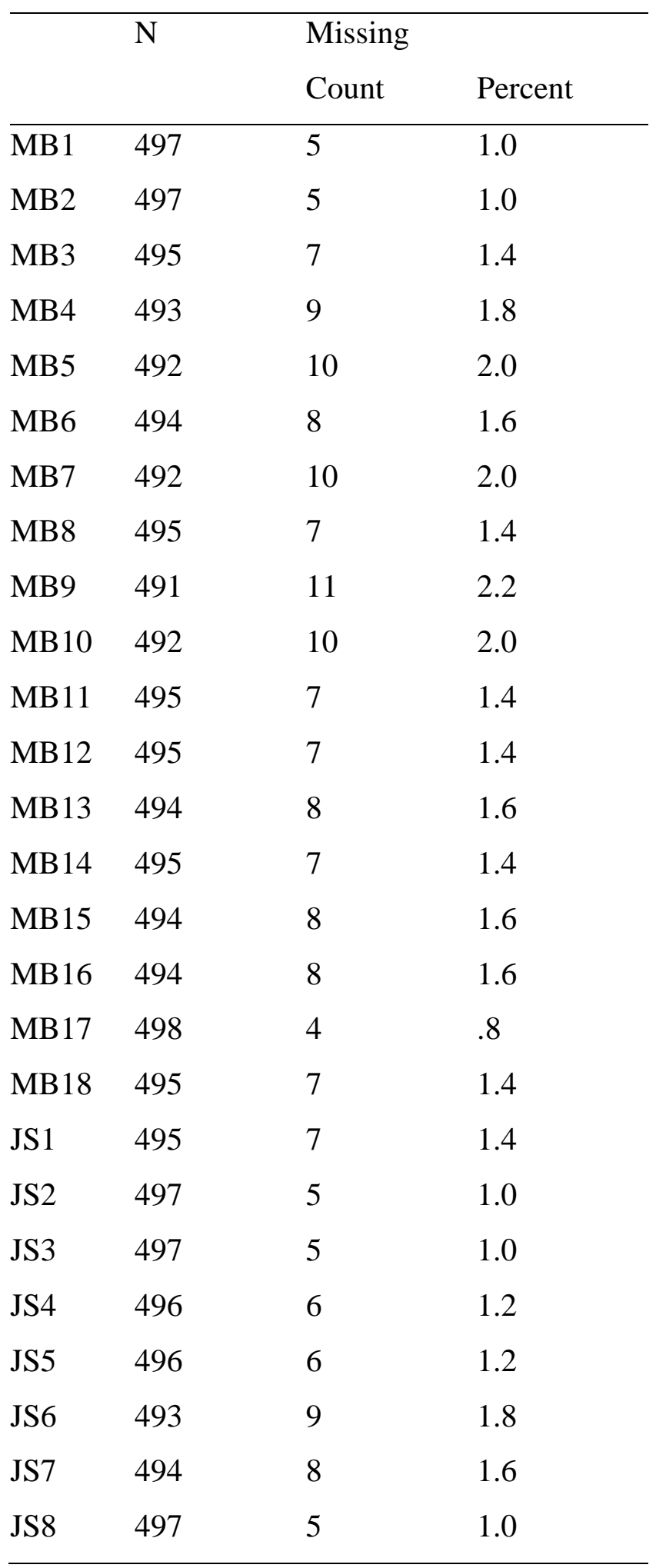




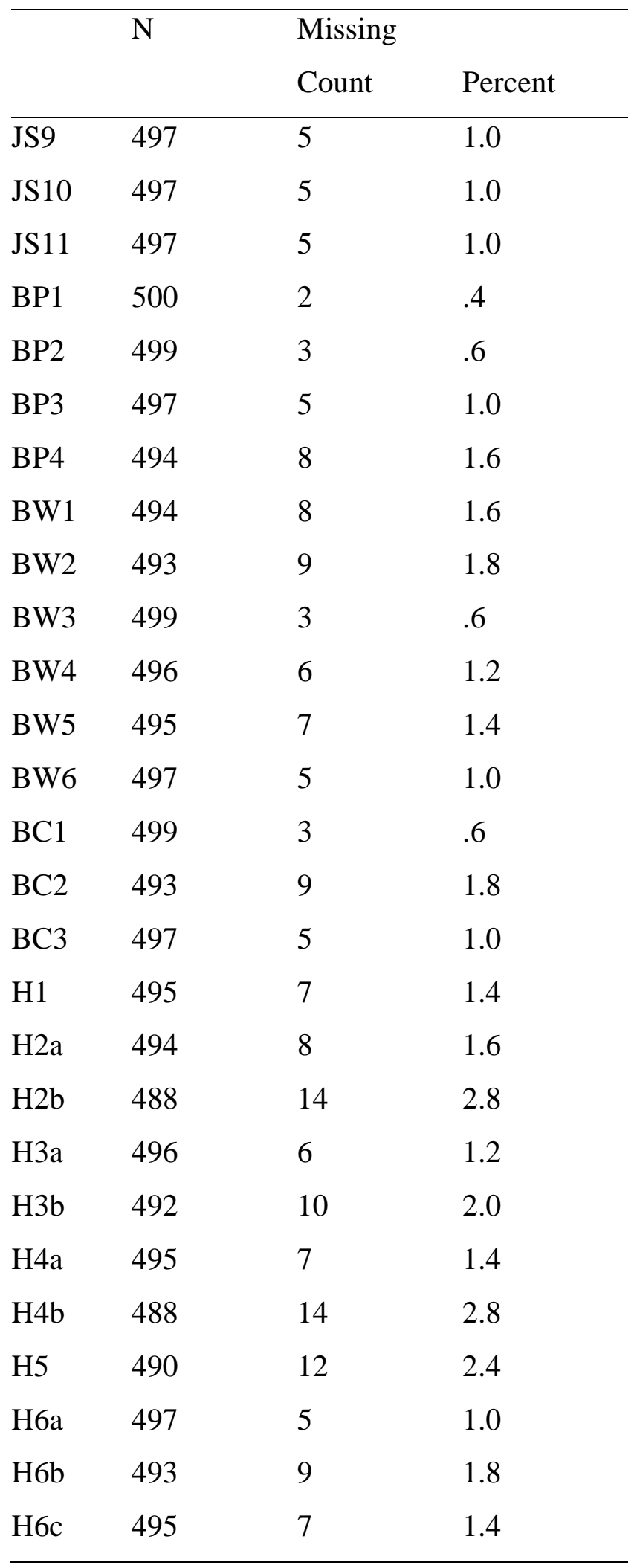




\begin{tabular}{llll}
\hline & $\mathrm{N}$ & $\begin{array}{l}\text { Missing } \\
\text { Count }\end{array}$ & Percent \\
\hline H7 & 497 & 5 & 1.0 \\
GEND & 497 & 5 & 1.0 \\
STAT & 496 & 6 & 1.2 \\
EDUC & 497 & 5 & 1.0 \\
TENUR & 495 & 7 & 1.4 \\
\hline
\end{tabular}


Table 17. Frequency Distribution of the Status of Participants

\begin{tabular}{llllll}
\hline & & Frequency & Percent & $\begin{array}{l}\text { Valid } \\
\text { Percent }\end{array}$ & $\begin{array}{l}\text { Cumulative } \\
\text { Percent }\end{array}$ \\
\hline \multirow{6}{*}{ Valid } & Deputy Governor & 124 & 24.7 & 25.0 & 25.0 \\
& District Governor & 218 & 43.4 & 44.0 & 69.0 \\
& Civil Inspector & 42 & 8.4 & 8.5 & 77.4 \\
& Central bureaucrat & 58 & 11.6 & 11.7 & 89.1 \\
& Trainee & 54 & 10.8 & 10.9 & 100.0 \\
\multirow{2}{*}{ Missing } & Total & 496 & 98.8 & 100.0 & \\
\hline
\end{tabular}


Table 18. Frequency Distribution of the Tenure of Participants

\begin{tabular}{llllll}
\hline & & Frequency & Percent & $\begin{array}{l}\text { Valid } \\
\text { Percent }\end{array}$ & $\begin{array}{l}\text { Cumulative } \\
\text { Percent }\end{array}$ \\
\hline \multirow{6}{*}{ Valid } & Less than 5 years & 72 & 14.3 & 14.5 & 14.5 \\
& 5-10 year & 96 & 19.1 & 19.4 & 33.9 \\
& 11-15 year & 105 & 20.9 & 21.2 & 55.2 \\
& 16-20 year & 37 & 7.4 & 7.5 & 62.6 \\
& More than 20 years & 185 & 36.9 & 37.4 & 100.0 \\
\multirow{2}{*}{ Missing } & Total & 495 & 98.6 & 100.0 & \\
\hline
\end{tabular}

Table 19. Frequency Distribution of the Education Level of Participants

\begin{tabular}{llllll}
\hline & & Frequency & Percent & $\begin{array}{l}\text { Valid } \\
\text { Percent }\end{array}$ & $\begin{array}{l}\text { Cumulative } \\
\text { Percent }\end{array}$ \\
\hline \multirow{4}{*}{ Valid } & $\begin{array}{l}\text { Under- } \\
\text { graduate }\end{array}$ & 240 & 47.8 & 48.3 & 48.3 \\
& Master & 201 & 40.0 & 40.4 & 88.7 \\
& Doctoral and up & 56 & 11.2 & 11.3 & 100.0 \\
\multirow{2}{*}{ Missing } & Total & 497 & 99.0 & 100.0 & \\
Total & System & 5 & 1.0 & & \\
\hline
\end{tabular}


Table 20. Frequency Distribution of the Participants' Gender

\begin{tabular}{llllll}
\hline & & Frequency & Percent & \multicolumn{2}{c}{ Valid Percent } \\
\hline \multirow{4}{*}{ Valid } & Male & 486 & 96.8 & 97.8 & 97.8 \\
& Female & 11 & 2.2 & 2.2 & 100.0 \\
& Total & 497 & 99.0 & 100.0 & \\
Missing & System & 5 & 1.0 & & \\
Total & & 502 & 100.0 & & \\
\hline
\end{tabular}

Table 21. Frequency Distribution of Indicators of Perceived HRQoL

\begin{tabular}{cllcccc} 
& & Frequency & Percent & $\begin{array}{c}\text { Valid } \\
\text { Percent }\end{array}$ & $\begin{array}{c}\text { Cumulative } \\
\text { Percent }\end{array}$ \\
\cline { 2 - 6 } & & Excellent & 15 & 3.0 & 3.0 & 3.0 \\
& & Very good & 87 & 17.3 & 17.6 & 20.6 \\
In general, would & & Good & 349 & 69.5 & 70.5 & 91.1 \\
you say your & Valid & Fair & 39 & 7.8 & 7.9 & 99.0 \\
health is & & Poor & 5 & 1.0 & 1.0 & 100.0 \\
(H1) & & Total & 495 & 98.6 & 100.0 & \\
& Missing & System & 7 & 1.4 & & \\
& Total & & 502 & 100.0 & &
\end{tabular}

The following questions are about activities you might do during a typical day. Does your health now limit you in these activities? If so, how much?

\begin{tabular}{|c|c|c|c|c|c|c|}
\hline \multirow{6}{*}{$\begin{array}{l}\text { Moderate activities, such as } \\
\text { moving a table, pushing a } \\
\text { vacuum cleaner, cycling, or } \\
\text { swimming }(\mathrm{H} 2 \mathrm{a})\end{array}$} & \multirow{3}{*}{ Valid } & $\begin{array}{l}\text { No, not limited } \\
\text { at all }\end{array}$ & 332 & 66.1 & 67.2 & 67.2 \\
\hline & & $\begin{array}{l}\text { Yes, limited a } \\
\text { little }\end{array}$ & 137 & 27.3 & 27.7 & 94.9 \\
\hline & & $\begin{array}{l}\text { Yes, limited a } \\
\text { lot }\end{array}$ & 25 & 5.0 & 5.1 & 100.0 \\
\hline & & Total & 494 & 98.4 & 100.0 & \\
\hline & Missing & System & 8 & 1.6 & & \\
\hline & Total & & 502 & 100.0 & & \\
\hline \multirow{4}{*}{$\begin{array}{l}\text { Climbing several flights of } \\
\text { stairs } \\
\text { (H2b) }\end{array}$} & \multirow{4}{*}{ Valid } & $\begin{array}{l}\text { No, not limited } \\
\text { at all }\end{array}$ & 371 & 73.9 & 76.0 & 76.0 \\
\hline & & $\begin{array}{l}\text { Yes, limited a } \\
\text { little }\end{array}$ & 105 & 20.9 & 21.5 & 97.5 \\
\hline & & $\begin{array}{l}\text { Yes, limited a } \\
\text { lot }\end{array}$ & 12 & 2.4 & 2.5 & 100.0 \\
\hline & & Total & 488 & 97.2 & 100.0 & \\
\hline
\end{tabular}




\begin{tabular}{llcccc}
\hline & & Frequency & Percent & $\begin{array}{c}\text { Valid } \\
\text { Percent }\end{array}$ & $\begin{array}{c}\text { Cumulative } \\
\text { Percent }\end{array}$ \\
\cline { 2 - 5 } & & & & & \\
Missing & System & 14 & 2.8 & \\
& & 502 & 100.0 &
\end{tabular}

During the past 4 weeks, how much of the time have you had any of the following

problems with your work or other regular daily activities as a result of your physical health?

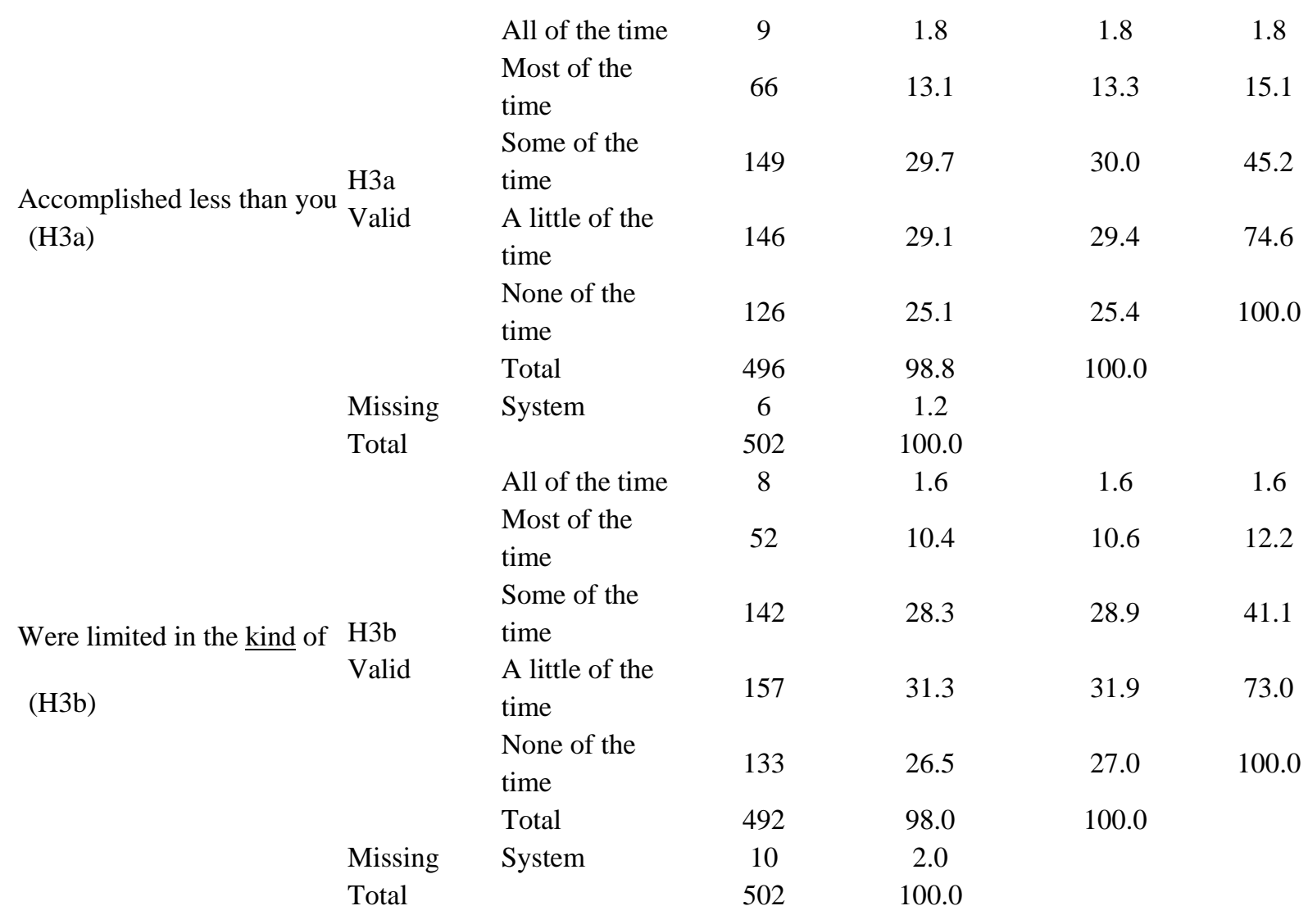

During the past 4 weeks, how much of the time have you had any of the following

problems with your work or other regular daily activities as a result of any emotional

problems (such as feeling depressed or anxious)?

\begin{tabular}{llcccc} 
& $\begin{array}{l}\text { All of the time } \\
\text { Most of the }\end{array}$ & 12 & 2.4 & 2.4 & 2.4 \\
$\begin{array}{l}\text { Accomplished less than you } \\
\text { (H4a) }\end{array}$ & 83 & 16.5 & 16.8 & 19.2 \\
& $\begin{array}{l}\text { Hame } \\
\text { Valid }\end{array}$ & 170 & 33.9 & 34.3 & 53.5 \\
& $\begin{array}{l}\text { Some of the } \\
\text { time } \\
\text { A little of the } \\
\text { time }\end{array}$ & 135 & 26.9 & 27.3 & 80.8 \\
\hline
\end{tabular}




\begin{tabular}{|c|c|c|c|c|c|c|}
\hline & & & Frequency & Percent & $\begin{array}{l}\text { Valid } \\
\text { Percent }\end{array}$ & $\begin{array}{l}\text { Cumulative } \\
\text { Percent }\end{array}$ \\
\hline & & $\begin{array}{l}\text { None of the } \\
\text { time }\end{array}$ & 95 & 18.9 & 19.2 & 100.0 \\
\hline & & Total & 495 & 98.6 & 100.0 & \\
\hline & Missing & System & 7 & 1.4 & & \\
\hline \multirow{10}{*}{$\begin{array}{l}\text { Did work or other activities } \\
(\mathrm{H} 4 \mathrm{~b})\end{array}$} & Total & & 502 & 100.0 & & \\
\hline & & All of the time & 13 & 2.6 & 2.7 & 2.7 \\
\hline & & $\begin{array}{l}\text { Most of the } \\
\text { time }\end{array}$ & 63 & 12.5 & 12.9 & 15.6 \\
\hline & $\mathrm{H} 4 \mathrm{~b}$ & $\begin{array}{l}\text { Some of the } \\
\text { time }\end{array}$ & 166 & 33.1 & 34.0 & 49.6 \\
\hline & Valid & $\begin{array}{l}\text { A little of the } \\
\text { time }\end{array}$ & 141 & 28.1 & 28.9 & 78.5 \\
\hline & & $\begin{array}{l}\text { None of the } \\
\text { time }\end{array}$ & 105 & 20.9 & 21.5 & 100.0 \\
\hline & & Total & 488 & 97.2 & 100.0 & \\
\hline & Missing & System & 14 & 2.8 & & \\
\hline & Total & & 502 & 100.0 & & \\
\hline & & Not at all & 240 & 47.8 & 49.0 & 49.0 \\
\hline \multirow{2}{*}{\multicolumn{2}{|c|}{$\begin{array}{l}\text { During the past } 4 \text { weeks, } \\
\text { how much did pain interfere H5 }\end{array}$}} & A little bit & 163 & 32.5 & 33.3 & 82.2 \\
\hline & & Moderately & 57 & 11.4 & 11.6 & 93.9 \\
\hline with your normal work & Valid & Quite bit & 26 & 5.2 & 5.3 & 99.2 \\
\hline \multirow{2}{*}{\multicolumn{2}{|c|}{$\begin{array}{l}\text { (including both work outside } \\
\text { the home and housework)? }\end{array}$}} & Extremely & 4 & .8 & .8 & 100.0 \\
\hline & & Total & 490 & 97.6 & 100.0 & \\
\hline \multirow{2}{*}{$\underline{(\mathrm{H} 5)}$} & Missing & System & 12 & 2.4 & & \\
\hline & Total & & 502 & 100.0 & & \\
\hline
\end{tabular}

These questions are about how you feel and how things have been with you during the

past 4 weeks. For each question, please give the one answer that comes closest to the way you have been feeling. How much of the time during the past 4 weeks...

\begin{tabular}{|c|c|c|c|c|c|c|}
\hline \multirow{8}{*}{$\begin{array}{l}\text { Have you felt calm and } \\
\text { peaceful? } \\
\text { (H6a) }\end{array}$} & \multirow{6}{*}{$\begin{array}{l}\text { H6a } \\
\text { Valid }\end{array}$} & All of the time & 24 & 4.8 & 4.8 & 4.8 \\
\hline & & $\begin{array}{l}\text { Most of the } \\
\text { time }\end{array}$ & 215 & 42.8 & 43.3 & 48.1 \\
\hline & & $\begin{array}{l}\text { Some of the } \\
\text { time }\end{array}$ & 164 & 32.7 & 33.0 & 81.1 \\
\hline & & $\begin{array}{l}\text { A little of the } \\
\text { time }\end{array}$ & 87 & 17.3 & 17.5 & 98.6 \\
\hline & & $\begin{array}{l}\text { None of the } \\
\text { time }\end{array}$ & 7 & 1.4 & 1.4 & 100.0 \\
\hline & & Total & 497 & 99.0 & 100.0 & \\
\hline & Missing & System & 5 & 1.0 & & \\
\hline & Total & & 502 & 100.0 & & \\
\hline
\end{tabular}




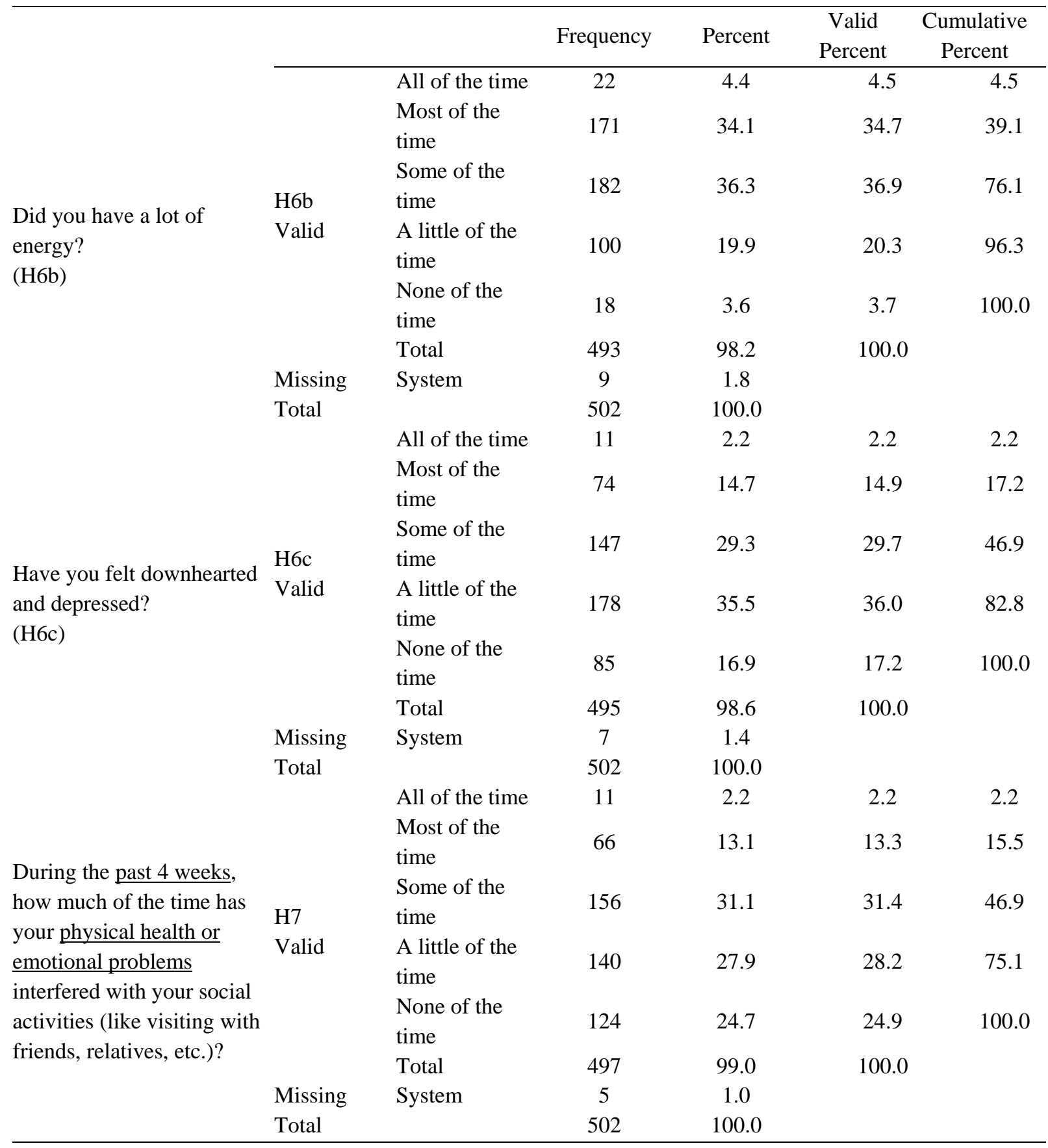


Table 22. Frequency Distribution of Indicators of Perceived Burnout

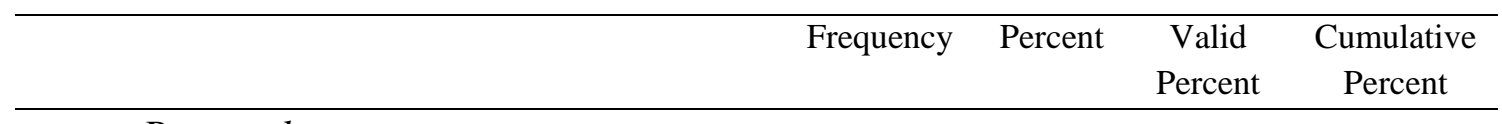

Personal

Burnout

\begin{tabular}{|c|c|c|c|c|c|c|}
\hline \multirow{8}{*}{$\begin{array}{l}\text { How often do you feel } \\
\text { tired? }\end{array}$} & \multirow{5}{*}{$\begin{array}{l}\text { BP1 } \\
\text { Valid }\end{array}$} & Always & 30 & 6.0 & 6.0 & 6.0 \\
\hline & & Often & 180 & 35.9 & 36.0 & 42.0 \\
\hline & & Sometimes & 203 & 40.4 & 40.6 & 82.6 \\
\hline & & Seldom & 76 & 15.1 & 15.2 & 97.8 \\
\hline & & $\begin{array}{l}\text { Never/almost } \\
\text { never }\end{array}$ & 11 & 2.2 & 2.2 & 100.0 \\
\hline & & Total & 500 & 99.6 & 100.0 & \\
\hline & Missing & System & 2 & .4 & & \\
\hline & Total & & 502 & 100.0 & & \\
\hline \multirow{8}{*}{$\begin{array}{l}\text { How often are you } \\
\text { physically exhausted? }\end{array}$} & \multirow{6}{*}{$\begin{array}{l}\text { BP2 } \\
\text { Valid }\end{array}$} & Always & 17 & 3.4 & 3.4 & 3.4 \\
\hline & & Often & 152 & 30.3 & 30.5 & 33.9 \\
\hline & & Sometimes & 205 & 40.8 & 41.1 & 74.9 \\
\hline & & Seldom & 105 & 20.9 & 21.0 & 96.0 \\
\hline & & $\begin{array}{l}\text { Never/almost } \\
\text { never }\end{array}$ & 20 & 4.0 & 4.0 & 100.0 \\
\hline & & Total & 499 & 99.4 & 100.0 & \\
\hline & Missing & System & 3 & .6 & & \\
\hline & Total & & 502 & 100.0 & & \\
\hline \multirow{8}{*}{$\begin{array}{l}\text { How often are you } \\
\text { emotionally exhausted? }\end{array}$} & \multirow{6}{*}{$\begin{array}{l}\text { BP3 } \\
\text { Valid }\end{array}$} & Always & 29 & 5.8 & 5.8 & 5.8 \\
\hline & & Often & 172 & 34.3 & 34.6 & 40.4 \\
\hline & & Sometimes & 182 & 36.3 & 36.6 & 77.1 \\
\hline & & Seldom & 92 & 18.3 & 18.5 & 95.6 \\
\hline & & $\begin{array}{l}\text { Never/almost } \\
\text { never }\end{array}$ & 22 & 4.4 & 4.4 & 100.0 \\
\hline & & Total & 497 & 99.0 & 100.0 & \\
\hline & Missing & System & 5 & 1.0 & & \\
\hline & Total & & 502 & 100.0 & & \\
\hline \multirow{4}{*}{$\begin{array}{l}\text { How often do you } \\
\text { think: 'I can't take it } \\
\text { anymore"? }\end{array}$} & & Always & 6 & 1.2 & 1.2 & 1.2 \\
\hline & BP4 & Often & 54 & 10.8 & 10.9 & 12.1 \\
\hline & Valid & Sometimes & 136 & 27.1 & 27.5 & 39.7 \\
\hline & & Seldom & 144 & 28.7 & 29.1 & 68.8 \\
\hline
\end{tabular}




\begin{tabular}{llcccc}
\hline & & Frequency & Percent & $\begin{array}{c}\text { Valid } \\
\text { Percent }\end{array}$ & $\begin{array}{c}\text { Cumulative } \\
\text { Percent }\end{array}$ \\
\hline & Never/almost & 154 & 30.7 & 31.2 & 100.0 \\
& never & & & & \\
& Total & 494 & 98.4 & 100.0 & \\
Missing & System & 8 & 1.6 & & \\
Total & & 502 & 100.0 & &
\end{tabular}

Work-

related Burnout

\begin{tabular}{|c|c|c|c|c|c|c|}
\hline \multirow{8}{*}{$\begin{array}{l}\text { Is your work } \\
\text { emotionally exhausting? }\end{array}$} & & $\begin{array}{l}\text { To a very high } \\
\text { degree }\end{array}$ & 60 & 12.0 & 12.1 & 12.1 \\
\hline & & To a high degree & 209 & 41.6 & 42.3 & 54.5 \\
\hline & BW1 & Somewhat & 155 & 30.9 & 31.4 & 85.8 \\
\hline & Valid & To a low degree & 51 & 10.2 & 10.3 & 96.2 \\
\hline & & $\begin{array}{l}\text { To a very low } \\
\text { degree }\end{array}$ & 19 & 3.8 & 3.8 & 100.0 \\
\hline & & Total & 494 & 98.4 & 100.0 & \\
\hline & Missing & System & 8 & 1.6 & & \\
\hline & Total & & 502 & 100.0 & & \\
\hline \multirow{8}{*}{$\begin{array}{l}\text { Do you feel burnt out } \\
\text { because of your work? }\end{array}$} & & $\begin{array}{l}\text { To a very high } \\
\text { degree }\end{array}$ & 33 & 6.6 & 6.7 & 6.7 \\
\hline & & To a high degree & 133 & 26.5 & 27.0 & 33.7 \\
\hline & BW2 & Somewhat & 174 & 34.7 & 35.3 & 69.0 \\
\hline & Valid & To a low degree & 91 & 18.1 & 18.5 & 87.4 \\
\hline & & $\begin{array}{l}\text { To a very low } \\
\text { degree }\end{array}$ & 62 & 12.4 & 12.6 & 100.0 \\
\hline & & Total & 493 & 98.2 & 100.0 & \\
\hline & Missing & System & 9 & 1.8 & & \\
\hline & Total & & 502 & 100.0 & & \\
\hline \multirow{8}{*}{$\begin{array}{l}\text { Do you feel worn out at } \\
\text { the end of the working } \\
\text { day? }\end{array}$} & & Always & 28 & 5.6 & 5.6 & 5.6 \\
\hline & & Often & 176 & 35.1 & 35.3 & 40.9 \\
\hline & & Sometimes & 188 & 37.5 & 37.7 & 78.6 \\
\hline & $\begin{array}{l}\text { BW3 } \\
\text { Valid }\end{array}$ & Seldom & 86 & 17.1 & 17.2 & 95.8 \\
\hline & & $\begin{array}{l}\text { Never/almost } \\
\text { never }\end{array}$ & 21 & 4.2 & 4.2 & 100.0 \\
\hline & & Total & 499 & 99.4 & 100.0 & \\
\hline & Missing & System & 3 & .6 & & \\
\hline & Total & & 502 & 100.0 & & \\
\hline \multirow{4}{*}{$\begin{array}{l}\text { Are you exhausted in } \\
\text { the morning at the } \\
\text { thought of another day } \\
\text { at work? }\end{array}$} & & Always & 21 & 4.2 & 4.2 & 4.2 \\
\hline & BW4 & Often & 91 & 18.1 & 18.3 & 22.6 \\
\hline & Valid & Sometimes & 165 & 32.9 & 33.3 & 55.8 \\
\hline & & Seldom & 141 & 28.1 & 28.4 & 84.3 \\
\hline
\end{tabular}




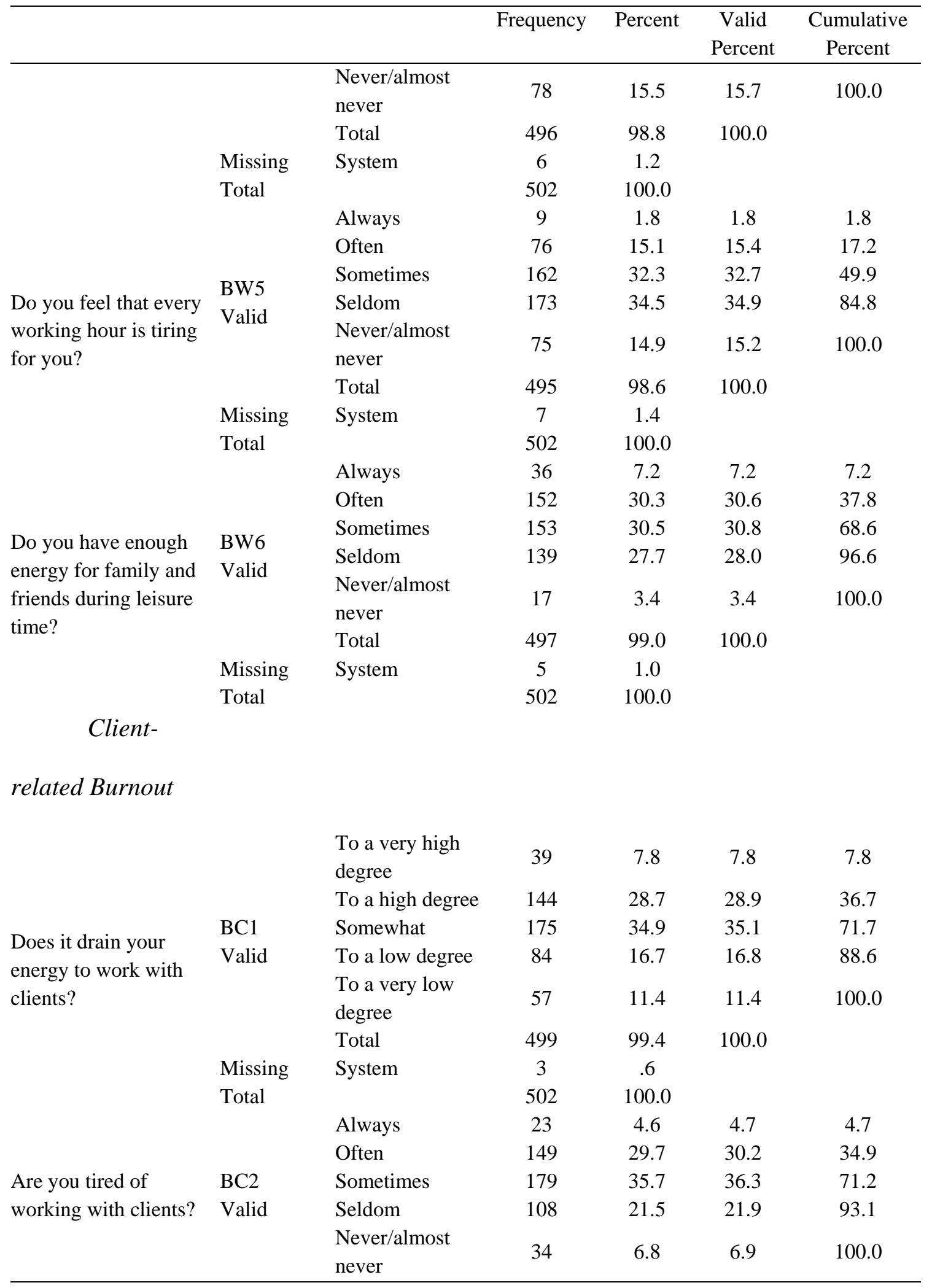




\begin{tabular}{|c|c|c|c|c|c|c|}
\hline & & & Frequency & Percent & $\begin{array}{c}\text { Valid } \\
\text { Percent }\end{array}$ & $\begin{array}{c}\text { Cumulative } \\
\text { Percent }\end{array}$ \\
\hline & & Total & 493 & 98.2 & 100.0 & \\
\hline & Missing & System & 9 & 1.8 & & \\
\hline & Total & & 502 & 100.0 & & \\
\hline \multirow{8}{*}{$\begin{array}{l}\text { Do you sometimes } \\
\text { wonder how long you } \\
\text { will be able to continue } \\
\text { working with clients? }\end{array}$} & \multirow{6}{*}{$\begin{array}{l}\text { BC3 } \\
\text { Valid }\end{array}$} & Always & 22 & 4.4 & 4.4 & 4.4 \\
\hline & & Often & 76 & 15.1 & 15.3 & 19.7 \\
\hline & & Sometimes & 157 & 31.3 & 31.6 & 51.3 \\
\hline & & Seldom & 137 & 27.3 & 27.6 & 78.9 \\
\hline & & $\begin{array}{l}\text { Never/almost } \\
\text { never }\end{array}$ & 105 & 20.9 & 21.1 & 100.0 \\
\hline & & Total & 497 & 99.0 & 100.0 & \\
\hline & Missing & System & 5 & 1.0 & & \\
\hline & Total & & 502 & 100.0 & & \\
\hline
\end{tabular}


Table 23. Frequenc y Distribution of Indicators of Job-related Stress

\begin{tabular}{|c|c|c|c|c|c|}
\hline & & Frequency & Percent & Valid & Cumulative \\
\hline & & & & Percent & Percent \\
\hline & Strongly Disagree & 62 & 12.4 & 12.5 & 12.5 \\
\hline & Disagree & 141 & 28.1 & 28.5 & 41.0 \\
\hline I have felt fidgety or & Neutral & 63 & 12.5 & 12.7 & 53.7 \\
\hline nervous as a result of & Agree & 193 & 38.4 & 39.0 & 92.7 \\
\hline my job. & Strongly Agree & 36 & 7.2 & 7.3 & 100.0 \\
\hline (JS1) & Total & 495 & 98.6 & 100.0 & \\
\hline Missing & System & 7 & 1.4 & & \\
\hline Total & & 502 & 100.0 & & \\
\hline & Strongly Disagre & 42 & 8.4 & 8.5 & 8.5 \\
\hline & Disagree & 145 & 28.9 & 29.2 & 37.6 \\
\hline it hard to cnendVolid & Neutral & 57 & 11.4 & 11.5 & 49.1 \\
\hline enough time with my & Agree & 182 & 36.3 & 36.6 & 85.7 \\
\hline fomily & Strongly Agree & 71 & 14.1 & 14.3 & 100.0 \\
\hline tamy & Total & 497 & 99.0 & 100.0 & \\
\hline Missing & System & 5 & 1.0 & & \\
\hline Total & & 502 & 100.0 & & \\
\hline & Strongly Disagree & 43 & 8.6 & 8.7 & 8.7 \\
\hline & Disagree & 151 & 30.1 & 30.4 & 39.0 \\
\hline & Neutral & 44 & 8.8 & 8.9 & 47.9 \\
\hline more than I should & Agree & 194 & 38.6 & 39.0 & 86.9 \\
\hline (IS3) & Strongly Agree & 65 & 12.9 & 13.1 & 100.0 \\
\hline$(\mathrm{JSJ})$ & Total & 497 & 99.0 & 100.0 & \\
\hline Missing & System & 5 & 1.0 & & \\
\hline Total & & 502 & 100.0 & & \\
\hline I spend so much time & Strongly Disagree & 57 & 11.4 & 11.5 & 11.5 \\
\hline at work; I cannot see & Disagree & 182 & 36.3 & 36.7 & 48.2 \\
\hline
\end{tabular}




\begin{tabular}{|c|c|c|c|c|c|c|}
\hline & & & Frequency & Percent & Valid & Cumulative \\
\hline & & & & & Percent & Percent \\
\hline the forest for the trees & & Neutral & 90 & 17.9 & 18.1 & 66.3 \\
\hline (JS4) & & Agree & 129 & 25.7 & 26.0 & 92.3 \\
\hline & & Strongly Agree & 38 & 7.6 & 7.7 & 100.0 \\
\hline & & Total & 496 & 98.8 & 100.0 & \\
\hline & Missing & System & 6 & 1.2 & & \\
\hline & Total & & 502 & 100.0 & & \\
\hline & & Strongly Disagre & 37 & 7.4 & 7.5 & 7.5 \\
\hline & & Disagree & 175 & 34.9 & 35.3 & 42.7 \\
\hline Working here leaves & & Neutral & 73 & 14.5 & 14.7 & 57.5 \\
\hline little time for other & Valid & Agree & 175 & 34.9 & 35.3 & 92.7 \\
\hline activities & & Strongly Agree & 36 & 7.2 & 7.3 & 100.0 \\
\hline (JS5) & & Total & 496 & 98.8 & 100.0 & \\
\hline & Missing & System & 6 & 1.2 & & \\
\hline & Total & & 502 & 100.0 & & \\
\hline & & Strongly Disagre & 64 & 12.7 & 13.0 & 13.0 \\
\hline & & Disagree & 179 & 35.7 & 36.3 & 49.3 \\
\hline I frequently get the & & Neutral & 75 & 14.9 & 15.2 & 64.5 \\
\hline feeling I am married & & Agree & 140 & 27.9 & 28.4 & 92.9 \\
\hline to the company & & Strongly Agree & 35 & 7.0 & 7.1 & 100.0 \\
\hline (JS6) & & Total & 493 & 98.2 & 100.0 & \\
\hline & Missing & System & 9 & 1.8 & & \\
\hline & Total & & 502 & 100.0 & & \\
\hline & & Strongly Disagre & 51 & 10.2 & 10.3 & 10.3 \\
\hline . & & Disagree & 205 & 40.8 & 41.5 & 51.8 \\
\hline a & Valid & Neutral & 96 & 19.1 & 19.4 & 71.3 \\
\hline to itit & & Agree & 116 & 23.1 & 23.5 & 94.7 \\
\hline (נוהינ) & & Strongly Agree & 26 & 5.2 & 5.3 & 100.0 \\
\hline
\end{tabular}




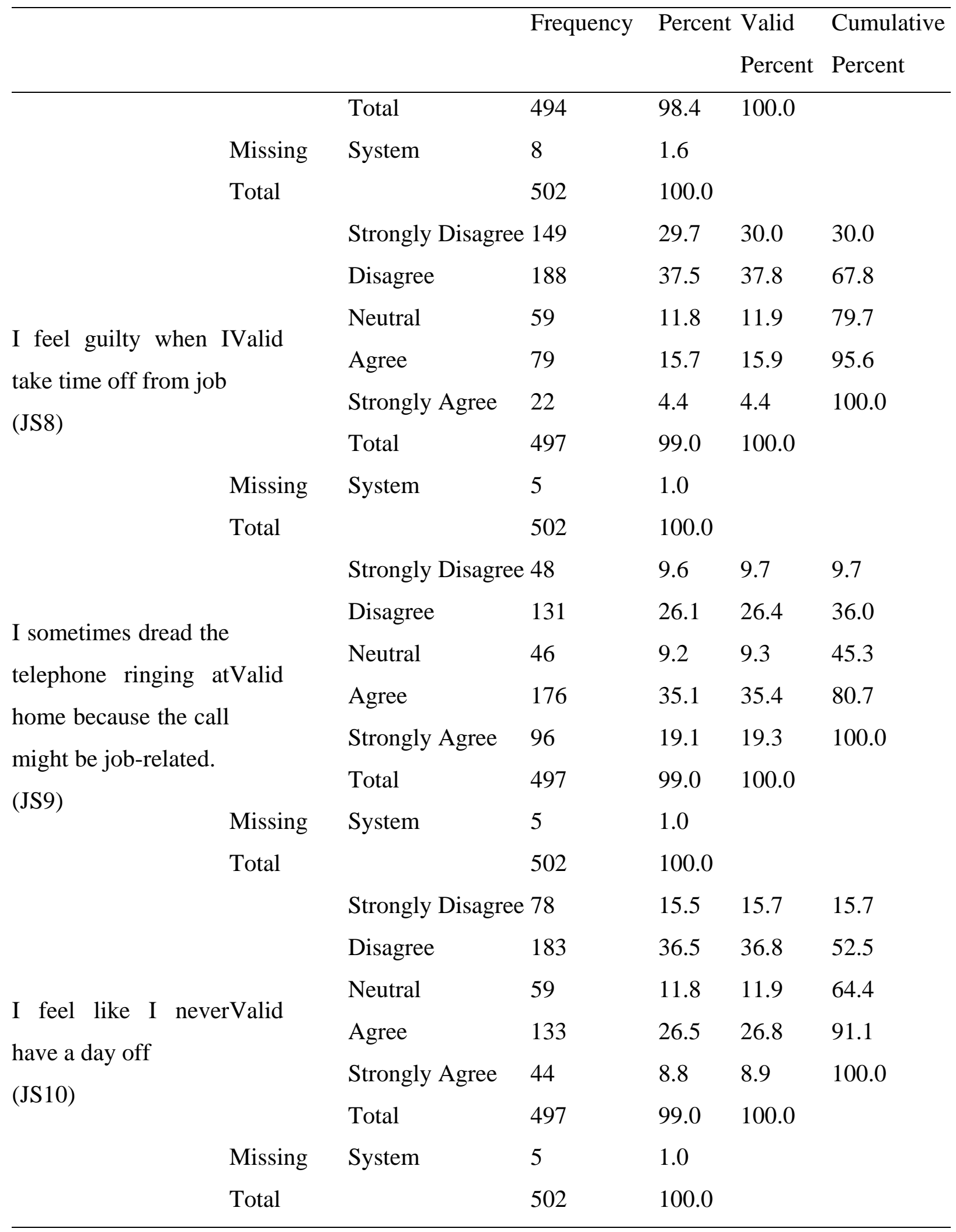




\begin{tabular}{|c|c|c|c|c|c|}
\hline & & Frequency & Percent & Valid & Cumulative \\
\hline & & & & Percent & Percent \\
\hline & Strongly Disagr & 26 & 5.2 & 5.2 & 5.2 \\
\hline & Disagree & 104 & 20.7 & 20.9 & 26.2 \\
\hline too many peopie at & Neutral & 93 & 18.5 & 18.7 & 44.9 \\
\hline my rever ion uevana & Agree & 194 & 38.6 & 39.0 & 83.9 \\
\hline 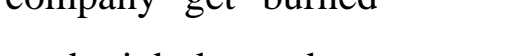 & Strongly Agree & 80 & 15.9 & 16.1 & 100.0 \\
\hline & Total & 497 & 99.0 & 100.0 & \\
\hline Missing & System & 5 & 1.0 & & \\
\hline Total & & 502 & 100.0 & & \\
\hline
\end{tabular}


Table 24. Frequency Distribution of Indicators of Mobbing

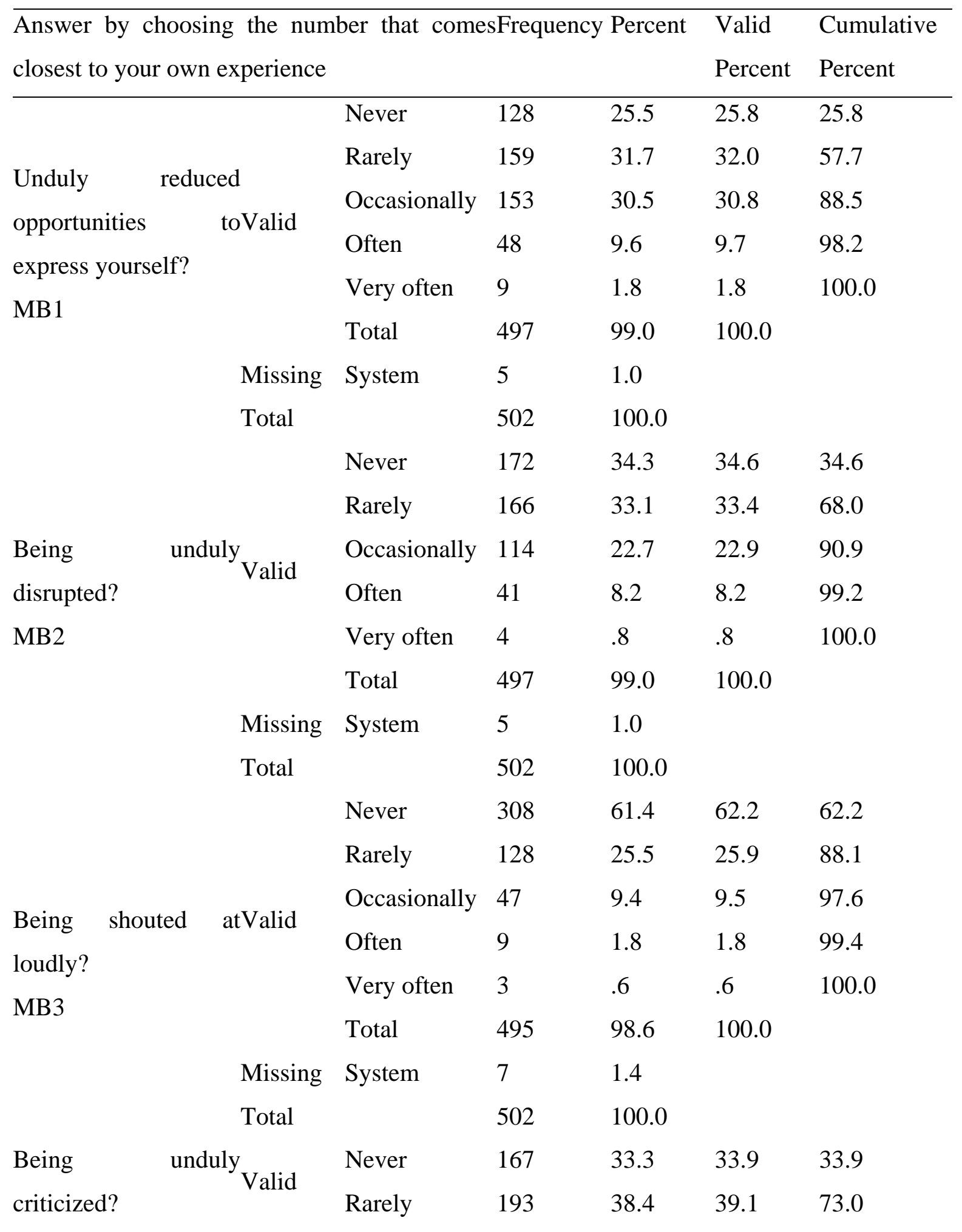




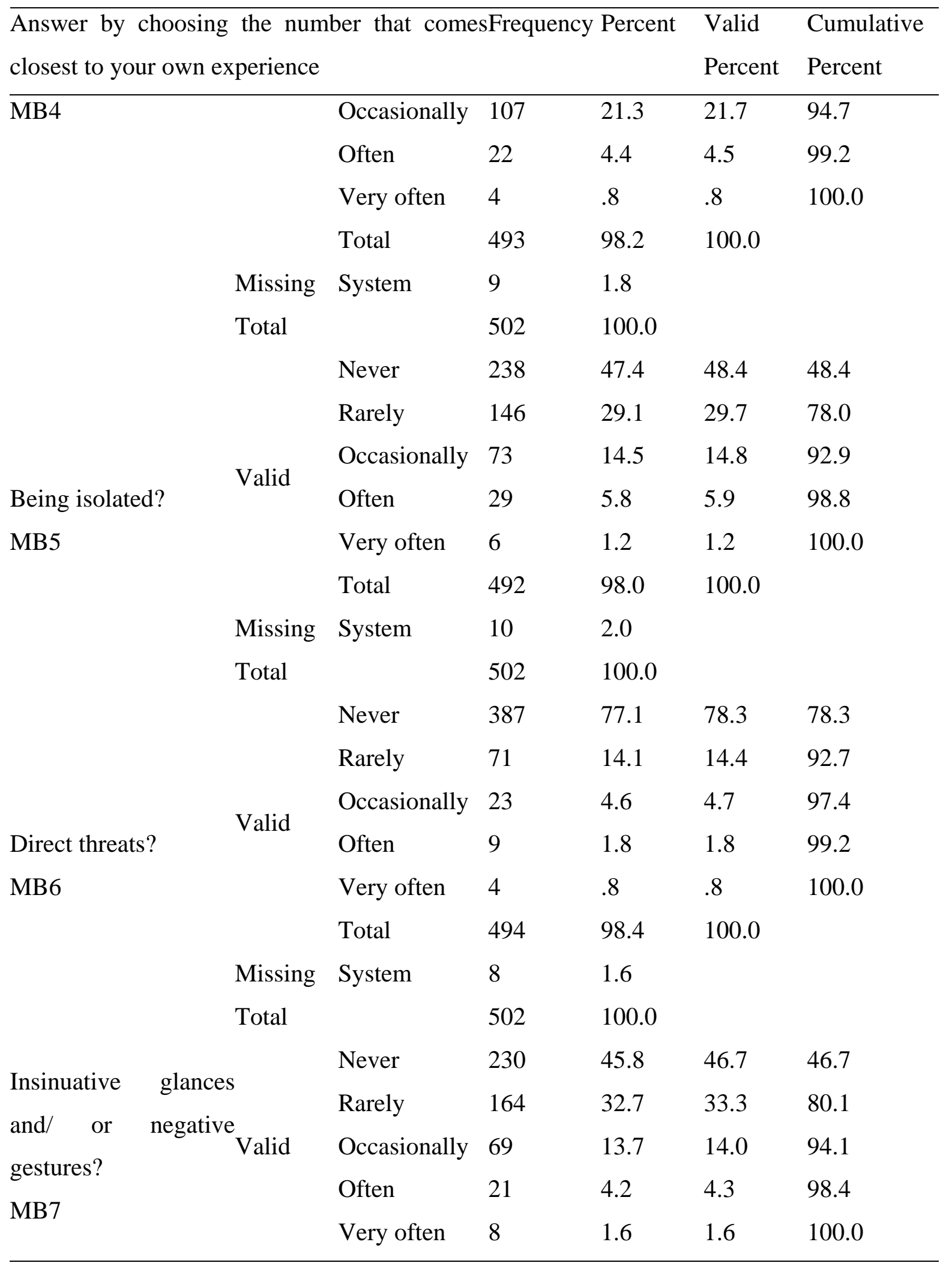




\begin{tabular}{|c|c|c|c|c|c|c|}
\hline $\begin{array}{l}\text { Answer by choosi } \\
\text { closest to your own }\end{array}$ & $\begin{array}{l}\text { the nun } \\
\text { xperience }\end{array}$ & ber that come & sFreq & Percent & $\begin{array}{l}\text { Valid } \\
\text { Percent }\end{array}$ & $\begin{array}{l}\text { Cumulative } \\
\text { Percent }\end{array}$ \\
\hline & & Total & 492 & 98.0 & 100.0 & \\
\hline & Missing & System & 10 & 2.0 & & \\
\hline & Total & & 502 & 100.0 & & \\
\hline & & Never & 216 & 43.0 & 43.6 & 43.6 \\
\hline & & Rarely & 188 & 37.5 & 38.0 & 81.6 \\
\hline & & Occasionally & 65 & 12.9 & 13.1 & 94.7 \\
\hline Accusations? & 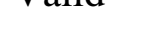 & Often & 19 & 3.8 & 3.8 & 98.6 \\
\hline MB8 & & Very often & 7 & 1.4 & 1.4 & 100.0 \\
\hline & & Total & 495 & 98.6 & 100.0 & \\
\hline & Missing & System & 7 & 1.4 & & \\
\hline & Total & & 502 & 100.0 & & \\
\hline & & Never & 213 & 42.4 & 43.4 & 43.4 \\
\hline & & Rarely & 147 & 29.3 & 29.9 & 73.3 \\
\hline & & Occasionally & 72 & 14.3 & 14.7 & 88.0 \\
\hline Deng silecreu at. & valu & Often & 44 & 8.8 & 9.0 & 96.9 \\
\hline IVID & & Very often & 15 & 3.0 & 3.1 & 100.0 \\
\hline & & Total & 491 & 97.8 & 100.0 & \\
\hline & Missing & System & 11 & 2.2 & & \\
\hline & Total & & 502 & 100.0 & & \\
\hline & & Never & 325 & 64.7 & 66.1 & 66.1 \\
\hline & & Rarely & 111 & 22.1 & 22.6 & 88.6 \\
\hline & & Occasionally & 35 & 7.0 & 7.1 & 95.7 \\
\hline merusar of spean we & & Often & 16 & 3.2 & 3.3 & 99.0 \\
\hline & & Very often & 5 & 1.0 & 1.0 & 100.0 \\
\hline DIVID & & Total & 492 & 98.0 & 100.0 & \\
\hline & Missing & System & 10 & 2.0 & & \\
\hline & Total & & 502 & 100.0 & & \\
\hline
\end{tabular}




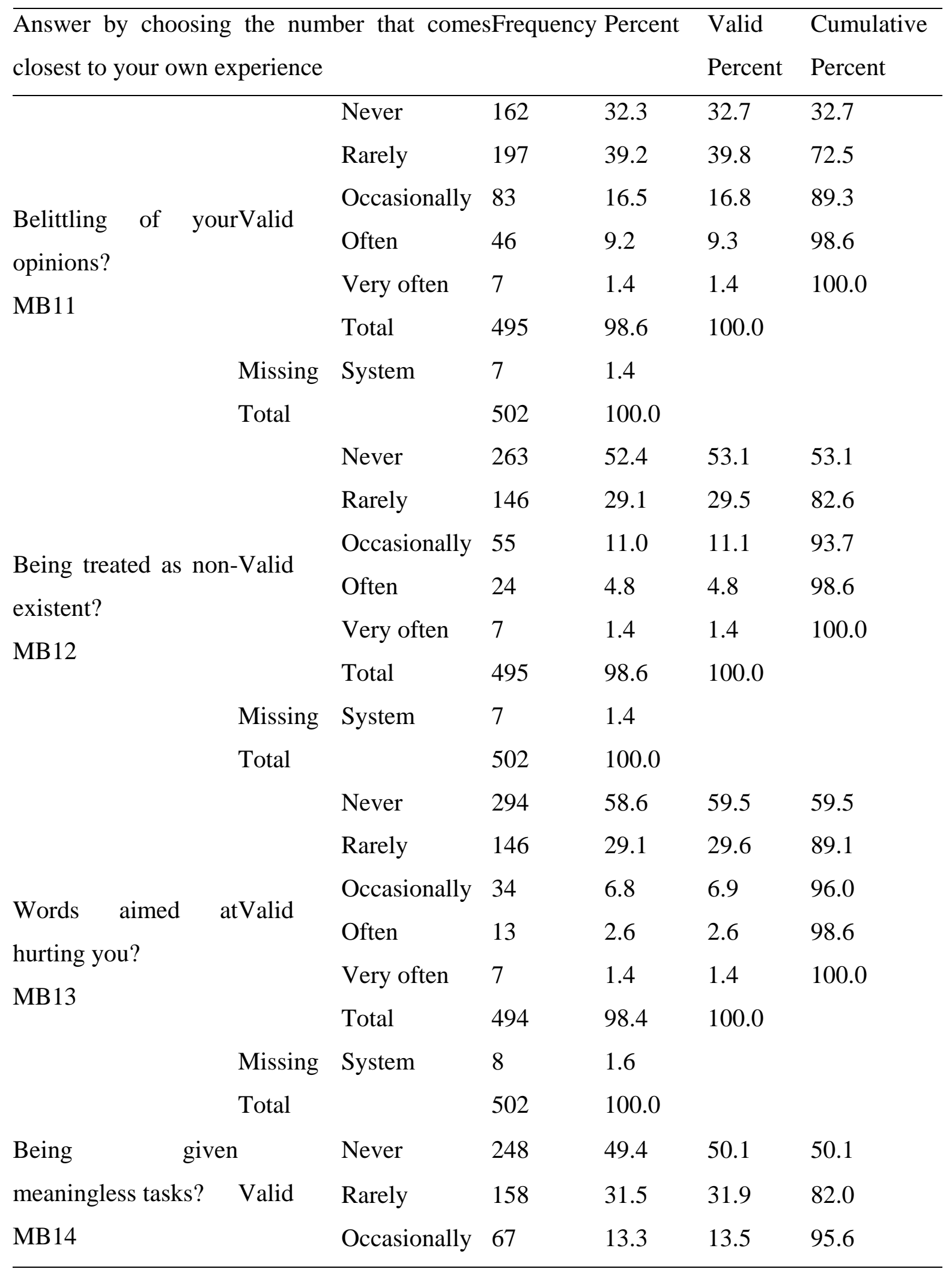




\begin{tabular}{|c|c|c|c|c|c|}
\hline $\begin{array}{l}\text { Answer by choosing the num } \\
\text { closest to your own experience }\end{array}$ & ber that come & sFreq & Percent & $\begin{array}{l}\text { Valid } \\
\text { Percent }\end{array}$ & $\begin{array}{l}\text { Cumulative } \\
\text { Percent }\end{array}$ \\
\hline & Often & 18 & 3.6 & 3.6 & 99.2 \\
\hline & Very often & 4 & .8 & .8 & 100.0 \\
\hline & Total & 495 & 98.6 & 100.0 & \\
\hline Missing & System & 7 & 1.4 & & \\
\hline Total & & 502 & 100.0 & & \\
\hline & Never & 325 & 64.7 & 65.8 & 65.8 \\
\hline & Rarely & 108 & 21.5 & 21.9 & 87.7 \\
\hline Having malicious & Occasionally & 40 & 8.0 & 8.1 & 95.7 \\
\hline rumors spread behind & Often & 16 & 3.2 & 3.2 & 99.0 \\
\hline your back? & Very often & 5 & 1.0 & 1.0 & 100.0 \\
\hline MB15 & Total & 494 & 98.4 & 100.0 & \\
\hline Missing & System & 8 & 1.6 & & \\
\hline Total & & 502 & 100.0 & & \\
\hline & Never & 401 & 79.9 & 81.2 & 81.2 \\
\hline & Rarely & 61 & 12.2 & 12.3 & 93.5 \\
\hline & Occasionally & 19 & 3.8 & 3.8 & 97.4 \\
\hline f & Often & 8 & 1.6 & 1.6 & 99.0 \\
\hline sir & Very often & 5 & 1.0 & 1.0 & 100.0 \\
\hline IVID IO & Total & 494 & 98.4 & 100.0 & \\
\hline Missing & System & 8 & 1.6 & & \\
\hline Total & & 502 & 100.0 & & \\
\hline & Never & 351 & 69.9 & 70.5 & 70.5 \\
\hline Having your work & Rarely & 99 & 19.7 & 19.9 & 90.4 \\
\hline judged in an incorrect & Occasionally & 31 & 6.2 & 6.2 & 96.6 \\
\hline and insulting manner? & Often & 10 & 2.0 & 2.0 & 98.6 \\
\hline MB17 & Very often & 7 & 1.4 & 1.4 & 100.0 \\
\hline & Total & 498 & 99.2 & 100.0 & \\
\hline
\end{tabular}




\begin{tabular}{|c|c|c|c|c|c|}
\hline \multicolumn{4}{|c|}{$\begin{array}{l}\text { Answer by choosing the number that comesFrequency Percent } \\
\text { closest to your own experience }\end{array}$} & $\begin{array}{l}\text { Valid } \\
\text { Percent }\end{array}$ & $\begin{array}{l}\text { Cumulative } \\
\text { Percent }\end{array}$ \\
\hline \multirow{7}{*}{$\begin{array}{l}\text { Having your sense of Valid } \\
\text { judgment questioned? } \\
\text { MB18 }\end{array}$} & System & 4 & .8 & & \\
\hline & & 502 & 100.0 & & \\
\hline & Never & 182 & 36.3 & 36.8 & 36.8 \\
\hline & Rarely & 203 & 40.4 & 41.0 & 77.8 \\
\hline & Occasionally & 79 & 15.7 & 16.0 & 93.7 \\
\hline & Often & 20 & 4.0 & 4.0 & 97.8 \\
\hline & Very often & 11 & 2.2 & 2.2 & 100.0 \\
\hline MIBI8 & Total & 495 & 98.6 & 100.0 & \\
\hline Missing & System & 7 & 1.4 & & \\
\hline Total & & 502 & 100.0 & & \\
\hline
\end{tabular}


APPENDIX S: CORRELATION MATRICES 
Table 25. Correlation Matrix of HRQoL

\begin{tabular}{|c|c|c|c|c|c|c|c|c|c|c|c|c|c|c|}
\hline & & & I1 & $\mathrm{H} 2 \mathrm{a}$ & $\mathrm{H} 2 \mathrm{~b}$ & H3a & $\mathrm{H} 3 \mathrm{~b}$ & $\mathrm{H} 4 \mathrm{a}$ & $\mathrm{H} 4 \mathrm{~b}$ & H5 & H6a & H6b & H6c & $\mathrm{H} 7$ \\
\hline \multirow{5}{*}{ H1 } & Pearson & & & & & & & & & & & & & \\
\hline & Correlatio & 1 & & & & & & & & & & & & \\
\hline & $\mathrm{n}$ & & & & & & & & & & & & & \\
\hline & Sig. (2- & & & & & & & & & & & & & \\
\hline & tailed) & & & & & & & & & & & & & \\
\hline & $\mathrm{N}$ & 502 & & & & & & & & & & & & \\
\hline \multirow{6}{*}{$\mathrm{H} 2 \mathrm{a}$} & Pearson & & & & & & & & & & & & & \\
\hline & Correlatio & $.386^{* *}$ & 1 & & & & & & & & & & & \\
\hline & $\mathrm{n}$ & & & & & & & & & & & & & \\
\hline & $\begin{array}{l}\text { Sig. (2- } \\
\text { tailed) }\end{array}$ & .000 & & & & & & & & & & & & \\
\hline & $\mathrm{N}$ & 502 & 502 & & & & & & & & & & & \\
\hline & Pearson & & & & & & & & & & & & & \\
\hline \multirow{4}{*}{$\mathrm{H} 2 \mathrm{~b}$} & Correlatio & $.328^{* * *}$ & $.607^{* *}$ & 1 & & & & & & & & & & \\
\hline & $\mathrm{n}$ & & & & & & & & & & & & & \\
\hline & $\begin{array}{l}\text { Sig. (2- } \\
\text { tailed) }\end{array}$ & .000 & .000 & & & & & & & & & & & \\
\hline & $\mathrm{N}$ & 502 & 502 & 502 & & & & & & & & & & \\
\hline \multirow{5}{*}{$\mathrm{H} 3 \mathrm{a}$} & Pearson & & & & & & & & & & & & & \\
\hline & Correlatio & $.342^{\text {*** }}$ & $.446^{* *}$ & $.382^{* *}$ & & 1 & & & & & & & & \\
\hline & $\mathrm{n}$ & & & & & & & & & & & & & \\
\hline & $\begin{array}{l}\text { Sig. (2- } \\
\text { tailed) }\end{array}$ & .000 & .000 & .000 & & & & & & & & & & \\
\hline & $\mathrm{N}$ & 502 & 502 & 502 & & 502 & & & & & & & & \\
\hline
\end{tabular}




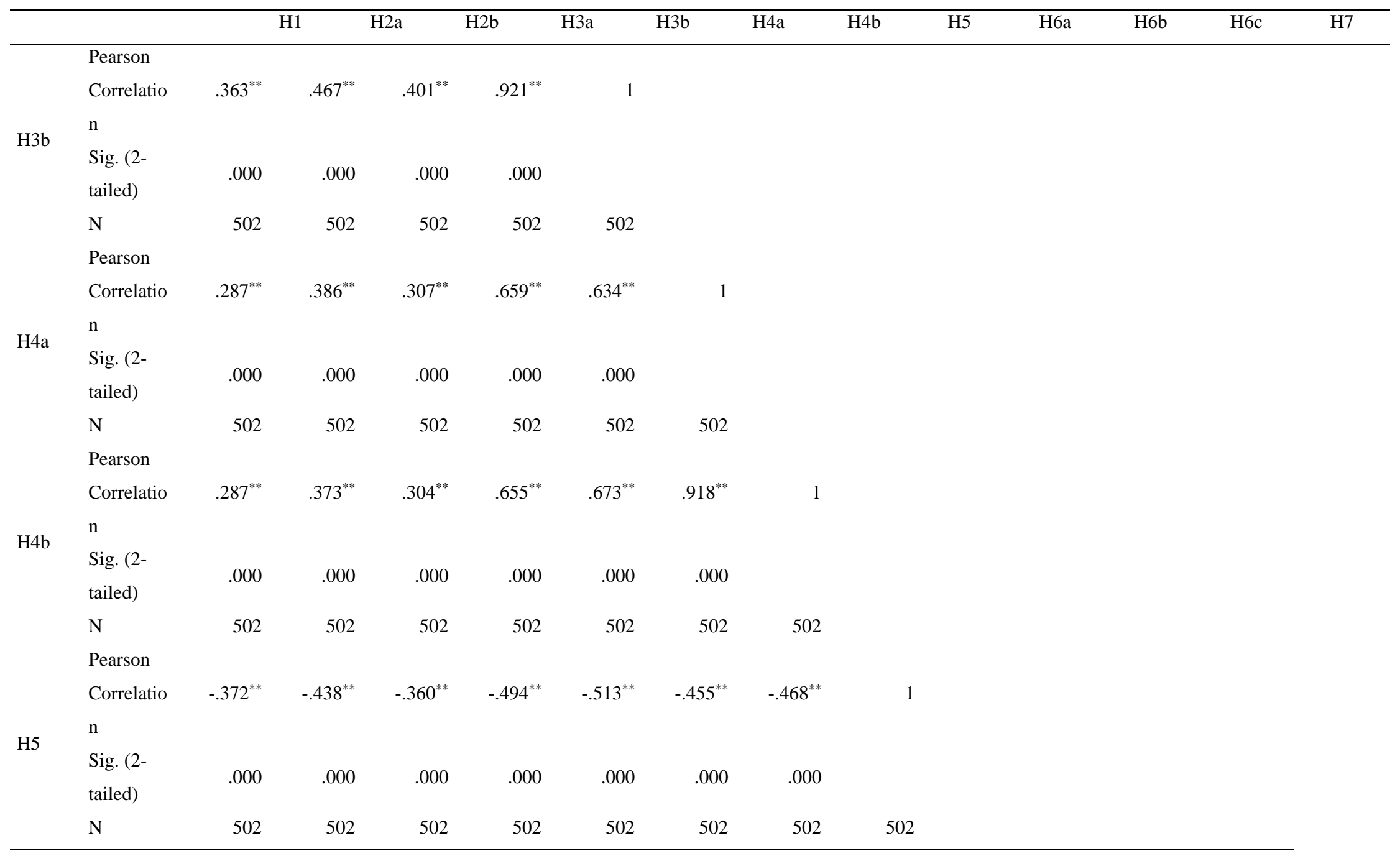




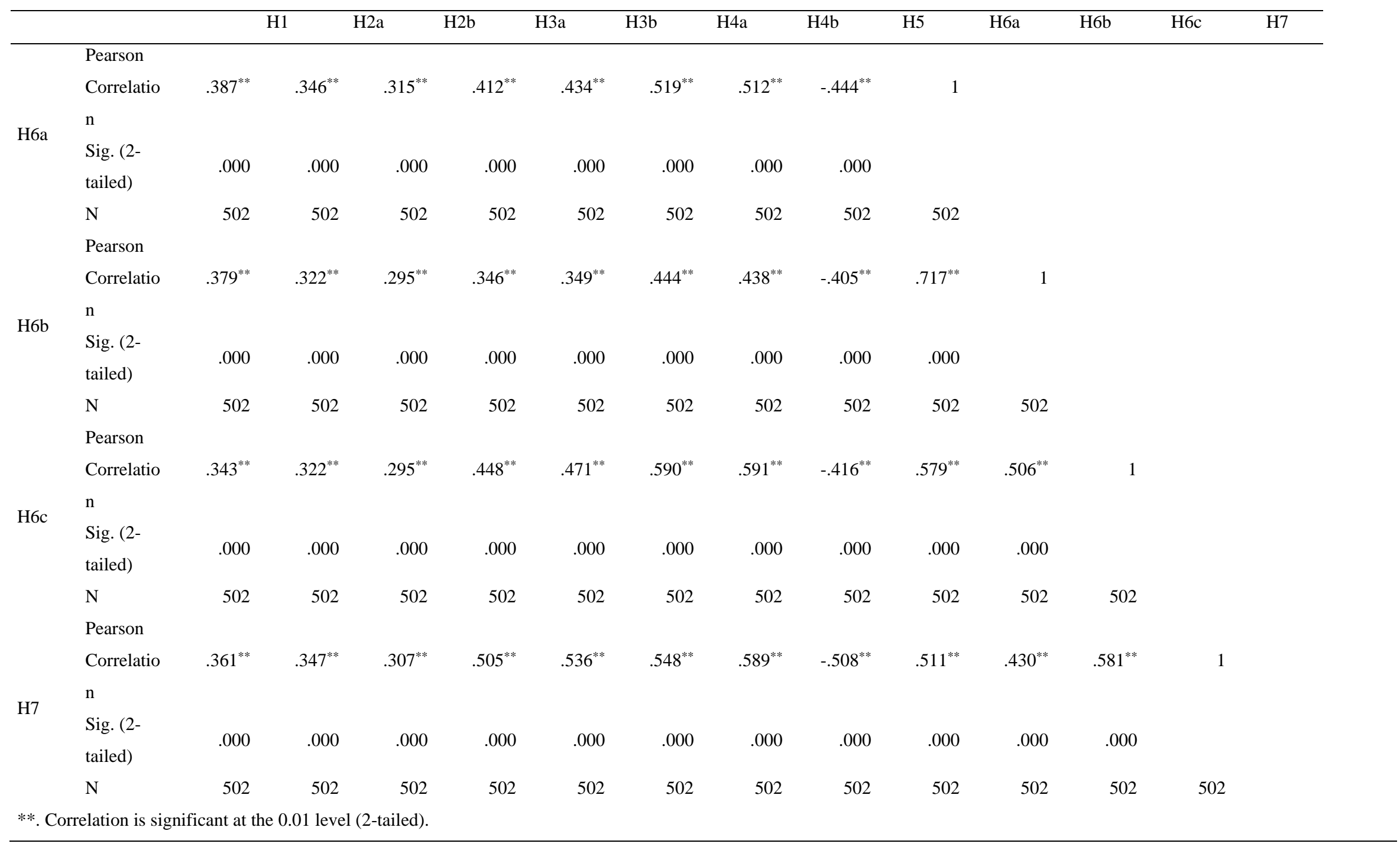


Table 26. Correlation Matrix of Burnout

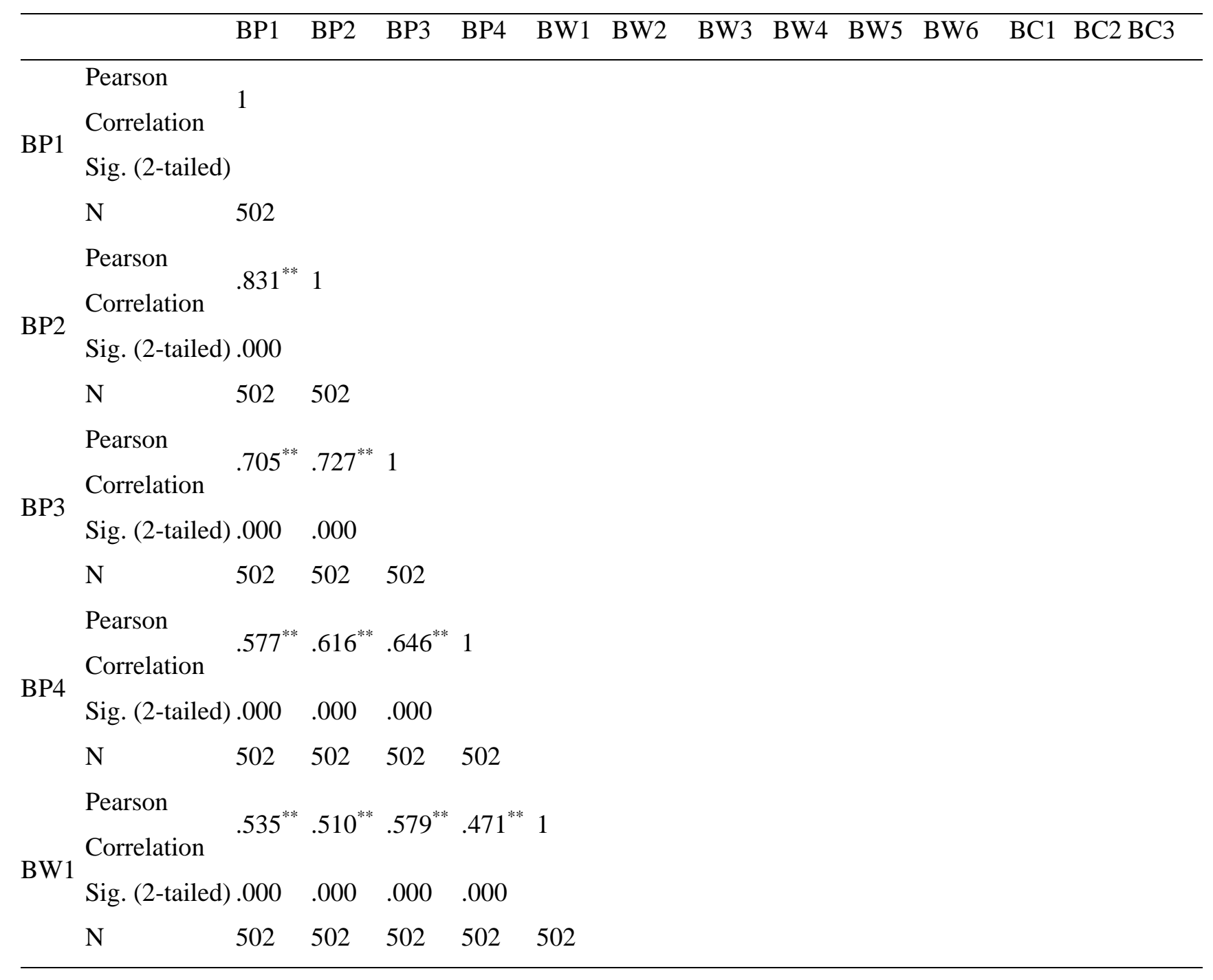




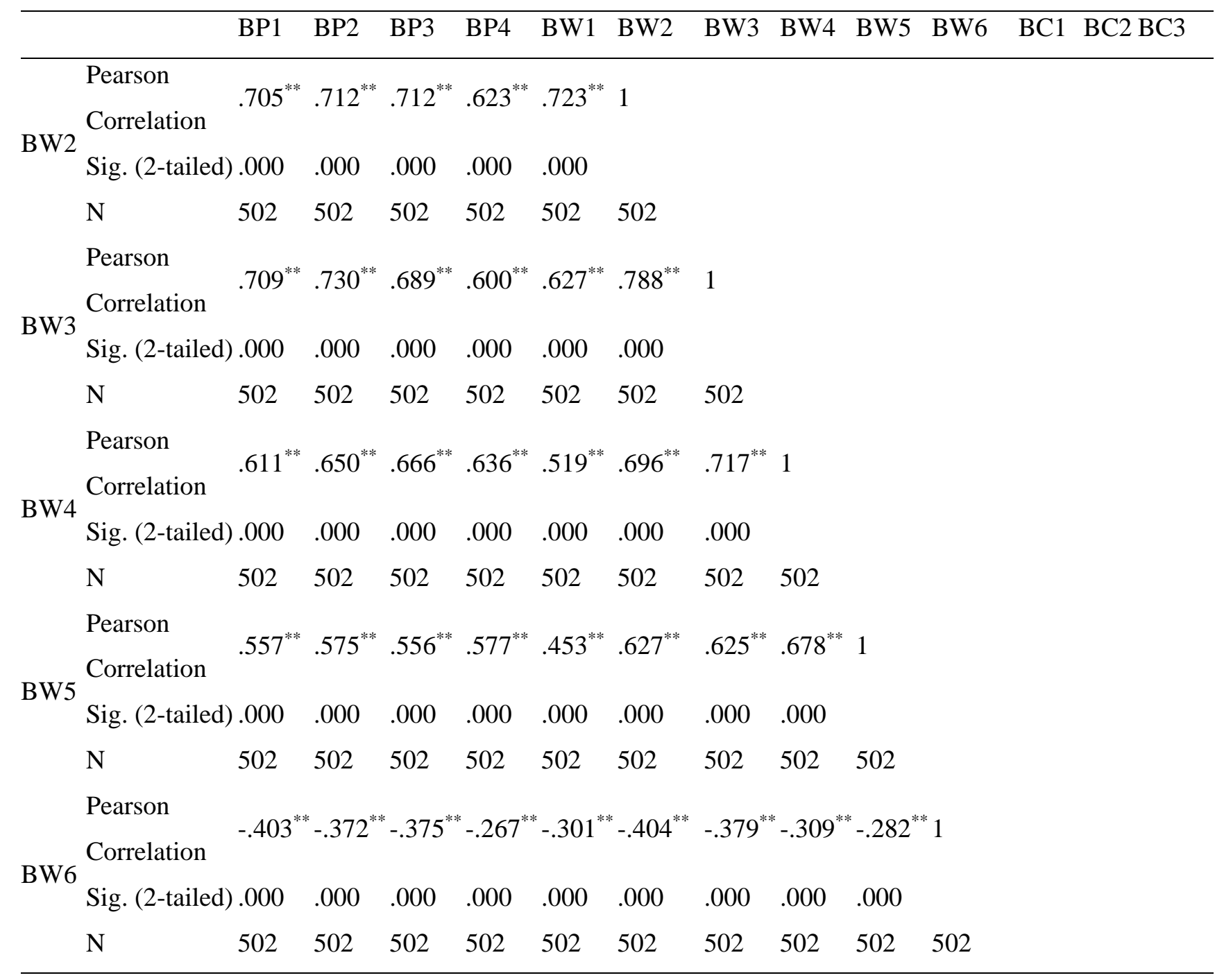




\begin{tabular}{|c|c|c|c|c|c|c|c|c|c|c|c|c|}
\hline & & BP1 & $\mathrm{BP} 2$ & BP3 & $\mathrm{BP} 4$ & BW1 & BW2 & BW3 & BW4 & BW5 & BW6 & BC1 BC2 BC3 \\
\hline \multirow{3}{*}{ BC1 } & $\begin{array}{l}\text { Pearson } \\
\text { Correlation }\end{array}$ & $.532^{* *}$ & $.497^{* *}$ & $.491^{* *}$ & $.393^{* *}$ & $.485^{* *}$ & $.543^{* *}$ & $.554^{* *}$ & $.516^{* *}$ & $.482^{* *}$ & $-.287^{* *}$ & \multirow[t]{2}{*}{1} \\
\hline & Sig. (2-tailed) & .000 & .000 & .000 & .000 & .000 & .000 & .000 & .000 & .000 & .000 & \\
\hline & $\mathrm{N}$ & 502 & 502 & 502 & 502 & 502 & 502 & 502 & 502 & 502 & 502 & 502 \\
\hline \multirow{3}{*}{$\mathrm{BC} 2$} & $\begin{array}{l}\text { Pearson } \\
\text { Correlation }\end{array}$ & $.549^{* *}$ & $.523^{* *}$ & $.489^{* *}$ & $.400^{* *}$ & $.491^{* *}$ & $.543^{* *}$ & $.548^{* *}$ & $.526^{* *}$ & $.480^{* * *}$ & $-.311^{* *}$ & $.868^{* *} 1$ \\
\hline & Sig. (2-tailed) & .000 & .000 & .000 & .000 & .000 & .000 & .000 & .000 & .000 & .000 & .000 \\
\hline & $\mathrm{N}$ & 502 & 502 & 502 & 502 & 502 & 502 & 502 & 502 & 502 & 502 & $502 \quad 502$ \\
\hline \multirow{3}{*}{ BC3 } & $\begin{array}{l}\text { Pearson } \\
\text { Correlation }\end{array}$ & $.510^{* *}$ & $.505^{* *}$ & $.469^{* *}$ & $.533^{* *}$ & $.394^{* *}$ & $.528^{* *}$ & $.499^{* *}$ & $.548^{* *}$ & $.514^{* *}$ & $-.241^{* *}$ & $.652^{* *} \cdot 674$ \\
\hline & Sig. (2-tailed) & .000 & .000 & .000 & .000 & .000 & .000 & .000 & .000 & .000 & .000 & $.000 \quad .000$ \\
\hline & $\mathrm{N}$ & 502 & 502 & 502 & 502 & 502 & 502 & 502 & 502 & 502 & 502 & $\begin{array}{lll}502 & 502 & 502\end{array}$ \\
\hline
\end{tabular}


Table 27. Correlation Matrix of Job-related Stress

\begin{tabular}{|c|c|c|c|c|c|c|c|c|c|c|c|c|}
\hline & & JS1 & JS2 & JS3 & JS4 & JS5 & JS6 & JS7 & JS8 & JS9 & JS10 & JS11 \\
\hline & Pearson Correlation & 1 & & & & & & & & & & \\
\hline \multirow[t]{3}{*}{ JS1 } & Sig. (2-tailed) & & & & & & & & & & & \\
\hline & $\mathrm{N}$ & 502 & & & & & & & & & & \\
\hline & Pearson Correlation & $.434^{* *}$ & 1 & & & & & & & & & \\
\hline \multirow[t]{3}{*}{ JS2 } & Sig. (2-tailed) & .000 & & & & & & & & & & \\
\hline & $\mathrm{N}$ & 502 & 502 & & & & & & & & & \\
\hline & Pearson Correlation & $.497^{* *}$ & $.701^{* *}$ & 1 & & & & & & & & \\
\hline \multirow[t]{3}{*}{ JS3 } & Sig. (2-tailed) & .000 & .000 & & & & & & & & & \\
\hline & $\mathrm{N}$ & 502 & 502 & 502 & & & & & & & & \\
\hline & Pearson Correlation & $.383^{* *}$ & $.455^{* *}$ & $.494^{* *}$ & 1 & & & & & & & \\
\hline \multirow[t]{3}{*}{ JS4 } & Sig. (2-tailed) & .000 & .000 & .000 & & & & & & & & \\
\hline & $\mathrm{N}$ & 502 & 502 & 502 & 502 & & & & & & & \\
\hline & Pearson Correlation & $.411^{* *}$ & $.673^{* *}$ & $.665^{* *}$ & $.569^{* *}$ & 1 & & & & & & \\
\hline \multirow[t]{3}{*}{ JS5 } & Sig. (2-tailed) & .000 & .000 & .000 & .000 & & & & & & & \\
\hline & $\mathrm{N}$ & 502 & 502 & 502 & 502 & 502 & & & & & & \\
\hline & Pearson Correlation & $.394^{* *}$ & $.585^{* *}$ & $.614^{* *}$ & $.448^{* *}$ & $.639^{* *}$ & 1 & & & & & \\
\hline \multirow[t]{2}{*}{ JS6 } & Sig. (2-tailed) & .000 & .000 & .000 & .000 & .000 & & & & & & \\
\hline & $\mathrm{N}$ & 502 & 502 & 502 & 502 & 502 & 502 & & & & & \\
\hline
\end{tabular}




\begin{tabular}{|c|c|c|c|c|c|c|c|c|c|c|c|c|}
\hline \multirow{3}{*}{ JS7 } & Pearson Correlation & $.382^{* *}$ & $.581^{* *}$ & $.549^{* *}$ & $.584^{* *}$ & $.579^{* *}$ & $.539^{* *}$ & 1 & & & & \\
\hline & Sig. (2-tailed) & .000 & .000 & .000 & .000 & .000 & .000 & & & & & \\
\hline & $\mathrm{N}$ & 502 & 502 & 502 & 502 & 502 & 502 & 502 & & & & \\
\hline \multirow{3}{*}{ JS8 } & Pearson Correlation & $.238^{* *}$ & $.293^{* *}$ & $.317^{* *}$ & $.308^{* *}$ & $.413^{* *}$ & $.460^{* *}$ & $.360^{* *}$ & 1 & & & \\
\hline & Sig. (2-tailed) & .000 & .000 & .000 & .000 & .000 & .000 & .000 & & & & \\
\hline & $\mathrm{N}$ & 502 & 502 & 502 & 502 & 502 & 502 & 502 & 502 & & & \\
\hline \multirow{3}{*}{ JS9 } & Pearson Correlation & $.484^{* *}$ & $.422^{* *}$ & $.490^{* * *}$ & $.403^{* *}$ & $.499^{* *}$ & $.503^{* *}$ & $.447^{* *}$ & $.379^{* *}$ & 1 & & \\
\hline & Sig. (2-tailed) & .000 & .000 & .000 & .000 & .000 & .000 & .000 & .000 & & & \\
\hline & $\mathrm{N}$ & 502 & 502 & 502 & 502 & 502 & 502 & 502 & 502 & 502 & & \\
\hline \multirow{3}{*}{$\begin{array}{l}\text { JS1 } \\
0\end{array}$} & Pearson Correlation & $.399^{* *}$ & $.414^{* *}$ & $.412^{* *}$ & $.392^{* *}$ & $.525^{* *}$ & $.495^{* *}$ & $.445^{* *}$ & $.532^{* * *}$ & $.587^{* *}$ & 1 & $.419^{* *}$ \\
\hline & Sig. (2-tailed) & .000 & .000 & .000 & .000 & .000 & .000 & .000 & .000 & .000 & & .000 \\
\hline & $\mathrm{N}$ & 502 & 502 & 502 & 502 & 502 & 502 & 502 & 502 & 502 & 502 & 502 \\
\hline \multirow{3}{*}{$\begin{array}{l}\text { JS1 } \\
1\end{array}$} & Pearson Correlation & $.449^{* * *}$ & $.543^{* *}$ & $.580^{* *}$ & $.382^{* *}$ & $.546^{* *}$ & $.517^{* *}$ & $.502^{* *}$ & $.333^{* *}$ & $.496^{* *}$ & $.419^{* *}$ & 1 \\
\hline & Sig. (2-tailed) & .000 & .000 & .000 & .000 & .000 & .000 & .000 & .000 & .000 & .000 & \\
\hline & $\mathrm{N}$ & 502 & 502 & 502 & 502 & 502 & 502 & 502 & 502 & 502 & 502 & 502 \\
\hline
\end{tabular}


Table 28. Correlation Matrix of Mobbing

\begin{tabular}{|c|c|c|c|c|c|c|c|c|c|c|c|c|c|c|c|c|c|c|}
\hline & MB1 & MB2 & MB3 & MB4 & MB5 & MB6 & MB7 & MB8 & MB9 & MB10 & MB11 & MB12 & MB13 & MB14 & MB15 & MB16 & MB17 & MB18 \\
\hline $\begin{array}{l}\text { Pearson } \\
\text { Correlation }\end{array}$ & 1 & & & & & & & & & & & & & & & & & \\
\hline Sig. (2-tailed) & & & & & & & & & & & & & & & & & & \\
\hline $\mathrm{N}$ & 502 & & & & & & & & & & & & & & & & & \\
\hline $\begin{array}{l}\text { Pearson } \\
\text { Correlation }\end{array}$ & $.809^{* *}$ & 1 & & & & & & & & & & & & & & & & \\
\hline Sig. (2-tailed) & .000 & & & & & & & & & & & & & & & & & \\
\hline $\mathrm{N}$ & 502 & 502 & & & & & & & & & & & & & & & & \\
\hline $\begin{array}{l}\text { Pearson } \\
\text { Correlation }\end{array}$ & $.595^{* * *}$ & $.614^{* * *}$ & 1 & & & & & & & & & & & & & & & \\
\hline Sig. (2-tailed) & .000 & .000 & & & & & & & & & & & & & & & & \\
\hline $\mathrm{N}$ & 502 & 502 & 502 & & & & & & & & & & & & & & & \\
\hline $\begin{array}{l}\text { Pearson } \\
\text { Correlation }\end{array}$ & $.673^{* *}$ & $.726^{* * *}$ & $.609^{* *}$ & 1 & & & & & & & & & & & & & & \\
\hline Sig. (2-tailed) & .000 & .000 & .000 & & & & & & & & & & & & & & & \\
\hline $\mathrm{N}$ & 502 & 502 & 502 & 502 & & & & & & & & & & & & & & \\
\hline $\begin{array}{l}\text { Pearson } \\
\text { Correlation }\end{array}$ & $.606^{* *}$ & $.640^{* *}$ & $.537^{* *}$ & $.673^{* * *}$ & 1 & & & & & & & & & & & & & \\
\hline Sig. (2-tailed) & .000 & .000 & .000 & .000 & & & & & & & & & & & & & & \\
\hline $\mathrm{N}$ & 502 & 502 & 502 & 502 & 502 & & & & & & & & & & & & & \\
\hline $\begin{array}{l}\text { Pearson } \\
\text { Correlation }\end{array}$ & $.438^{* *}$ & $.542^{* *}$ & $.562^{* *}$ & $.583^{* *}$ & $.553^{* *}$ & 1 & & & & & & & & & & & & \\
\hline Sig. (2-tailed) & .000 & .000 & .000 & .000 & .000 & & & & & & & & & & & & & \\
\hline $\mathrm{N}$ & 502 & 502 & 502 & 502 & 502 & 502 & & & & & & & & & & & & \\
\hline
\end{tabular}




\begin{tabular}{|c|c|c|c|c|c|c|c|c|c|c|c|c|c|c|c|c|c|c|}
\hline & MB1 & MB2 & MB3 & MB4 & MB5 & MB6 & MB7 & MB8 & MB9 & MB10 & MB11 & MB12 & MB13 & MB14 & MB15 & MB16 & MB17 & MB18 \\
\hline $\begin{array}{l}\text { Pearson } \\
\text { Correlation }\end{array}$ & $.603^{* *}$ & $.650^{* *}$ & $.594^{* *}$ & $.680^{* *}$ & $.706^{* *}$ & $.571^{* *}$ & 1 & & & & & & & & & & & \\
\hline Sig. (2-tailed) & .000 & .000 & .000 & .000 & .000 & .000 & & & & & & & & & & & & \\
\hline $\mathrm{N}$ & 502 & 502 & 502 & 502 & 502 & 502 & 502 & & & & & & & & & & & \\
\hline $\begin{array}{l}\text { Pearson } \\
\text { Correlation }\end{array}$ & $.568^{* *}$ & $.591^{* *}$ & $.578^{* *}$ & $.726^{* *}$ & $.637^{* *}$ & $.588^{* *}$ & $.716^{* *}$ & 1 & & & & & & & & & & \\
\hline Sig. (2-tailed) & .000 & .000 & .000 & .000 & .000 & .000 & .000 & & & & & & & & & & & \\
\hline $\mathrm{N}$ & 502 & 502 & 502 & 502 & 502 & 502 & 502 & 502 & & & & & & & & & & \\
\hline $\begin{array}{l}\text { Pearson } \\
\text { Correlation }\end{array}$ & $.619^{* *}$ & $.647^{* *}$ & $.598^{* *}$ & $.661^{* *}$ & $.623^{* *}$ & $.554^{* *}$ & $.664^{* * *}$ & $.660^{* *}$ & 1 & & & & & & & & & \\
\hline Sig. (2-tailed) & .000 & .000 & .000 & .000 & .000 & .000 & .000 & .000 & & & & & & & & & & \\
\hline $\mathrm{N}$ & 502 & 502 & 502 & 502 & 502 & 502 & 502 & 502 & 502 & & & & & & & & & \\
\hline $\begin{array}{l}\text { Pearson } \\
\text { Correlation }\end{array}$ & $.551^{* *}$ & $.556^{* *}$ & $.571^{* *}$ & $.548^{* *}$ & $.576^{* *}$ & $.506^{* *}$ & $.610^{* * *}$ & $.611^{* *}$ & $.664^{* *}$ & 1 & & & & & & & & \\
\hline Sig. (2-tailed) & .000 & .000 & .000 & .000 & .000 & .000 & .000 & .000 & .000 & & & & & & & & & \\
\hline $\mathrm{N}$ & 502 & 502 & 502 & 502 & 502 & 502 & 502 & 502 & 502 & 502 & & & & & & & & \\
\hline $\begin{array}{l}\text { Pearson } \\
\text { Correlation }\end{array}$ & $.631^{* *}$ & $.640^{* * *}$ & $.553^{* *}$ & $.640^{* *}$ & $.618^{* *}$ & $.475^{* *}$ & $.647^{* * *}$ & $.597^{* *}$ & $.700^{* *}$ & $.615^{* *}$ & 1 & & & & & & & \\
\hline Sig. (2-tailed) & .000 & .000 & .000 & .000 & .000 & .000 & .000 & .000 & .000 & .000 & & & & & & & & \\
\hline $\mathrm{N}$ & 502 & 502 & 502 & 502 & 502 & 502 & 502 & 502 & 502 & 502 & 502 & & & & & & & \\
\hline $\begin{array}{l}\text { Pearson } \\
\text { Correlation }\end{array}$ & $.573^{* *}$ & $.567^{* *}$ & $.529^{* *}$ & $.566^{* *}$ & $.614^{* *}$ & $.519^{* *}$ & $.650^{* *}$ & $.642^{* *}$ & $.665^{* *}$ & $.640^{* *}$ & $.704^{* *}$ & 1 & & & & & & \\
\hline Sig. (2-tailed) & .000 & .000 & .000 & .000 & .000 & .000 & .000 & .000 & .000 & .000 & .000 & & & & & & & \\
\hline $\mathrm{N}$ & 502 & 502 & 502 & 502 & 502 & 502 & 502 & 502 & 502 & 502 & 502 & 502 & & & & & & \\
\hline $\begin{array}{l}\text { Pearson } \\
\text { Correlation }\end{array}$ & $.569^{* *}$ & $.593^{* *}$ & $.563^{* *}$ & $.620^{* *}$ & $.592^{* *}$ & $.545^{* *}$ & $.613^{* *}$ & $.683^{* *}$ & $.638^{* *}$ & $.598^{* * *}$ & $.574^{* *}$ & $.634^{* *}$ & & 1 & & & & \\
\hline
\end{tabular}




\begin{tabular}{|c|c|c|c|c|c|c|c|c|c|c|c|c|c|c|c|c|c|c|c|}
\hline & MB1 & MB2 & MB3 & MB4 & MB5 & MB6 & MB7 & MB8 & MB9 & MB10 & MB11 & MB12 & MB13 & MB14 & MB15 & MB16 & MB17 & MB18 & \\
\hline Sig. (2-tailed) & .000 & .000 & .000 & .000 & .000 & .000 & .000 & .000 & .000 & .000 & .000 & .000 & & & & & & & \\
\hline $\mathrm{N}$ & 502 & 502 & 502 & 502 & 502 & 502 & 502 & 502 & 502 & 502 & 502 & 502 & 502 & & & & & & \\
\hline $\begin{array}{l}\text { Pearson } \\
\text { Correlation }\end{array}$ & $.498^{* *}$ & $.562^{* * *}$ & $.469^{* *}$ & $.552^{* * *}$ & $.517^{* *}$ & $.509^{* * *}$ & $.560^{* * *}$ & $.603^{* *}$ & $.560^{* *}$ & $.501^{* *}$ & $.506^{* *}$ & $.577^{* *}$ & $.596^{* *}$ & 1 & & & & & \\
\hline Sig. (2-tailed) & .000 & .000 & .000 & .000 & .000 & .000 & .000 & .000 & .000 & .000 & .000 & .000 & .000 & & & & & & \\
\hline $\mathrm{N}$ & 502 & 502 & 502 & 502 & 502 & 502 & 502 & 502 & 502 & 502 & 502 & 502 & 502 & 502 & & & & & \\
\hline $\begin{array}{l}\text { Pearson } \\
\text { Correlation }\end{array}$ & $.492^{* * *}$ & $.561^{* *}$ & $.460^{* * *}$ & $.572^{* *}$ & $.617^{* *}$ & $.517^{* *}$ & $.611^{* *}$ & $.655^{* *}$ & $.553^{* *}$ & $.500^{* * *}$ & $.505^{* *}$ & $.575^{* *}$ & $.604^{* *}$ & $.645^{* *}$ & 1 & 1 & & & \\
\hline Sig. (2-tailed) & .000 & .000 & .000 & .000 & .000 & .000 & .000 & .000 & .000 & .000 & .000 & .000 & .000 & .000 & & & & & \\
\hline $\mathrm{N}$ & 502 & 502 & 502 & 502 & 502 & 502 & 502 & 502 & 502 & 502 & 502 & 502 & 502 & 502 & 502 & & & & \\
\hline $\begin{array}{l}\text { Pearson } \\
\text { Correlation }\end{array}$ & $.451^{* *}$ & $.456^{* * *}$ & $.557^{* *}$ & $.480^{* *}$ & $.467^{* *}$ & $.496^{* *}$ & $.531^{* * *}$ & $.520^{* * *}$ & $.557^{* *}$ & $.530^{* * *}$ & $.499^{* * *}$ & $.563^{* *}$ & $.677^{* *}$ & $.460^{* *}$ & $.507^{* * *}$ & 1 & 1 & & \\
\hline Sig. (2-tailed) & .000 & .000 & .000 & .000 & .000 & .000 & .000 & .000 & .000 & .000 & .000 & .000 & .000 & .000 & .000 & & & & \\
\hline $\mathrm{N}$ & 502 & 502 & 502 & 502 & 502 & 502 & 502 & 502 & 502 & 502 & 502 & 502 & 502 & 502 & 502 & 502 & & & \\
\hline $\begin{array}{l}\text { Pearson } \\
\text { Correlation }\end{array}$ & $.501^{* *}$ & $.525^{* *}$ & $.560^{* *}$ & $.576^{* *}$ & $.547^{* *}$ & $.558^{* * *}$ & $.602^{* * *}$ & $.647^{* * *}$ & $.647^{* *}$ & $.593^{* *}$ & $.570^{* *}$ & $.621^{* *}$ & $.722^{* * *}$ & $.591^{* *}$ & $.681^{* *}$ & $.717^{* *}$ & 1 & & \\
\hline Sig. (2-tailed) & .000 & .000 & .000 & .000 & .000 & .000 & .000 & .000 & .000 & .000 & .000 & .000 & .000 & .000 & .000 & .000 & & & \\
\hline $\mathrm{N}$ & 502 & 502 & 502 & 502 & 502 & 502 & 502 & 502 & 502 & 502 & 502 & 502 & 502 & 502 & 502 & 502 & 502 & & \\
\hline $\begin{array}{l}\text { Pearson } \\
\text { Correlation }\end{array}$ & $.540^{* *}$ & $.557^{* *}$ & $.491^{* *}$ & $.613^{* *}$ & $.569^{* * *}$ & $.479^{* * *}$ & $.637^{* * *}$ & $.691^{* * *}$ & $.650^{* * *}$ & $.576^{* *}$ & $.604^{* *}$ & $.558^{* *}$ & $.621^{* *}$ & $.572^{* *}$ & $.593^{* *}$ & $.523^{* *}$ & $.638^{* *}$ & & 1 \\
\hline Sig. (2-tailed) & .000 & .000 & .000 & .000 & .000 & .000 & .000 & .000 & .000 & .000 & .000 & .000 & .000 & .000 & .000 & .000 & .000 & & \\
\hline $\mathrm{N}$ & 502 & 502 & 502 & 502 & 502 & 502 & 502 & 502 & 502 & 502 & 502 & 502 & 502 & 502 & 502 & 502 & 502 & & 502 \\
\hline
\end{tabular}




\section{LIST OF REFERENCES}

Adams, A. (1992). Bullying at work: how to confront and overcome it. London: Virgo Press.

Akbolat, M., \& Isik, O. (2008). The level of burnout among medical staff, Hacettepe Saglik Idaresi Dergisi, 11(2), pp. 229-254.

Anagnostopoulos, F., \& Niakas, D. (2010). Job burnout, health-related quality of life, and sickness absence in Greek health professionals. European Psychologist, 15(2), 132.

Aneshensel, C.S., Rutter, C.M., and Lachenbruch, P.A. (1991). Social structure, stress, and mental health: Competing conceptual and analytic models. American Sociological Review. 56:166-178.

Ari, G., and Tuncay, A. (2010). The relationship between trust in immediate managers in hospital and burnout, Ankara Universitesi IIBF Dergisi, 24(4), pp. 113-135.

Bakker, A. B., \& Demerouti, E. (2007), The job demands-resources model: state of the art, Journal of Managerial Psychology, 22 (3), 309-328.

Baron, R. A., \& Neuman, J. H. (1996). Workplace violence and workplace aggression: Evidence on their relative frequency and potential causes. Aggressive Behavior, 22, 161-173.

Bickel, R. (2007). Multilevel analysis for applied research: It's just regression!. Guilford Press.

Bjrökqvist K., \& Osterman, K. (1992). Work harassment scale. Retrieved February 12, 2014 from http://www.vasa.abo.fi/svf/up/Scales/WHS-English.pdf

Bjrökqvist K., Osterman K., \& Hjelt-Back, M. (1992a): The Work Harassment Scale. Vasa, Finland: Abo Akademi University.

Bjrökqvist K., Osterman K., \& Hjelt-Back, M. (1994a): Aggression among university employees. Aggressive Behavior, 20, 173-184. 
Blasé, J., \& Blasé, J. (2003). The phenomenology of principal mistreatment: teacher’s perspectives. Journal of Educational Administration, 41, 367-422.

Boomsma, A. \& Hoogland, J. J. (2001). The robustness of LISREL modeling revisited. Structural Equation Modeling: Present and Future, 139-168.

Breckler, S. J. (1990). Applications of covariance structure modeling in psychology: Cause for concern?. Psychological bulletin, 107(2).

Brown H. E. A., Tinsley, S.D. (2000). Applied Multivariate Statistics. Academic Press. CA, USA.

Byrne, B.M. (2010). Structural equation modeling with AMOS. New York, NY: LEA Publisher.Buss, A. H. (1961). The psychology of aggression. New York: Wiley.

Cahoon, A. R., \& J. I. A. Rowney. (1989). A comparison of burnout across public/private sector managers, Journal of Health and Human Resources Administration ,79-94.

Calder, B. J., Phillips, L. W., \& Tybout, A. M. (1982). The concept of external validity. Journal of Consumer Research, 240.

Caplan, R. D., Sidney C., \& French J. P.R. (1975). Relationship of cessation of smoking with job stress, personality, and social support. Journal of Applied Psychology, 60, 211-219.

Caplan, R. D., Sidney C., \& French J. P.R. (1975). relationship of cessation of smoking with job stress, personality, and social support. Journal of Applied Psychology, 60, 211-219.

Centers for Disease Control and Prevention (2000). Measuring Healthy Days: Population Assessment of Health-related Quality of Life. Atlanta, GA: Centers for Disease Control and Prevention; 2000. Retrieved 26 October 2013, from http://www.cdc.gov/hrqol/pdfs/mhd.pdf. 
Chang, E. M., Daly, J. W., Hancock, K. M., Bidewell, J., Johnson, A., Lambert, V. A., et al. (2006). The relationships among workplace stressors, coping methods, demographic characteristics, and health in Australian nurses. Journal of Professional Nursing, 22(1).

Cronbach, L. J. (1951). Coefficient alpha and the internal structure of tests, Psychometrika, 16.

Cropanzano, R., Rupp, D. E., \& Byrne, Z. S. (2003). The relationship of emotional exhaustion to work attitudes, job performance, and organizational citizenship behaviors. Journal of Applied Psychology, 88, 160-169.

Cullen, F. T., Lemming, T., and Link, B. G. (1985). The impact of social support on police stress. Criminology, 23(3), 503-522.

Curran, P. J. (1994). The robustness of confirmatory factor analysis to model misspecification and violations of normality (Doctoral dissertation, Arizona State University). Davenport, N., Schwartz.

Davenport, N.; Schwartz, R.D. \& Elliott, G.P. (2003). Mobbing: Emotional abuse in the American workplace, (Translation: Osman C. ÖNERTOY). İstanbul: Sistem Yayınc1lık.

DeCoster, J. (1998). Overview of Factor Analysis. Retrieved 29 September 2013, from http://www.stat-help.com/notes.html

Deliorman, R., Boz, I., Yigit, I. \& Yildiz, S. (2010). An alternative instrument to measure burnout: Copenhagen burnout inventory, Yonetim, 20(63), pp. 77-99.

Delmas, M. A., and Toffel, M. W. (2008). Organizational responses to environmental demands: Opening the black box. Strategic Management Journal, 29(10).

Demerouti, E., Bakker A. B., Nachreinier, F. \& Schaufeli W. B. (2001), The job demandsresources model of burnout, Journal of Applied Psychology, 86 (3), 499-512. 
DeShon, R. P. (1998). A cautionary note on measurement error corrections in structural equation models. Psychological Methods, 3, 412-423.

Diab, (2015). Turkish Ministry of Interior Introductory Book (2015), Retrieved 12 February 2015, from http://www.diab.gov.tr/kurumlar/diab.gov.tr/strateji/multimedya/tanitimkitabi.pdf

Dillman, A. D. (2007). Mail and internet survey. New Jersey: John Wiley \& Sons, Inc., Hoboken,

Dziegielewski, S.F., Mansur, A. F., \& Tengilimoglu, D., (2010). The Effect of the mobbing on organizational commitment in the hospital setting: a field study, journal of social service research, 36:2, 128-141.

Etzion, D. (1984). Moderating effect of social support on the stress-burnout relationship, Journal of Applied Psychology, 69, 615-622.

Freudenberger H. J. (1974). Staff burnout. Journal of Social Issues 30(1).

Freudenberger HJ. 1975. The staff burnout syndrome in alternative institutions. Psychother. Theory Res. Pract. 12:72-83

Gamst, G., Meyers, L. S., \& Guarino, A. J. (2008). Analysis of variance designs: A conceptual and computational approach with SPSS and SAS. Cambridge University Press.

Gandek, B., Ware, J. E., Aaronson, N. K., Apolone, G., Bjorner, J. B., Brazier, J. E., ... \& Sullivan, M. (1998). Cross-validation of item selection and scoring for the SF-12 Health Survey in nine countries: results from the IQOLA Project. Journal of clinical epidemiology, 51(11), 1171-1178.

Garson, G. D. (2015). Structural Equation Modeling. Asheboro, NC: Statistical Associates Publishers. 
George, D., \& Mallery, P. (2003). SPSS for Windows step by step: A simple guide and reference. 11.0 update (4th ed.). Boston: Allyn \& Bacon.

Gill, A. S., Alan, Flaschner, B., \& Shachar, M. (2006). Mitigating stress and burnout by implementing transformational- leadership. International Journal of Contemporary Hospitality Management 18(6), pp. 469- 481.

Gliner, A. J. \& Morgan G. A. (2000). Research methods in applied settings: an integrated approach to design and analysis, Lawrence Erlbaum Associates.

Gmelch, W. H. and Gates G.. (1998). The impact of personal, professional and organizational characteristics on administrator burnout. Journal of Educational Administration 36, no. 2: 146- 159.

Gozler, K. (2003), Idare hukuku [administrative law], Bursa: Ekin Kitabevi.

Grunau G. (2007). Mobbing and burnout: are they linked? Walden University. Retrieved 12 February 2014, from http://eds.b.ebscohost.com.ezproxy.net.ucf.edu/eds/detail?vid=2\&sid=017ff1d1-598849c3-9673b0ac500ca713\%40sessionmgr113\&hid=109\&bdata=JnNpdGU9ZWRzLWxpdmUmc2Nv cGU9c210ZQ\%3d\%3d\#db=psyh\&AN=2008-99020-113

Gul, H. (2012). Mobbing at workplaces and the mental health effects on employees, essential Notes in Psychiatry, Dr. Victor Olisah (Ed.). Retrieved 12 February 2014 from http://www.intechopen.com/books/essential-notes-in-psychiatry/mobbing-at-workplaceand-the-mental-healtheffects- on-employees.

Halbesleben, J. R. B., \& Buckley, M. R. (2004). Burnout in organizational life, Journal of 
Management, 30, 859-879.

Hooper et al. (2008). Structural equation modeling: guidelines for determining model fit, Electronic Journal of Business Research Methods, 6(1), p53-59.

Hornstein, H. A. (2003). Workplace incivility: an unavoidable product of human nature and organizational nurturing. Ivey Business Journal, 68(2), 1-7.

Hox, J.J. and Bechger, T.M. (1998). An introduction to structural equation modeling. Family Science Review, 11.

Hoyle, R. H. (1995). Structural equation modeling: concepts, issues, and applications. Thousand Oaks, CA: Sage Publications.

Illeridaresi, (2014). The general list of districts. Retrieved May 15, 2014 from http://www.illeridaresi.gov.tr/ortak_icerik/illeridaresi/ilveilce/İlceler.pdf

Jamal, M., \& Baba, V. V. (1999). Job stress and burnout among Canadian managers and nurses: an empirical examination. Canadian Journal of Public Health. Revue canadienne de sante publique, 91(6), 454-458.

Kaplan, D. (2000). Structural equation modeling: Foundation and extensions. Thousand Oaks, CA: Sage Publications.

Karasu, K. (2002). Mulki idare amirligi meslegi (Eng: The occupation of Turkish state representative). In Turkiye`de Mulki Idarenin Gelecegi, eds. Cahit Emre, pp. 113-151. Ankara: Icisleri Bakanligi Strateji Merkezi.

Keashly, L. (1998). Emotional abuse in the workplace: Conceptual and empirical issues. Journal of Emotional Abuse, I, 85-117.

Keashly, L. (2001). Interpersonal and systemic aspects of emotional abuse at work: the target's 
perspective. Violence and Victims, 16(3), 233-268.

Keashly, L., Trott, V., \& MacLean, L. M. (1994). Abusive behavior in the workplace: A preliminary investigation. Violence and Victims, 9, 341-357.

Keller, S. D., Ware Jr, J. E., Bentler, P. M., Aaronson, N. K., Alonso, J., Apolone, G., \& Gandek, B. (1998). Use of structural equation modeling to test the construct validity of the SF-36 health survey in ten countries: Results from the IQOLA project. Journal of clinical epidemiology, 51(11), 1179-1188

Kline, R. B. (2005). Principles and practice of structural equation modeling. New York, NY: The Guilford Press.

Kristensen T. S., Borritz M., Villadsen,E., Christensen, K. B. (2005). The Copenhagen burnout inventory: a new tool for the assessment of burnout. Work \& Stress. 19(3), p192-207.

Kubilay, M. (1998). Turkiye`de mulki idare sistemi (Eng: Territorial state system in Turkey). Turk Idare Dergisi 70(420), pp. 111-134.

Kuruuzum, A., Anafarta, N. and Irmak S. (2008). Predictors of burnout among middle managers in the Turkish hospitality industry. International Journal of Contemporary Hospitality Management, 20(2), 186- 198.

Kutanis R. \& Karakiraz, A. (2013). Measuring burnout of scholars with Copenhagen burnout scale, Isletme Bilim Dergisi, 1(2), pp. 13-30.

Lee, R. T. and Ashforth B. E. (1993). A longitudinal study of burnout among supervisors and managers: Comparisons between the Leiter and Maslach (1988) and Golembiewki et al. (1986) models. Organizational Behavior and Human Decision Process 54(3). 
Leiter, M. P. (1993). Burnout as a developmental process: consideration of models. Professional Burnout: Recent Developments in Theory and Research.

Leiter, M. P. \& Maslach, C. (2000). Preventing burnout and building engagement: a complete program for organizational renewal. San Francisco: Jossey Bass

Leka, S., Jain, A. (2010). Health impact of psychosocial hazards at work: an overview. World Health Organization, Geneva, Switzerland.

Leymann, H. (1990). Mobbing and psychological terror. Violence and Victims, 5, 119-126.

Leymann, H. (1996). The content and development of mobbing at work. European Journal of Work and Organizational Psychology, 5, 165-184.

Liefooghe, A. P. D. (2004). Bullying at work: An introduction to the symposium. British Journal of Guidance and Counseling, 32, 264-267.

MacCallum, R. C., Roznowski, M., and Necowitz, L. B. (1992). Model modifications in covariance structure analysis: the problem of capitalization on chance. Psychological bulletin, 111(3).

Martinussen, M., Richardsen, A., and Burke, R. (2007). Job demands, job resources, and burnout among police officers. Journal of Criminal Justice, 35(3).

Maruish M.E \& DeRosa, M.A., (2009). A guide to the integration of certified short form survey scoring and data quality evaluation capabilities. Lincoln, RI: Quality Metric Incorporated

Marushi, M. E. and Turner-Bowker, D.M. (2009). A guide to the development of certified modes of short form survey administration, Lincoln, RI: Quality Metric Incorporated.

Maslach C, and Jackson SE. (1981). The measurement of experienced burnout. J. Occup. Behav. 2:99-113. 
Maslach C. (1976). Burned-out. Hum. Behav. 5:16-22.

Maslach, C., Schaufeli, W., \& Leiter, M. P. (2001). Job burnout. Annual Review of Psychology, $52,397-422$.

Maydeu-Olivares, A. \& García-Forero, C. (2010). Goodness of fit testing. In Peterson, P., Baker, E., \& McGaw, B. (Eds). International Encyclopedia of Education (3rd ed.) (pp. 190-196). Oxford: Elsevier.

Messer, B. L., \& Dillman, D. A. (2011). Surveying the general public over the Internet using address-based sampling and mail contact procedures. Public Opinion Quarterly, 75(3), $429-457$

Millar, M. M., \& Dillman, D. A. (2011). Improving response to web and mixed-mode surveys. Public Opinion Quarterly, 75(2), 249-269.

Mohren, D. C. L., Swaen, G.M., Kant, I., van Amelsvort, L.G.., Borm, P. J.., \& Galama, J. M. (2003). Common infections and the role of burnout in a Dutch working population. Journal of Psychosomatic Medicine, 55, 201-208.

Montgomery, A., Mostert, K., and Jackson, L. (2005). Burnout and health of primary school educators in the north-west province. South African Journal of Education, 25(4).

Namie, G., \& Namie, R. (2000). Workplace bullying: the silent epidemic, Employee Rights Quarterly, 1, 1-12.

Newsom, J. (2012). Nested models, model modifications, and correlated errors. Retrieved February 13, 2014 from http://www.upa.pdx.edu/IOA/newsom/semclass/ho_nested.pdf. Okutan, E., Yildiz, S., \& Konuk, F. (2013). Burnout syndrome in working life, Cankiri Iktisadi ve Idari Bilimler Dergisi, 3(2), pp.1-17. 
Ortega A., Brenner S. O., \& Leather, P. (2007). Occupational stress, coping and personality in the police: An SEM study. International Journal of Police Science \& Management, 9(1), 36-50.

Osterman, K., Bjorqvist, K., Lagerspetz, K. M. J., Kaukiainen, A., Landau, S. F., Adam, F., A., \& Caprara, G. V. (1998). Cross-cultural evidence of female indirect aggression. Aggressive Behavior, 24, 1-8.

Pai, C.W. and Wan, T.T.H. (1997)."Confirmatory Analysis of Health Outcome Indicators: The 36-Item Short-Form Health Survey (SF-36)." Journal of Rehabilitation Outcomes Research, 1(2).

Parker, D. F., \& DeCotiis, T. A. (1983). Organizational determinants of job stress. Organizational Behavior and Human Performance, 32, 160-177.

Schaufeli, W. \& Enzmann, E. (1998). The burnout companion to study and practice: a critical analysis, Taylor \& Francis Inc. Philadelphia: PA.

Schermelleh-Engel, K., Moosbrugger, H., \& Müller, H. (2003). Evaluating the fit of structural equation models: Tests of significance and descriptive goodness-of-fit measures. Methods of psychological research online, 8(2), 23-74.

Sezen, S. (2011). International versus domestic explanations of administrative reforms: The case of Turkey. International Review of Administrative Sciences, 77(2), 322-346.

Thompson, B. M., Kirk, A., and Brown, D. F. (2005). Work based support, emotional exhaustion, and spillover of work stress to the family environment: A study of policewomen. Stress and Health, 21(3), 199-207.

TMoI, (2014). Ministry of Interior. Retrieved 18 February 2014, from 
https://www.linkedin.com/company/i-i-leri-bakanl-

Tourigny, L., Baba, V. V., \& Lituchy, T. R. (2005). Job Burnout among Airline Employees in Japan A Study of the Buffering Effects of Absence and Supervisory Support. International Journal of Cross Cultural Management, 5(1), 67-85.

Trochim, M.K.W. (2001). The research methods knowledge base, Cincinnati: OH, Cornel University.

Tumkaya, S., Cam, S., \& Cavusoglu, I. (2009). The adaptation of reliability and validity of short version of burnout scale to Turkish, C.U. Sosyal Bilimler Enstitusu Dergisi, 18(1), pp. 387-398.

The Turkish Constitution of 1982 (2015). The Grand National Assembly of Turkey. Retrieved March 28, 2015 from http://global.tbmm.gov.tr/docs/constitution_en.pdf

Ursin, H., \& Eriksen, H. R. (2004). The cognitive activation theory of stress. Psychoneuroendocrinology, 29, 567-592.

Wan, T.T.H. (1982). Stressful life events, social-support networks, and gerontological health: A prospective study. Lexington Books.

Wan, T.T.H. (2002). Evidence-Based Health Care Management: Multivariate Modeling Approaches. Boston: Kluwer Academic Publishers.

Wan, T.T.H., Pai, C.W, \& Wan, G. J. (1998). Organizational and market determinants of HMOs' performance in preventive practice. Journal of Health Care Quality 20(3): 14-129.

Ware Jr, J. E., Keller, S. D., Bentler, P. M., Aaronson, N. K., Alonso, J., Apolone, G., \& Gandek, B. (1998). Use of structural equation modeling to test the construct validity of the SF-36 health survey in ten countries: Results from the IQOLA project. Journal of clinical 
epidemiology, 51(11), 1179-1188.

Ware, J. E. (2003). Conceptualization and measurement of health-related quality of life: comments on an evolving field. Archives of physical medicine and rehabilitation, 84, S43-S51.

Ware, J. E., Bjorner, J. B., \& Kosinski, M. (2000). Practical implications of item response theory and computerized adaptive testing: a brief summary of ongoing studies of widely used headache impact scales. Medical care, II73-II82.

Wiese, L., Rothmann, S., and Storm, K. (2003). Coping, stress and burnout in the South African police service in KwaZulu-Natal, SA Journal of Industrial Psychology 29(4).

Williams, L. J. (1995). Covariance structure modeling in organizational research: Problems with the method versus applications of the method. Journal of Organizational Behavior, 16(3). Retrieved 29 September 2013, from http://onlinelibrary.wiley.com/doi/10.1002/job.4030160305/abstract;jsessionid=2773D69 3CD54937B107E318D24846D88.f04t02?deniedAccessCustomisedMessage=\&userIsAut henticated $=$ false

Wornham, D. (2003). A descriptive investigation of morality and victimization at work. Journal of Business Ethics, 45(1/2), 29-40.

Xie, J. L., \& Johns, G. (1995). Job scope and stress: Can job scope be too high? Academy of Management Journal, 38(5), 1288-1309

Zhang, Z. \& Wang, L. (2009). Statistical power analysis for growth curve models using SAS. Behavior Research Methods, 41(4), 1083. 